\title{
MELATONIN AND SEX HORMONES AMONG ROTATING SHIFT NURSES
}

\author{
by \\ Annie Rose Langley \\ A thesis submitted to the Department of Community Health and Epidemiology \\ In conformity with the requirements for \\ the degree of Master of Science \\ Queen's University \\ Kingston, Ontario, Canada \\ (September, 2010)
}

Copyright (CAnnie Langley, 2010 


\begin{abstract}
Background: In 2007, the International Agency for Research on Cancer classified shift-work involving circadian disruption as a "probable carcinogen." One proposed pathway for this relationship involves nighttime light exposure and subsequent decreases in melatonin production. It is postulated that melatonin, a cancer-protective hormone, may influence patterns of sex hormone production that in turn influence breast cancer risk. The purpose of this study was to investigate the relationships between night shift-work history, melatonin and sex hormone levels among shift-working women.
\end{abstract}

Methods: 82 pre-menopausal nurses who work a rotating shift pattern of two days (7AM-7PM), two nights (7PM-7AM), followed by five days off participated in two study periods approximately six months apart (in summer and winter), each taking place during a day shift of the normal rotating shift pattern. Creatinine-adjusted melatonin metabolite concentrations were measured from morning void urine samples, and estradiol, estrone, progesterone and prolactin concentrations were measured from fasting blood samples taken at the same time. Other pertinent information was collected by measurement (weight, height) and by self-report via questionnaire. We examined melatonin-sex hormone relationships within each of two seasons, and across seasons, to investigate two hypothesized latency periods for influences of melatonin levels on sex hormones. Multivariate linear regression was used to explore relationships, with adjustment for confounders including age and body mass index.

Results: An inverse relationship between melatonin and estradiol was suggested in winter $(\beta=$ $0.13, \mathrm{p}=0.11)$, and a positive relationship was suggested for increasing estrone with increasing melatonin tertile in summer $(\mathrm{p}=0.07)$, after multivariate adjustments. Melatonin was not associated with other hormones in either season. On investigation of a longer latency period, melatonin in the first season was not associated with sex hormones in the second season. While 
those working night shifts for 20 years or more had higher mean levels of estradiol, estrone and progesterone, results were not statistically different from those with a shorter history of night work.

Conclusions: The results of this study do not provide evidence to support the proposed biological pathway involving altered melatonin and sex hormone levels as intermediates between shift-work and breast cancer risk. 


\section{Co-Authorship}

This thesis presents work completed by Annie Langley in collaboration with her thesis supervisors Drs. Kristan Aronson and Charles Graham. The larger study on which this thesis is based was designed by Drs. Kristan Aronson, Charles Graham, Ian Janssen, Glenville Jones,

Harriet Richardson, Joan Tranmer and PhD student Anne Grundy, and received funding from the Workplace Safety and Insurance Board of Ontario (WSIB). Additional financial support was provided by Breast Cancer Action Kingston (BCAK) for the assessment of sex hormones (not a part of the original study objectives).

The purpose of this research, to investigate relationships between melatonin and sex hormones, was originally presented by Dr. Kristan Aronson with the additional objective to study longitudinal relationships suggested by Annie Langley. The statistical analysis, interpretation of study results, and preparation of the thesis manuscript and chapters were completed by Annie Langley under the supervision of Drs. Kristan Aronson and Charles Graham. The thesis manuscript received additional editorial support from other co-authors Anne Grundy, Dr. Joan Tranmer and Dr. Harriet Richardson. Annie Langley assisted other students Mark McPherson, Lindsay Kobayashi and Anne Grundy with the immunoassays for melatonin assessment in the WSIB study, a portion of which were used in this thesis. 


\section{Acknowledgements}

I would like to thank my supervisors for their assistance and mentorship with this project. I am very thankful for the opportunity to be a part of the WSIB study and to contribute to Dr. Aronson's research program on shift-work. I also appreciate the welcoming atmosphere of the Dr. Graham lab and your patience and assistance with the laboratory assays. Thank you both for all of your expertise, support and for believing in my abilities.

I am also thankful for the support of faculty, staff and students in the department of Community Health \& Epidemiology. The dedication of faculty and staff has made this program a truly satisfying academic experience, and the support and friendliness of fellow students ensured a collaborative and encouraging learning environment. I am also very fortunate to have had the opportunity to work in the stimulating, professional environment of the Division of Cancer Care \& Epidemiology at the Queen's Cancer Research Institute (QCRI).

I am very grateful for the many nurses who participated in this study, and to the dedicated WSIB study personnel and students including Mark MacPherson, Anne Grundy, Lindsay Kobayashi, Kathy Bowes, Deborah Emerton, Karen Loller and Krista Smith. Thanks to WSIB coinvestigators for your valuable editorial input on my work.

I would like to acknowledge student funding through the Queen's University Terry Fox Award in Transdisciplinary Cancer Research in Partnership with the Canadian Institutes of Health Research and the Franklin Bracken Fellowship, for which I am very grateful.

Lastly, I would like to thank my friends and family, especially my aunt Dr. Janet Ashbury, for their continued support with this work - I am truly humbled by your pride in my accomplishments. 


\section{Table of Contents}

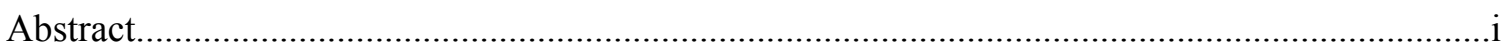

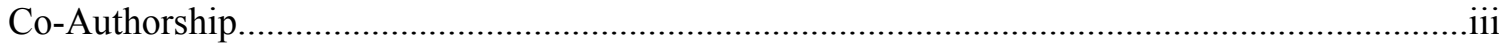

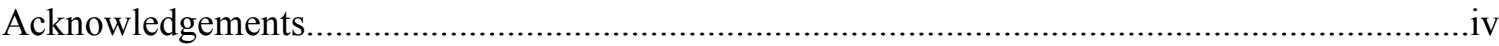

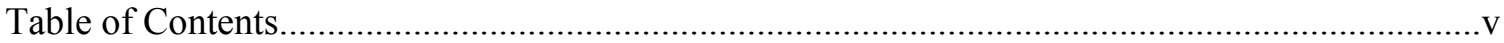

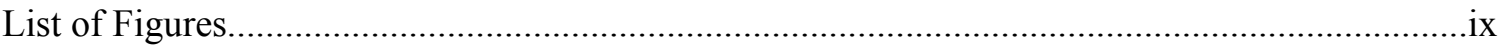

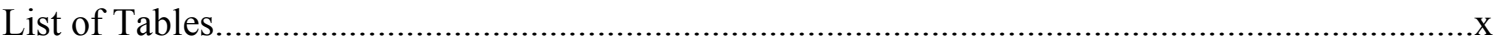

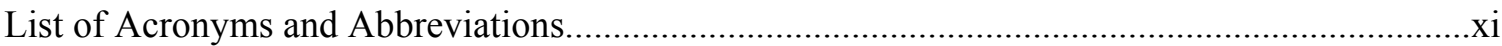

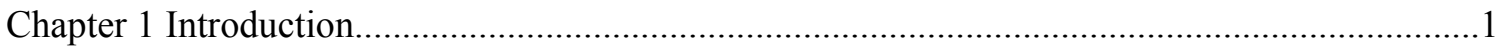

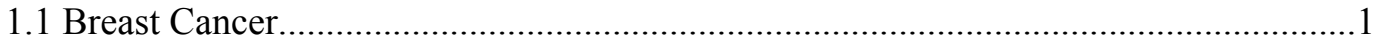

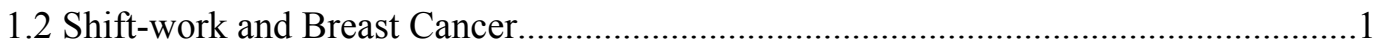

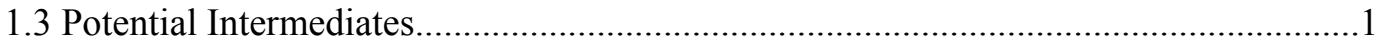

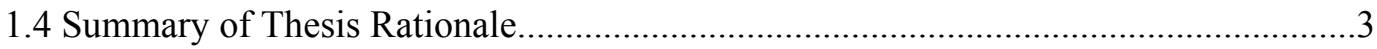

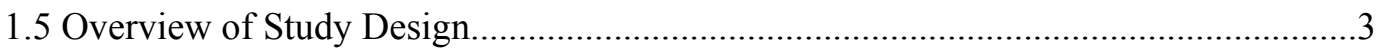

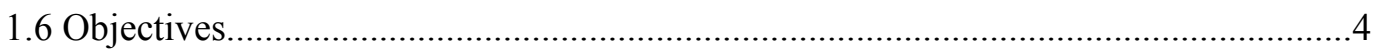

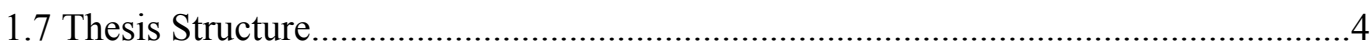

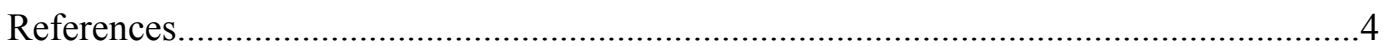

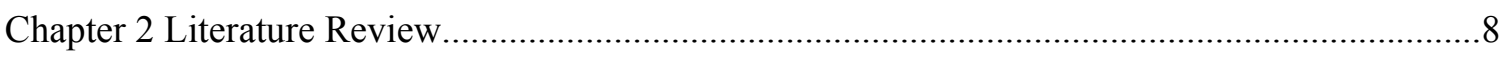

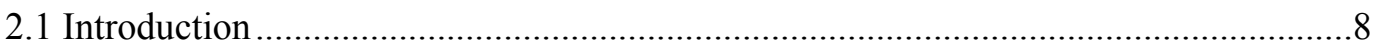

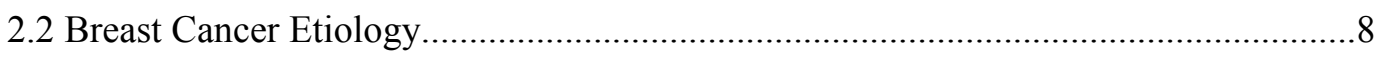

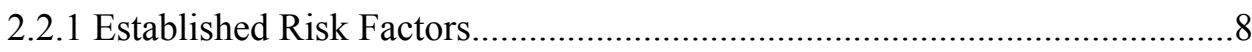

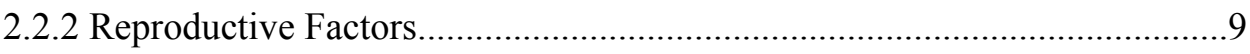

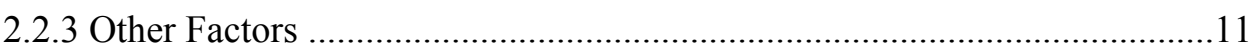

2.3 Shift-work and Breast Cancer.............................................................................. 11

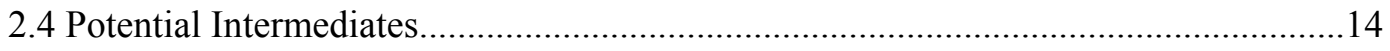

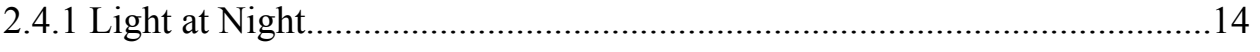

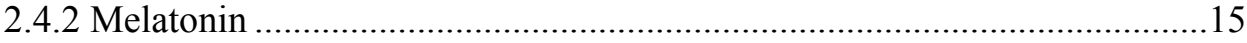

2.4.3 Light at Night and Melatonin Levels......................................................16

2.4.4 Biomarkers of Melatonin.........................................................................18

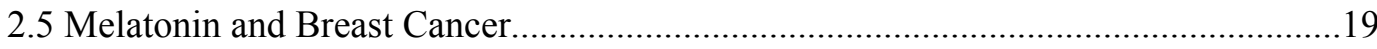

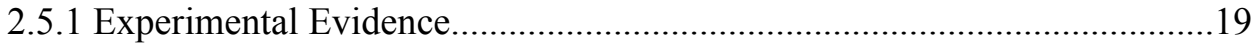

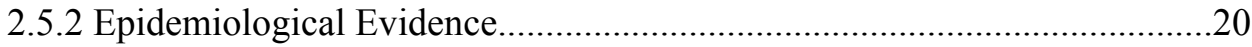


2.5.3 Mechanisms of Cancer Protection.................................................................20

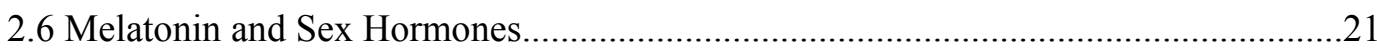

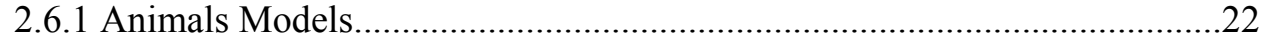

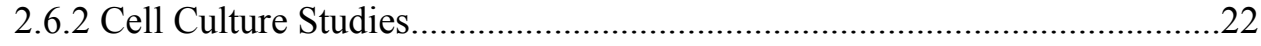

2.6.3 Experimental Studies on Humans...........................................................23

2.6.4 Observational Studies on Humans...........................................................24

2.6.5 Limitations of Observational Research.....................................................26

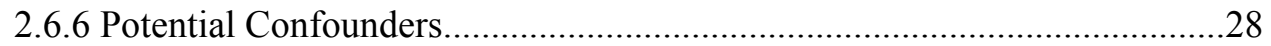

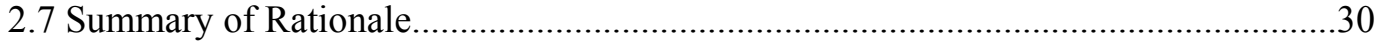

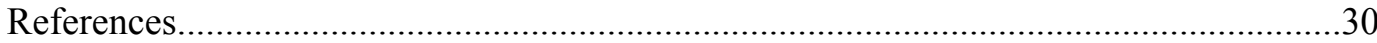

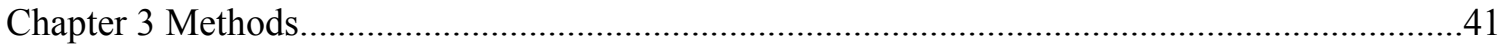

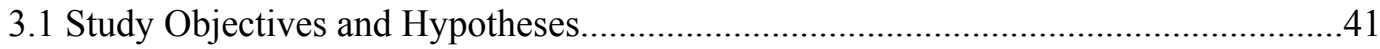

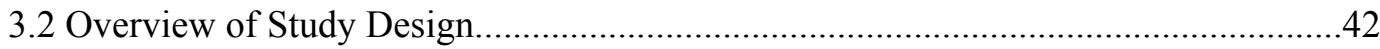

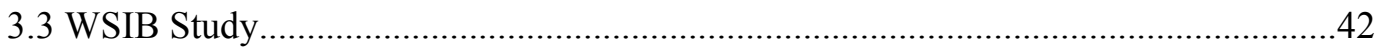

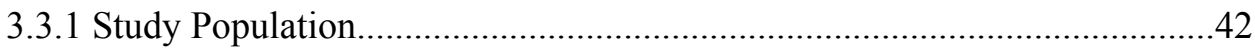

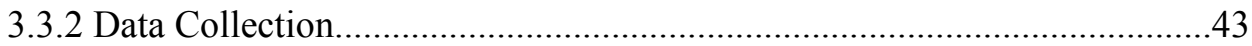

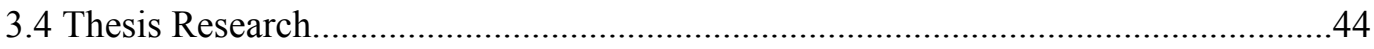

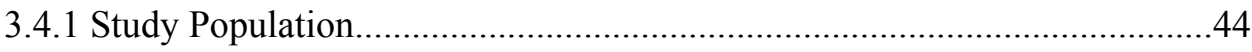

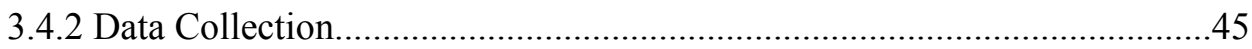

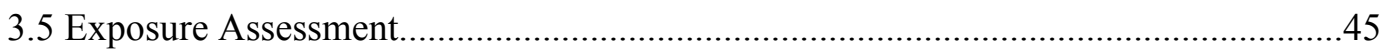

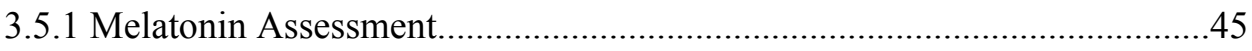

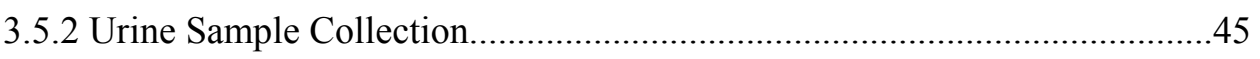

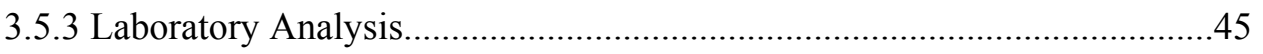

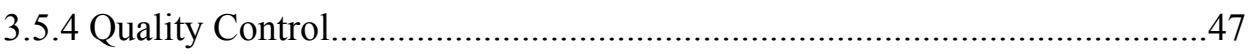

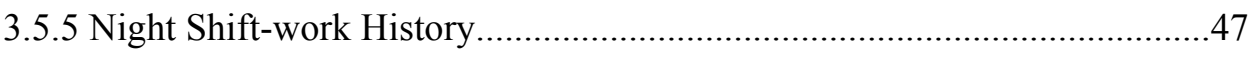

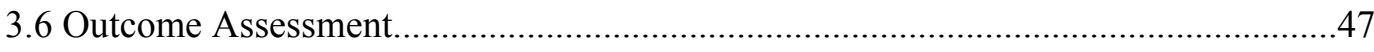

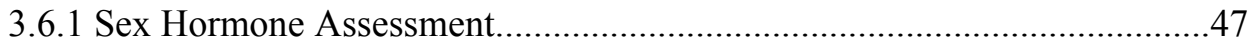

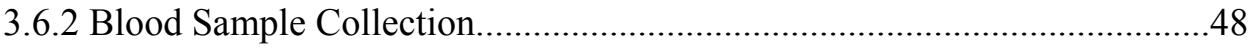

3.6.3 Laboratory Analysis............................................................................. 49

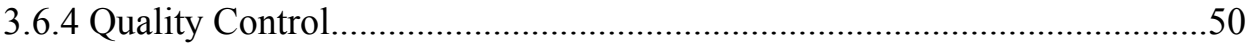

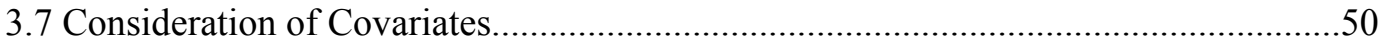

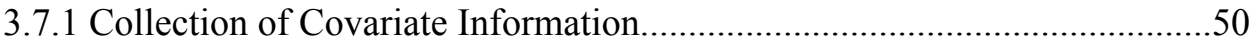

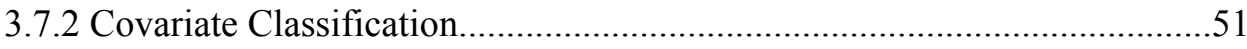




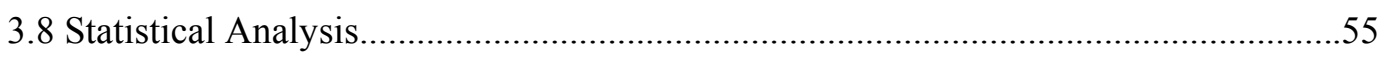

3.8.1 Subject Participation and Final Sample Sizes.............................................55

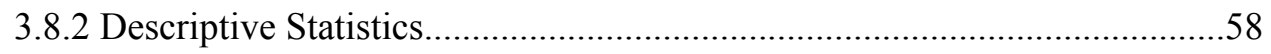

3.8.3 Bivariate Exposure-Outcome Relationships.............................................59

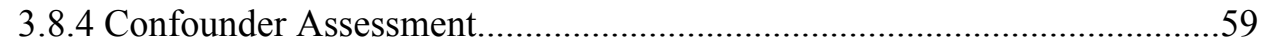

3.8.5 Sensitivity Analysis and Regression Diagnostics.....................................61

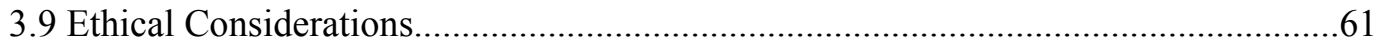

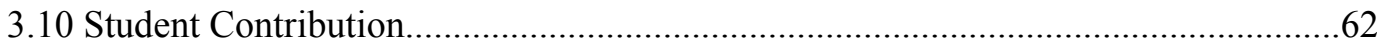

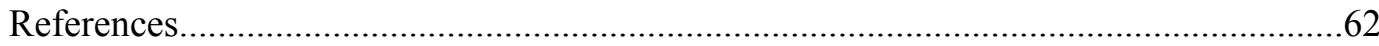

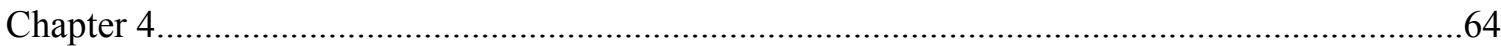

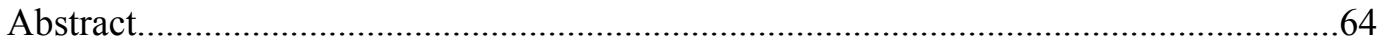

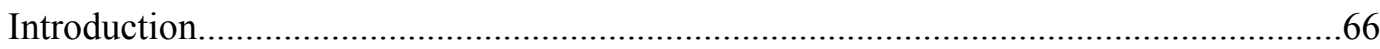

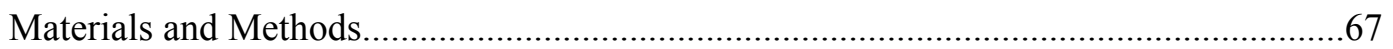

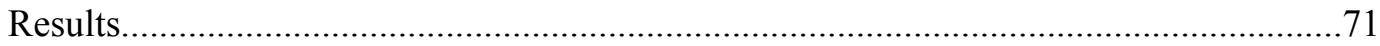

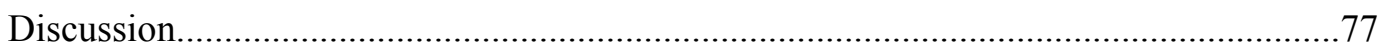

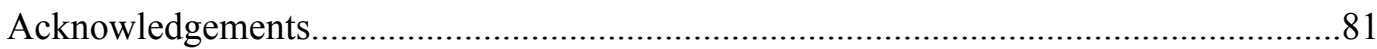

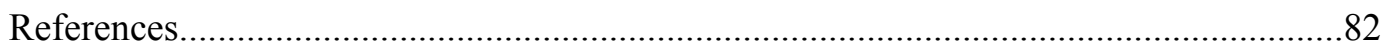

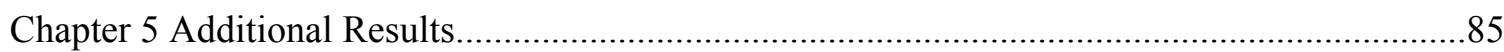

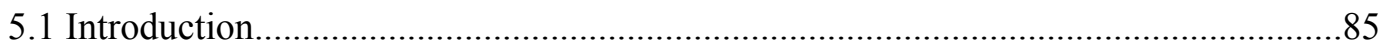

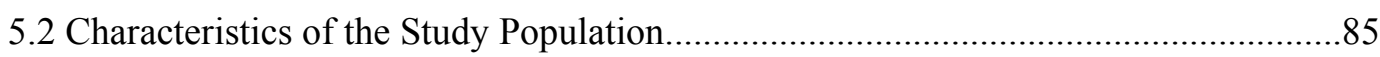

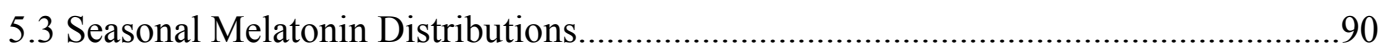

5.4 Distributions and Determinants of Sex Hormones...................................................92

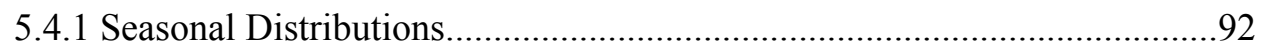

5.4.2 Sex Hormones by Menstrual Cycle Stage................................................97

5.4.3 Sex Hormones and Other Reproductive Factors.......................................100

5.4.4 Sex Hormone Inter-relationships..........................................................103

5.5 Bivariate Melatonin-Sex Hormone Relationships...................................................... 104

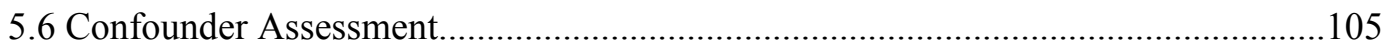

5.7 Regression Diagnostics and Sensitivity Analyses................................................... 105

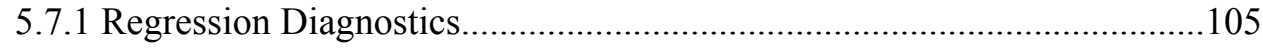

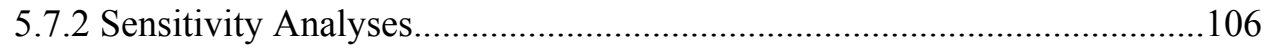

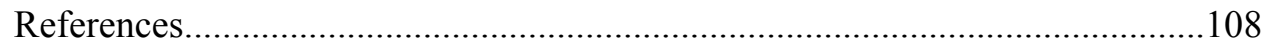

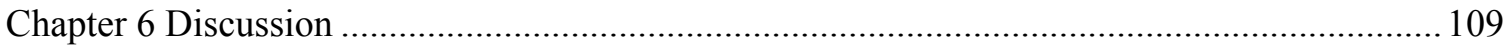




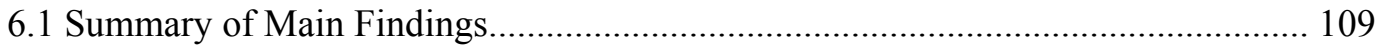

6.1.1 Seasonal Distributions of Melatonin and Sex Hormones..................................... 109

6.1.2 Other Determinants of Sex Hormones.....................................................109

6.1.3 Melatonin-Sex Hormone Relationships...................................................111

6.1.4 Night Shift-work and Sex Hormones....................................................115

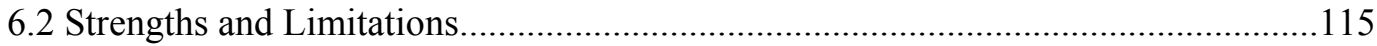

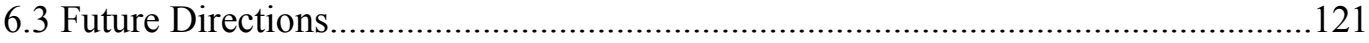

6.4 Contribution of Research and Conclusions..............................................................122

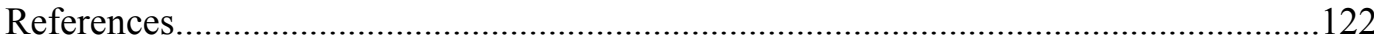

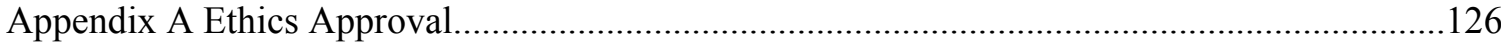

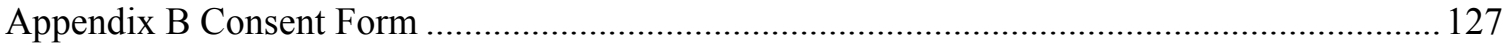

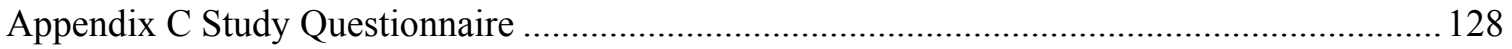

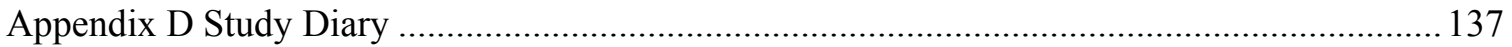

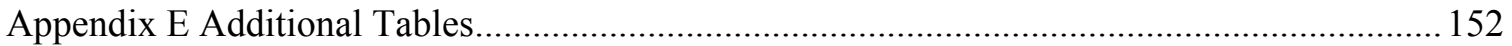




\section{List of Figures}

\section{Chapter 1}

1.1 Shift-work and breast cancer risk - proposed biological pathway

Chapter 2

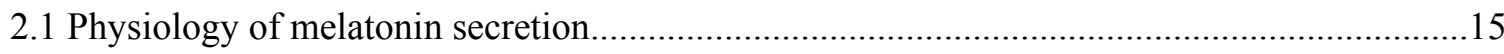

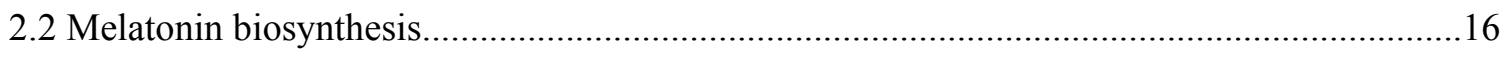

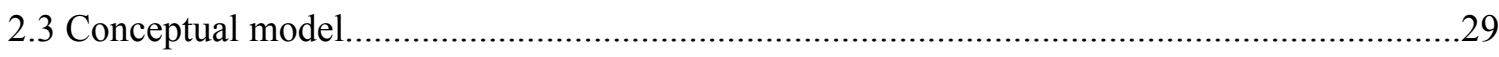

\section{Chapter 3}

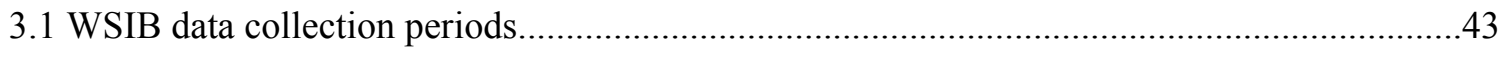

3.2 Changes in sex hormones over the menstrual cycle .........................................................52

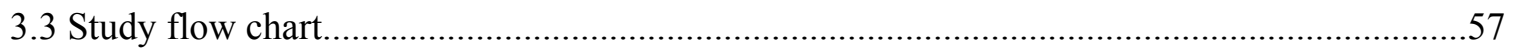

\section{Chapter 4}

Figure 1 Multivariate-adjusted geometric means of sex hormones by melatonin tertile......

\section{Chapter 5}

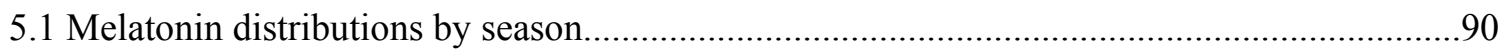

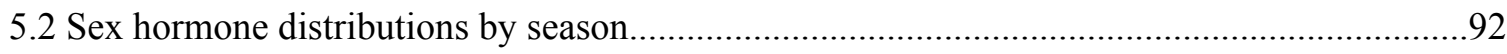

5.3 Geometric sex hormone means by menstrual cycle.............................................................99

5.4 Geometric sex hormone means by menstrual cycle and oral contraceptive use.....................102

\section{Appendix E}

Figure 1 Multivariate-adjusted associations between melatonin and sex hormones. .158 


\section{List of Tables}

\section{Chapter 3}

3.1 Final sample sizes

\section{Chapter 4}

Table 1 Baseline characteristics of the study population. .71

Table 2 Seasonal characteristics of the study population. 72

Table 3 Multivariate-adjusted associations between melatonin (continuous) and sex hormones (all log-transformed) .73

Table 4 Multivariate-adjusted associations between night shift-work (continuous; under 20 vs.

$20+$ years) and sex hormones (log-transformed) .76

\section{Chapter 5}

5.1 Baseline characteristics of study population by degree of study participation. .87

5.2 Seasonal characteristics of the study population. .88

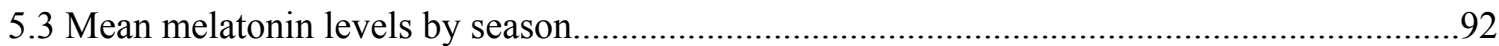

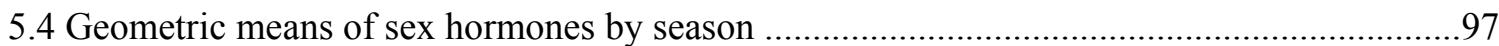

5.5 Mean sex hormone levels by menstrual cycle stage and season...........................................98

5.6 Bivariate associations of reproductive characteristics and sex hormones............................101

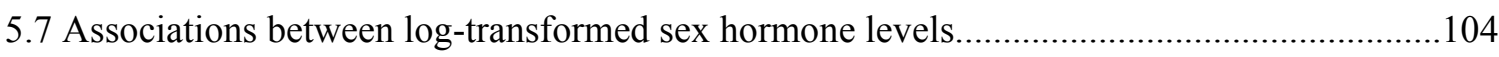

5.8 Bivariate relationships between log-transformed melatonin and sex hormones.....................104

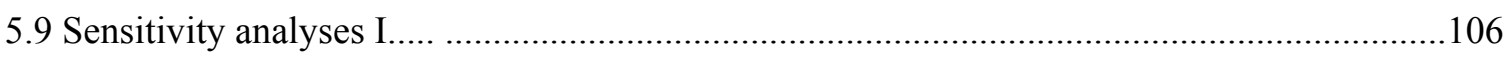

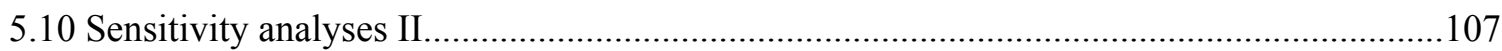

\section{Chapter 6}

6.1 Post-hoc power calculations.

\section{Appendix E}

Table 1 Bivariate associations between potential confounders and sex hormones.

Table 2 Associations between melatonin and sex hormones. 156

Table 3 Association of night shift-work history with sex hormone levels .157 


\section{List of Acronyms and Abbreviations}

\begin{tabular}{|c|c|}
\hline ANCOVA & Analysis of covariance \\
\hline ANOVA & Analysis of variance \\
\hline aMT6-s & 6-sulfatoxymelatonin \\
\hline BCAK & Breast Cancer Action Kingston \\
\hline BMI & Body mass index \\
\hline BRCA1/2 & Breast cancer genes $1 / 2$ \\
\hline $\mathrm{CI}$ & $95 \%$ Confidence interval \\
\hline $\mathrm{CV}$ & Coefficient of variation \\
\hline DHEAS & Dehydroepiandrosterone sulfate \\
\hline ELISA & Enzyme-linked immunosorbent assay \\
\hline ER & Estrogen receptor \\
\hline FSH & Follicle stimulating hormone \\
\hline HICL & Hospitals In Common Laboratory \\
\hline HRT & Hormone replacement therapy \\
\hline IARC & International Agency for Research on Cancer \\
\hline $\mathrm{KGH}$ & Kingston General Hospital \\
\hline LAN & Light at night \\
\hline LH & Luteinizing hormone \\
\hline MUMC & McMaster University Medical Centre \\
\hline NHS & Nurses Health Study \\
\hline OR & Odds ratio \\
\hline $\mathrm{OC}$ & Oral contraceptives \\
\hline PR & Progesterone receptor \\
\hline $\mathrm{R}^{2}$ & R-squared value \\
\hline RIA & Radioimmunoassay \\
\hline $\mathrm{RR}$ & Relative risk \\
\hline SAS & Statistical Analysis Software \\
\hline $\mathrm{SCN}$ & Suprachiasmatic nucleus \\
\hline SERM & Selective estrogen receptor modulator \\
\hline WSIB & Workplace Safety and Insurance Board \\
\hline
\end{tabular}




\section{Chapter 1 Introduction}

\subsection{Breast Cancer}

As the leading cause of cancer incidence and the second leading cause of cancer death (1), breast cancer is a tremendous burden to the health and well-being of Canadian women. In 2010, 23,300 new cases and 5,400 breast cancer deaths are expected in Canada (1). Globally, breast cancer is the leading cause of both cancer incidence and death among women (2). Despite much research in the field of breast cancer etiology, the causes of this disease remain largely unknown. With less than half of new cases explained by established risk factors $(3,4)$, there is a continued need to search for additional etiologic influences.

\subsection{Shift-work and Breast Cancer}

In 2007, the International Agency for Research on Cancer (IARC) classified shift-work as a probable carcinogen (Group 2A) (5) based on limited epidemiological evidence demonstrating modestly increased risks of cancer of the breast (6-9), prostate $(10,11)$, colon $(12)$ and endometrium (13), and sufficient experimental evidence that demonstrated biological plausibility for this link. The majority of research has focused on shift-work and the risk of breast cancer, a hormonally dependent malignancy, as some of the earliest hypotheses upon which this research is based were hormonal in nature $(14,15)$. Meta-analyses indicate that shift-workers are at a statistically significant $40-50 \%$ increased risk of breast cancer $(16,17)$.

\subsection{Potential Intermediates}

A potential mechanism linking shift-work to increased breast cancer risk is by way of irregular light exposure, specifically exposure to light at night (LAN) (18). The biological basis for this hypothesis involves melatonin, a hormone whose production is suppressed by light exposure (19) and which may have cancer-protective properties (20). As such, exposure to LAN may increase breast cancer risk through reductions in melatonin (Figure 1.1). 
Figure 1.1 Shift-work and breast cancer risk - proposed biological pathway

\begin{tabular}{c}
$\begin{array}{c}\text { Shift Work } \\
\text { Patterns }\end{array} \longrightarrow \uparrow$ Light at Night $\longrightarrow$ Melatonin $\longrightarrow \uparrow \begin{array}{c}\text { Breast Cancer } \\
\text { Risk }\end{array}$ \\
\hline
\end{tabular}

This conceptual pathway, as described in several reviews $(6,16,17,21,22)$, has been developed through the collection of epidemiological and experimental evidence. Epidemiological studies have observed associations between shift-work, LAN, and increased breast cancer risk $(16,17)$; between shift-work, LAN, and decreased melatonin levels $(18,23-25)$; and between decreased melatonin levels and increased breast cancer risk $(6,26-28)$. Some of these relationships have been validated in experimental studies, including direct carcinogenic effects of exposure to LAN in animal models $(29,30)$, and cancer protective effects of melatonin in animal models (31-36) and cell culture studies $(31,37,37,38)$. The strong experimental evidence as described provides the most compelling evidence for the carcinogenicity of shift-work given the clear biological plausibility for this pathway.

Despite this evidence, there is little consensus on exactly how melatonin confers breast cancer protection. One potential mechanism involves interactions of melatonin with sex hormones, originally described by Cohen in 1978 (14). This hormonal pathway is supported by strong evidence for a relationship between melatonin and cancer of the breast specifically, given the hormone dependency of this disease. Sex hormones play a critical role in the etiology of breast cancer, with many of the strongest breast cancer risk factors believed to confer risk through increasing cumulative lifetime exposure to these hormones (39-42). Increased endogenous sex hormone levels have also been associated with increased breast cancer risk (43-47) and direct carcinogenic effects of sex hormones have been demonstrated in mammary tissue $(32,48-50)$. Interaction of melatonin with sex hormones are most well-known in seasonally breeding species, where melatonin levels, influenced by season and daylight, control several aspects of reproduction (51-53). Studies of human reproduction $(21,54-61)$ and experimental melatonin trials $(60,62-66)$ have supported these relationships in humans under certain reproductive, 
pathological and pharmacological conditions. Epidemiological studies have sought to characterize these relationships in an observational setting which is of greater relevance to normal human physiology; however, the results have been less than convincing (67-71).

\subsection{Summary of Thesis Rationale}

It is of primary importance to identify and understand the pathways linking shift-work and LAN to increased breast cancer risk such that strategies may be developed to minimize health impacts of this work schedule. One possible pathway involves melatonin and its inhibitory influence on sex hormone levels. For this pathway to be scientifically validated, confirmation from observational studies on humans, of more direct relevance to human health, is required.

Through elucidating a clearer biological model, evidence for the carcinogenicity of shiftwork, for which epidemiological research has been weak or inconsistent, may be better supported. If increased sex hormone levels are considered an intermediate to increased breast cancer risk, associations between altered melatonin production and sex hormone levels could add strength to our understanding of this pathway. Improved knowledge and appreciation of these relationships may enhance the magnitude and timeliness of policy responses towards the health of shiftworking women. With over $25 \%$ of Canadian working women performing regular shift-work at some point in their lives (72), this is an important public health concern in need of further study.

\subsection{Overview of Study Design}

To examine potential relationships between melatonin and sex hormone levels, an observational study of pre-menopausal nurses at Kingston General Hospital (KGH) was conducted. These nurses worked a rotating pattern of two days (7AM-7PM), two nights (7PM7AM), followed by five days off. This thesis research was a sub-set of a larger observational study lead by Dr. Kristan Aronson (73) that involved a series of seasonal study periods over two years. Melatonin and sex hormone levels were measured from urine and blood samples, respectively, provided by nurses in both winter and summer seasons. Covariate information was collected by measurement (height and weight) and self-report via questionnaire and study diary. 


\subsection{Objectives}

The primary goal of this thesis was to examine relationships between melatonin and sex hormones among pre-menopausal rotating shift nurses. Cross-sectional relationships, within each of two seasons, and longitudinal relationships, across seasons, were explored to investigate two latency periods. Associations of night shift-work history and sex hormones were also assessed.

\subsection{Thesis Structure}

The chapters of this thesis consist of a literature review on the current state of knowledge of shift-work, potential intermediates and breast cancer risk; a description of research methodology; a manuscript formatted for Chronobiology International, additional results not presented in the manuscript; and, a general discussion of main research findings that includes strengths and limitations, comparisons to other studies, and suggestions for future research.

\section{References}

1. Canadian Cancer Society's Steering Committee. Canadian cancer statistics 2010. Toronto: Canadian Cancer Society; 2010.

2. Parkin DM, Bray F, Ferlay J, Pisani P. Global cancer statistics, 2002. CA Cancer J Clin. 2005 Mar-Apr;55(2):74-108.

3. Friedenreich CM, Marrett LD. Workshop report: Identification of research needs in breast cancer etiology. Chronic Dis Can. 2001;22(2):41-9.

4. Madigan MP, Ziegler RG, Benichou J, Byrne C, Hoover RN. Proportion of breast cancer cases in the united states explained by well-established risk factors. J Natl Cancer Inst. 1995 Nov 15;87(22):1681-5.

5. Straif K, Baan R, Grosse Y, Secretan B, Ghissassi FE, Bouvard V, et al. Carcinogenicity of shift-work, painting, and fire-fighting. The Lancet Oncology. 2007 12;8(12):1065-6.

6. Davis S, Mirick DK. Circadian disruption, shift-work and the risk of cancer: A summary of the evidence and studies in seattle. Cancer Causes Control. 2006;17(4):539-45.

7. Davis S, Mirick DK, Stevens RG. Night shift work, light at night, and risk of breast cancer. J Natl Cancer Inst. 2001 Oct 17;93(20):1557-62.

8. Schernhammer ES, Laden F, Speizer FE, Willett WC, Hunter DJ, Kawachi I, et al. Rotating night shifts and risk of breast cancer in women participating in the nurses' health study. J Natl Cancer Inst. 2001 Oct 17;93(20):1563-8.

9. Schernhammer ES, Kroenke CH, Laden F, Hankinson SE. Night work and risk of breast cancer. Epidemiology. 2006 Jan;17(1):108-11.

10. Kubo T, Ozasa K, Mikami K, Wakai K, Fujino Y, Watanabe Y, et al. Prospective cohort study of the risk of prostate cancer among rotating-shift workers: Findings from the japan collaborative cohort study. Am J Epidemiol;164(6):549-55.

11. Conlon M, Lightfoot N, Kreiger N. Rotating shift work and risk of prostate cancer. Epidemiology. 2007 January;18(1):182-3. 
12. Schernhammer ES, Laden F, Speizer FE, Willett WC, Hunter DJ, Kawachi I, et al. Nightshift work and risk of colorectal cancer in the nurses' health study. J Natl Cancer Inst. 2003 Jun 4;95(11):825-8.

13. Viswanathan AN, Hankinson SE, Schernhammer ES. Night shift work and the risk of endometrial cancer. Cancer Res. 2007 Nov 1;67(21):10618-22.

14. Cohen M, Lippman M, Chabner B. Role of the pineal gland in etiology and treatment of breast cancer. The Lancet. 1978 10/14;312(8094):814-6.

15. Stevens RG. Electric power use and breast cancer: A hypothesis. Am J Epidemiol. 1987 Apr;125(4):556-61.

16. Erren TC, Pape HG, Reiter RJ, Piekarski C. Chronodisruption and cancer. Naturwissenschaften. 2008 May;95(5):367-82.

17. Megdal SP, Kroenke CH, Laden F, Pukkala E, Schernhammer ES. Night work and breast cancer risk: A systematic review and meta-analysis. Eur J Cancer. 2005 Sep;41(13):2023-32.

18. Schernhammer ES, Schulmeister K. Melatonin and cancer risk: Does light at night compromise physiologic cancer protection by lowering serum melatonin levels? Br J Cancer. 2004 Mar 8;90(5):941-3.

19. McIntyre IM, Norman TR, Burrows GD, Armstrong SM. Quantal melatonin suppression by exposure to low intensity light in man. Life Sci;45(4):327-32.

20. Grant SG, Melan MA, Latimer JJ, Witt-Enderby PA. Melatonin and breast cancer: Cellular mechanisms, clinical studies and future perspectives. Expert Rev Mol Med. 2009 Feb 5;11:e5.

21. Brzezinski A. Melatonin in humans. N Engl J Med. 1997 Jan 16;336(3):186-95.

22. Srinivasan V, Spence DW, Pandi-Perumal SR, Trakht I, Esquifino AI, Cardinali DP, et al. Melatonin, environmental light, and breast cancer. Breast Cancer Res Treat. 2008 Apr;108(3):339-50.

23. Borugian MJ, Gallagher RP, Friesen MC, Switzer TF, Aronson KJ. Twenty-four-hour light exposure and melatonin levels among shift workers. Journal of Occupational \& Environmental Medicine. 2005 December;47(12):1268-75.

24. Burch JB, Yost MG, Johnson W, Allen E. Melatonin, sleep, and shift work adaptation. JOEM. Sept 2005; 47(9):893-901.

25. Hansen AM, Garde AH, Hansen J. Diurnal urinary 6-sulfatoxymelatonin levels among healthy Danish nurses during work and leisure time. Chronobiol Int. 2006;23(6):1203-15.

26. Schernhammer ES, Hankinson SE. Urinary melatonin levels and breast cancer risk. J Natl Cancer Inst. 2005 Jul 20;97(14):1084-7.

27. Schernhammer ES, Hankinson SE. Urinary melatonin levels and postmenopausal breast cancer risk in the nurses' health study cohort. Cancer Epidemiol Biomarkers Prev. 2009 Jan;18(1):74-9.

28. Schernhammer ES, Berrino F, Krogh V, Secreto G, Micheli A, Venturelli E, et al. Urinary 6sulfatoxymelatonin levels and risk of breast cancer in postmenopausal women. J Natl Cancer Inst. 2008 Jun 18;100(12):898-905.

29. Mhatre MC, Shah PN, Juneja HS. Effect of varying photoperiods on mammary morphology, DNA synthesis, and hormone profile in female rats. J Nat Cancer Inst. 1984 Jun;72(6):1411-6

30. Shah PN, Mhatre MC, Kothari LS. Effect of melatonin on mammary carcinogenesis in intact and pinealectomized rats in varying photoperiods. Cancer Res. 1984 Aug;44(8):3403-7.

31. Cos S, Sánchez-Barceló EJ. Melatonin and mammary pathological growth. Front Neuroendocrinol. 2000 4;21(2):133-70.

32. Cos S, Sanchez-Barcelo EJ. Melatonin, experimental basis for a possible application in breast cancer prevention and treatment. Histol Histopathol. 2000 Apr;15(2):637-47.

33. Sanchez-Barcelo EJ, Cos S, Fernandez R, Mediavilla MD. Melatonin and mammary cancer: A short review. Endocr Relat Cancer. 2003 Jun;10(2):153-9.

34. Blask DE, Pelletier DB, Hill SM, Lemus-Wilson A, Grosso DS, Wilson ST, et al. Pineal melatonin inhibition of tumor promotion in the N-nitroso-N-methylurea model of mammary 
carcinogenesis: Potential involvement of antiestrogenic mechanisms in vivo. J Cancer Res Clin Oncol. 1991;117(6):526-32.

35. Tamarkin L, Cohen M, Roselle D, Reichert C, Lippman M, Chabner B. Melatonin inhibition and pinealectomy enhancement of 7,12-dimethylbenz(a)anthracene-induced mammary tumors in the rat. Cancer Res. 1981 Nov;41(11 Pt 1):4432-6.

36. Kothari L. Effect of melatonin on the mammary gland morphology, DNA synthesis, hormone profiles and incidence of mammary cancer in rats. In: Gupta D, Attanasio A, Reiter RJ, editors. The pineal gland and cancer. London: Brain Research Promotion; 1988. p. 210-219.

37. Blask DE, Hill SM. Effects of melatonin on cancer: Studies on MCF-7 human breast cancer cells in culture. J Neural Transm Suppl. 1986;21:433-49.

38. Cos S, Sanchez-Barcelo EJ. Differences between pulsatile or continuous exposure to melatonin on MCF-7 human breast cancer cell proliferation. Cancer Lett. 1994 Sep 30;85(1):105-9.

39. Dumitrescu RG, Cotarla I. Understanding breast cancer risk -- where do we stand in 2005? J Cell Mol Med. 2005 Jan-Mar;9(1):208-21.

40. Hankinson SE, Colditz GA, Willett WC. Towards an integrated model for breast cancer etiology: The lifelong interplay of genes, lifestyle, and hormones. Breast Cancer Res. 2004;6(5):213-8.

41. Hulka BS, Moorman PG. Breast cancer: Hormones and other risk factors. Maturitas. 2008 Sep-Oct;61(1-2):203,13; discussion 213.

42. Singletary KW, Gapstur SM. Alcohol and breast cancer: Review of epidemiologic and experimental evidence and potential mechanisms. JAMA. 2001 Nov 7;286(17):2143-51.

43. Key T, Appleby P, Barnes I, Reeves G, Endogenous Hormones and Breast Cancer Collaborative Group. Endogenous sex hormones and breast cancer in postmenopausal women: Reanalysis of nine prospective studies. J Nat Cancer Inst. 2002 Apr 17;94(8):606-16.

44. Woolcott C, Shvetsov Y, Stanczyk F, Wilkens L, White K, Caberto C, et al. Plasma sex hormone concentrations and breast cancer risk in an ethnically diverse population of postmenopausal women: The multiethnic cohort study. Endocr Relat Cancer. 2009 Nov 10.

45. Kaaks R, Berrino F, Key T, Rinaldi S, Dossus L, Biessy C, et al. Serum sex steroids in premenopausal women and breast cancer risk within the european prospective investigation into cancer and nutrition (EPIC). J Natl Cancer Inst. 2005 May 18;97(10):755-65.

46. Eliassen AH, Missmer SA, Tworoger SS, Spiegelman D, Barbieri RL, Dowsett M, et al. Endogenous steroid hormone concentrations and risk of breast cancer among premenopausal women. J Natl Cancer Inst. 2006 Oct 4;98(19):1406-15.

47. Thomas HV, Key TJ, Allen DS, Moore JW, Dowsett M, Fentiman IS, et al. A prospective study of endogenous serum hormone concentrations and breast cancer risk in premenopausal women on the island of guernsey. Br J Cancer. 1997;75(7):1075-9.

48. Russo IH, Russo J. Role of hormones in mammary cancer initiation and progression. J Mammary Gland Biol Neoplasia. 1998 Jan;3(1):49-61.

49. Key TJ, Verkasalo PK, Banks E. Epidemiology of breast cancer.Lancet Oncol.2001 Mar;2(3):133-40.

50. Yue W, Santen RJ, Wang JP, Li Y, Verderame MF, Bocchinfuso WP, et al. Genotoxic metabolites of estradiol in breast: Potential mechanism of estradiol induced carcinogenesis. $\mathrm{J}$ Steroid Biochem Mol Biol. 2003 Sep;86(3-5):477-86.

51. Arendt J. Melatonin and the mammalian pineal gland. London: Chapman and Hall; 1995.

52. Reiter RJ. Neuroendocrine effects of light. Int J Biometeorol. 1991 Nov;35(3):169-75.

53. Weaver DR, Stehle JH, Stopa EG, Reppert SM. Melatonin receptors in human hypothalamus and pituitary: Implications for circadian and reproductive responses to melatonin. J Clin Endocrinol Metab. 1993 Feb;76(2):295-301.

54. Cagnacci A, Volpe A. Influence of melatonin and photoperiod on animal and human reproduction. J Endocrinol Invest. 1996 Jun;19(6):382-411. 
55. Aleandri V, Spina V, Morini A. The pineal gland and reproduction. Hum Reprod Update. 1996 May-Jun;2(3):225-35.

56. Luboshitzky R, Lavie P. Melatonin and sex hormone interrelationships--a review. J Pediatr Endocrinol Metab. 1999 May-Jun;12(3):355-62.

57. Brzezinski A, Lynch HJ, Seibel MM, Deng MH, Nader TM, Wurtman RJ. The circadian rhythm of plasma melatonin during the normal menstrual cycle and in amenorrheic women. $\mathrm{J}$ Clin Endocrinol Metab. 1988 May;66(5):891-5.

58. Berga SL, Mortola JF, Yen SS. Amplification of nocturnal melatonin secretion in women with functional hypothalamic amenorrhea. J Clin Endocrinol Metab. 1988 Jan;66(1):242-4.

59. Waldhauser F, Weiszenbacher G, Frisch H, Zeitlhuber U, Waldhauser M, Wurtman RJ. Fall in nocturnal serum melatonin during prepuberty and pubescence. Lancet. 1984 Feb;1(8373):362-5.

60. Bellipanni G, Bianchi P, Pierpaoli W, Bulian D, Ilyia E. Effects of melatonin in perimenopausal and menopausal women: A randomized and placebo controlled study. Exp Gerontol. 2001 Feb;36(2):297-310.

61. Luboshitzky R, Lavie P. Melatonin and sex hormone interrelationships--a review. J Pediatr Endocrinol Metab. 1999 May-Jun;12(3):355-62.

62. Kripke DF, Kline LE, Shadan FF, Dawson A, Poceta JS, Elliott JA. Melatonin effects on luteinizing hormone in postmenopausal women: A pilot clinical trial NCT00288262. BMC Womens Health. 2006 May 16;6:8.

63. Pawlikowski M, Kolomecka M, Wojtczak A, Karasek M. Effects of six months melatonin treatment on sleep quality and serum concentrations of estradiol, cortisol, dehydroepiandrosterone sulfate, and somatomedin C in elderly women. Neuro Endocrinol Lett. 2002 Apr;23 Suppl 1:17-9.

64. Nordlund JJ, Lerner AB. The effects of oral melatonin on skin color and on the release of pituitary hormones. J Clin Endocrinol Metab. 1977 Oct;45(4):768-74.

65. Wright J, Aldhous M, Franey C, English J, Arendt J. The effects of exogenous melatonin on endocrine function in man. Clin Endocrinol (Oxf). 1986 Apr;24(4):375-82.

66. Voordouw BC, Euser R, Verdonk RE, Alberda BT, de Jong FH, Drogendijk AC, et al. Melatonin and melatonin-progestin combinations alter pituitary-ovarian function in women and can inhibit ovulation. J Clin Endocrinol Metab. 1992 Jan;74(1):108-17.

67. Danforth DN,Jr, Tamarkin L, Mulvihill JJ, Bagley CS, Lippman ME. Plasma melatonin and the hormone-dependency of human breast cancer. J Clin Oncol. 1985 Jul;3(7):941-8.

68. Schernhammer ES, Rosner B, Willett WC, Laden F, Colditz GA, Hankinson SE. Epidemiology of urinary melatonin in women and its relation to other hormones and night work. Cancer Epidemiol Biomarkers Prev. 2004 Jun;13(6):936-43.

69. Schernhammer ES, Kroenke CH, Dowsett M, Folkerd E, Hankinson SE. Urinary 6sulfatoxymelatonin levels and their correlations with lifestyle factors and steroid hormone levels. J Pineal Res. 2006 Mar;40(2):116-24.

70. Nagata C, Nagao Y, Yamamoto S, Shibuya C, Kashiki Y, Shimizu H. Light exposure at night, urinary 6-sulfatoxymelatonin, and serum estrogens and androgens in postmenopausal japanese women. Cancer Epidemiol Biomarkers Prev. 2008 Jun;17(6):1418-23.

71. Okatani Y, Morioka N, Wakatsuki A. Changes in nocturnal melatonin secretion in perimenopausal women: Correlation with endogenous estrogen concentrations. J Pineal Res. 2000 Mar;28(2):111-8.

72. Shields M. Shift work and health. Health Rep. 2002 Jul;13(4):11-33.

73. Aronson KJ, Richardson H, Tranmer J, Graham CH, Janssen I, Jones G. Occupational and other factors as determinants of melatonin levels among rotating shift nurses. 2007-2010 (\$447 769). 


\section{Chapter 2 Literature Review}

\subsection{Introduction}

This chapter begins with a brief overview of established breast cancer risk factors and a description of the hormone-dependency of the disease. Shift-work is introduced as a probable breast carcinogen and research on this link is evaluated. Potential biological models for this relationship are described with a focus on melatonin and sex hormones as possible intermediates.

\subsection{Breast Cancer Etiology}

\subsubsection{Established Risk Factors}

Recognized breast cancer risk factors include demographic, genetic, lifestyle, and reproductive characteristics. Beyond sex, age is the strongest risk factor, with risk roughly doubling for every ten year increase in age until menopause (1). Family history also has a role, with a recent pooled analysis of 52 epidemiological studies presenting statistically significant relative risks of 1.8, 2.9, and 3.9 for women with one, two, and three affected first degree relatives, respectively, compared to women with no family history (2). In terms of population attributable risk, close to $10 \%$ of breast cancer cases are due to a family history of breast cancer (3), with mutations in the tumor suppressor genes BRCA1 and BRCA2 believed to account for most familial clustering $(4,5)$. Lifestyle factors with established etiologic influences include obesity, physical activity, and alcohol consumption, and there are some differences in risk depending on menopausal status (pre/post). Whereas post-menopausal obesity is believed to double risk, pre-menopausal obesity appears to confer cancer protection (6). With this reasoning, the risk reduction from physical activity is strongest after menopause, possibly through reducing post-menopausal obesity (7). Studies have also demonstrated associations between alcohol consumption and increased breast cancer risk in both pre- and post-menopausal women $(8,9)$, with alcohol the only well-established dietary risk factor to date. 
Several important reproductive risk factors include early age at menarche, late age at menopause, late age at first full-term pregnancy, low parity, and the use of hormonal medications such as hormone replacement therapy (HRT) and to a lesser degree, oral contraceptives (OC) (1, 10). Other determinants of risk listed in a recent review include country of birth, personal history of breast cancer, high breast density (risk estimates $>4.0$ ), atypical hyperplasia of the breast, high dose radiation to the chest, and postmenopausal high bone density (risk estimates 2.1-4.0) (11).

\subsubsection{Reproductive Factors}

Breast cancer is understood as a hormone-dependent malignancy, with sex hormones playing a critical etiologic role. Carcinogenic influences of estrogen are explained through several mechanisms including stimulation of breast epithelial cell proliferation (12), mutagenic properties of estrogen metabolites (13-15), and to a lesser degree, through immunosuppressive effects (15). Studies suggest that progesterone and prolactin may act synergistically with estrogen at the breast epithelial cell to enhance proliferation and tumor development $(16,17)$.

Given this key role, several factors that increase breast cancer risk are believed to augment lifetime exposure to sex hormones. Most obvious are the influences of ages at menarche and menopause. A review (1) describes a three-fold increased risk of breast cancer for menarche before the age of 11, and a two-fold increased risk for menopause after the age of 54, with these risks conferred through increased lifetime ovulations and the associated prolonged exposure to cycling ovarian hormones (10). There is also evidence that the reduction in lifetime ovulations that occurs with increased parity and breastfeeding protects against breast cancer (11).

Obesity, physical activity, and alcohol consumption may also have roles in this hormonal pathway. Regarding obesity, as adipocytes (fat cells) are the primary site of estrogen production after menopause (18), post-menopausal obesity has been associated with a two-fold increased risk of breast cancer (1). In contrast, risk reduction is observed with pre-menopausal obesity, which may occur through reduced ovulatory frequency (10). Several hormonal mechanisms may explain 
the decreased breast cancer risk observed with physical activity, including delays in the age at menarche, regulation of weight gain, and the control of bioavailable hormone levels (10). Further, the increased breast cancer risk associated with alcohol consumption in both pre- and postmenopausal women acts most likely through increasing endogenous estrogen levels $(8,19-21)$.

Regarding endogenous sex hormone levels and breast cancer risk, a pooled analysis of nine prospective studies of post-menopausal women involving 663 breast cancer cases reported increased risks for increasing concentrations of several estrogen and androgen sub-types in blood (22). These findings have been replicated in newer prospective studies that include more ethnically diverse populations $(23,24)$. Studies have also demonstrated significant associations between plasma prolactin levels and post-menopausal breast cancer risk (25). Among premenopausal women, the role of endogenous sex hormones is less clear. Associations have been observed between increased estradiol $(26,27)$ and androgen $(27,28)$ levels and breast cancer risk; however, the relations of different hormones and are not consistent across studies (26-29). Nevertheless, these inconsistent results may be due to the highly cyclical nature of sex hormones in pre-menopausal women and the associated difficulties with obtaining accurate measures (27).

Given the critical role of sex hormones as described, several breast cancer prevention strategies have been developed to reduce endogenous sex hormone levels or to neutralize their effects, including increased physical activity, decreased alcohol consumption, and reducing postmenopausal obesity (30). More drastic approaches include surgery and chemoprevention, targeted specifically to highly susceptible women. Prophylactic bilateral oophrectomy (removal of the ovaries) through the suppression of ovarian hormone production reduces breast cancer risk by 50$70 \%$ (31). In fact, the discovery of the effects of this procedure by Beatson in 1896 was the founding event in the recognition for a role of sex hormones in the etiology of this disease (32). Selective estrogen receptor modulators (SERM) reduce the risk of estrogen-receptor (ER) positive breast cancer by reducing estrogenic influence on breast cells (33). Aromatase inhibitors, which block the major source of estrogen in post-menopausal women (34), are used for the 
prevention of breast cancer recurrence with potential for use as a general chemopreventive agent (18).

Given the critical role of sex hormones as described, it is suggested that hormone receptor positive vs. negative breast cancers are etiologically separate diseases, with sex hormones and their associated risk factors playing different roles in each cancer sub-type (35).

\subsubsection{Other Factors}

Despite several etiologic influences identified thus far, fewer than half of new breast cancer cases may be explained by established risk factors $(3,36)$. The discrepancy in breast cancer incidence between developed and developing countries (37), while in part explained by differences in disease detection and reproductive or lifestyle factors, has led some to suggest that breast cancer is a disease of the modern, industrialized society (38), influenced by societal and environmental exposures (39). In 1987, Stevens hypothesized that the increasing breast cancer incidence in industrialized countries may be in part explained by the rising use of artificial light at night (LAN) (40). This hypothesis has since been extended to include shift-work, brought about in industrialized countries for the 24-hr provision of medical care and other services (41), as a major source of LAN and probable breast cancer agent. As with other risk factors, evidence suggests that the link between shift-work and breast cancer risk may be hormonally mediated.

\subsection{Shift-work and Breast Cancer}

The International Agency for Research on Cancer (IARC) recently classified shift-work that involves circadian disruption as probable carcinogen (Group 2A) (42). Shift-work generally refers to work outside of standard daytime work hours, either beginning before 6AM or ending after 7PM (41), with some shift schedules believed to alter the body's internal day-night (circadian) rhythms (43). Most evidence of risk thus far has been observed for breast cancer, with findings from both retrospective and prospective epidemiological studies, and summary risk estimates quantified by meta-analyses. 
Case-control studies of shift-work and breast cancer have compared shift-work history of breast cancer cases and healthy controls; with past shift-work assessed through employment- and pension-based registries as well as by questionnaire and interview. A study of Norwegian telegraph operators of the merchant navy, which assessed work history through a seamen registry, reported a null or slightly increased risk of breast cancer $(\mathrm{OR}=4.3,95 \% \mathrm{CI} 0.7-26)$ for shift-working women (> 3 years) compared to women with no shift-work experience (44). Using a similar approach, a Danish study found that women who spent at least six months at jobs that involve regular night shifts had a statistically significant $50 \%$ increased risk compared to population controls, with work history assessed through a national pension registry (45). A register-linked case-control study nested within a Norwegian nurse registry also observed an increased breast cancer risk $(\mathrm{OR}=2.21,95 \% \mathrm{CI} 1.1-4.45)$ for nurses who had worked nights for 30 or more years compared to nurses who had not worked nights since nursing school (46).

Other retrospective studies have obtained more detailed shift-work histories through personal interviews and questionnaires, although these exposure assessments may be less objective and subject to recall errors. A questionnaire-based case-control study in the USA observed an increased breast cancer risk $(\mathrm{OR}=1.6,95 \% \mathrm{CI} 1.0-2.5)$ for women reporting having ever worked the 'graveyard' shift (started work after 7PM and finished by 9AM) compared to those who did not (47). In another interview-based case-control study nested in the Long Island Breast Cancer Project, shift-work was actually cancer protective: $\geq 8$ years of night shifts (at $>1$ night/ week) was associated with a $68 \%$ risk reduction $(\mathrm{OR}=0.3295 \% \mathrm{CI} 0.12-0.83)$, and a history of any overnight shift-work equated to a $45 \%$ reduced risk $(\mathrm{OR}=0.55,95 \% \mathrm{CI} 0.32-0.94)$ (48). Lastly, a recent case-control study, which assessed work history by telephone interview, presented a possible increased breast cancer risk among long-term shift-workers $(\geq 20$ years; OR $=2.48$ 95\% CI 0.62-9.99), while having ever worked nights did not influence risk (49).

Two studies of shift-work and breast cancer risk nested within the Nurses Health Study 
(NHS) prospective cohorts observed statistically significant increased breast cancer risks for nurses who reported working rotating shifts (have night shifts at least three times per month while also working days and evenings) prior to their cancer diagnosis $(50,51)$. The first study, which included both pre- and post-menopausal women, found that nurses who followed this shift pattern for at least 30 years had a statistically significant $36 \%$ increased risk compared to non-shiftworking nurses (50). The second study, restricted to pre-menopausal women, found a statistically significant $79 \%$ increased risk for nurses with at least 15 years of rotating shift experience (51).

Two more recent population-based cohort studies in Sweden (52) and China (53) found no evidence for an association. In the first study, shift-work history was only approximated using census data linked to a job-exposure matrix that identified jobs where shift-work was common (52). This creates the potential for misclassification of shift-work experience, which if nondifferential, may have biased effect estimates to the null. The second study used a similar job exposure matrix as well as questionnaire, yet neither assessment revealed associations of shiftwork and breast cancer risk including with analysis of long-term shift-work (20-30 years) (53).

Despite inconsistencies of research to date, some epidemiological studies as described have observed increased risks of breast cancer among shift-workers, with the strongest and most consistent evidence for longer term night shift-work (20-30 years) $(46,50,51)$. Research has been summarized in two meta-analyses, which present statistically significant summary risk estimates of $40-50 \%$ increased breast cancer risk for shift-workers who are defined as "night-time workers" (54) and "shift-workers" (including both night-time and rotating shift-workers) (55).

The conflicting results for associations between shift-work and breast cancer risk may be in part explained by inconsistent definitions and assessments of shift-work history in different studies. In April 2009, IARC convened a workshop to better define "shift-work" and to make recommendations for improved exposure assessment in studies of shift-work and cancer risk (56). It was recommended that shift-work be defined according to the level of displacement of the work day from the natural solar day, and that when feasible, future studies should include aspects 
of shift-work duration, intensity, cumulative exposure and timing within an individual's lifetime. Such comprehensive exposure assessment tools may help to elucidate the carcinogenicity of shiftwork and may help to identify the most harmful aspects of shift-work such that healthier shift schedules may be developed $(57,58)$.

It is important to note that the classification of shift-work as a probable carcinogen, while based on limited or conflicting epidemiologic evidence, was supported by abundant experimental evidence and biologically plausible models for carcinogenic potential, described below (42).

\subsection{Potential Intermediates}

\subsubsection{Light at Night}

One possible mechanism to explain the increased breast cancer risk observed in shiftworkers involves irregular light exposure patterns. In fact, research on shift-work and cancer was originally stimulated by a hypothesis describing increasing exposure to artificial light at night (LAN) as a possible explanation for increasing breast cancer incidence in industrialized countries (40). Ecological studies have since revealed co-distributions of LAN and cancer incidence at the population level, including breast, prostate, colon and lung cancers $(59,60)$. However, such "light pollution" may simply indicate of other features of industrial life that are difficult to assess at the ecological level, and so associations may be confounded. During typical shift-work schedules, workers experience both abnormal amounts and timing of light exposure $(61,62)$, with LAN of particular concern (63). Besides shift-work, epidemiological studies have revealed associations between other indicators of exposure to LAN and breast cancer risk, including being awake late at night, interrupted sleeping patterns, and greater nighttime residential light exposure $(47,48)$.

More direct evidence for the role of LAN comes from studies on the blind and in

laboratory animals. Research has shown a lower incidence of breast cancer among blind women (64) and a dose-response relationship of decreasing cancer risk with increasing degree of visual blindness (65). In laboratory studies where rodents are exposed to constant light, increased mammary tumor incidence and growth are observed $(66,67)$. In one elaborate experiment of rats 
bearing human breast cancer xenografts, a dose-response relationship was observed for increasing tumor growth with increasing light exposure (68).

The biological plausibility for LAN as an intermediate in the causal pathway of shiftwork and breast cancer is strong, as supported by the 'melatonin hypothesis' proposed by Stevens in 1987 (40). This theory describes melatonin, a cancer-protective hormone, as the intermediary link, with production of this hormone greatly suppressed by exposure to LAN (see Figure 1.1).

\subsubsection{Melatonin}

Melatonin is produced primarily by the pineal gland (69), which belongs to a larger phototransductive system that organizes bodily functions and physiology to the $24 \mathrm{~h}$ light-dark (circadian) cycle (70). External signals of light and darkness are received by specialized photoreceptor cells of the retina, which transmit this information to the suprachiasmatic nucleus (SCN)of the hypothalamus, otherwise known as the 'central biological clock'. Transmission of these signals from the SCN to the pineal gland moderates the synthesis and secretion of melatonin, with secretion enhanced by darkness and inhibited by light (Figure 2.1) (70).

Figure 2.1 Physiology of melatonin secretion

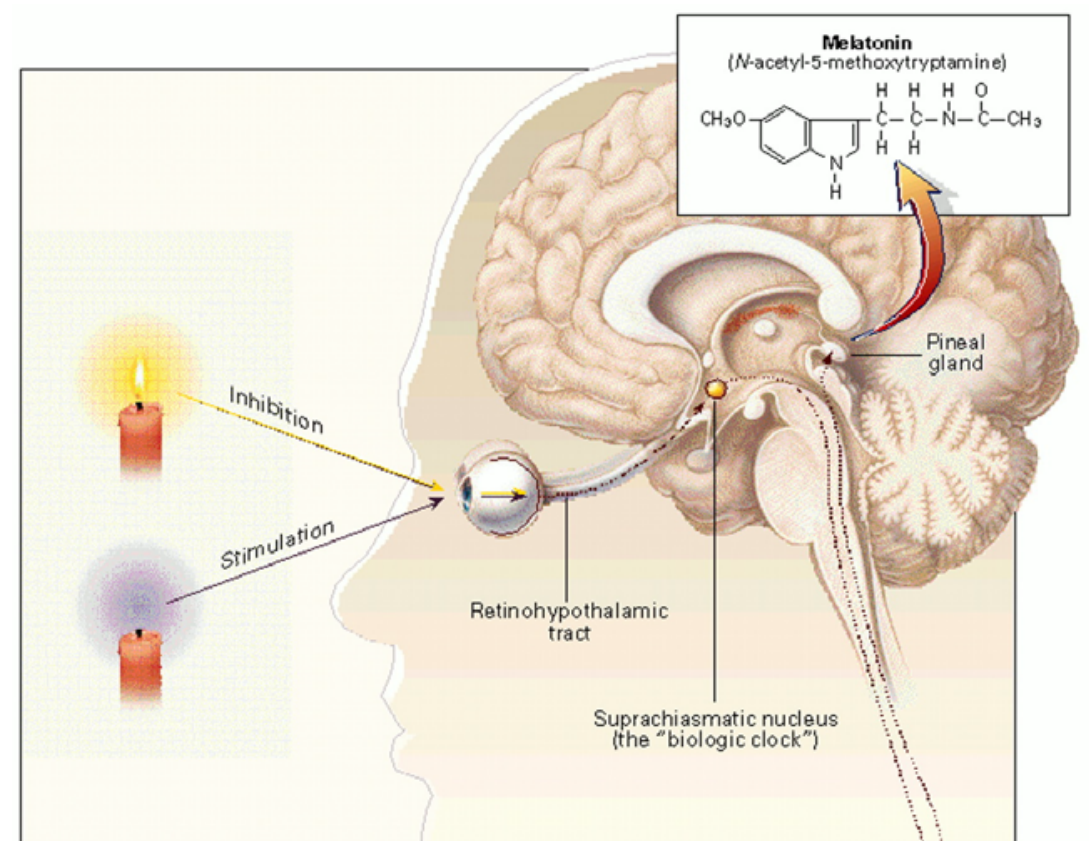

Brzezinski A. Melatonin in humans. N Eng J Med. 1997;336(3):186-95.(Reprinted with permission) 
Within the pineal gland, melatonin is synthesized from tryptophan through a series of enzymatic reactions, outlined in Figure 2.2. The activity of the enzymes involved is stimulated by 'dark signals' received by the SCN (71). Upon synthesis and accumulation, melatonin passively diffuses from the pineal gland to the bloodstream, where it quickly re-distributes to nearly all body tissues (72). Within its target sites, melatonin conveys information on the daily rhythms of light and darkness, allowing bodily functions to be synchronized to this cycle (73). Melatonin levels may therefore be considered both an indicator and regulator of circadian rhythms (74).

Figure 2.2 Melatonin biosynthesis

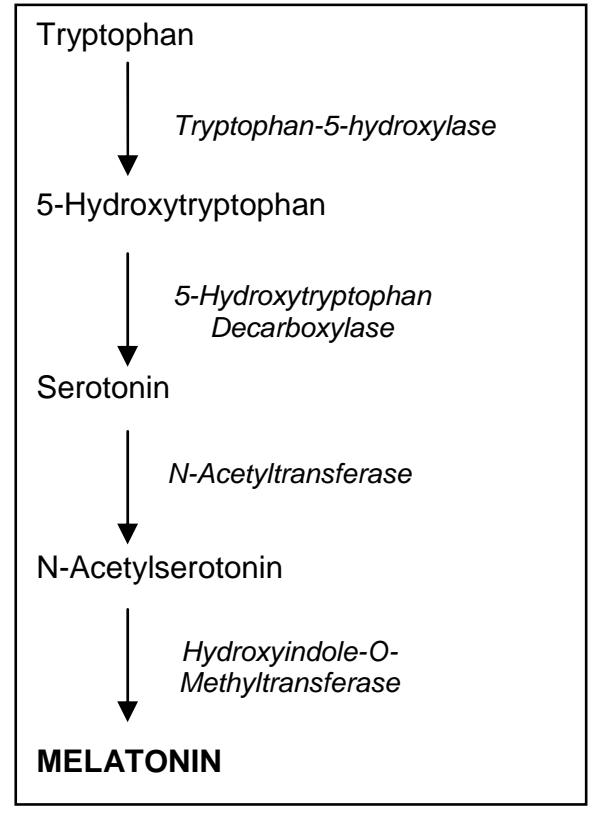

\subsubsection{Light at Night and Melatonin Levels}

With melatonin secretion enhanced by darkness, circulating melatonin levels rise and fall throughout the night and day (70). The majority of melatonin is secreted at night, from 2-4AM, with almost no day-time production (75). Despite large inter-individual variability in melatonin secretion $(76,77)$, peak nocturnal melatonin levels have demonstrated stability within individuals (78-80), with measures reasonably reproducible over a period of three-to-five years $(63,81)$. With light as the major moderator of melatonin secretion, exposure to LAN has the potential to both suppress nightly melatonin production and to alter the timing of peak melatonin secretion (69). 
Controlled experimental studies have assessed the impact of exposure to LAN on melatonin levels in humans. One study in which human subjects were exposed to varying intensities of LAN for one hour observed a robust dose-response relationship for suppression of melatonin with light, with minimal suppression at light intensities within the domestic light range (200 lux) and maximal suppression at the highest light intensities (2000-2500 lux, equivalent to natural outdoor light conditions) (82). Other studies have shown similar dose-response relationships and suppression of melatonin with domestic light intensities $(83,84)$.

Researchers are beginning to study these factors through epidemiological or biomarker studies of shift-work nurses, which show significantly reduced melatonin secretion under workplace circumstances of LAN exposure $(79,85,86)$. These studies have assessed nightly melatonin secretion through measurement of 6-sulfatoxymelatonin (aMT6-s), the primary melatonin metabolite, in morning void urine (see Section 2.4.4). Yamauchi et al. (85) and Hansen et al. (86) observed reduced aMT6-s levels among nurses when working nights compared to days and during days off, and Schernhammer et al. (79) observed a significant inverse association of aMT6-s levels and the number of nights worked in the two weeks preceding urine sampling.

Other biomarker studies have used direct measures of light intensity for more accurate assessment of exposure to LAN. Grundy et al. (62) observed a significant association between light intensity during sleeping hours and waking void aMT6-s levels among rotating shift nurses at Kingston General Hospital. Further, aMT6-s levels were significantly lower among night vs. day working nurses. Borugian et al. (61) found that shift-working nurses had irregular amounts and timing of light exposure, as well as reduced melatonin during sleep compared to day workers.

In addition to reduced melatonin secretion, some studies have suggested that shift-work and LAN may alter the timing of melatonin secretion, causing possible variations in the circadian rhythms of melatonin production $(61,87-89)$. A recent review suggests that such variations in rhythmic melatonin secretion among permanent night shift-workers do not completely re- 
synchronize to the altered light-dark cycle (90). For example, although the timing of peak melatonin production may be shifted, this shift may not coordinate entirely with the new circadian phase of the shift schedule. As melatonin is a major synchronizer for the rhythms of several downstream body functions and physiology, such disturbances in rhythmic melatonin secretion may lead to imbalances between the day-night cycle and the body's circadian timing, (circadian disruption) (91). These results have raised questions of whether the relationship of LAN and breast cancer risk is mediated through simple reductions in melatonin production, or through more complex disruptions of the circadian timing system (92). Variations in circadian rhythms of melatonin production with shift-work are not consistently observed across studies (62, 93, 94), and these results are likely dependent on the particular shift-work patterns studied. It has been argued by our research group that several of the relationships observed in the literature between shift-work and altered circadian melatonin production may be limited by the use of functional as opposed to chronological time points for comparisons of melatonin level across shift groups $(62,95)$. As such, differences in rhythmic melatonin secretion observed between groups may be due to inconsistent times of day of sample collection and not true circadian variation.

\subsubsection{Biomarkers of Melatonin}

Endogenous circulating melatonin levels can be characterized by biomarkers in blood, saliva and urine. Whereas blood and saliva samples can measure melatonin concentration directly, urine samples can assess levels of the major melatonin metabolite, 6-sulfatoxymelatonin (aMT6-s) (96). Although melatonin concentrations in blood are considered the gold standard for assessment of circulating melatonin levels (96), research often seeks to capture other biologically relevant measures such as total nocturnal melatonin output, peak nocturnal melatonin secretion and variations in the rhythms of melatonin production. Such measures can be assessed using urine and saliva samples, which are often more feasible than blood sampling. For example, as urinary melatonin metabolites accumulate between excretions, aMT6-s levels measured from morning 
void urine are a reflection of both the nocturnal melatonin secretion peak $(\mathrm{r}=0.68, \mathrm{p}<0.0001)$ and the total nocturnal melatonin output $(\mathrm{r}=0.74, \mathrm{p}<0.0001)$, with morning void levels accounting for close to $70 \%$ of total circulating melatonin from the previous night $(97,98)$. The sole urine sample required here is considerably more practical than the extensive blood sampling that would otherwise be required to assess this cumulative dose. Likewise, for the characterization of circadian variations in melatonin production, saliva measures are both highly accurate and of improved feasibility compared to blood sampling (96).

\subsection{Melatonin and Breast Cancer}

Melatonin's hypothesized role as an intermediate between shift-work, LAN and breast cancer risk is supported by both experimental and epidemiological research. Whereas epidemiological research has demonstrated correlations between melatonin and breast cancer risk in humans, experimental studies using animal models and cell culture have demonstrated direct anti-carcinogenic properties of melatonin and have also provided insight into the potential biological mechanisms through which melatonin may confer breast cancer protection.

\subsubsection{Experimental Evidence}

Laboratory studies have implicated a strong protective role for melatonin in breast cancer incidence and progression. In animal models, melatonin supplementation reduces the incidence and growth of mammary tumors $(12,16,99,100)$, whereas melatonin depletion through constant light exposure or pinealectomy (pineal gland removal) stimulates mammary tumor development $(101,102)$. Further, the stimulatory effect of pinealectomy is attenuated by melatonin supplementation (101). Strong evidence is also provided by studies of the human breast cancer cell line MCF-7, where proliferation and invasiveness of these cells is suppressed by melatonin $(12,103)$. Interestingly, these effects are strongest at peak physiological melatonin concentrations $(1 \mathrm{nM})(103)$, and when the melatonin concentration of the culture media is changed every $12 \mathrm{hr}$ (1nM night; 1pM day), replicating the human physiological melatonin cycle (104). 


\subsubsection{Epidemiological Evidence}

Several epidemiological studies have examined the association between melatonin and breast cancer risk. Case-control studies have observed reduced morning void aMT6-s levels among breast cancer cases compared to healthy controls $(105,106)$. Inverse relationships have also been observed between aMT6-s levels and tumor size (106), and malignancy status (107). From an etiological perspective, these studies are limited by the assessment of melatonin levels following breast cancer diagnosis and treatment, as it is unknown whether current melatonin levels are representative of those prior to cancer development, of etiologic relevance.

A few case-control studies nested in existing cohorts and using stored urine samples are not constrained by this temporality issue. These studies, nested within the Nurses Health Studies (NHS) I/II, and the Hormones and Diet in the Etiology of Breast Cancer Risk cohorts, all observed statistically significant $40-50 \%$ risk reductions for women with the highest vs. lowest quartiles of morning void aMT6-s, with adjustment for other important risk factors (108-110). Using similar methods, another study nested in the Guernsey III cohort found no association; however, melatonin was characterized here by the total urinary aMT6-s output over $24 \mathrm{hr}$, which

provides less information regarding both the amplitude and timing of melatonin production (111).

Epidemiological studies have also examined the role of melatonin in breast cancer progression. A meta-analysis of 10 clinical trials of melatonin supplementation in solid tumor patients shows significantly improved one-year survival across all cancers including breast (112).

\subsubsection{Mechanisms of Cancer Protection}

Melatonin may confer its cancer-protective effects through several molecular mechanisms. One potential pathway involves inhibitory influences on sex hormone levels, originally described by Cohen in 1978 (113). This hormonal mechanism is supported by strong evidence for a relationship between melatonin and cancer of the breast specifically, given the hormone-dependency of this disease, and is biologically plausible given the critical role of sex hormones in the etiology of breast cancer (see Section 2.2.2). 
Other proposed cancer-protective properties of melatonin include antioxidant action, immodulatory function and direct anti-mitotic and pro-apoptotic properties. A strong role for melatonin in free radical scavenging (anti-oxidant) pathways has been proposed, which may confer cancer protection through preventing oxidative DNA damage (114). In fact, these properties apply not only to melatonin but also to the hormone's secondary, tertiary and quaternary metabolites (115) making melatonin a highly effective anti-oxidant, stronger even than vitamin E, glutathione, and mannitol (114). Melatonin has also been shown to augment the differentiation and activity of several immune cell types, which may enhance both the detection and destruction of tumors by the immune system (116). Finally, other studies have suggested direct anti-mitotic and pro-apoptotic activities for melatonin, potentially mediated through upregulation of tumor suppressor gene p53 and downregulation of oncogene bcl-2 (117).

Intuitively, melatonin's cancer-protective potential may rely on the amount of melatonin secreted. Additionally, as melatonin receptor density and sensitivity vary through the circadian cycle (118), the timing of melatonin secretion is important to the hormone's downstream effects. Besides suppressed peak melatonin secretion, phase-shifting of melatonin production may also be important. This latter effect may confer breast cancer risk through other mechanisms than those described including through alterations in the expression of clock genes (91).

\subsection{Melatonin and Sex Hormones}

Inhibition of sex hormones was one of the first hypotheses to explain melatonin's cancerprotective effects (113). Interactions of melatonin and sex hormones are most well-known in seasonally breeding species, where melatonin levels, influenced by seasonal changes in daylength, synchronize mating and birth to season (119-121). This is believed to occur through melatonin's action at receptor sites in the hypothalamic-pituitary reproductive axis (121-124), where the hormone is proposed to inhibit both the pulsatile secretion of gonadotropin-releasing hormone $(\mathrm{GnRH})$ and the pituitary responses to this hormone, thereby indirectly downregulating the production of sex hormones in the gonads (125). Down-regulation of sex hormone levels by 
melatonin has been observed in several mammalian species, both seasonally and non-seasonally breeding (125-128).

Scientists have proposed similar seasonal influences of human reproduction $(70,128$ 131), and relationships between melatonin and sex hormones have been observed in humans under various reproductive and pathological conditions. Unusually high melatonin levels are associated with anovulation, oophrectomy (134), and other abnormal ovarian functions $(70,132$, 133). Further, relationships between melatonin and sex hormone levels have been observed at the onset of puberty $(70,135)$ and menopause $(134,136)$. High affinity melatonin receptors have been located at various points in the human reproductive axis, including in the hypothalamus, pituitary (121) and ovary (137). Studies of breast cancer patients support these relationships as they relate to cancer development: melatonin levels are significantly inversely related to the hormone receptor content, and therefore the hormone dependency, of breast tumors $(138,139)$.

Experimental research has attempted to confirm relationships of melatonin and sex hormones in animal models, cell culture studies and controlled human experiments. A few epidemiological studies have also sought to characterize these relationships in an observational setting, of greater relevance to normal human biology. Detailed evidence of these studies follows.

\subsubsection{Animal Models}

Studies on animal models have replicated many of the observations of seasonally breeding mammals described above. In rats, mechanisms of melatonin depletion (pinealectomy or constant light exposure) have been shown to enhance gonadal function (140), conceivably through increases in sex hormone levels, whereas supplementation delays the onset of puberty and the pubertal increases in sex hormones (141). In addition, melatonin administration in rats has been shown to block ovulation and the associated surge of luteinizing hormone (LH) (142).

\subsubsection{Cell Culture Studies}

In addition to the indirect neuroendocrine mechanism described thus far, cell culture 
studies have proposed a second direct mechanism to explain melatonin's regulation of sex hormones and subsequent influence on breast cancer risk. This direct pathway occurs at the level of the breast tumor cell, where melatonin may interfere with estrogen-mediated signaling. This mechanism has been put forth based on findings from in vitro studies involving the human breast cancer cell line MCF-7, as described in recent reviews $(99,143)$. In support of this pathway are the following: anti-proliferative effects of melatonin are seen only in cells expressing the estrogen receptor (12); estradiol-induced proliferation and invasiveness of these cells is inhibited by melatonin $(12,144)$; sensitivity of these cells to anti-estrogens such as tamoxifen is enhanced by melatonin (145); transfection of additional melatonin receptors potentiates melatonin's antiproliferative effect only in cells expressing the estrogen receptor (146); and lastly, melatonin has been shown to downregulate expression of the estrogen receptor $(147,148)$, and numerous estrogen-regulated proteins, growth factors and proto-oncogenes $(149,150)$.

Taken together, these observations point to a role for melatonin in the tumor cell estrogen signaling pathway. Proposed mechanisms of action include downregulation of the estrogen receptor (ER) (147), and inhibition of the binding of the estrogen-ER complex to its DNA estrogen response element (151). These potential mechanisms are unlike those of traditional antiestrogens (SERMs), which interfere with binding of estrogen to the ER at the cell surface (33).

\subsubsection{Experimental Studies on Humans}

Given the hypothesized role for melatonin in human reproduction as described above, several trials have explored melatonin's potential as a contraceptive agent. These studies have observed decreases in estrogen levels and at times, inhibition of ovulation with pharmacological doses of melatonin (152-154). Studies have also observed reduced LH $(136,153,155,156)$ and progesterone (153) with melatonin administration. However, these results are not consistent across studies $(157,158)$, and given the pharmacologic doses of melatonin used, it is unknown whether these relationships observed in some studies also occur under normal human physiology. 
Besides melatonin supplementation, experimental studies in humans have also examined the influence of controlled laboratory exposure to LAN or electromagnetic radiation (also implicated in the melatonin hypothesis) on melatonin and sex hormone levels $(157,159)$. In one study, while exposure to LAN suppressed nocturnal melatonin production, these changes were not associated with alterations in estradiol production among 44 healthy young women (157). Likewise, in another study where women were exposed to electromagnetic fields, decreases in melatonin secretion were not accompanied by changes in sex hormones (159). In these studies, it may be the case that such acute changes in melatonin secretion are not strong enough to elicit subsequent measurable changes in sex hormones over the course of a night. It is possible that chronic alterations in melatonin production, which may occur following long-term shift-work or melatonin supplementation, are required to lead to measurable changes in sex hormone levels.

\subsubsection{Observational Studies on Humans}

While some experimental studies have indicated inverse relationships between melatonin and sex hormones under certain laboratory conditions, few epidemiological studies have explored these relationships in an observational setting, of greater relevance to normal human physiology. In the first study to examine these relationships, Danforth et al. (138) observed no association between melatonin and any of the hormones measured (estrone, estradiol, progesterone, FSH and LH) among a group of pre- and post-menopausal breast cancer cases, healthy controls and highrisk controls $(n=93)$. Melatonin level was characterized by the day-to-night difference in serum melatonin levels, and as such, may not have adequately captured the biologically relevant peak nocturnal secretion. Furthermore, only bivariate associations were presented with no adjustments for potential confounders which may conceal true relationships (see Section 2.6.6).

In a trial melatonin supplementation over peri-menopause, baseline melatonin levels

(prior to supplementation) from nighttime saliva samples were inversely correlated with FSH ( $\mathrm{r}=$ $-0.322, \mathrm{p}<0.05)$ and $\mathrm{LH}(\mathrm{r}=-0.314, \mathrm{p}<0.05)$ but were not related to estrogen, progesterone or prolactin levels among the group of pre-, peri- and post-menopausal women (136). This study 
was similarly limited by the uncontrolled influences of potential confounding, and the assessment of melatonin level from saliva samples, which is not ideal to capture peak melatonin production (see Section 2.4.4). Further, given that many hormone-related breast cancer risk factors vary by menopausal status (see Section 2.2.2), proposed relationships between melatonin and sex hormones may also differ in post- vs. pre-menopausal women. By pooling these groups for analysis, relationships may be more difficult to assess. Subsequent studies have examined associations of melatonin and sex hormones among distinct menopausal groups and have accounted for important confounders in the analysis.

One study, which sought to characterize changes in melatonin and estradiol over menopause, found a strong inverse correlation between peak plasma melatonin and estradiol $(\mathrm{r}=$ 0.661, $\mathrm{p}<0.0005)(134)$. Biological sampling at a consistent menstrual stage controlled for this strong influence on sex hormone levels, and potential confounding effects of hormone medication was prevented by excluding its use for one year prior to the study. However, this result was restricted to a specific study subgroup of pre-menopausal women aged 40-50 years $(n=25)$.

Relationships between melatonin and sex hormone levels have also been investigated in the NHS cohorts, with adjustment for several other health, lifestyle and reproductive variables. The first of these, published in 2004, involved 80 pre-menopausal women who had not used hormonal medications for six months (79). Morning void aMT6-s levels were associated with bioavailable estradiol (circulating estradiol not bound to plasma proteins; $r=-0.25, p=0.05$ ), and progesterone $(r=0.31, p=0.01)$ levels measured during the luteal menstrual stage; although these relationships were slightly attenuated and no longer significant after adjustment for age and BMI. No association was observed between aMT6-s and total estradiol (bioavailable and proteinbound), estrone or prolactin levels, as measured during the luteal stage. Despite these findings, women who reported 15 years or more of rotating night shift-work had higher levels of total, bioavailable and free estradiol $(+14.3 \%, p=0.04 ;+29 \%, p=0.03$ and $+29 \%, p=0.02$, 
respectively) compared to women with no night shift experience. No association was observed between melatonin or night shift history and luteal estradiol, estrone or progesterone levels.

In 2006, the same group published a second study involving an additional 384 women, also mostly premenopausal and belonging to the NHS (160). Although this study no longer excluded the use of hormonal medications, information on their use and on alcohol consumption, physical activity, and several breast cancer risk factors was available and adjusted for in the analysis. A statistically significant but weak association was observed between aMT6-s level and overall estrone sulfate levels $(\mathrm{r}=0.13, \mathrm{p}=0.02)$, and a step-wise decline in follicular estradiol levels with increasing quartiles of aMT6-s was suggested $(p=0.07)$.

More recently, these relationships have been explored among 206 post-menopausal Japanese women (161). Despite controlling for the influences of hormonal medications and menstrual cycle stage (subjects were post-menopausal and use of hormonal medications was excluded), no association was observed between morning void aMT6-s (defined by tertiles) and any sex hormone assayed (estrone, estradiol, testosterone and DHEAS ) after adjustments for age, BMI, smoking status, alcohol intake and day length. It is possible that influences of melatonin on sex hormone production are more relevant to pre-menopausal women given the greater role of ovarian steroid production prior to menopause. Nevertheless, years of night work was associated with increased estrone $(\mathrm{p}=0.03)$ and having worked nights in the three years prior to study was statistically significantly associated with increased estrone and estradiol (p-values not reported).

\subsubsection{Limitations of Observational Research}

Despite some convincing evidence for relationships between melatonin and sex hormones in humans under certain reproductive, pathological and pharmacological conditions, the results of observational research exploring these relationships are less convincing. Many studies are limited by small sample size, the pooled analysis of pre- and post-menopausal women, and uncontrolled influences of potential confounders. However, it is possible that under normal conditions (i.e. minimal exposure to LAN), melatonin is not associated with sex hormones. As it is of interest to 
know whether these relationships mediate the shift-work-cancer link, it may be more relevant to study groups who perform regular shift-work or who have greater LAN exposure. Given the changes in melatonin experienced under these conditions, great extremes in exposure variability are likely and may aid in the statistical identification of melatonin-sex hormone relationships.

An additional limitation of studies to date is the examination of only cross-sectional relationships, as acknowledged by Schernhammer et al. (160): "a potential limitation of our study is its cross-sectional nature"; and by Nagata et al. (161): "the cross-sectional relations between serum estrogens and urinary melatonin levels may not fully reflect the long-term effects of exposure to light at night on estrogen and melatonin." As peak nocturnal melatonin secretion has demonstrated stability within individuals $(65,82)$, it is assumed in several studies that melatonin measures used to explore cross-sectional relationships are representative of long-term melatonin and that those relationships observed are representative of long-term influences of melatonin on sex hormones. However, seasonal differences in melatonin secretion have been described (119, $162,163)$, and it is therefore possible that cross-sectional melatonin measures are representative of levels for a more limited seasonal period. Longitudinal studies that measure melatonin and sex hormones across seasons may therefore provide additional information to these relationships.

It is biologically plausible that changes in melatonin levels have a delayed effect or latency period in influencing sex hormone levels. This has been suggested by experimental melatonin trials in humans. In one trial, the daily administration of pharmacologic doses of melatonin (300mg) lead to significantly decreased plasma progesterone and estradiol levels after four months use, compared to levels during the first medication month or to those of nonmedicated controls (153). In another study, the daily administration of physiological doses of melatonin (2mg) resulted in significantly decreased plasma estradiol levels after six months use, compared to baseline concentrations (154). In investigating proposed relationships of melatonin and sex hormones, it may therefore be important to consider possible latency effects. 


\subsubsection{Potential Confounders}

Factors that may influence both melatonin and sex hormone levels include OC use (164167), age $(70,134,168)$, BMI $(79,160,169)$, smoking $(160,168-170)$, alcohol $(168,171)$ and caffeine intake $(156,176,177)$, physical activity $(79,168,172-175)$, and time of day $(70,168,177)$.

Many of these variables have opposing influences on sex hormone and melatonin levels, and there are some differences for the relative importance of acute vs. long-term influences. Studies have demonstrated anti-estrogenic effects of current smoking in premenopausal women $(178,179)$ whereas both current and long-term smoking (cumulative pack-years) have been related to reduced melatonin (160). Likewise, current average alcohol consumption has been associated with increased sex hormone levels $(168,179)$, yet both acute (last $24-\mathrm{hr})(180)$ and long-term (171) intake have been related to reduced melatonin. Average daily caffeine intake has been associated with decreased sex hormone levels (181) and caffeine trials have observed similar reductions in melatonin $(156,176,177)$. In terms of physical activity, average higherintensity exercise completed per week has been associated with reduced sex hormone levels (79, 168) yet increased melatonin levels (79). Melatonin levels are also influenced acutely during and immediately following physical activity $(172,173)$. Lastly, melatonin and some sex hormones show diurnal variation, with levels tending to peak at night $(70,177,182)$ or early morning $(168)$.

Other variables are predictive of either melatonin or sex hormone levels only. For example, medications such as diuretics, NSAIDs, beta-blockers and sedatives have been shown to influence melatonin $(161,183,184)$, but no influence of these medications on sex hormones was identified in the literature. On the other hand, variables highly influential of sex hormone levels include menstrual cycle stage $(167,168,185)$ and pregnancy/ lactation $(168,186)$, yet it is unclear whether these variables influence melatonin $(128,132,165,187)$. Nevertheless, given their strong influences on sex hormone levels, potential confounding by these variables should not be overlooked. In addition, recent food consumption appears to influence both prolactin (188) and possibly estradiol levels (168), but has no reported influence on melatonin secretion. 
Figure 2.3 Conceptual Model

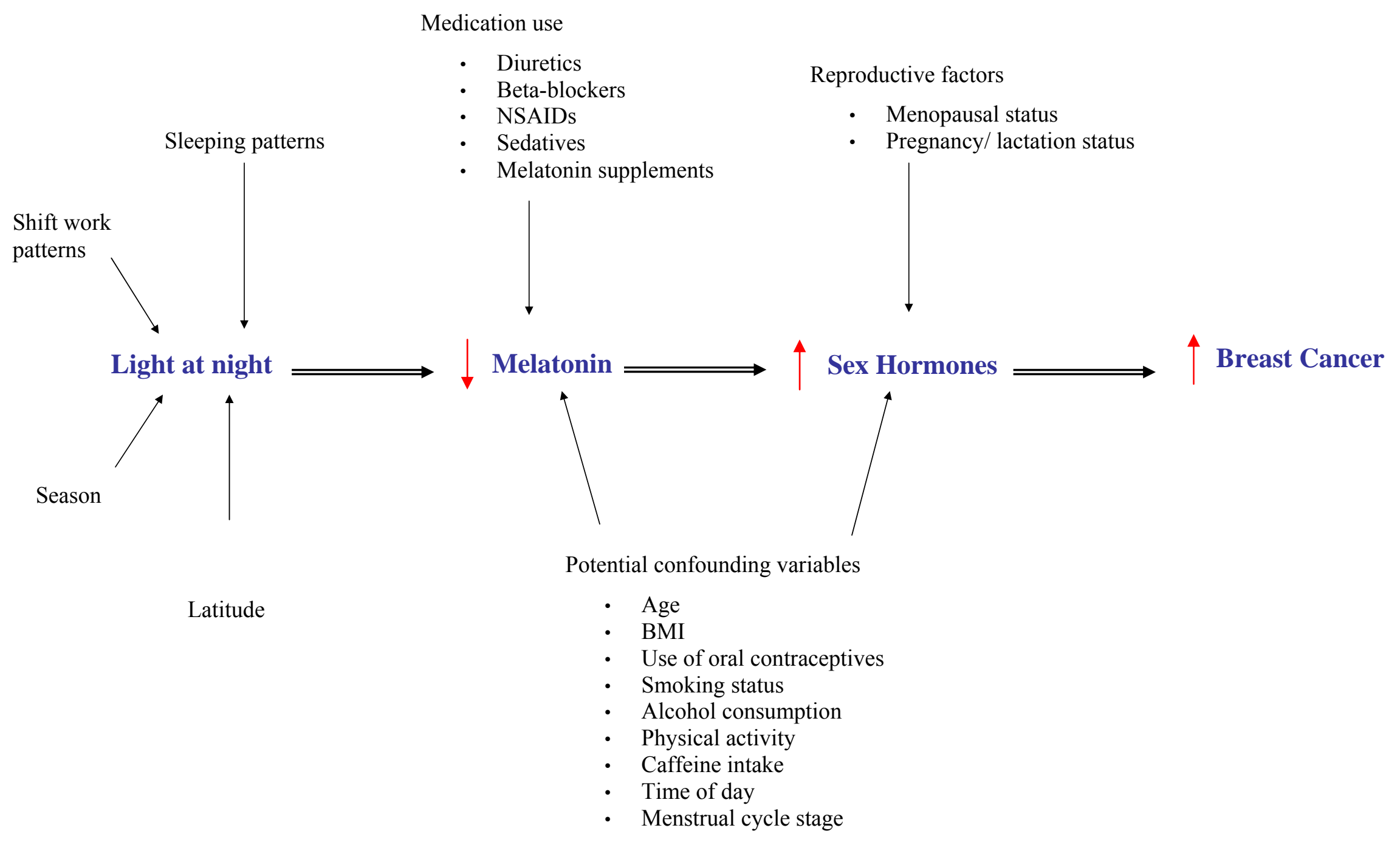




\subsection{Summary of Rationale}

The conceptual model linking shift-work, LAN and melatonin levels to an increased breast cancer risk (Figure 2.3) has been proposed through the compilation of epidemiological and experimental evidence. Epidemiological studies have observed relationships between shift-work, LAN and increased breast cancer risk $(45-48,50,51,54,55,189)$; between shift-work, LAN and decreased melatonin levels $(61,63,89,190)$; and finally, between decreased melatonin levels and increased breast cancer risk (108-110, 189). Some of these relationships have also been observed in experimental studies, including direct carcinogenic effects of LAN in animal models $(66,67)$, and direct cancer-protective effects of melatonin in animal models $(12,16,99-102)$ and cell culture studies $(12,103,103,104)$. It is the robust findings of experimental research to date, including several biologically plausible mechanisms, which enabled the classification of shiftwork as a probable carcinogen by IARC despite some limitations in human evidence. Many of these proposed biological models await demonstration in humans to further substantiate the carcinogenicity of shift-work, and to determine the relevance of these pathways to public health.

One potential mechanism for the shift-work breast cancer link involves inhibitory influences of melatonin on sex hormone production. Despite evidence for the role of melatonin in reproduction and regulation of sex hormones in other mammals (119-121, 125-128), and for relationships between melatonin and sex hormones in humans under various reproductive, pathological $(70,128-130,132,133,135,136)$ and experimental $(136,152-156)$ conditions, observational studies have produced less convincing results $(79,134,138,160,161)$. For proposed influences of melatonin on sex hormone levels to be scientifically validated, greater confirmation from observational studies on humans, of more direct relevance to normal human physiology, is required.

An identification and understanding of the pathways linking shift-work and LAN exposure to increased breast cancer risk is of critical importance to the development of strategies 
to minimize health impacts of this work schedule. Additionally, establishing a stronger biological model for this conceptual pathway will assist in supporting the overall hypothesis for the carcinogenicity of shift-work. With over $25 \%$ of Canadian working women performing regular shift-work at some point in their lives (41), this is an important public health concern in need of further study.

\section{References}

1. McPherson K, Steel CM, Dixon JM. ABC of breast diseases. Breast cancer-epidemiology, risk factors, and genetics. BMJ. 2000 Sep 9;321(7261):624-8.

2. Collaborative Group on Hormonal Factors in Breast Cancer. Familial breast cancer: Collaborative reanalysis of individual data from 52 epidemiological studies including 58,209 women with breast cancer and 101,986 women without the disease. Lancet. 2001 Oct 27;358(9291):1389-99.

3. Madigan MP, Ziegler RG, Benichou J, Byrne C, Hoover RN. Proportion of breast cancer cases in the united states explained by well-established risk factors. J Natl Cancer Inst. 1995 Nov 15;87(22):1681-5.

4. de Jong MM, Nolte IM, te Meerman GJ, van der Graaf WT, Oosterwijk JC, Kleibeuker JH, et al. Genes other than BRCA1 and BRCA2 involved in breast cancer susceptibility. J Med Genet. 2002 Apr;39(4):225-42.

5. Narod SA. Modifiers of risk of hereditary breast cancer. Oncogene. 2006 Sep 25;25(43):5832-6.

6. Hunter DJ, Willett WC. Diet, body size, and breast cancer. Epidemiol Rev.1993;15(1):110-32

7. Friedenreich CM, Courneya KS, Bryant HE. Influence of physical activity in different age and life periods on the risk of breast cancer. Epidemiology. 2001 Nov.;12(6):604-12.

8. Singletary KW, Gapstur SM. Alcohol and breast cancer: Review of epidemiologic and experimental evidence and potential mechanisms. JAMA. 2001 Nov 7;286(17):2143-51.

9. Baan R, Straif K, Grosse Y, Secretan B, El Ghissassi F, Bouvard V, et al. Carcinogenicity of alcoholic beverages. Lancet Oncol. 2007 Apr;8(4):292-3.

10. Hankinson SE, Colditz GA, Willett WC. Towards an integrated model for breast cancer etiology: The lifelong interplay of genes, lifestyle, and hormones. Breast Cancer Res. 2004;6(5):213-8.

11. Hulka BS, Moorman PG. Breast cancer: Hormones and other risk factors. Maturitas. 2008 Sep-Oct;61(1-2):203,13; discussion 213.

12. Cos S, Sánchez-Barceló EJ. Melatonin and mammary pathological growth. Front Neuroendocrinol. 2000 4;21(2):133-70.

13. Yager JD. Endogenous estrogens as carcinogens through metabolic activation. J Natl Cancer Inst Monogr. 2000;(27)(27):67-73.

14. Yue W, Santen RJ, Wang JP, Li Y, Verderame MF, Bocchinfuso WP, et al. Genotoxic metabolites of estradiol in breast: Potential mechanism of estradiol induced carcinogenesis. $\mathrm{J}$ Steroid Biochem Mol Biol. 2003 Sep;86(3-5):477-86.

15. Kovacs EJ, Messingham KA, Gregory MS. Estrogen regulation of immune responses after injury. Mol Cell Endocrinol. 2002 Jul 31;193(1-2):129-35. 
16. Cos S, Sanchez-Barcelo EJ. Melatonin, experimental basis for a possible application in breast cancer prevention and treatment. Histol Histopathol. 2000 Apr;15(2):637-47.

17. Key TJ, Verkasalo PK, Banks E. Epidemiology of breast cancer. Lancet Oncol. 2001 Mar;2(3):133-40.

18. Blaha P, Dubsky P, Fitzal F, Bachleitner-Hofmann T, Jakesz R, Gnant M, et al. Breast cancer chemoprevention - a vision not yet realized. Eur J Cancer Care (Eng). 2009 Sep;18(5):438-46

19. Dorgan JF, Baer DJ, Albert PS, Judd JT, Brown ED, Corle DK, et al. Serum hormones and the alcohol-breast cancer association in postmenopausal women. J Natl Cancer Inst. 2001 May 2;93(9):710-5.

20. Reichman ME, Judd JT, Longcope C, Schatzkin A, Clevidence BA, Nair PP, et al. Effects of alcohol consumption on plasma and urinary hormone concentrations in premenopausal women. J Natl Cancer Inst. 1993 May 5;85(9):722-7.

21. Reichman ME, Judd JT, Longcope C, Schatzkin A, Clevidence BA, Nair PP, et al. Effects of alcohol consumption on plasma and urinary hormone concentrations in premenopausal women. J Natl Cancer Inst. 1993 May 5;85(9):722-7.

22. Key T, Appleby P, Barnes I, Reeves G, Endogenous Hormones and Breast Cancer Collaborative Group. Endogenous sex hormones and breast cancer in postmenopausal women: Reanalysis of nine prospective studies. J Natl Cancer Inst. 2002 Apr;94(8):606-16.

23. Woolcott C, Shvetsov Y, Stanczyk F, Wilkens L, White K, Caberto C, et al. Plasma sex hormone concentrations and breast cancer risk in an ethnically diverse population of postmenopausal women: The multiethnic cohort study. Endocr Relat Cancer. 2009 Nov 10.

24. Kaaks R, Rinaldi S, Key TJ, Berrino F, Peeters PH, Biessy C, et al. Postmenopausal serum androgens, oestrogens and breast cancer risk: The european prospective investigation into cancer and nutrition. Endocr Relat Cancer. 2005 Dec;12(4):1071-82.

25. Hankinson SE, Willett WC, Michaud DS, Manson JE, Colditz GA, Longcope C, et al. Plasma prolactin levels and subsequent risk of breast cancer in postmenopausal women. J Natl Cancer Inst. 1999;91(7):629-634.

26. Thomas HV, Key TJ, Allen DS, Moore JW, Dowsett M, Fentiman IS, et al. A prospective study of endogenous serum hormone concentrations and breast cancer risk in premenopausal women on the island of guernsey. Br J Cancer. 1997;75(7):1075-9.

27. Eliassen AH, Missmer SA, Tworoger SS, Spiegelman D, Barbieri RL, Dowsett M, et al. Endogenous steroid hormone concentrations and risk of breast cancer among premenopausal women. J Natl Cancer Inst. 2006 Oct 4;98(19):1406-15.

28. Kaaks R, Berrino F, Key T, Rinaldi S, Dossus L, Biessy C, et al. Serum sex steroids in premenopausal women and breast cancer risk within the european prospective investigation into cancer and nutrition (EPIC). J Natl Cancer Inst. 2005 May 18;97(10):755-65.

29. Sturgeon SR, Potischman N, Malone KE, Dorgan JF, Daling J, Schairer C, et al. Serum levels of sex hormones and breast cancer risk in premenopausal women: A case-control study (USA). Cancer Causes Control. 2004 Feb;15(1):45-53.

30. Travis RC, Key TJ. Oestrogen exposure and breast cancer risk. Breast Cancer Res. 2003;5(5):239-47.

31. Rebbeck TR, Lynch HT, Neuhausen SL, Narod SA, Van't Veer L, Garber JE, et al. Prophylactic oophorectomy in carriers of BRCA1 or BRCA2 mutations. N Eng1 J Med. 2002 May 23;346(21):1616-22.

32. Forrest AP. Beatson: Hormones and the management of breast cancer. J R Coll Surg Edinb. 1982 Sep;27(5):253-63.

33. Powles TJ. Prevention of breast cancer using SERMs. Adv Exp Med Biol. 2008;630:232-6. 
34. Murphy MJ,Jr. Molecular action and clinical relevance of aromatase inhibitors. Oncologist. 1998;3(2):129-30.

35. Althuis MD, Fergenbaum JH, Garcia-Closas M, Brinton LA, Madigan MP, Sherman ME. Etiology of hormone receptor-defined breast cancer: A systematic review of the literature. Cancer Epidemiol Biomarkers Prev. 2004 Oct;13(10):1558-68.

36. Friedenreich CM, Marrett LD. Workshop report: Identification of research needs in breast cancer etiology. Chronic Dis Can. 2001;22(2):41-9.

37. Parkin DM, Bray F, Ferlay J, Pisani P. Global cancer statistics, 2002. CA Cancer J Clin. 2005 Mar-Apr;55(2):74-108.

38. Stevens RG, Davis S. The melatonin hypothesis: Electric power and breast cancer. Environ Health Perspect. 1996 Mar;104 Suppl 1:135-40.

39. Sasco AJ. Breast cancer and the environment. Horm Res. 2003;60 Suppl 3:50.

40. Stevens RG. Electric power use and breast cancer: A hypothesis. Am J Epidemiol. 1987 Apr;125(4):556-61.

41. Shields M. Shift work and health. Health Rep. 2002 Jul;13(4):11-33.

42. Straif K, Baan R, Grosse Y, Secretan B, Ghissassi FE, Bouvard V, et al. Carcinogenicity of shift-work, painting, and fire-fighting. The Lancet Oncology. 2007 12;8(12):1065-6.

43. Erren TC, Reiter RJ. Defining chronodisruption. J Pineal Res. 2009 Apr;46(3):245-7.

44. Tynes T, Hannevik M, Andersen A, Vistnes AI, Haldorsen T. Incidence of breast cancer in norwegian female radio and telegraph operators.Cancer Causes Control.1996 Mar;7(2):197-204

45. Hansen J. Increased breast cancer risk among women who work predominantly at night. Epidemiology. 2001 Jan;12(1):74-7.

46. Lie JA, Roessink J, Kjaerheim K. Breast cancer and night work among norwegian nurses. Cancer Causes Control. 2006 Feb;17(1):39-44.

47. Davis S, Mirick DK, Stevens RG. Night shift work, light at night, and risk of breast cancer. J Natl Cancer Inst. 2001 Oct 17;93(20):1557-62.

48. O'Leary ES, Schoenfeld ER, Stevens RG, Kabat GC, Henderson K, Grimson R, et al. Shift work, light at night, and breast cancer on long island, new york. Am J Epidemiol. 2006 Aug 15;164(4):358-66.

49. Pesch B, Harth V, Rabstein S, Baisch C, Schiffermann M, Pallapies D, et al. Night work and breast cancer - results from the german GENICA study. Scand J Work Environ Health. 2010 Mar;36(2):134-41.

50. Schernhammer ES, Laden F, Speizer FE, Willett WC, Hunter DJ, Kawachi I, et al. Rotating night shifts and risk of breast cancer in women participating in the nurses' health study. J Natl Cancer Inst. 2001 Oct 17;93(20):1563-8.

51. Schernhammer ES, Kroenke CH, Laden F, Hankinson SE. Night work and risk of breast cancer. Epidemiology. 2006 Jan;17(1):108-11.

52. Schwartzbaum J, Ahlbom A, Feychting M. Cohort study of cancer risk among male and female shift workers. Scand J Work Environ Health. 2007 Oct;33(5):336-43.

53. Pronk A, Ji BT, Shu XO, Xue S, Yang G, Li HL, et al. Night-shift work and breast cancer risk in a cohort of chinese women. Am J Epidemiol. 2010 May 1;171(9):953-9.

54. Megdal SP, Kroenke CH, Laden F, Pukkala E, Schernhammer ES. Night work and breast cancer risk: A systematic review and meta-analysis. Eur J Cancer. 2005 Sep;41(13):2023-32.

55. Erren TC, Pape HG, Reiter RJ, Piekarski C. Chronodisruption and cancer. Naturwissenschaften. 2008 May;95(5):367-82.

56. Stevens RG, Hansen J, Costa G, Haus E, Kauppinen T, Aronson KJ, et al. Defining 'shift work' for use in epidemiological studies of cancer, IARC working group report. In press . 
57. Erren TC, Pape HG, Piekarski C, Reiter RJ. Not all shifts are equal: It's time for comprehensive exposure metrics in chronodisruption research. Cancer Res. 2008 May 15;68(10):4011.

58. Erren TC, Reiter RJ, Piekarski C. Chronodisruption and melatonin: The need for sensible exposure metrics in epidemiological studies. J Pineal Res. 2008;45(3):335-336.

59. Kloog I, Haim A, Stevens RG, Portnov BA. Global co-distribution of light at night (LAN) and cancers of prostate, colon, and lung in men. Chronobiol Int. 2009 Jan;26(1):108-25.

60. Kloog I, Haim A, Stevens RG, Barchana M, Portnov BA. Light at night co-distributes with incident breast but not lung cancer in the female population of israel. Chronobiol Int. 2008 Feb;25(1):65-81.

61. Borugian MJ, Gallagher RP, Friesen MC, Switzer TF, Aronson KJ. Twenty-four-hour light exposure and melatonin levels among shift workers. Journal of Occupational \& Environmental Medicine. 2005 December;47(12):1268-75.

62. Grundy A, Sanchez M, Richardson H, Tranmer J, Borugian M, Graham CH, et al. Light intensity exposure, sleep duration, physical activity, and biomarkers of melatonin among rotating shift nurses. Chronobiol Int. 2009 Oct;26(7):1443-61.

63. Schernhammer ES, Schulmeister K. Melatonin and cancer risk: Does light at night compromise physiologic cancer protection by lowering serum melatonin levels? Br J Cancer. 2004 Mar 8;90(5):941-3.

64. Kliukiene J, Tynes T, Andersen A. Risk of breast cancer among norwegian women with visual impairment. Br J Cancer. 2001 Feb 2;84(3):397-9.

65. Pukkala E, Ojamo M, Rudanko SL, Stevens RG, Verkasalo PK. Does incidence of breast cancer and prostate cancer decrease with increasing degree of visual impairment. Cancer Causes Control. 2006 May;17(4):573-6.

66. Mhatre MC, Shah PN, Juneja HS. Effect of varying photoperiods on mammary morphology, DNA synthesis, and hormone profile in female rats. J Natl Cancer Inst.1984 Jun;72(6):1411-6

67. Shah PN, Mhatre MC, Kothari LS. Effect of melatonin on mammary carcinogenesis in intact and pinealectomized rats in varying photoperiods. Cancer Res. 1984 Aug;44(8):3403-7.

68. Blask DE, Brainard GC, Dauchy RT, Hanifin JP, Davidson LK, Krause JA, et al. Melatonindepleted blood from premenopausal women exposed to light at night stimulates growth of human breast cancer xenografts in nude rats. Cancer Res. 2005 Dec 1;65(23):11174-84.

69. Macchi MM, Bruce JN. Human pineal physiology and functional significance of melatonin. Front Neuroendocrinol. 2004 Sep-Dec;25(3-4):177-95.

70. Brzezinski A. Melatonin in humans. N Engl J Med. 1997 Jan 16;336(3):186-95.

71. Klein DC, Coon SL, Roseboom PH, Weller JL, Bernard M, Gastel JA, et al. The melatonin rhythm-generating enzyme: Molecular regulation of serotonin $\mathrm{N}$-acetyltransferase in the pineal gland. Recent Prog Horm Res. 1997;52:307,57; discussion 357-8.

72. Cardinali DP, Pevet P. Basic aspects of melatonin action. Sleep Med Rev. 1998 Aug;2(3):175-90.

73. Armstrong SM, Redman JR. Melatonin: A chronobiotic with anti-aging properties? Med Hypotheses. 1991 Apr;34(4):300-9.

74. Srinivasan V, Spence DW, Pandi-Perumal SR, Trakht I, Esquifino AI, Cardinali DP, et al. Melatonin, environmental light, and breast cancer. Breast Cancer Res Treat. 2008 Apr;108(3):339-50.

75. Snyder SH, Axelrod J, Zweig M. Circadian rhythm in the serotonin content of the rat pineal gland: Regulating factors. J Pharmacol Exp Ther. 1967 Nov;158(2):206-13.

76. Lerchl A, Partsch CJ. Reliable analysis of individual human melatonin profiles by complex cosinor analysis. J Pineal Res. 1994 Mar;16(2):85-90. 
77. Bergiannaki JD, Soldatos CR, Paparrigopoulos TJ, Syrengelas M, Stefanis CN. Low and high melatonin excretors among healthy individuals. J Pineal Res. 1995 Apr;18(3):159-64.

78. Arendt J. Radioimmunoassayable melatonin: Circulating patterns in man and sheep. Prog Brain Res. 1979;52:249-58.

79. Schernhammer ES, Rosner B, Willett WC, Laden F, Colditz GA, Hankinson SE. Epidemiology of urinary melatonin in women and its relation to other hormones and night work. Cancer Epidemiol Biomarkers Prev. 2004 Jun;13(6):936-43.

80. Vijayalaxmi, Thomas CR,Jr, Reiter RJ, Herman TS. Melatonin: From basic research to cancer treatment clinics. J Clin Oncol. 2002 May 15;20(10):2575-601.

81. Travis RC, Allen NE, Peeters PH, van Noord PA, Key TJ. Reproducibility over 5 years of measurements of 6-sulphatoxymelatonin in urine samples from postmenopausal women. Cancer Epidemiol Biomarkers Prev. 2003 Aug;12(8):806-8.

82. McIntyre IM, Norman TR, Burrows GD, Armstrong SM. Human melatonin suppression by light is intensity dependent. J Pineal Res. 1989;6(2):149-56.

83. Lewy AJ, Wehr TA, Goodwin FK, Newsome DA, Markey SP. Light suppresses melatonin secretion in humans. Science. 1980 Dec 12;210(4475):1267-9.

84. Brainard GC, Hanifin JP, Greeson JM, Byrne B, Glickman G, Gerner E, et al. Action spectrum for melatonin regulation in humans: Evidence for a novel circadian photoreceptor. $\mathrm{J}$ Neurosci. 2001 Aug 15;21(16):6405-12.

85. Yamauchi H, Iwamoto M, Harada N. Physiological effects of shift work on hospital nurses. J Hum Ergol (Tokyo). 2001 Dec;30(1-2):251-4.

86. Marie Hansen $\AA$, Helene Garde A, Hansen J. Diurnal urinary 6- Sulfatoxymelatonin levels among healthy danish nurses during work and leisure time. Chronobiology International: The Journal of Biological \& Medical Rhythm Research. 2006 11;23(6):1203-15.

87. Sack RL, Blood ML, Lewy AJ. Melatonin rhythms in night shift workers. Sleep. 1992 Oct;15(5):434-41.

88. Quera-Salva MA, Defrance R, Claustrat B, De Lattre J, Guilleminault C. Rapid shift in sleep time and acrophase of melatonin secretion in short shift work schedule. Sleep. 1996 Sep;19(7):539-43.

89. Burch JB, Yost MG, Johnson W, Allen E. Melatonin, sleep, and shift work adaptation. J Occup Environ Med. 2005 Sep;47(9):893-901.

90. Folkard S. Do permanent night workers show circadian adjustment? A review based on the endogenous melatonin rhythm. Chronobiol Int. 2008 Apr;25(2):215-24.

91. Stevens RG. Circadian disruption and breast cancer: From melatonin to clock genes. Epidemiology. 2005 Mar;16(2):254-8.

92. Hrushesky WJ, Blask DE. Re: Melatonin and breast cancer: A prospective study. J Natl Cancer Inst. 2004 Jun 2;96(11):888-9.

93. Dumont M, Benhaberou-Brun D, Paquet J. Profile of 24-h light exposure and circadian phase of melatonin secretion in night workers. J Biol Rhythms. 2001 Oct;16(5):502-11.

94. Roden M, Koller M, Pirich K, Vierhapper H, Waldhauser F. The circadian melatonin and cortisol secretion pattern in permanent night shift workers.Am J Physiol. 1993 Jul;265:R261-7

95. Grundy AL. Determinants and methods of assessment of melatonin levels among rotating shift nurses [dissertation]. Kingston, ON: Queen's University; 2008.

96. Nowak R, McMillen IC, Redman J, Short RV. The correlation between serum and salivary melatonin concentrations and urinary 6-hydroxymelatonin sulphate excretion rates: Two noninvasive techniques for monitoring human circadian rhythmicity. Clin Endocrinol (Oxf). 1987 Oct;27(4):445-52. 
97. Cook MR, Graham C, Kavet R, Stevens RG, Davis S, Kheifets L. Morning urinary assessment of nocturnal melatonin secretion in older women. J Pineal Res. 2000 Jan;28(1):41-7.

98. Graham C, Cook MR, Kavet R, Sastre A, Smith DK. Prediction of nocturnal plasma melatonin from morning urinary measures. J Pineal Res. 1998 May;24(4):230-8.

99. Sanchez-Barcelo EJ, Cos S, Fernandez R, Mediavilla MD. Melatonin and mammary cancer: A short review. Endocr Relat Cancer. 2003 Jun;10(2):153-9.

100. Blask DE, Pelletier DB, Hill SM, Lemus-Wilson A, Grosso DS, Wilson ST, et al. Pineal melatonin inhibition of tumor promotion in the N-nitroso-N-methylurea model of mammary carcinogenesis: Potential involvement of antiestrogenic mechanisms in vivo. J Cancer Res Clin Oncol. 1991;117(6):526-32.

101. Tamarkin L, Cohen M, Roselle D, Reichert C, Lippman M, Chabner B. Melatonin inhibition and pinealectomy enhancement of 7,12-dimethylbenz(a)anthracene-induced mammary tumors in the rat. Cancer Res. 1981 Nov;41(11 Pt 1):4432-6.

102. Kothari L. Effect of melatonin on the mammary gland morphology, DNA synthesis, hormone profiles and incidence of mammary cancer in rats. In: Gupta D, Attanasio A, Reiter RJ, editors. The pineal gland and cancer. London:Brain Research Promotion;1988. p.210-219

103. Blask DE, Hill SM. Effects of melatonin on cancer: Studies on MCF-7 human breast cancer cells in culture. J Neural Transm Suppl. 1986;21:433-49.

104. Cos S, Sanchez-Barcelo EJ. Differences between pulsatile or continuous exposure to melatonin on MCF-7 human breast cancer cell proliferation Cancer Lett.1994 Sep;85(1):105-9

105. Bartsch C, Bartsch H, Jain AK, Laumas KR, Wetterberg L. Urinary melatonin levels in human breast cancer patients. J Neural Transm. 1981;52(4):281-94.

106. Bartsch C, Bartsch H, Karenovics A, Franz H, Peiker G, Mecke D. Nocturnal urinary 6sulphatoxymelatonin excretion is decreased in primary breast cancer patients compared to age-matched controls and shows negative correlation with tumor-size. J Pineal Res. 1997 Sep;23(2):53-8.

107. Skene DJ, Bojkowski CJ, Currie JE, Wright J, Boulter PS, Arendt J. 6-sulphatoxymelatonin production in breast cancer patients. J Pineal Res. 1990;8(3):269-76.

108. Schernhammer ES, Berrino F, Krogh V, Secreto G, Micheli A, Venturelli E, et al. Urinary 6sulfatoxymelatonin levels and risk of breast cancer in postmenopausal women. J Natl Cancer Inst. 2008 Jun 18;100(12):898-905.

109. Schernhammer ES, Hankinson SE. Urinary melatonin levels and breast cancer risk. J Natl Cancer Inst. 2005 Jul 20;97(14):1084-7.

110. Schernhammer ES, Hankinson SE. Urinary melatonin levels and postmenopausal breast cancer risk in the nurses' health study cohort. Cancer Epidemiol Biomarkers Prev. 2009 Jan;18(1):74-9.

111. Travis RC, Allen DS, Fentiman IS, Key TJ. Melatonin and breast cancer: A prospective study. J Natl Cancer Inst. 2004 Mar 17;96(6):475-82.

112. Mills E, Wu P, Seely D, Guyatt G. Melatonin in the treatment of cancer: A systematic review of randomized controlled trials and meta-analysis. J Pineal Res.2005 Nov;39(4):360-6

113. Cohen M, Lippman M, Chabner B. Role of the pineal gland in the etiology and treatment of breast cancer. The Lancet. 1978 10/14;312(8094):814-6.

114. Reiter RJ. The role of the neurohormone melatonin as a buffer against macromolecular oxidative damage. Neurochem Int. 1995 Dec;27(6):453-60.

115. Tan DX, Manchester LC, Terron MP, Flores LJ, Reiter RJ. One molecule, many derivatives: A never-ending interaction of melatonin with reactive oxygen and nitrogen species? J Pineal Res. 2007 Jan;42(1):28-42. 
116. Fraschini F, Demartini G, Esposti D, Scaglione F. Melatonin involvement in immunity and cancer. Biol Signals Recept. 1998 Jan-Feb;7(1):61-72.

117. Cui P, Luo Z, Zhang H, Su Y, Li A, Li H, et al. Effect and mechanism of melatonin's action on the proliferation of human umbilical vein endothelial cells. J Pineal Res. 2006 Nov;41(4):358-62.

118. Witt-Enderby PA, Bennett J, Jarzynka MJ, Firestine S, Melan MA. Melatonin receptors and their regulation: Biochemical and structural mechanisms.Life Sci. 2003 Apr;72(20):2183-98.

119. Arendt J. Melatonin and the mammalian pineal gland. London: Chapman and Hall; 1995.

120. Reiter RJ. Neuroendocrine effects of light. Int J Biometeorol. 1991 Nov;35(3):169-75.

121. Weaver DR, Stehle JH, Stopa EG, Reppert SM. Melatonin receptors in human hypothalamus and pituitary: Implications for circadian and reproductive responses to melatonin. J Clin Endocrinol Metab. 1993 Feb;76(2):295-301.

122. Malpaux B, Migaud M, Tricoire H, Chemineau P. Biology of mammalian photoperiodism and the critical role of the pineal gland and melatonin.J Biol Rhythms.2001 Aug;16(4):336-47

123. Dubocovich ML, Rivera-Bermudez MA, Gerdin MJ, Masana MI. Molecular pharmacology, regulation and function of mammalian melatonin receptors.Front Biosci.2003 Sep;8:d1093-108

124. Revel FG, Masson-Pevet M, Pevet P, Mikkelsen JD, Simonneaux V. Melatonin controls seasonal breeding by a network of hypothalamic targets.Neuroendocrinology.2009;90(1):1-14

125. Reiter RJ. The pineal and its hormones in the control of reproduction in mammals. Endocr Rev. 1980 Spring;1(2):109-31.

126. Lincoln G. Melatonin modulation of prolactin and gonadotrophin secretion. systems ancient and modern. Adv Exp Med Biol. 1999;460:137-53.

127. Malpaux B, Thiery JC, Chemineau P. Melatonin and the seasonal control of reproduction. Reprod Nutr Dev. 1999 May-Jun;39(3):355-66.

128. Aleandri V, Spina V, Morini A. The pineal gland and reproduction. Hum Reprod Update. 1996 May-Jun;2(3):225-35.

129. Cagnacci A, Volpe A. Influence of melatonin and photoperiod on animal and human reproduction. J Endocrinol Invest. 1996 Jun;19(6):382-411.

130. Luboshitzky R, Lavie P. Melatonin and sex hormone interrelationships--a review. J Pediatr Endocrinol Metab. 1999 May-Jun;12(3):355-62.

131. Rojansky N, Brzezinski A, Schenker JG. Seasonality in human reproduction: An update. Hum Reprod. 1992 Jul;7(6):735-45.

132. Brzezinski A, Lynch HJ, Seibel MM, Deng MH, Nader TM, Wurtman RJ. The circadian rhythm of plasma melatonin during the normal menstrual cycle and in amenorrheic women. $\mathrm{J}$ Clin Endocrinol Metab. 1988 May;66(5):891-5.

133. Berga SL, Mortola JF, Yen SS. Amplification of nocturnal melatonin secretion in women with functional hypothalamic amenorrhea. J Clin Endocrinol Metab. 1988 Jan;66(1):242-4.

134. Okatani Y, Morioka N, Wakatsuki A. Changes in nocturnal melatonin secretion in perimenopausal women: Correlation with endogenous estrogen concentrations. J Pineal Res. 2000 Mar;28(2):111-8.

135. Waldhauser F, Weiszenbacher G, Frisch H, Zeitlhuber U, Waldhauser M, Wurtman RJ. Fall in nocturnal serum melatonin during prepuberty and pubescence. Lancet. $1984 \mathrm{Feb}$ $18 ; 1(8373): 362-5$.

136. Bellipanni G, Bianchi P, Pierpaoli W, Bulian D, Ilyia E. Effects of melatonin in perimenopausal and menopausal women: A randomized and placebo controlled study. Exp Gerontol. 2001 Feb;36(2):297-310. 
137. Yie SM, Brown GM, Liu GY, Collins JA, Daya S, Hughes EG, et al. Melatonin and steroids in human pre-ovulatory follicular fluid: Seasonal variations and granulosa cell steroid production. Hum Reprod. 1995 Jan;10(1):50-5.

138. Danforth DN,Jr, Tamarkin L, Mulvihill JJ, Bagley CS, Lippman ME. Plasma melatonin and the hormone-dependency of human breast cancer. J Clin Oncol. 1985 Jul;3(7):941-8.

139. Tamarkin L, Danforth D, Lichter A, DeMoss E, Cohen M, Chabner B, et al. Decreased nocturnal plasma melatonin peak in patients with estrogen receptor positive breast cancer. Science. 1982 May 28;216(4549):1003-5.

140. Kinson GA, Peat F. The influences of illumination, melatonin and pinealectomy on testicular function in the rat. Life Sci I. 1971 Mar 1;10(5):259-69.

141. Aubert ML, Rivest RW, Lang U, Winiger BP, Sizonenko PC. Delayed sexual maturation induced by daily melatonin administration eliminates the LH response to naloxone despite normal responsiveness to GnRH in juvenile male rats. Neuroendocrinology. 1988 Jul;48(1):72-80.

142. Ying SY, Greep RO. Inhibition of ovulation by melatonin in the cyclic rat. Endocrinology. 1973 Jan;92(1):333-5.

143. Cos S, Gonzalez A, Martinez-Campa C, Mediavilla MD, Alonso-Gonzalez C, SanchezBarcelo EJ. Estrogen-signaling pathway: A link between breast cancer and melatonin oncostatic actions. Cancer Detect Prev. 2006;30(2):118-28.

144. Cos S, Fernandez R, Guezmes A, Sanchez-Barcelo EJ. Influence of melatonin on invasive and metastatic properties of MCF-7 human breast cancer cells. Cancer Res. 1998 Oct 1;58(19):4383-90.

145. Wilson ST, Blask DE, Lemus-Wilson AM. Melatonin augments the sensitivity of MCF-7 human breast cancer cells to tamoxifen in vitro. J Clin Endocrinol Metab. 1992 Aug;75(2):669-70.

146. Yuan L, Collins AR, Dai J, Dubocovich ML, Hill SM. MT(1) melatonin receptor overexpression enhances the growth suppressive effect of melatonin in human breast cancer cells. Mol Cell Endocrinol. 2002 Jun 28;192(1-2):147-56.

147. Molis TM, Spriggs LL, Hill SM. Modulation of estrogen receptor mRNA expression by melatonin in MCF-7 human breast cancer cells. Mol Endocrinol. 1994 Dec;8(12):1681-90.

148. Molis TM, Walters MR, Hill SM. Melatonin modulation of estrogen receptor expression in MCF-7 human breast cancer cells. Int J Oncol. 1993;3:687-694.

149. Molis TM, Spriggs LL, Jupiter Y, Hill SM. Melatonin modulation of estrogen-regulated proteins, growth factors, and proto-oncogenes in human breast cancer. J Pineal Res. 1995 Mar;18(2):93-103.

150. Cos S, Blask DE. Melatonin modulates growth factor activity in MCF-7 human breast cancer cells. J Pineal Res. 1994 Aug;17(1):25-32.

151. Rato AG, Pedrero JG, Martinez MA, del Rio B, Lazo PS, Ramos S. Melatonin blocks the activation of estrogen receptor for DNA binding. FASEB J. 1999 May;13(8):857-68.

152. Kripke DF, Kline LE, Shadan FF, Dawson A, Poceta JS, Elliott JA. Melatonin effects on luteinizing hormone in postmenopausal women: A pilot clinical trial NCT00288262. BMC Womens Health. 2006 May 16;6:8.

153. Voordouw BC, Euser R, Verdonk RE, Alberda BT, de Jong FH, Drogendijk AC, et al. Melatonin and melatonin-progestin combinations alter pituitary-ovarian function in women and can inhibit ovulation. J Clin Endocrinol Metab. 1992 Jan;74(1):108-17.

154. Pawlikowski M, Kolomecka M, Wojtczak A, Karasek M. Effects of six months melatonin treatment on sleep quality and serum concentrations of estradiol, cortisol, 
dehydroepiandrosterone sulfate, and somatomedin C in elderly women. Neuro Endocrinol Lett. 2002 Apr;23 Suppl 1:17-9.

155. Nordlund JJ, Lerner AB. The effects of oral melatonin on skin color and on the release of pituitary hormones. J Clin Endocrinol Metab. 1977 Oct;45(4):768-74.

156. Wright J, Aldhous M, Franey C, English J, Arendt J. The effects of exogenous melatonin on endocrine function in man. Clin Endocrinol (Oxf). 1986 Apr;24(4):375-82.

157. Graham C, Cook MR, Gerkovich MM, Sastre A. Examination of the melatonin hypothesis in women exposed at night to EMF or bright light. Environ Health Perspect. 2001 May;109(5):501-7.

158. Siegrist C, Benedetti C, Orlando A, Beltran JM, Tuchscherr L, Noseda CM, et al. Lack of changes in serum prolactin, FSH, TSH, and estradiol after melatonin treatment in doses that improve sleep and reduce benzodiazepine consumption in sleep-disturbed, middle-aged, and elderly patients. J Pineal Res. 2001 Jan;30(1):34-42.

159. Davis S, Mirick DK, Chen C, Stanczyk FZ. Effects of 60-hz magnetic field exposure on nocturnal 6-sulfatoxymelatonin, estrogens, luteinizing hormone, and follicle-stimulating hormone in healthy reproductive-age women: Results of a crossover trial. Ann Epidemiol. 2006 Aug; 16(8):622-31.

160. Schernhammer ES, Kroenke CH, Dowsett M, Folkerd E, Hankinson SE. Urinary 6sulfatoxymelatonin levels and their correlations with lifestyle factors and steroid hormone levels. J Pineal Res. 2006 Mar;40(2):116-24.

161. Nagata C, Nagao Y, Yamamoto S, Shibuya C, Kashiki Y, Shimizu H. Light exposure at night, urinary 6-sulfatoxymelatonin, and serum estrogens and androgens in postmenopausal japanese women. Cancer Epidemiol Biomarkers Prev. 2008 Jun;17(6):1418-23.

162. Wehr TA. Melatonin and seasonal rhythms. J Biol Rhythms. 1997 Dec;12(6):518-27.

163. Wehr TA, Duncan WC,Jr, Sher L, Aeschbach D, Schwartz PJ, Turner EH, et al. A circadian signal of change of season in patients with seasonal affective disorder. Arch Gen Psychiatry. 2001 Dec;58(12):1108-14.

164. Pike MC, Spicer DV, Dahmoush L, Press MF. Estrogens, progestogens, normal breast cell proliferation, and breast cancer risk. Epidemiol Rev. 1993;15(1):17-30.

165. Wright Jr KP, Badia P. Effects of menstrual cycle phase and oral contraceptives on alertness, cognitive performance, and circadian rhythms during sleep deprivation. Behav Brain Res. 1999;103(2):185-94.

166. Hendrick JC, Crasson M, Hagelstein MT, Bruls E, Legros JJ. Urinary excretion of 6sulphatoxymelatonin in normal subjects: Statistical approach to the influence of age and sex. Ann Endocrinol (Paris). 2002 Feb;63(1):3-7.

167. Gaspard UJ, Romus MA, Gillian D, Duvivier J, Demey-Ponsart E, Franchimont P. Plasma hormone levels in women receiving new oral contraceptives containing ethinyl estradiol plus levonorgestrel or desogestrel. Contraception. 1983;27(6):577-590.

168. Verkasalo PK, Thomas HV, Appleby PN, Davey GK, Key TJ. Circulating levels of sex hormones and their relation to risk factors for breast cancer: A cross-sectional study in 1092 pre- and postmenopausal women (united kingdom). Cancer Causes and Control. $2001 ; 12(1): 47-59$.

169. Webley GE, Leidenberger F. The circadian pattern of melatonin and its positive relationship with progesterone in women. J Clin Endocrinol Metab. 1986 Aug;63(2):323-8.

170. Daniel M, Martin AD, Drinkwater DT. Cigarette smoking, steroid hormones, and bone mineral density in young women. Calcif Tissue Int. 1992 Apr;50(4):300-5.

171. Danel T, Touitou Y. Alcohol consumption does not affect melatonin circadian synchronization in healthy men. Alcohol and Alcoholism;41(4):386-90. 
172. Carr DB, Reppert SM, Bullen B, Skrinar G, Beitins I, Arnold M, et al. Plasma melatonin increases during exercise in women. J Clin Endocrinol Metab. 1981 Jul;53(1):224-5.

173. Bullen BA, Skrinar GS, McArthur JW, Carr DB. Exercise effect upon plasma melatonin levels in women: Possible physiological significance. Can J Appl Sport Sci. 1982 Jun;7(2):90-7.

174. Buxton OM, L'Hermite-Baleriaux M, Hirschfeld U, Cauter E. Acute and delayed effects of exercise on human melatonin secretion. J Biol Rhythms. 1997 Dec;12(6):568-74.

175. Atkinson G, Drust B, Reilly T, Waterhouse J. The relevance of melatonin to sports medicine and science. Sports Med. 2003;33(11):809-31.

176. Wright KP,Jr, Badia P, Myers BL, Plenzler SC, Hakel M. Caffeine and light effects on nighttime melatonin and temperature levels in sleep-deprived humans. Brain Res. 1997 Jan 30;747(1):78-84.

177. Babkoff H, French J, Whitmore J, Sutherline R. Single-dose bright light and/or caffeine effect on nocturnal performance. Aviat Space Environ Med. 2002;73(4):341-50.

178. Sterzik K, Strehler E, De Santo M, Trumpp N, Abt M, Rosenbusch B, et al. Influence of smoking on fertility in women attending an in vitro fertilization program. Fertil Steril. 1996 Apr;65(4):810-4.

179. Westhoff C, Gentile G, Lee J, Zacur H, Helbig D. Predictors of ovarian steroid secretion in reproductive-age women. Am J Epidemiol. 1996 Aug 15;144(4):381-8.

180. Stevens RG, Davis S, Mirick DK, Kheifets L, Kaune W. Alcohol consumption and urinary concentration of 6-sulfatoxymelatonin in healthy women. Epidemiology. 2000 Nov;11(6):660-5.

181. Kotsopoulos J, Eliassen AH, Missmer SA, Hankinson SE, Tworoger SS. Relationship between caffeine intake and plasma sex hormone concentrations in premenopausal and postmenopausal women. Cancer. 2009 Jun 15;115(12):2765-74.

182. Fujimoto VY, Clifton DK, Cohen NL, Soules MR. Variability of serum prolactin and progesterone levels in normal women: The relevance of single hormone measurements in the clinical setting. Obstetrics \& Gynecology. 1990;76(1):71-78.

183. Murphy PJ, Badia P, Myers BL, Boecker MR, Wright KP,Jr. Nonsteroidal antiinflammatory drugs affect normal sleep patterns in humans. Physiol Behav. 1994 Jun;55(6):1063-6.

184. Djeridane Y, Touitou Y. Chronic diazepam administration differentially affects melatonin synthesis in rat pineal and harderian glands. Psychopharmacology (Berl). 2001 Apr;154(4):403-7.

185. Anttila L, Koskinen P, Irjala K, Kaihola HL. Reference intervals for serum sex steroids and gonadotropins in regularly menstruating women. Acta Obstet Gynecol Scand. 1991;70(6):475-81.

186. Svennersten-Sjaunja K, Olsson K. Endocrinology of milk production. Domest Anim Endocrinol;29(2):241-58.

187. Berga SL, Yen SS. Circadian pattern of plasma melatonin concentrations during four phases of the human menstrual cycle. Neuroendocrinology. 1990 May;51(5):606-12.

188. Yen SSC. Prolactin in human reproduction. In: Yen SSC, Jaffe RB, editors. Reproductive Endocrinology: Physiology, Pathophysiology and Clinical Management. Philadelphia: W.B. Saunders Co.; 1991. p. 357-388.

189. Davis S, Mirick DK. Circadian disruption, shift work and the risk of cancer: A summary of the evidence and studies in seattle. Cancer Causes Control. 2006;17(4):539-45.

190. McIntyre IM, Norman TR, Burrows GD, Armstrong SM. Quantal melatonin suppression by exposure to low intensity light in man. Life Sci. 1989;45(4):327-32. 


\section{Chapter 3}

\section{Methods}

\subsection{Study Objectives and Hypotheses}

The main purpose of this thesis was to examine relationships between melatonin and sex hormone levels among a group of pre-menopausal shift-working nurses, with the specific objectives to:

1. Describe the seasonal distributions of sex hormone (estradiol, estrone, progesterone, prolactin) concentrations in blood, and urinary melatonin metabolites levels among premenopausal nurses:

Hypothesis: melatonin levels were hypothesized to be highly variable with mean levels variable by season given differences in day-length and natural light exposure. Sex hormone distributions were anticipated to be highly variable due to differences in personal and reproductive factors. Seasonal variability in sex hormones was expected if such findings were evident for melatonin.

2. Examine cross-sectional relationships between melatonin and sex hormone levels, within each of two seasons:

Hypothesis: given experimental evidence and proposed biological pathways, melatonin levels were hypothesized to be inversely related to sex hormone levels.

3. Investigate potential longitudinal relationships between melatonin and sex hormone levels across seasons:

Hypothesis: influences of changes in melatonin on sex hormone levels may require a certain latency period, given evidence from melatonin supplementation in humans. The change in season was predicted to cause changes in melatonin levels which would, in turn, lead to changes in sex hormone levels following a seasonal latency period.

4. Examine associations between night shift-work history and sex hormone levels: 
Hypothesis: given the proposed biological pathway, duration of night shift-work history was suspected to be positively associated with sex hormone levels.

\subsection{Overview of Study Design}

To examine potential relationships between melatonin and sex hormone levels, an observational study of pre-menopausal shift-working nurses at Kingston General Hospital (KGH) was conducted. This thesis research was a sub-set of a larger observational study, Occupational and other factors as determinants of melatonin levels among rotating shift nurses (1), lead by Dr.

Kristan Aronson. The purpose of this larger study, funded by the Workplace Safety and Insurance Board of Ontario (WSIB), is to determine the relationships of light exposure patterns, physical activity, and other factors with melatonin levels among shift-working nurses, with the goal of identifying modifiable determinants of melatonin levels as intermediates in the pathway to cancer. The general methodological details of this study ("WSIB study") are described below.

\subsection{WSIB Study}

\subsubsection{Study Population}

Female rotating shift-work nurses were the source population for the WSIB study. Female registered nurses and registered practical nurses, recruited from $\mathrm{KGH}$, were eligible for study participation if they followed the standard full-time rotating shift-work pattern of two 12-hr days (7AM-7PM), followed by two 12-hr nights (7PM-7AM), followed by five days off. The focus on rotating shift-work nurses in this study was based on the predicted influence of LAN and the subsequent changes in melatonin levels. Exclusion criteria included pregnancy or lactating in the past six months and current use of melatonin supplements. These criteria were used to restrict the influences of strong predictors of melatonin levels not of interest to the study.

A total of 123 subjects were accrued from a pool of approximately 700 full-time rotating shift-work nurses at KGH, from April 2008 to February 2009. The study was advertised by 
information letters that were sent to all full-time nurses and by presentations, information booths, and posters displayed throughout the hospital. Eligibility and exclusion criteria were described in all study advertisements such that women could self-select for participation. From this method of selection, it is unknown how many of the approximately 700 full-time rotating shift-work nurses at $\mathrm{KGH}$ were eligible for study recruitment but chose not to participate. As such, the typical "response rate" cannot be calculated.

Interested subjects were advised to contact the study coordinator and a brief interview was arranged to provide information regarding study participation and informed consent. Prior to interview, subjects were provided a consent and study guide as well as all study materials.

\subsubsection{Data Collection}

Subjects were asked to participate in four separate data collection periods, each 48 -hr in duration and lasting over the course of two consecutive day or night shifts, in both summer and winter. Nurses were recruited for study participation in two cohorts due to limited numbers of study instruments such as light intensity meters and pedometers. Cohort A, recruited in the summer of 2008, completed summer data collection first (during May-Aug 2008), followed by winter data collection (Oct-Dec 2008). Cohort B, recruited in the winter of 2008/09, completed winter data collection first (Dec 2008-Mar 2009), followed by summer data collection (Apr-Jun 2009) (Figure 3.1). Within each season, subjects took part in both day shift and night shift data collection periods, with the order of these based on convenience.

Figure 3.1 WSIB data collection periods

\begin{tabular}{|lllll}
2 day \\
shifts
\end{tabular}


Upon study enrollment, subjects completed a questionnaire for personal information and a history of health, lifestyle and employment characteristics. During each study period, subjects completed a diary to obtain information on recent physical activity, lighting conditions while sleeping, smoking, alcohol and caffeine consumption, use of medications, and sleep duration/ timing; wore a light data meter to record ambient light exposure; wore a pedometer to record physical activity; and provided timed urine and saliva samples for the assessment of melatonin biomarkers at fixed time points. In addition, self-identified pre-menopausal subjects were requested to provide an eight-hour fasting blood sample during the day-shift study periods in each season, with these restrictions based on cost. Blood samples were collected for the validation of melatonin biomarkers measured in urine, and for the assessment of other biomarkers of interest such as sex hormone levels (not part of the original WSIB objectives). Additional funding for the analysis of sex hormones was granted from Breast Cancer Action Kingston (BCAK) (2).

\subsection{Thesis Research}

\subsubsection{Study Population}

This thesis research used a sub-sample of the WSIB study; specifically, pre-menopausal participants for who blood samples were collected (for the assessment of sex hormones). In total, 94 pre-menopausal women consented to participate in the WSIB study and were assigned a study identification number. Of these, five dropped out of the study before taking part in any data collection (two withdrew and three were lost to follow-up). Of the remaining 89 pre-menopausal subjects who participated, two did not take part in the day shift study periods (the focus of this thesis) and were therefore removed from the study sample. In addition, two women who did not consent to provide blood samples and three women who consented but who did not provide blood were excluded. In total, 82 pre-menopausal WSIB subjects ( $87.2 \%$ of the original 94$)$ comprised the study sample for this thesis (see Section 3.8.1 for more details). 


\subsubsection{Data Collection}

Of the four study periods comprising the greater WSIB study (Figure 3.1), only day shift collections (in summer and winter) were considered for this thesis as blood samples were provided during these periods only. Further, this thesis used only a subset of the data collected over the course of the second day, including: the morning void urine and 8-hr fasting blood samples (collected from 5-7AM) and diaries completed during each study period. This use of seasonal data allowed for the investigation of both cross-sectional (within each of two seasons) and longitudinal relationships (across seasons) between melatonin and sex hormone levels.

\subsection{Exposure Assessment}

\subsubsection{Melatonin Assessment}

The main exposure of interest for this thesis was melatonin, as characterized by levels of the primary urinary melatonin metabolite, 6-sulfatoxymelatonin (aMTs-6), measured from morning void urine samples. Morning void aMTs-6 levels were used to capture peak nocturnal melatonin secretion (see Section 2.4.4), the biologically relevant exposure (see Section 2.5.3).

\subsubsection{Urine Sample Collection}

Participants were given a standard $120 \mathrm{~mL}$ urine collection container and were instructed to collect morning void urine upon waking, from 5-7AM before commencement of their day shift. Upon arrival at $\mathrm{KGH}$, urine samples were retrieved by the hospital porter system and delivered to the KGH Core Laboratory. Samples were kept refrigerated until retrieval from KGH within 48-hr. Next, samples were processed, aliquoted and stored at -80'C until melatonin analysis.

\subsubsection{Laboratory Analysis}

Concentrations of aMTs- 6 were measured from urine samples using the Bühlmann aMTs-6 enzyme-linked immunosorbent assay (ELISA) kit (ALPCO, Salem NH), a commonly used commercially available tool. This assay is comparable to the radioimmunoassay (RIA), 
considered the gold standard for aMTs-6 measurement $(\mathrm{r}=0.969)(3)$. This competitive ELISA employs the antibody capture technique to quantify aMTs-6. Urine samples and a set of known standards were added to the wells of a microtiter plate. Biotinylated aMTs- 6 was added to the plate to compete with aMTs-6 in the samples for binding of highly specific aMTs-6 antibodies. Biotinylated aMTs-6-anti-body complexes bind to second polyclonal antibodies that are attached to the microtiter plate surface. An enzyme label, streptavidin conjugated to horseradish peroxidase, was added to the plate and a colored product formed when it bound to the antibody complexes on the plate. The intensity of the colored product is proportional to the amount of antibody complexes attached to the plate and therefore inversely proportional to the amount of aMTs-6 in the urine samples. A spectrophotometer set to $450 \mathrm{~nm}$ was used to measure the color intensity. Using a set of standard samples, a standard curve of color intensity and corresponding aMTs-6 concentration was produced, from which sample aMTs- 6 concentrations were calculated.

To account for variability in the diluteness of urine samples, and the influences that this may have on aMTs- 6 concentrations, aMTs-6 levels were adjusted for creatinine concentration, an approach commonly taken in studies involving urinary hormone assessment. Creatinine is a useful marker of urine diluteness, as it is produced by the kidney and excreted in urine at a relatively constant rate (4). Creatinine concentration was measured from the same urine samples used for melatonin analysis, by the Parameter ${ }^{\mathrm{TM}}$ Creatinine Assay (R\&D Systems, Minneapolis, $\mathrm{MN})$. In this chemical analysis assay, samples were treated with an alkaline picrate solution, which produces a colored product proportional to the creatinine concentration. The intensity of the colored product formed was measured using a spectrophotometer set to $490 \mathrm{~nm}$. Using a set of known creatinine standards, a standard curve was generated to relate color intensity to creatinine concentration, from which creatinine concentrations for each urine sample were calculated. 


\subsubsection{Quality Control}

All urine samples were run in duplicate and an average aMTs-6/ creatinine concentration and coefficient of variation (CV) were calculated for each sample (median CVs for aMTs-6 and creatinine were $9.1 \%$ and $10.0 \%$, respectively). To ensure data quality, assays for which the standard curve poorly fit the sample standards $\left(\mathrm{R}^{2}<0.95\right)$ were repeated. Additionally, samples for which aMTs- 6 concentrations were outside the range of the assay's standard curve were reanalyzed using appropriately adjusted sample dilutions.

\subsubsection{Night Shift-work History}

A secondary exposure of interest to this study was night shift-work history. In the study questionnaire, participants completed an employment history including details on shift type (day vs. night) and duration (years) for each job. These variables were used to calculate the number of years of work that involved $50 \%$ or more night shifts (years night shift-work) for each person.

\subsection{Outcome Assessment}

\subsubsection{Sex Hormone Assessment}

The outcomes of interest for this thesis were levels of four sex hormones (estradiol, estrone, progesterone and prolactin), measured directly from blood samples. Circulating sex hormone levels measured from blood most accurately characterize the biologically meaningful 'dose'. Urinary sex hormone metabolite levels are often used as a more feasible approach in epidemiological studies, but these levels reflect not only differences in circulating hormone levels (of interest) but also differences in hormone metabolism and excretion.

Sex hormone levels are highly variable in pre-menopausal women, fluctuating with several reproductive and personal influences (see Section 2.6.6). Given this variability, the validity of a single measure to portray long-term sex hormone levels, of relevance to breast cancer risk, has been questioned. Two prospective studies nested within the NHS II cohort have 
found single blood measurements of some sex hormones to reasonably characterize long-term measures over one (5) and two-three years (6). In one study, the reproducibility of sex hormones (estradiol, estrone, estrone sulfate, progesterone) over one year, measured by the intraclass correlation coefficient (ICC), ranged from ICC $=0.52-0.71$, with the exception of luteal estradiol levels (ICC $=0.19$, or 0.49 with exclusion of anovulatory cycles) (5). The second study, however, found sex hormones to be less reproducible across a two-three year period (6). Estrogen reliability ranged from ICC $=0.38$ (estradiol) to 0.64 (estrone sulfate) in the follicular stage, and from 0.44 (estrone) to 0.69 (estrone sulfate) in the luteal stage. The reliability of prolactin was high $(\mathrm{ICC}=0.64$, averaged across menstrual stages $)$, and of progesterone low $(\mathrm{ICC}=0.29$, luteal stage). Considering these results, whether proposed increases in sex hormone levels following reductions in melatonin with shift-work are stable, is unclear.

Many steps were taken to reduce or standardize the influences of strong predictors on sex hormone levels across study participants. Subjects were excluded from the study if they had been pregnant or lactating in the previous six months. Participants were instructed to fast for 8 -hr prior to blood sample collection and to provide blood samples at a consistent time of day (5-7AM). Information on the exact timing of blood sample collection was gathered such that any residual influences could be explored. Unfortunately, no information was collected to describe whether blood samples were actually fasting or not. In light of recruitment restraints, subjects were not excluded by OC use; however, information regarding their use was collected such that this influence could be explored. Likewise, while logistical difficulties prevented the scheduling of data collections across consistent menstrual cycle stage, information on stage was collected.

\subsubsection{Blood Sample Collection}

Participants provided a 30mL blood sample at KGH from 5-7AM, on the same day 
and within the same time frame of urine sample collection. Samples were immediately retrieved by the KGH porter system and delivered to the KGH Core Laboratory for analysis.

\subsubsection{Laboratory Analysis}

Sex hormone levels were measured using standard medical diagnostic immunoassays available at KGH and the McMaster University Medical Centre (MUMC). Immunoassays are bioanalytical tools that quantify biological compounds using antibody-antigen reactions. A label attached to either the antigen or antibody produces a signal upon antigen-antibody binding allowing for the detection and quantification of the analyte (7). Serum levels of progesterone (nmol/L), estradiol (pmol/L) and prolactin (ug/L) were measured at the KGH Core Laboratory by paramagnetic particle, chemiluminescent immunoassays using the Beckman Coulter UniCel Dxl 800 Access ${ }^{\circledR}$ System, as outlined in the KGH Clinical Laboratory Services Reference Manual. Analyses were completed by laboratory staff following sample delivery by the hospital porter system. Serum estrone levels ( $\mathrm{pmol} / \mathrm{L})$ were measured by radioimmunoassay at the MUMC, as

outlined in the Hospitals in Common Laboratory Reference Manual (available at www.hicl.on.ca) as this assay was not available at KGH. Blood samples for estrone analysis were processed, aliquoted and frozen in the KGH lab prior to shipment, and were delivered on ice to MUMC.

These standard hormone immunoassays are commonly used in both medical diagnostics and in epidemiological research on sex hormones (8-11). However, a lack of standardized, validated assays is described as a major limitation of research to date (12), supported by large inconsistencies in sex hormone ranges observed across studies (13). The lack of gold standard tools for objective sex hormone measurement makes it difficult to assess the validity of the immunoassays available. In addition, the reproducibility of techniques available is difficult to assess given the challenges in accounting for the highly variable nature of sex hormone levels that fluctuate with many personal and reproductive characteristics. Recently, mass-spectrometry based 
methods have been proposed as an alternative with potential for improved accuracy and precision $(12,14)$; however, the large cost and training required limits its use in epidemiological studies.

\subsubsection{Quality Control}

Sex hormone levels were assessed independently for each blood sample. Instruments used for hormone assessment are calibrated daily by hospital staff, and all samples are run with two or more controls (for which sex hormone levels are known) to ensure precision and accuracy of the results. Inter-assay precision of these tests, as reported by the KGH Clinical Laboratory Services Reference Manual, are CV $=5-10 \%$ for prolactin, $\mathrm{CV}=10-20 \%$ estradiol and $\mathrm{CV}=8$ $10 \%$ progesterone. Precision values for the estrone analysis are not reported by MUMC, but other reports suggest inter-assay precision of $7-11 \%$ for this test at different laboratories (15).

\subsection{Consideration of Covariates}

\subsubsection{Collection of Covariate Information}

Covariate information was collected from the WSIB study questionnaire, completed at study enrollment (baseline covariates; Appendix C), and from the study diaries, completed over the course of data collections (seasonal covariates; Appendix D). As the questionnaire and diary were designed based on the overall objectives of the larger WSIB study, not all information collected in these instruments was relevant to this thesis. Important covariates were identified $a$ priori from the literature (Section 2.6.6) and only information relating to these variables was collected from the study instruments. Covariates of interest included personal and lifestyle characteristics, medication use, and reproductive factors, described below.

Some important covariates were controlled for by study design: women who had been pregnant or lactating in the previous six months were excluded, and time of day and current food consumption were controlled for by collecting samples at consistent times of day, and by asking participants to fast for 8-hr prior to blood sample collection. 


\subsubsection{Covariate Classification}

Two important potential confounders identified from the literature were age and BMI. Age at the time of study commencement, measured in years, was determined using self-reported date of birth from the study questionnaire. BMI $\left(\mathrm{kg} / \mathrm{m}^{2}\right)$ was determined objectively through height $(\mathrm{m})$ and weight $(\mathrm{kg})$ measurements taken by the study coordinator at study enrollment.

Menopausal status and menstrual cycle stage are important reproductive factors of interest due to their strong influences on sex hormone levels. Participants were self-identified premenopausal women, as declared at baseline in the questionnaire (still menstruating vs. no longer menstruating). In addition, nurses reported menopausal status during data collections in the study diaries. Some nurses, formerly classified as pre-menopausal at initial assessment, reported subsequent cessation of menstruation during the study periods. These women, likely perimenopausal (transitioning from pre- to post-menopausal), were kept in the analysis to avoid limiting sample size, and the influence of these women on final study results was assessed.

In the study diaries, subjects were asked to report the first day of their last menstrual period. From this, a categorical variable for menstrual cycle stage was determined by counting the number of days since the start of the last menstrual period ( $0-10$ days $=$ follicular phase, 11-16 days $=$ mid-cycle/ ovulatory phase, $>16$ days $=$ luteal phase), based on an assumed 28-day cycle . Although information on exact menstrual day was available, this information was conceptualized categorically for analysis based on biologically meaningful timing with respect to estrogen and progesterone hormone levels (16-18), and to minimize the potential for misclassification.

Estrogen levels tend to peak mid-cycle and remain higher in the luteal compared to follicular stages while progesterone levels rise through the cycle, peaking in the final luteal stage. While the “ovulatory peak" may be defined more narrowly as the 16-32 hours mid-cycle during which LH levels peak, a broader mid-cycle phase was chosen here to capture relevant changes in estrogen 
and progesterone levels (Figure 3.2).

Figure 3.2 Changes in sex hormones over the menstrual cycle

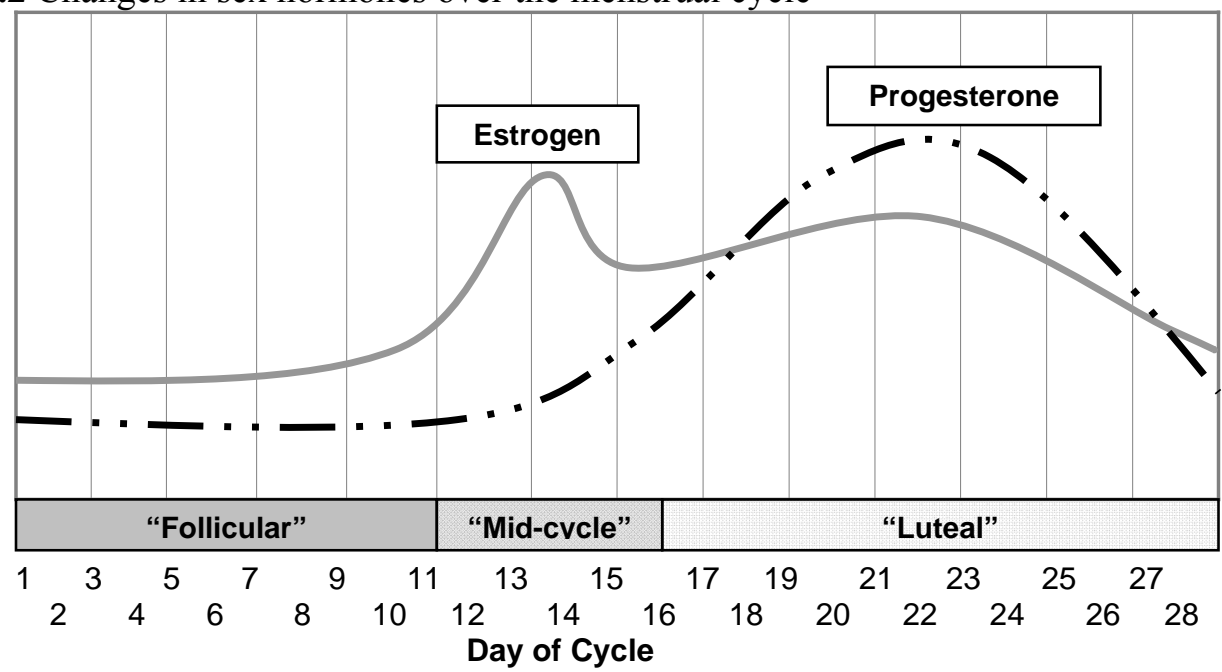

In terms of misclassification, as cycle length was not ascertained, categories had to be

defined assuming a 28-day menstrual cycle length, with the upper limit of the luteal category left open ended to accommodate women reporting over 28 days since the start of their last menstruation. That most variability in menstrual cycle length is accounted for by differences in the length of the follicular phase (19) makes this classification especially challenging. For example, a woman who reports 11 days since her last menstrual period could be in either the follicular phase or at mid-cycle, depending on the length of her follicular phase. Misclassification of cycle stage could be most limited if information on menstrual cycle length was also available; however, the use of broad menstrual phase categories minimized misclassification in this study.

For five women who were missing menstrual cycle stage information in the study diary (but who reported "still menstruating"), current menstrual stage was estimated using menstrual cycle information provided in the night shift WSIB study period (completed one month prior to day shift study period, and for which exact dates of completion were available; see Section 3.3.2). Assuming a 28 day cycle, information of the first day of the last menstrual period in the previous 
month was used to estimate the woman's current cycle stage. Current OC use (Y/N) use was also assessed from the study diary, where nurses reported whether they had taken prescribed birth control medications in the past $24 \mathrm{hr}$.

Lifestyle characteristics included smoking, alcohol and caffeine intake, and physical activity. While information regarding both usual and recent consumption and practice patterns was collected from the questionnaire and study diary, these variables were classified according to their biologically plausible and reported influences on sex hormone and melatonin levels in the literature and based on their assessments in previous studies of these relationships. Current smoking status was assessed in the questionnaire (smoker vs. non-smoker). In addition, participants were asked if they had smoked over 100 cigarettes in their lifetime, allowing nonsmokers to be further categorized as "never" vs. "past" smokers. Given the small number of current and past smokers, further analysis on amount smoking was not conducted.

Alcoholic beverage consumption was also assessed from the questionnaire, where nurses reported the average number and types (beer, wine or spirits) of alcoholic beverages consumed per week during different decades of their life. The most recent decade of life was considered the most etiologically relevant period, and a continuous variable for average total alcoholic beverages (all types combined) consumed per week was generated (drinks/ week).

Information regarding caffeine consumption was available from the study diary, where subjects reported the number and type of caffeinated beverages consumed in the 24-hr period preceding blood and urine sample collection. This was used to estimate average daily caffeine consumption, and was conceptualized as the number of caffeinated beverages consumed per day (drinks/ day). A limitation of this measure is the sole assessment of caffeinated beverage consumption, as caffeine may also be consumed from food sources. Also, as this measure was 
assessed from data collected during a working day, this may not be representative of usual caffeine consumption (including both working and non-working days).

Information regarding physical activity was also available from the study diary, which collected information on the type (i.e. walking, aerobics, etc), intensity (light, moderate and heavy), frequency and duration of all activities completed over the previous 30 days. Moderate physical activity was described as that which increases the heart rate and breathing rate and which may cause light sweating, and heavy physical activity as that which involves a substantial increase in heart rate and breathing rate with heavy sweating. Total moderate-to-heavy physical activity, of interest to sex hormone and melatonin levels, was calculated in hours per week (hrs/wk). In addition, given the limited moderate-to-heavy physical activity levels observed, total physical activity (all intensities) was collected (hrs/wk) and considered for confounder analysis.

For descriptive proposes, some continuous variables were presented in categories based on biological or clinical relevance. These variables were kept continuous for regression analysis to maintain information and precision of the data. Age (years) was categorized by decade (20-29, $30-39,40-49,50+)$, and BMI $\left(\mathrm{kg} / \mathrm{m}^{2}\right)$ by the standard classifications of underweight $(\mathrm{BMI}<$ 18.5), normal (18.5-24.9), overweight (25-29.9) and obese ( $\geq 30)$. Average weekly alcohol consumption was described categorically as $0,1-2,3-4$ and 5+ drinks per week and daily caffeinated beverage consumption as $0,1-2$ and $3+$ drinks per day. Total and moderate-to-heavy physical activity were described categorically as $0,1-2,>2-4$ and $>4$ hrs per week.

Additional logistical variables including season of data collection and time at blood sample collection were considered for influences on the relations under study. Season (summer vs. winter) was considered a potential effect modifier of melatonin-sex hormone relationships. Time of day at blood sample was considered a possible predictor of sex hormone levels (Section 2.6.6), conceptualized as before vs. after $8 \mathrm{AM}$ (within 1-hr of advised timing for collection). 


\subsection{Statistical Analysis}

All statistical analyses were completed using SAS (Version 9.2, SAS Inst., Cary, NC). Analyses were conducted separately for each sex hormone. Only data collections that had both melatonin and sex hormone measures were considered for analysis, except for the longitudinal analysis which required only melatonin from 'season one', and sex hormones from 'season two'.

\subsubsection{Subject Participation and Final Sample Sizes}

Of the 82 study participants, 46 were recruited in cohort A and 36 in cohort B (see Figure 3.1). Of the 46 women recruited in cohort A, all 46 took part in the first study period (summer '08), but two of these women were missing blood and another woman missing urine. In addition, one woman's melatonin level was outside the range of the assay's detection limits ( $n=42$ total). 38 women of cohort A remained for winter data collection, but one woman was missing blood, another two women missing urine and another woman's melatonin was outside of detectable limits $(\mathrm{n}=34$ total). Of the eight women $(17.4 \%)$ lost across seasons, four withdrew from the study and four became ineligible (two became part-time and two pregnant; Figure 3.3).

The remaining 36 study participants (of the 82 total) were recruited in cohort B. 35 of these women took part in the first study period (winter '08/09), but two women were missing blood samples and two melatonin measures were beyond detectable limits $(\mathrm{n}=31$ total). Four of these 35 women (11.4\%) were lost across seasons (one withdrew, two were lost to follow-up, and one began working days only and was no longer eligible for study participation), and one woman in this cohort joined late, taking part in only the second season of data collection, thereby giving a sample of 32 for the second season's data collection (summer '09). However, four of these 32 women were missing blood samples and another two missing urine ( $\mathrm{n}=26$ total; Figure 3.3).

In total, 51 women had measurable urine and blood samples for both seasons and 31 women for one ( $\mathrm{n}=133$ total). Of the 31 women with data for one season, 12 were lost across the 
change in season (eight cohort A, and four cohort B, see above); one woman (cohort B) joined the study late and took part in only the second season's collection, and the remaining 18 women with actually took part in both seasons' data collections but for one season they were missing either blood $(n=9)$ or urine $(n=5)$ samples, or their melatonin level was beyond detectable limits $(n=$ 4). Seasonally, there were 68 full data collections for summer and 65 for winter (Figure 3.3).

While 142 blood samples were collected from 82 subjects (cohort A: 44 summer, 37 winter; cohort B: 33 winter, 28 summer), some samples were missing measures for certain sex hormones, and other samples were not considered for analysis as the participant lacked the accompanying urine sample (or melatonin level was beyond detectable limits). Of the 142 blood samples collected, 3 samples were missing estradiol measurements, 4 estrone, 5 progesterone, and another 5 missing prolactin (17 missing outcomes total). In some instances, blood samples sent to KGH did not undergo all sex hormone analyses requested $(n=9$ total: 1 estradiol, 2 estrone, 4 progesterone, 2 prolactin). In other cases, blood tests were displaced during retrieval from the KGH laboratory, and could not be recovered electronically since the Laboratory Information System changed over the course of this study $(n=5: 1$ estrone, 2 estradiol, 1 progesterone, 1 prolactin). In addition, one blood sample hemolysed following delays and could not be analyzed for estrone. Lastly, two prolactin measures were unused due to macroprolactin present in the blood sample, which artificially increases prolactin levels causing inaccurate measurement (20).

Because no single blood sample was missing measures for all hormones, the total number of observations is still 133 (equivalent to the number of observations with melatonin measures) despite the sample sizes for each specific sex hormone being less (Figure 3.3). Also, there was some overlap between missing hormones with other missing data (urine samples missing or melatonin could not be measured). Accounting for these factors, the following sample sizes were obtained for each sex hormone, outlined in Table 3.1 below. 
Figure 3.3 Study flow chart

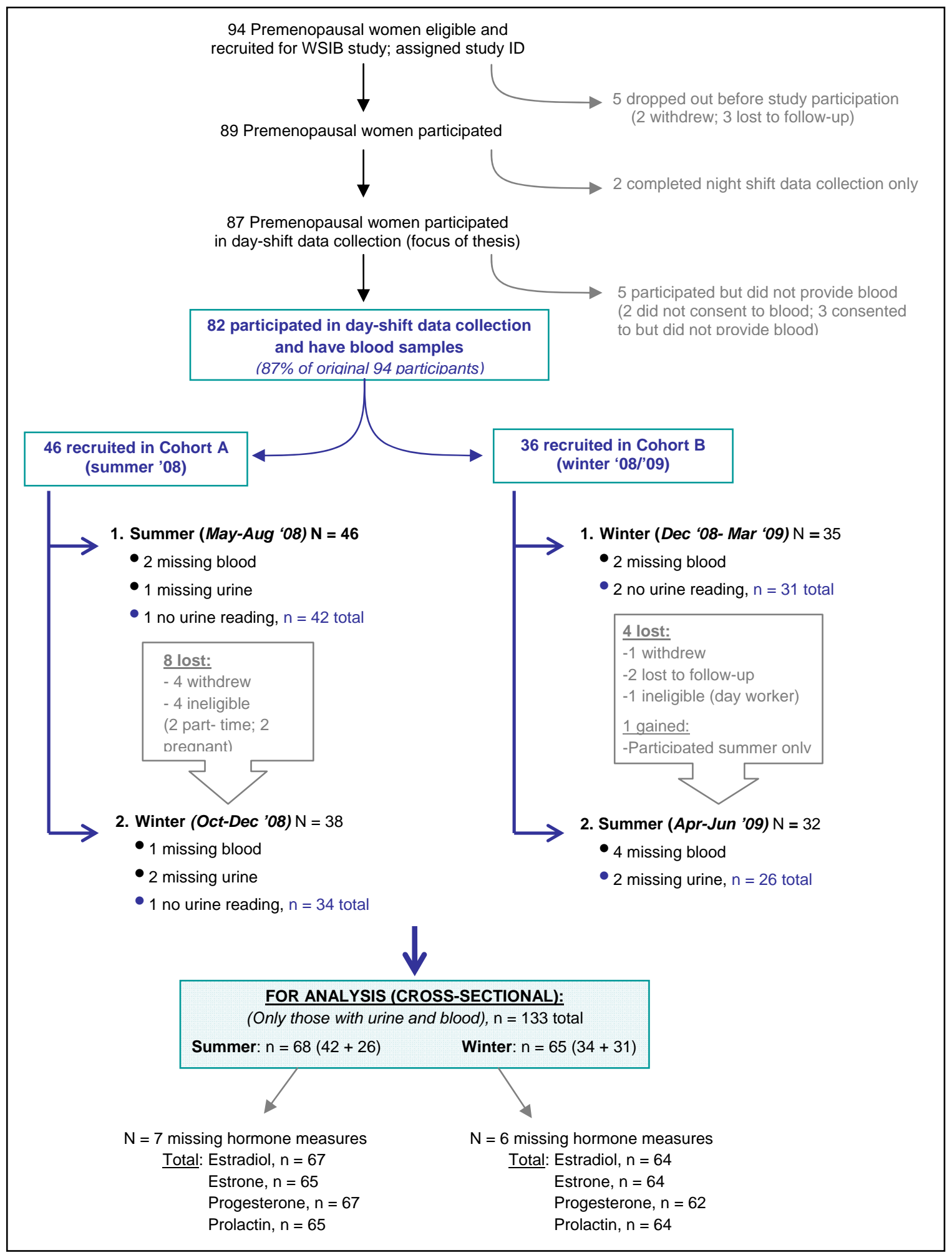


Table 3.1 Final sample sizes

\begin{tabular}{lcccc}
\hline Analysis & Estradiol & Estrone & Progesterone & Prolactin \\
\hline $\begin{array}{l}\text { Cross-sectional }(n=12) \\
\quad \text { Summer }\end{array}$ & 67 & 65 & 67 & 65 \\
$\quad$ Winter & 64 & 64 & 62 & 64 \\
$\quad$ Pooled seasons & 131 & 129 & 129 & 129 \\
Longitudinal $(n=4)$ & & & & \\
$\quad$ Across seasons* & 60 & 60 & 60 & 60 \\
\hline
\end{tabular}

*Melatonin 'season 1', sex hormones 'season 2'

For cross-sectional analyses, relationships with melatonin were assessed for each sex hormone separately, by season. Analyses were also conducted using data pooled across seasons when seasonal relationships were not meaningfully different $(n=12$ potential analyses total). For the longitudinal analyses, melatonin levels from the first season were assessed in relation to sex hormone levels from the second season ( $\mathrm{n}=4$ analyses). Given the use of cross-seasonal data, this analysis was restricted to nurses who participated in both study periods. Although only 51 women have full data for both periods, the sample size for this analysis was slightly larger $(\mathrm{n}=$ 60 ) as women were required to have only urine samples for season one (for melatonin assessment) and blood samples for season two (for sex hormone assessment).

\subsubsection{Descriptive Statistics}

Characteristics of the study population (baseline and seasonal) were described including means and standard deviations for continuous variables and frequency distributions for categorical variables. Seasonal distributions of continuous creatinine-adjusted aMTs-6 and sex hormone levels were described including means and standard deviations. Distributions were assessed for normality and were log-transformed to create more normal distributions. Geometric means (calculated by back-transforming the means of the log-transformed distributions) were compared across seasons by the difference of least squares means estimates using linear mixed 
modeling with a random subject effect (to account for the dependency of multiple observations by the same individual). This approach was chosen over the paired t-test to increase sample size, since unlike the paired t-test, this difference test was not limited to subjects with paired data only.

Geometric mean sex hormone levels were also compared across menstrual cycle stages using the ANOVA F-test. Associations between other reproductive factors with sex hormone levels were similarly assessed to explore other determinants of sex hormone variability in the study population. Lastly, inter-relationships between sex hormones were assessed. As data was pooled across seasons for these later two analyses (with some individuals participating in both seasons), relationships were assessed using linear mixed modeling with a random subject effect.

\subsubsection{Bivariate Exposure-Outcome Relationships}

Bivariate melatonin-sex hormone relationships were assessed for all analyses, using generalized linear regression modeling, to facilitate comparison to previous research which has limited confounder adjustments. Bivariate relationships between years of night shift-work history and sex hormones were also assessed. Linear mixed modeling with a random subject effect was used to account for the dependency of two sex hormone measures provided by some women. This modeling strategy adjusts for the artificially deflated variance that occurs with correlated data, thereby reducing the risk of type I error (21). Under this approach, subjects may contribute varying repetitions of measurements: given the small number of repetitions for this study (two), random-slope modeling was considered unnecessary. Both time-variant (seasonal) and constant (baseline) covariates can be included in regression models allowing for both stable and changing characteristics of the study population to account for variability in the outcomes (22).

\subsubsection{Confounder Assessment}

A systematic strategy was used to assess confounding of melatonin-sex hormone relationships by various personal, lifestyle and reproductive characteristics. For the cross- 
sectional analyses, stratified by season, if final multi-variate models did not vary meaningfully by season (parameter estimates were in the same direction and of similar magnitude), data was pooled across seasons to increase sample size. Here, a separate confounder selection was performed using the pooled data (as seasonal models did not necessarily adjust for the same confounders), and interaction by season was assessed in the final multivariate model. If interaction was significant, results from these pooled models were not interpreted. For the pooled seasonal models, linear mixed modeling was used to account for the dependency of multiple observations provided by the same individual (see above). For the longitudinal analysis (melatonin 'season 1'; sex hormones 'season 2'), potential confounders measured during the second seasons' data collection were assessed for confounding of relationships, based on the predicted influence of these variables on sex hormones also measured at this time.

Initially, bivariate associations were assessed between potential confounders and each sex hormone: associations meeting the liberal screening criterion of $p \leq 0.20$ (to improve the sensitivity of detecting confounders) were considered to potentially confound melatonin-sex hormone relationships, and were put forth to a backwards change-in-estimate confounder selection procedure. In this procedure, all potential confounders are initially included in the model, and variables are deleted individually in a step-wise fashion. At each step, the variable that causes the smallest change in the main exposure effect upon deletion is removed. This backwards deletion ends when the removal of any remaining variable in the model causes a $10 \%$ or greater change in the main exposure effect (23). Menstrual cycle stage, age and BMI were identified a priori as important confounders due to strong biologically plausible influences on sex hormone and melatonin levels, and a base model including these variables was set prior to confounder selection. Other potential confounders considered included OC use, smoking status, alcohol and caffeine consumption, and physical activity levels (Section 2.6.6). 
Based on the final-adjusted models, further analysis using melatonin tertiles was conducted to explore potential non-linear relationships or threshold effects. Further divisions of melatonin (e.g. using quartiles or quintiles) were not used given scarcity and large variability in the data. Melatonin tertiles were calculated using all data (pooled across seasons), and were kept consistent for all analyses to facilitate comparison. Geometric means of sex hormones were calculated from the least squares means estimates put forth by ANCOVA analysis, adjusting for confounders, and were compared by melatonin tertile using a linear test for trend.

A similar analysis strategy was used for confounder assessment and model building of relationships of years of night shift-work and sex hormones, except that linear mixed regression modeling was used from the outset as data was pooled across seasons. Using the final-adjusted models, further analysis was conducted here to compare geometric sex hormone means by categorical night shift history: under 20 vs. 20 or more years was chosen as a reasonable division given the clinical relevance of this duration of shift-work to breast cancer risk.

\subsubsection{Sensitivity Analysis and Regression Diagnostics}

Sensitivity analyses were conducted to assess whether relationships changed with consideration of peri-menopausal status, the time of day of blood sample collection, OC use, the seasonal order of data collection (longitudinal analysis) and when non-transformed variables were used for analyses. Regression diagnostics including residual analysis, outlier assessment and influence diagnostics were performed to assess adherence of data to the regression assumptions.

\subsection{Ethical Considerations}

Ethics approval for this thesis was obtained from the Queen's University Research Ethics Board (Appendix A). This study employed informed consent, where one copy of the consent form (Appendix B) was retained by participants. There were no anticipated harms nor direct benefits to 
participants; however, future benefits were anticipated including increased knowledge of cancer mechanisms in humans. Subjects were provided a $\$ 200$ honorarium to compensate for their time.

To ensure confidentiality of information, participants were assigned anonymous study identification numbers, used for all study instruments and biological samples. All identifying information was kept in locked filing cabinets that were available only to study personnel. Computerized data files contained no identifying information. Access to the study identification number key was restricted to three members of the study, including the study coordinator, and was used solely for contacting study participants for scheduling data collection periods.

\subsection{Student Contribution}

The larger WSIB parent study provided an opportunistic sample of nurses in whom relationships of melatonin and sex hormones could be investigated. Examining these relationships among premenopausal nurses (who provided blood samples) was presented as a thesis project by Dr. Kristan Aronson. While sex hormone assays were conducted by KGH core laboratory staff, the student was responsible for completing melatonin analysis for this project.

\section{References}

1. Aronson KJ, Richardson H, Tranmer J, Graham CH, Janssen I, Jones G. Occupational and other factors as determinants of melatonin levels among rotating shift nurses. 20072010(\$447 769).

2. Aronson KJ. Hormones and breast cancer risk. 2009-2010(\$20 000).

3. Peniston-Bird JF, Di WL, Street CA, Edwards R, Little JA, Silman RE. An enzyme immunoassay for 6-sulphatoxy-melatonin in human urine. J Pineal Res. 1996 Mar;20(2):51-6.

4. Miller RC, Brindle E, Holman DJ, Shofer J, Klein NA, Soules MR, et al. Comparison of specific gravity and creatinine for normalizing urinary reproductive hormone concentrations. Clin Chem. 2004 May;50(5):924-32.

5. Michaud DS, Manson JE, Spiegelman D, Barbieri RL, Sepkovic DW, Bradlow HL, et al. Reproducibility of plasma and urinary sex hormone levels in premenopausal women over a one-year period. Cancer Epidemiol Biomarkers Prev. 1999 Dec;8(12):1059-64.

6. Missmer SA, Spiegelman D, Bertone-Johnson ER, Barbieri RL, Pollak MN, Hankinson SE. Reproducibility of plasma steroid hormones, prolactin, and insulin-like growth factor levels among premenopausal women over a 2- to 3-year period. Cancer Epidemiol Biomarkers Prev. 2006 May;15(5):972-8.

7. Diamandis EP, Christopoulos TK. The biotin-(strept)avidin system: Principles and applications in biotechnology. Clin Chem. 1991 May;37(5):625-36. 
8. Bernstein L, Yuan JM, Ross RK, Pike MC, Hanisch R, Lobo R, et al. Serum hormone levels in pre-menopausal chinese women in shanghai and white women in los angeles: Results from two breast cancer case-control studies. Cancer Causes Control. 1990 Jul;1(1):51-8.

9. Madigan MP, Troisi R, Potischman N, Dorgan JF, Brinton LA, Hoover RN. Serum hormone levels in relation to reproductive and lifestyle factors in postmenopausal women (united states). Cancer Causes Control. 1998 Mar;9(2):199-207.

10. Wang B, Mi M, Wang J, Wei N, Zhang Q, Zhu J, et al. Does the increase of endogenous steroid hormone levels also affect breast cancer risk in chinese women? A case-control study in chongqing, china. Int J Cancer. 2009 Apr 15;124(8):1892-9.

11. Eliassen AH, Missmer SA, Tworoger SS, Spiegelman D, Barbieri RL, Dowsett M, et al. Endogenous steroid hormone concentrations and risk of breast cancer among premenopausal women. J Natl Cancer Inst. 2006 Oct 4;98(19):1406-15.

12. Stanczyk FZ, Lee JS, Santen RJ. Standardization of steroid hormone assays: Why, how, and when? Cancer Epidemiol Biomarkers Prev. 2007 Sep;16(9):1713-9.

13. Key TJ, Appleby PN, Reeves GK, Roddam A, Dorgan JF, Longcope C, et al. Body mass index, serum sex hormones, and breast cancer risk in postmenopausal women. J Natl Cancer Inst. 2003 Aug 20;95(16):1218-26.

14. Demers LM. Testosterone and estradiol assays: Current and future trends. Steroids. 2008 Dec 12;73(13):1333-8.

15. Gail MH, Fears TR, Hoover RN, Chandler DW, Donaldson JL, Hyer MB, et al. Reproducibility studies and interlaboratory concordance for assays of serum hormone levels: Estrone, estradiol, estrone sulfate, and progesterone. Cancer Epidemiol Biomarkers Prev. 1996 Oct;5(10):835-44.

16. Verkasalo PK, Thomas HV, Appleby PN, Davey GK, Key TJ. Circulating levels of sex hormones and their relation to risk factors for breast cancer: A cross-sectional study in 1092 pre- and postmenopausal women (united kingdom). Cancer Causes and Control. 2001;12(1):47-59.

17. Pike MC, Spicer DV, Dahmoush L, Press MF. Estrogens, progestogens, normal breast cell proliferation, and breast cancer risk. Epidemiol Rev. 1993;15(1):17-30.

18. The merck manuals online medical library: Home edition: Menstrual cycle: Biology of the female reproductive system [homepage on the Internet]. . 2007 Jul 2007. Available from: www.my-merck.net/mmhe/print/sec22/ch241/ch241e.htm.

19. Gaspard UJ, Romus MA, Gillian D, Duvivier J, Demey-Ponsart E, Franchimont P. Plasma hormone levels in women receiving new oral contraceptives containing ethinyl estradiol plus levonorgestrel or desogestrel. Contraception. 1983;27(6):577-590.

20. Smith TP, Kavanagh L, Healy ML, McKenna TJ. Technology insight: Measuring prolactin in clinical samples. Nat Clin Pract Endocrinol Metab. 2007 Mar;3(3):279-89.

21. Goldstein H. Multilevel statistical models. 2nd ed. London: Edward Arnold; 1995.

22. Hedeken D, Gibbons RD. Chapter 4: Mixed effects regression models for continuous outcomes. In: Longitudinal Data Analysis. Hoboken, New Jersey: John Wiley \& Sons Inc.; 2006. p. 101-158.

23. Rothman KJ, Greenland S. Modern epidemiology. 2nd ed. Philadelphia: Lippencott-Raven; 1998. 


\title{
Chapter 4 \\ Melatonin and sex hormones among rotating shift nurses
}

\begin{abstract}
Background: In 2007, the International Agency for Research on Cancer classified shift-work involving circadian disruption as a "probable carcinogen." One proposed pathway for this relationship involves nighttime light exposure and subsequent decreases in melatonin production. It is postulated that melatonin, a cancer-protective hormone, may influence patterns of sex hormone production that in turn influence breast cancer risk. The purpose of this study was to investigate the relationships between night shift-work history, melatonin and sex hormone levels among shift-working women.
\end{abstract}

Methods: 82 pre-menopausal nurses who work a rotating shift pattern of two days (7AM-7PM), two nights (7PM-7AM), followed by five days off participated in two study periods approximately six months apart (in summer and winter), each taking place during a day shift of the normal rotating shift pattern. Creatinine-adjusted melatonin metabolite concentrations were measured from morning void urine samples, and estradiol, estrone, progesterone and prolactin concentrations were measured from fasting blood samples taken at the same time. Other pertinent information was collected by measurement (weight, height) and by self-report via questionnaire. We examined melatonin-sex hormone relationships within each of two seasons, and across seasons, to investigate two hypothesized latency periods for influences of melatonin levels on sex hormones. Multivariate linear regression was used to explore relationships, with adjustment for confounders including age and body mass index.

Results: An inverse relationship between melatonin and estradiol was suggested in winter $(\beta=$ $0.13, \mathrm{p}=0.11$ ), and a positive relationship was suggested for increasing estrone with increasing 
melatonin tertile in summer $(\mathrm{p}=0.07)$, after multivariate adjustments. Melatonin was not associated with other hormones in either season. On investigation of a longer latency period, melatonin in the first season was not associated with sex hormones in the second season. While those working night shifts for 20 years or more had higher mean levels of estradiol, estrone and progesterone, results were not statistically different from those with a shorter history of night work.

Conclusions: The results of this study do not provide evidence to support the proposed biological pathway involving altered melatonin and sex hormone levels as intermediates between shift-work and breast cancer risk.

Keywords: shift-work, melatonin, sex hormones

Word count: 3285 (excluding abstract, tables and references) 


\section{INTRODUCTION}

The etiology of breast cancer is relatively unknown, with less than half of new cases explained by established risk factors $(1,2)$. Large global discrepancies in breast cancer incidence (3) have suggested a role for societal or environmental influences on this disease. In 1987, Stevens hypothesized that increasing breast cancer incidence in industrialized countries may be in part explained by the rising use of electric lighting, and more specifically, increased exposure to light at night (LAN) $(4,5)$. Melatonin, a hormone secreted by the pineal gland during darkness (6), was implicated in this pathway based on its cancer-protective effects, which may be mediated through interactions with sex hormones (7). It is postulated that exposure to LAN suppresses melatonin production leading to increases in sex hormones which may in turn increase breast cancer risk $(4,5)$.

Shift-work, a surrogate for LAN exposure, is associated with a modestly increased breast cancer risk in some epidemiologic studies, particularly those studies involving longer durations of shift-work (20-30 years) (8-10). Meta-analyses suggest that shift-workers have a 40-50\% increased risk of breast cancer $(11,12)$. Limited evidence in humans and sufficient evidence from experimental animals led to the classification of shift-work as a probable carcinogen by IARC in $2007(13)$.

While experimental evidence provides strong biologically plausible models for the carcinogenicity of shift-work, including LAN and subsequent disruptions of melatonin and sex hormone levels, these pathways have not been clearly elucidated in humans. The influence of melatonin on sex hormone levels is most well-known in seasonally breeding species, where melatonin levels, influenced by season and daylight, in turn control several aspects of reproduction (14-16). Studies of human reproduction $(6,17-24)$ and experimental melatonin trials $(23,25-29)$ have supported these relationships in humans under certain reproductive, pathological 
and pharmacological conditions. However, few epidemiologic studies have characterized these relationships under normal human physiology and results have been less convincing (30-33). Therefore, the purpose of this study was to examine relationships between melatonin, night shiftwork history, and sex hormone levels among a group of pre-menopausal shift-working nurses, as potential intermediates in the pathway to breast cancer.

\section{MATERIALS AND METHODS}

\section{Study population}

From April 2008 to February 2009, 94 premenopausal nurses who work the full-time rotating shift schedule of two 12-hr days (7AM-7PM), followed by two 12-hr nights (7PM-7AM), followed by five days off were recruited from Kingston General Hospital (KGH). The study was advertised through posters, and pamphlets that were sent to all full-time nurses at the hospital in an effort to recruit volunteers. Nurses were asked to self-exclude if they had been pregnant or lactating in the previous six months or if they used melatonin supplements. Seven women either

withdrew from the study or were lost to follow-up before data collection, and five women did not provide blood samples and so were excluded from the study. Eighty-two women (87\%) comprised the final study sample, and these women were recruited in two cohorts to facilitate data collection.

\section{Data collection}

Upon study enrollment, participants completed a questionnaire to gather personal information and a history of health, lifestyle and employment characteristics. Nurses took part in two study periods in summer and winter approximately 6 months apart, each during a day-shift of the regular shift schedule. During each study period, urine and blood samples were collected (from 5-7AM) and a diary was completed to obtain information on menstrual cycle stage, recent medication use, physical activity levels, caffeine consumption, and other seasonal characteristics. 
The collection of data across seasons allowed us to investigate two hypothesized time frames for influences of melatonin on sex hormones, [1] within each of two seasons and, [2] across seasons. Of the 82 nurses in this study, 68 participated in the summer study period and 65 in winter, with 51 women completing both study periods and 31 women participating once. Due to a few missing sex hormone measures ( 1 estradiol, 3 estrone, 3 progesterone, 3 prolactin) and covariate data, the final sample sizes for each analysis are slightly less than the number of women participating in each season.

\section{Melatonin assessment}

Melatonin levels were characterized by concentrations of the primary urinary melatonin metabolite, 6-sulfatoxymelatonin (aMTs-6), measured from first morning void urine samples. Urinary aMTs-6 levels correlate well with circulating melatonin levels in blood (34-36), and aMT6-s concentration in first morning void urine accurately characterizes peak nocturnal melatonin secretion and total nocturnal melatonin output, accounting for approximately $70 \%$ of total circulating melatonin from the previous night $(34,37)$. Nocturnal melatonin secretion has little variability within individuals over time $(31,38-40)$, and aMTs-6 assessment from a single morning void urine sample is highly reproducible over three-to-five years $(31,41)$.

Urine samples were processed, aliquoted and stored at $-80^{\circ} \mathrm{C}$ until the time of the melatonin analysis in the lab of Dr. Charles Graham at Queen's University. Concentrations of aMTs-6 were assayed using the Bühlmann aMTs-6 ELISA (ALPCO, Salem NH) and were adjusted for creatinine levels (aMTs- 6 divided by creatinine concentration) to account for variability in the diluteness of urine samples. Creatinine concentrations were measured from the same urine samples using the Parameter ${ }^{\mathrm{TM}}$ Creatinine Assay (R\&D Systems, Minneapolis, MN).

All urine samples for both aMTs- 6 and creatinine analyses were analyzed in duplicate and an average concentration and coefficient of variation $(\mathrm{CV})$ were calculated for each sample. 
Median CVs for aMTs-6 and creatinine were $9.1 \%$ and $10.0 \%$ respectively. To ensure data quality, assays for which the standard curve poorly fit the sample standards $\left(\mathrm{R}^{2}<0.95\right)$ were repeated. Additionally, samples for which aMTs- 6 or creatinine concentrations were out of range of the assay's standard curve were re-analyzed using appropriately adjusted dilutions.

\section{Sex hormone assessment}

Estradiol, estrone, progesterone and prolactin concentrations were measured in blood samples that were provided by nurses on the same day and within the same time frame (5-7AM) as urine samples. Nurses were instructed to fast for eight hours prior to blood collection $(30 \mathrm{~mL})$. Serum levels of progesterone (nmol/L), estradiol ( $\mathrm{pmol} / \mathrm{L})$ and prolactin $(\mathrm{ug} / \mathrm{L})$ were measured at the KGH Core Laboratory by paramagnetic particle, chemiluminescent immunoassays. Serum estrone levels (pmol/L) were measured by radioimmunoassay at the McMaster University Medical Centre (MUMC), as this assay was not available at KGH. Blood samples were processed, aliquoted and frozen at the KGH Core Laboratory prior to shipment to this centre.

All analyses were completed by hospital core laboratory staff, with blood samples analyzed separately and immediately upon retrieval by the lab. Instruments used for sex hormone assessment are calibrated daily by hospital staff, and all samples are run with two or more controls (for which sex hormone levels are known) to ensure precision and accuracy of the results. Inter-assay precision $(\mathrm{CV})$ of these tests, as reported by the KGH Clinical Laboratory Services Reference Manual, are 5-10\% for prolactin, 10-20\% for estradiol and 8-10\% for progesterone. Precision values are not available for the estrone analysis completed at the MUMC, but reports suggest inter-assay precision in the range of 7-11\% for different laboratories (42).

\section{Statistical analysis}

All statistical analyses were completed using SAS (Version 9.2, SAS Institute, Cary, NC). Natural logarithms of aMTs- 6 and sex hormones were used for analysis as transformed 
values more closely approximated normal distributions. Generalized linear regression modeling was used to examine relationships between melatonin and each sex hormone, assessed separately by season (summer and winter), and longitudinally across seasons. For the longitudinal analysis, melatonin levels from the first season were assessed in relation to sex hormone levels from the second season. Using a change-in-estimate confounder selection procedure $(\geq 10 \%$ change in the main exposure effect) confounders were identified (43), except for age, BMI, and menstrual cycle stage which were included in all models. For the cross-sectional analyses, if models did not vary by season (parameter estimates were in the same direction and of similar magnitude), data were pooled and linear mixed modeling was used to account for the dependency of observations provided by the same individual.

Based on the final multivariable-adjusted models, further analyses were conducted using melatonin tertiles to explore potential non-linear relationships or threshold effects. Adjusted geometric means of sex hormones were calculated for each tertile, and means were compared using a linear test for trend.

Relationships between sex hormone levels and years of night shift-work, conceptualized as the number of years working jobs that involved $50 \%$ or more night shifts, were also assessed. Linear mixed modeling was used to account for the dependency of two measures of sex hormones provided by some women. A similar confounder assessment was performed here, and further analysis was conducted to compare geometric means of sex hormones by long-term night shift history: under 20 vs. 20 or more years was chosen as a reasonable division given the clinical relevance of this duration of shift-work to breast cancer risk (8-10). 


\section{RESULTS}

Characteristics of the study population are presented in Tables 1 and 2. Most nurses (75\%) have worked night shifts for at least five years and over half of our sample $(51.7 \%)$ was overweight or obese according to their BMI classification (BMI $\geq 25 \mathrm{~kg} / \mathrm{m}^{2}$ ). Approximately $19 \%$ of participants reported current OC use. Categories of menstrual cycle stages were defined with respect to estrogen and progesterone levels: follicular (days 0-10), mid-cycle (days 11-16), and luteal (day 17+).

Table 1 Baseline characteristics of the study population $(\mathrm{n}=82)$

\begin{tabular}{lc}
\hline Characteristic & N (\%) \\
\hline Personal & \\
Age (years; mean \pm SD) & $35.8 \pm 8.2$ \\
BMI $\left(\mathrm{kg} / \mathrm{m}^{2}\right.$; mean $\left.\pm \mathrm{SD}\right)$ & $27.1 \pm 6.7$ \\
Ethnicity & \\
$\quad$ White & $79(96.3)$ \\
$\quad$ Non-white & $3(3.6)$ \\
Lifestyle & \\
Smoking & \\
$\quad$ Smoker & \\
$\quad$ Past-smoker & $11(13.4)$ \\
$\quad$ Never-smoker & $19(23.2)$ \\
Alcohol consumption & $52(63.4)$ \\
$\quad$ (drinks/ wk; mean \pm SD) & $3.4 \pm 3.8$ \\
History of night shift-work & \\
$\quad$ (years; mean \pm SD) & $11.0 \pm 8.4$ \\
$\quad$ 5 and under & \\
$\quad>5-10$ & $22(26.8)$ \\
$\quad>10-15$ & $28(34.2)$ \\
$>$ > 15-20 & $9(11.0)$ \\
$>$ 20 & $8(9.8)$ \\
&
\end{tabular}


Table 2 Seasonal characteristics of the study population

\begin{tabular}{lcc}
\multicolumn{1}{c}{ Characteristic } & $\begin{array}{c}\text { Summer }(\mathbf{n}=\mathbf{6 8}) * \\
\mathbf{N}(\mathbf{\%})\end{array}$ & $\begin{array}{c}\text { Winter (n = 65)* } \\
\mathbf{N}(\mathbf{\%})\end{array}$ \\
\hline $\begin{array}{l}\text { Reproductive } \\
\text { Menstrual Cycle Stage }\end{array}$ & \\
$\quad$ Follicular (days 1-10) & $26(38.2)$ & \\
$\quad$ Mid-cycle (days 11-16) & $10(14.7)$ & $22(33.9)$ \\
$\quad$ Luteal (day 17+) & $28(41.2)$ & $9(13.9)$ \\
$\quad$ Missing & $4(5.9)$ & $32(49.2)$ \\
Current oral contraceptive use & & $2(3.1)$ \\
$\quad$ Yes & $13(19.1)$ & $12(18.5)$ \\
$\quad$ No & $53(77.9)$ & $2(78.5)$ \\
$\quad$ Missing & $2(2.9)$ & \\
Lifestyle & & $4.67 \pm 5.45$ \\
Total physical activity (all intensities) & & \\
$\quad$ (hrs/ wk; mean \pm SD) & $4.43 \pm 4.15$ & $3.6 \pm 5.4$ \\
Moderate-to-heavy** physical activity & & \\
$\quad$ (hrs/ wk; mean \pm SD) & $3.3 \pm 3.7$ & $3.0 \pm 2.7$ \\
Caffeinated beverage consumption & & \\
$\quad$ (drinks/ day; mean \pm SD) & $3.3 \pm 3.3$ & \\
\hline
\end{tabular}

\footnotetext{
*An overlap of 51 women across seasons

**Moderate: that which increases the heart rate and breathing rate and which may cause light sweating; heavy: that which involves a substantial increase in heart rate and breathing rate with heavy sweating
}

Associations tested between melatonin (continuous and tertiles) and sex hormones were not statistically significant after consideration of confounders (Table 3; Figure 1). For estradiol, an inverse relationship with melatonin was suggested in winter (unadjusted: $\beta=-0.18, p=0.04$ ), but this result was slightly attenuated and no longer significant after confounder adjustment. This potential inverse relationship was less apparent with melatonin tertiles, as the geometric mean of estradiol peaked in the middle melatonin tertile. A positive relationship between estrone and melatonin was suggested in summer only, as geometric means of estrone increased with increasing melatonin tertile, the direction opposite to the study hypothesis. As relationships of melatonin with estradiol and estrone (although non-significant) varied meaningfully by season (parameter estimates were in opposite directions), data was kept stratified by season for these 
analyses. On investigation of a longer latency period, melatonin levels in the first season were not associated with estradiol or estrone levels in the second season.

No associations were suggested between melatonin and progesterone or prolactin in either season or by longitudinal analysis. As relationships (although non-significant) were similar by season (parameter estimates were in the same direction and of comparable magnitudes), data was pooled across seasons to increase sample size. In the pooled models, melatonin was still not associated with progesterone or prolactin.

Table 3 Multivariate-adjusted associations between melatonin (continuous) and sex hormones (all log-transformed)

\begin{tabular}{lcccc}
\hline \multirow{2}{*}{$\begin{array}{c}\text { Sex } \\
\text { Hormone }\end{array}$} & $\begin{array}{c}\text { Summer } \\
\text { Parameter } \\
\text { estimate } \\
(\mathrm{p} \text { value), } \mathrm{N}\end{array}$ & $\begin{array}{c}\text { Winter } \\
\text { Parameter } \\
\text { estimate } \\
(\mathrm{p} \text { value) }, \mathrm{N}\end{array}$ & $\begin{array}{c}\text { Longitudinal } \\
\text { Parameter } \\
\text { estimate } \\
(\mathrm{p} \text { value), }\end{array}$ & $\begin{array}{c}\text { Analysis } \\
\text { Parameter estimate } \\
(\mathrm{p} \text { value), N }\end{array}$ \\
\hline $\begin{array}{l}\text { Estradiol } \\
(\mathrm{pmol} / \mathrm{L})\end{array}$ & $0.005(0.94)^{\mathrm{a}}, 61$ & $-0.13(0.11)^{\mathrm{b}}, 56$ & $-0.05(0.54)^{\mathrm{c}}, 54$ & $\mathrm{NA}$ \\
$\begin{array}{l}\text { Estrone } \\
(\mathrm{pmol} / \mathrm{L})\end{array}$ & $0.05(0.36)^{\mathrm{a}}, 59$ & $-0.03(0.61)^{\mathrm{d}}, 59$ & $0.05(0.40)^{\mathrm{b}}, 53$ & $\mathrm{NA}$ \\
$\begin{array}{l}\text { Progesterone } \\
(\mathrm{nmol} / \mathrm{L})\end{array}$ & $0.07(0.46)^{\mathrm{a}}, 61$ & $0.14(0.22)^{\mathrm{a}}, 58$ & $-0.02(0.86)^{\mathrm{a}}, 56$ & $0.06(0.43)^{\mathrm{a}}, 119$ \\
$\begin{array}{l}\text { Prolactin } \\
(\mathrm{ug} / \mathrm{L})\end{array}$ & $0.01(0.78)^{\mathrm{e}}, 59$ & $0.003(0.94)^{\mathrm{f}}, 59$ & $-0.05(0.40)^{\mathrm{g}}, 52$ & $0.002(0.95)^{\mathrm{h}}, 118$ \\
\hline Adjusted & & & &
\end{tabular}

Adjusted for age, BMI, menstrual cycle stage, and:

a: OC use

b: OC use, alcohol consumption

c: alcohol consumption, caffeine consumption

d: OC use, alcohol and caffeine consumption, smoking status, total physical activity levels

e: OC use, smoking status

f: OC use, caffeine consumption

g: caffeine consumption, moderate-to-heavy physical activity

h: OC use, caffeine consumption, smoking status

(See Appendix E Table 2 for corresponding R-square values for each model; Appendix E Figure 1 for graphical depiction of multivariate-adjusted associations between melatonin and sex hormones) 
Figure 1 Multivariate-adjusted geometric means of sex hormones by melatonin tertile (I)

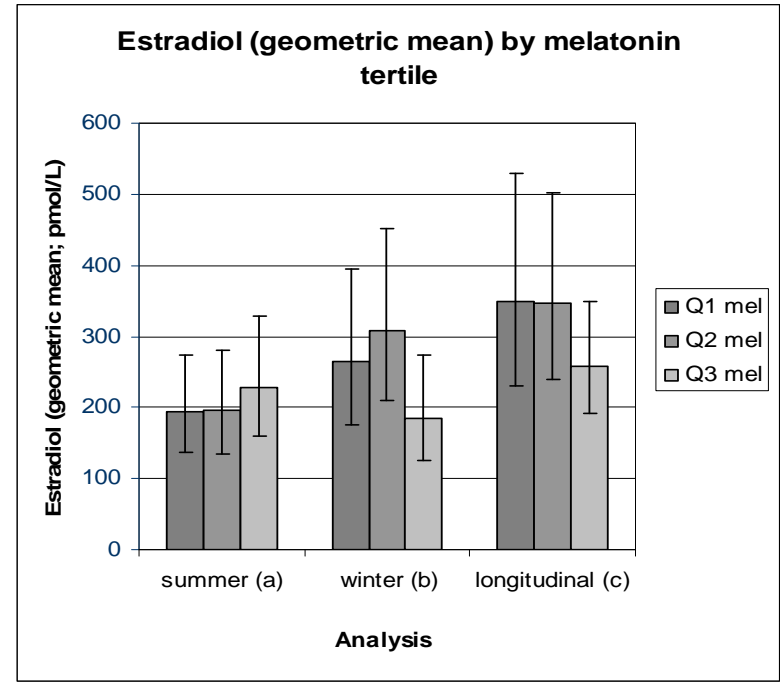

(II)

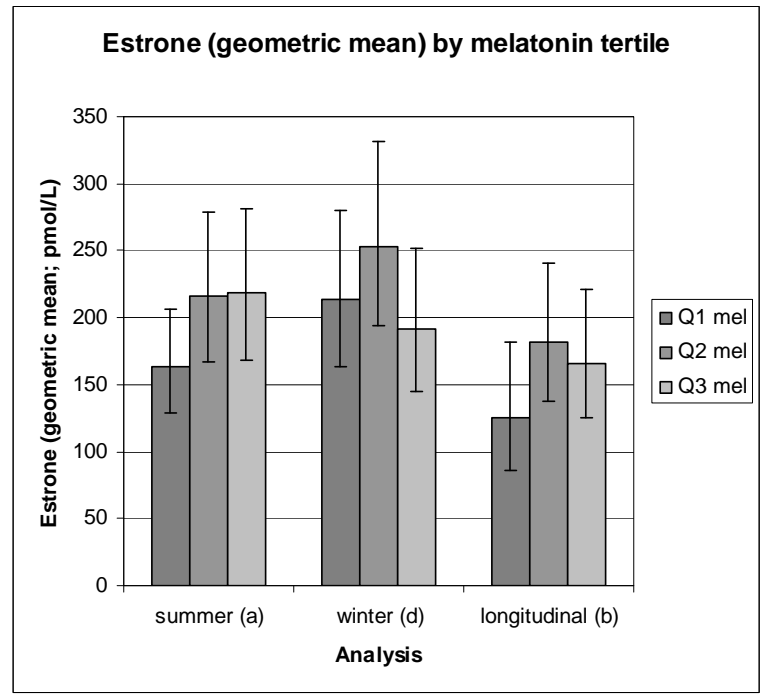




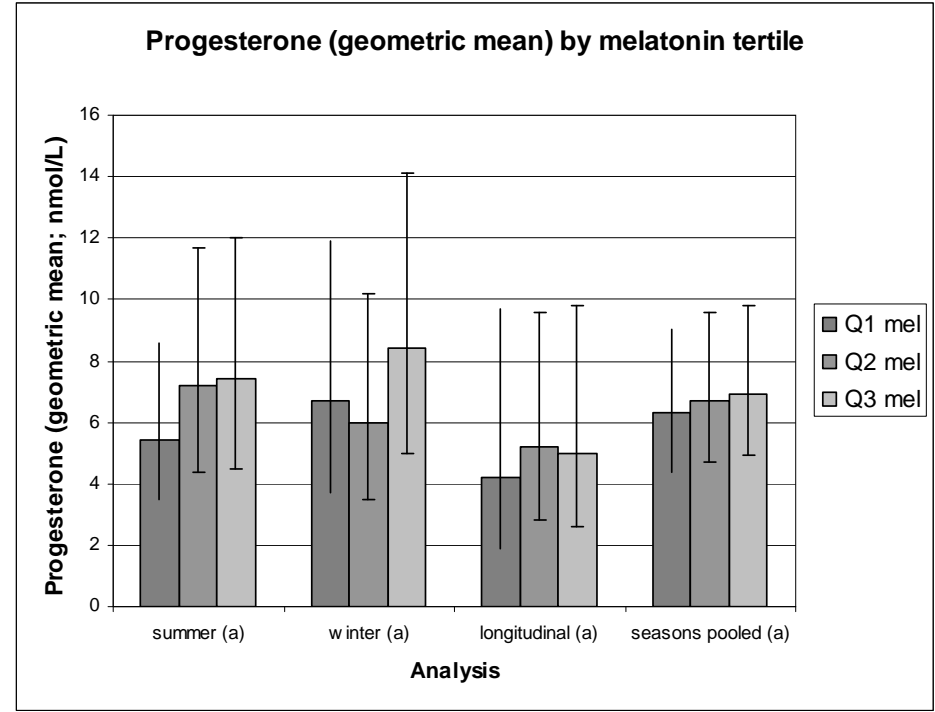

(IV)

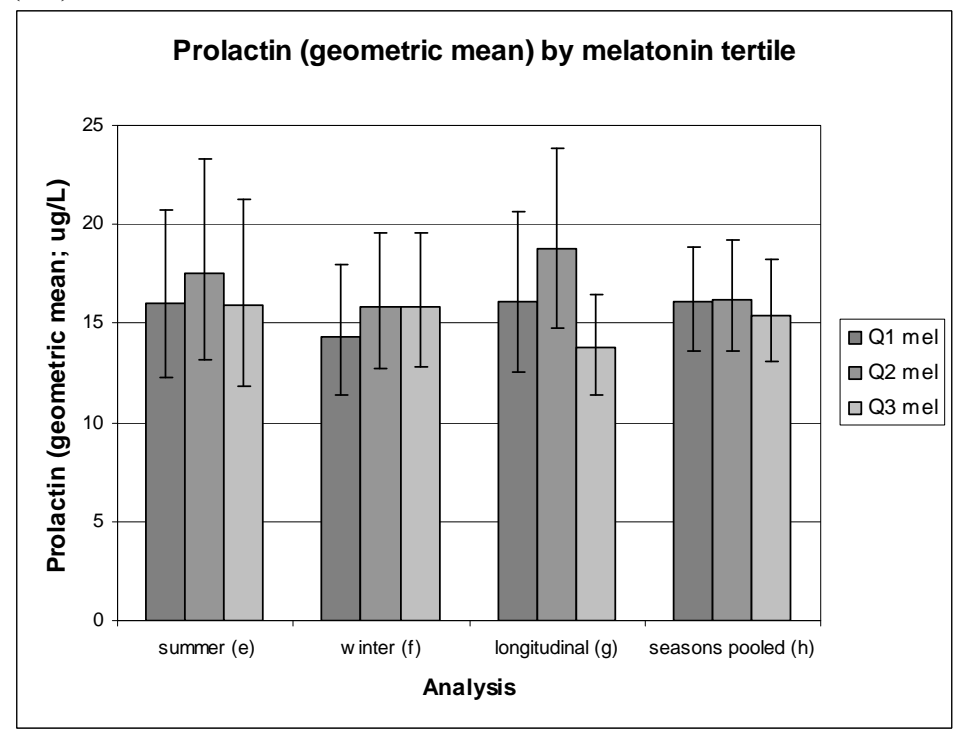

Adjusted for age, BMI, menstrual cycle stage, and:

a: OC use

b: OC use, alcohol consumption

c: alcohol consumption, caffeine consumption

d: OC use, alcohol consumption, caffeine consumption, smoking status, total physical activity levels

e: OC use, smoking status

f: OC use, caffeine consumption

g: caffeine consumption, moderate-to-heavy physical activity

h: OC use, caffeine consumption, smoking status

Tests for trend: estradiol: $\mathrm{p}=0.48,0.15,0.22$, respectively; estrone: $\mathrm{p}=0.07,0.51,0.10$;

progesterone: $\mathrm{p}=0.33,0.50,0.65,0.67$; prolactin: $\mathrm{p}=0.97,0.47,0.27,0.64$ 
Results were unchanged with exclusion of OC users $(n=13$ summer, $n=12$ winter, $n=8$ longitudinal), of nurses who provided blood samples after 8 AM $(n=32$ summer, $n=29$ winter, $n$ $=32$ longitudinal), or when non-transformed variables were used for analyses.

Multivariate-adjusted associations between night shift-work history (continuous years and $<20$ vs. $20+$ years) and sex hormones are presented in Table 4. Geometric means of estradiol, estrone and progesterone were consistently higher among longer term night shiftworkers ( $<20$ vs. $20+$ years), but were not statistically different. While statistically significant bivariate associations were observed between continuous years of night shift-work and estradiol, estrone, and progesterone levels, these findings were confounded by age and other variables, and so did not remain significant after multivariable adjustments.

Table 4 Multivariate-adjusted associations between night shift-work (continuous and under 20 vs. $20+$ years) and sex hormones (log-transformed)

\begin{tabular}{|c|c|c|c|c|c|}
\hline \multirow{2}{*}{$\begin{array}{l}\text { Sex } \\
\text { Hormone }\end{array}$} & \multicolumn{2}{|c|}{$\begin{array}{l}\text { Years of night shift-work } \\
\text { Parameter estimate ( } p \text { value) }\end{array}$} & \multicolumn{3}{|c|}{$\begin{array}{c}\text { Night shift-work }(<20 \text { vs. } 20+\text { years) } \\
\text { Geometric means }(95 \% \text { CI }) \text { of sex hormones }\end{array}$} \\
\hline & Unadjusted & $\begin{array}{l}\text { Multivariate- } \\
\text { adjusted }\end{array}$ & $\begin{array}{c}<20 \text { years } \\
(\mathrm{n}=67)\end{array}$ & $\begin{array}{c}20+\text { years } \\
(\mathrm{n}=15)\end{array}$ & $\begin{array}{l}\mathrm{p} \text { for } \\
\text { diff }\end{array}$ \\
\hline $\begin{array}{l}\text { Estradiol } \\
(\mathrm{pmol} / \mathrm{L})^{\mathrm{a}}\end{array}$ & $0.02(0.04)$ & $-0.002(0.87)$ & $\begin{array}{c}259.4 \\
(198.4-338.9)\end{array}$ & $\begin{array}{c}269.5 \\
(182.6-397.7)\end{array}$ & 0.84 \\
\hline $\begin{array}{l}\text { Estrone } \\
(\mathrm{pmol} / \mathrm{L})^{\mathrm{b}}\end{array}$ & $0.01(0.02)$ & $0.005(0.48)$ & $\begin{array}{c}209.1 \\
(174.3-250.8)\end{array}$ & $\begin{array}{c}258.6 \\
(197.9-337.9)\end{array}$ & 0.11 \\
\hline $\begin{array}{l}\text { Progesterone } \\
(\mathrm{nmol} / \mathrm{L})^{\mathrm{b}}\end{array}$ & $0.03(0.02)$ & $-0.002(0.86)$ & $7.05(4.60-10.8)$ & $7.51(4.28-13.2)$ & 0.79 \\
\hline $\begin{array}{l}\text { Prolactin } \\
(\mathrm{ug} / \mathrm{L})^{\mathrm{c}}\end{array}$ & $-0.006(0.27)$ & $0.002(0.79)$ & $16.5(13.4-20.2)$ & $15.7(11.8-20.8)$ & 0.71 \\
\hline
\end{tabular}

Adjusted for age, BMI, menstrual cycle stage, and:

a: OC use, alcohol consumption

b: OC use

c: OC use, caffeine consumption 


\section{DISCUSSION}

Overall, this study found no strong evidence for an association between melatonin, night shift-work history and sex hormone levels. While an inverse relationship between melatonin and estradiol was suggested in winter, and a step-wise increase in estrone with increasing melatonin tertiles suggested in summer, these results were not significant with confounder adjustment. Further, while longer term night shift-workers had higher levels of estrogens and progesterone, these results were not statistically significant.

Previous studies have identified inverse relationships between melatonin and follicle stimulating hormone (FSH) and luteinizing hormone (LH) (23), and estradiol (44) in observational settings; however, these results may be attributed to uncontrolled confounding. In a report from a melatonin trial of pre- and post-menopausal women, associations observed between baseline melatonin and FSH $(r=-0.322, p<0.05)$ and LH $(r=-0.314, p<0.05)$ levels did not account for potential confounders in the analysis (23). In another study that reported an inverse relationship between melatonin and estradiol $(\mathrm{r}=-0.661, \mathrm{p}<0.0005)$, only menstrual cycle stage and OC use were controlled; further, this relationship was confined to a small sub-group of premenopausal women aged 40-50 ( $\mathrm{n}=25)(44)$.

The results of more recent observational studies, having more comprehensive confounder assessment, have been less convincing. Two studies have investigated relationships between melatonin and sex hormones in women of the Nurses Health Study (NHS) cohort (30-31). Among 80 premenopausal nurses who did not use OCs, melatonin was associated with bioavailable estradiol (circulating estradiol not bound to plasma proteins; $\mathrm{r}=-0.25, \mathrm{p}=0.05$ ), and progesterone $(\mathrm{r}=0.31, \mathrm{p}=0.01)$ measured during the luteal menstrual stage: these relationships were slightly attenuated and no longer statistically significant after adjustment for age and BMI. No association was observed between aMT6-s and total estradiol (bioavailable and protein- 
bound), estrone or prolactin levels. Despite these findings, long duration of shift-work (15 years or more versus none) was associated with increased estradiol levels $(p=0.03)(30)$. Two years later, the same group published a second study involving an additional 384 women, also mostly premenopausal and belonging to the NHS (31). Melatonin was weakly associated with estrone sulfate levels $(r=0.13, p=0.02)$, and a step-wise decline in follicular estradiol levels was suggested for increasing quartile of melatonin $(\mathrm{p}=0.07)$. However, no other hormone (estrone, progesterone, dehydroepiandrostenedione (DHEA), dehydroepiandrostenedione sulfate (DHEAS), testosterone and androstenedione) was associated with melatonin. Most recently, among 206 post-menopausal Japanese women, no association was observed between melatonin and estradiol, estrone, testosterone or DHEAS, while having ever worked night shifts was related to increased estrone levels $(\mathrm{p}=0.006)(32)$.

While findings from observational studies have been mostly null, stronger support for inverse relationships between melatonin and sex hormones has been provided under various reproductive, pathological and experimental conditions. Unusually high melatonin levels have been associated with anovulation, oophrectomy and other abnormal ovarian conditions $(6,20,21$, 44), and some experimental melatonin trials have shown reductions in estrogen, $\mathrm{LH}, \mathrm{FSH}$, and even inhibition of ovulation with pharmacologic doses of melatonin $(23,25-29)$. If melatonin is truly related to sex hormones, it is possible that under extreme or unnatural conditions of melatonin and/ or sex hormone levels, relationships may be more apparent.

Along the lines of this type of reasoning, it could be expected that melatonin-sex hormone relationships may likewise be more evident among shift-workers, who may have disrupted melatonin secretion. Despite our recruitment of rotating shift nurses, a novel aspect of this study, no association between melatonin and sex hormones was evident. It is possible that the particular shift-work schedule studied is not "disruptive" enough to circadian rhythms to cause 
detectable changes in melatonin and/ or sex hormone levels. Further, given that risk estimates for shift-work and breast cancer are strongest and most consistent for longer durations of shift-work, our study population may not have had long enough durations of shift-work history for measurable associations between melatonin and sex hormones.

The longitudinal analysis, novel to this study, also did not reveal melatonin-sex hormone relationships. This additional analysis was conducted based on a hypothesized latency for the influence of changes in melatonin on sex hormone levels. The change in season was considered a possible source of melatonin variability which may cause subsequent changes in sex hormone production, either acutely or over the course of several months.

In addition to these strengths, there are some limitations. Large variability in sex hormone levels among participants created substantial "noise" in the data, limiting the ability to detect associations with variables, namely melatonin, for which effects may be small. While several steps were taken to reduce or standardize strong predictors of sex hormone levels across study participants (subjects were excluded if they had been pregnant or lactating in the previous six months; blood samples were instructed to be fasting and were collected at a consistent time of day), logistical difficulties prevented the scheduling of data collections across consistent menstrual cycle stage, and recruitment restraints prevented the exclusion of women who used OCs. That this work was nested within a larger observational study for which data collection strategies were guided by separate objectives explains some of these logistical limitations. While potential confounding by menstrual cycle stage and OC use was assessed and controlled for in the analyses, the large variability in sex hormone levels contributed by these influences may have limited study power. The small sample size may have similarly limited power, which may be of particular interest if proposed relationships between melatonin and sex hormones are small. 
Further, the assessment of menstrual cycle stage was incomplete; as data was not collected on menstrual cycle length, a 28-day cycle had to be assumed. Based on the reported first day of their last menstrual period, subjects were categorized into follicular (days 0-10), mid-cycle (days 11-16) and luteal menstrual stages (days 17+). This created potential misclassification among women with variable overall and phase-specific cycle lengths. The accuracy of this classification may have been improved if menstrual cycle length was known, or if women were scheduled to participate at specific stages of the menstrual cycle. Previous research based out of the NHS has ensured accuracy of menstrual stage by scheduling study participation at specific menstrual cycle days that can be reasonably assumed to accurately represent specific menstrual phases (follicular: 3-5 days following the onset of menstruation; luteal: 7-9 days prior to the onset of the next menstruation) $(30,31)$. However, this complex data collection scheduling is a challenge for observational studies.

The results of this study do not support the proposed biological pathway that involves altered melatonin and sex hormone levels as intermediates between shift-work and breast cancer risk. Nevertheless, these findings cannot refute the possible role for melatonin and sex hormones in breast cancer progression. In addition to the indirect neuroendocrine mechanism discussed in this paper, cell culture studies have proposed a second direct mechanism for interactions of melatonin and sex hormones at the level of the breast tumor cell where melatonin could interfere with estrogen-mediated proliferative signaling $(45,46)$. While this mechanism may not explain possible increases in breast cancer incidence among shift-workers, it still suggests a cancerprotective role for melatonin and emphasizes the importance of maintaining healthy melatonin levels. Several other cancer-protective properties of melatonin have been proposed including antioxidant properties, immodulatory functions, and direct anti-mitotic and pro-apoptotic pathways (47-49), which may be more relevant for the prevention of cancer initiation. Besides melatonin, 
several alternative pathways may explain increases in cancer risk among shift-workers, including behavioral or lifestyle changes (50), sleep disturbances (51), and stress (52).

Given the limitations in research on shift-work and breast cancer to date, including recent studies which show no associations $(53,54)$, the investigation of potential intermediates may help to clarify the existence and plausibility of this link. Further, the identification and understanding of the pathways mediating this link is of critical importance to the development of strategies to minimize the health impacts of this work schedule. This study contributes observational evidence concerning the relationships between melatonin and sex hormones, an area with few existing studies that have shown mostly null findings (30-32). However, given the sample size and large variability in the data, this study cannot rule out potential relationships between melatonin and sex hormones. Future studies with larger sample sizes and consistent menstrual variables may help to elucidate these mechanisms. Furthermore, future studies may consider investigating these relationships among women working more extreme shift schedules, or among longer term shiftworkers, for sufficient measurable changes in melatonin and/ or sex hormone levels to be observed.

\section{ACKNOWLEDGEMENTS}

We would like to thank all nurses at Kingston General Hospital who volunteered to participate in this study; Kathy Bowes, Deborah Emerton, Karen Lollar, and Krista Smith for assistance with data collection; and Mark McPherson, Lindsay Kobayashi and Shannyn MacDonald-Goodfellow for assistance with laboratory analyses. This study was funded by the Workplace Safety and Insurance Board (WSIB) of Ontario and Breast Cancer Action Kingston (BCAK). This work is part of a master's thesis, for which the student, Annie Langley, was supported by the Queen's University Terry Fox Award in Transdisciplinary Cancer Research in 
collaboration with the Canadian Institute for Health Research (CIHR) and the Franklin Bracken

graduate student award.

\section{REFERENCES}

1. Friedenreich CM, Marrett LD. Workshop report: Identification of research needs in breast cancer etiology. Chronic Dis Can. 2001;22(2):41-9.

2. Madigan MP, Ziegler RG, Benichou J, Byrne C, Hoover RN. Proportion of breast cancer cases in the united states explained by well-established risk factors. J Natl Cancer Inst. 1995 Nov 15;87(22):1681-5.

3. Parkin DM, Bray F, Ferlay J, Pisani P. Global cancer statistics, 2002. CA Cancer J Clin. 2005 Mar-Apr;55(2):74-108.

4. Stevens RG. Electric power use and breast cancer: A hypothesis. Am J Epidemiol. 1987 Apr;125(4):556-61.

5. Stevens RG, Davis S. The melatonin hypothesis: Electric power and breast cancer. Environ Health Perspect. 1996 Mar;104 Suppl 1:135-40.

6. Brzezinski A. Melatonin in humans. N Engl J Med. 1997 Jan 16;336(3):186-95.

7. Sanchez-Barcelo EJ, Cos S, Mediavilla D, Martinez-Campa C, Gonzalez A, Alonso-Gonzalez C. Melatonin-estrogen interactions in breast cancer. J Pineal Res. 2005 May;38(4):217-22.

8. Schernhammer ES, Laden F, Speizer FE, Willett WC, Hunter DJ, Kawachi I, et al. Rotating night shifts and risk of breast cancer in women participating in the nurses' health study. J Natl Cancer Inst. 2001 Oct 17;93(20):1563-8.

9. Schernhammer ES, Kroenke CH, Laden F, Hankinson SE. Night work and risk of breast cancer. Epidemiology. 2006 Jan;17(1):108-11.

10. Lie JA, Roessink J, Kjaerheim K. Breast cancer and night work among norwegian nurses. Cancer Causes Control. 2006 Feb;17(1):39-44.

11. Megdal SP, Kroenke CH, Laden F, Pukkala E, Schernhammer ES. Night work and breast cancer risk: A systematic review and meta-analysis. Eur J Cancer. 2005 Sep;41(13):2023-32.

12. Erren TC, Pape HG, Reiter RJ, Piekarski C. Chronodisruption and cancer. Naturwissenschaften. 2008 May;95(5):367-82.

13. Straif K, Baan R, Grosse Y, Secretan B, Ghissassi FE, Bouvard V, et al. Carcinogenicity of shift-work, painting, and fire-fighting. The Lancet Oncology. 2007 12;8(12):1065-6.

14. Arendt J. Melatonin and the mammalian pineal gland. London: Chapman and Hall; 1995.

15. Reiter RJ. Neuroendocrine effects of light. Int J Biometeorol. 1991 Nov;35(3):169-75.

16. Weaver DR, Stehle JH, Stopa EG, Reppert SM. Melatonin receptors in human hypothalamus and pituitary: Implications for circadian and reproductive responses to melatonin. J Clin Endocrinol Metab. 1993 Feb;76(2):295-301.

17. Cagnacci A, Volpe A. Influence of melatonin and photoperiod on animal and human reproduction. J Endocrinol Invest. 1996 Jun;19(6):382-411.

18. Aleandri V, Spina V, Morini A. The pineal gland and reproduction. Hum Reprod Update. 1996 May-Jun;2(3):225-35.

19. Luboshitzky R, Lavie P. Melatonin and sex hormone interrelationships--a review. J Pediatr Endocrinol Metab. 1999 May-Jun;12(3):355-62.

20. Brzezinski A, Lynch HJ, Seibel MM, Deng MH, Nader TM, Wurtman RJ. The circadian rhythm of plasma melatonin during the normal menstrual cycle and in amenorrheic women. $\mathrm{J}$ Clin Endocrinol Metab. 1988 May;66(5):891-5. 
21. Berga SL, Mortola JF, Yen SS. Amplification of nocturnal melatonin secretion in women with functional hypothalamic amenorrhea. J Clin Endocrinol Metab. 1988 Jan;66(1):242-4.

22. Waldhauser F, Weiszenbacher G, Frisch H, Zeitlhuber U, Waldhauser M, Wurtman RJ. Fall in nocturnal serum melatonin during prepuberty and pubescence. Lancet. 1984 Feb;1(8373):362-5.

23. Bellipanni G, Bianchi P, Pierpaoli W, Bulian D, Ilyia E. Effects of melatonin in perimenopausal and menopausal women: A randomized and placebo controlled study. Exp Gerontol. 2001 Feb;36(2):297-310.

24. Luboshitzky R, Lavie P. Melatonin and sex hormone interrelationships--a review. J Pediatr Endocrinol Metab. 1999 May-Jun;12(3):355-62.

25. Kripke DF, Kline LE, Shadan FF, Dawson A, Poceta JS, Elliott JA. Melatonin effects on luteinizing hormone in postmenopausal women: A pilot clinical trial NCT00288262. BMC Womens Health. 2006 May 16;6:8.

26. Voordouw BC, Euser R, Verdonk RE, Alberda BT, de Jong FH, Drogendijk AC, et al. Melatonin and melatonin-progestin combinations alter pituitary-ovarian function in women and can inhibit ovulation. J Clin Endocrinol Metab. 1992 Jan;74(1):108-17.

27. Pawlikowski M, Kolomecka M, Wojtczak A, Karasek M. Effects of six months melatonin treatment on sleep quality and serum concentrations of estradiol, cortisol, dehydroepiandrosterone sulfate, and somatomedin C in elderly women. Neuro Endocrinol Lett. 2002 Apr;23 Suppl 1:17-9.

28. Nordlund JJ, Lerner AB. The effects of oral melatonin on skin color and on the release of pituitary hormones. J Clin Endocrinol Metab. 1977 Oct;45(4):768-74.

29. Wright J, Aldhous M, Franey C, English J, Arendt J. The effects of exogenous melatonin on endocrine function in man. Clin Endocrinol (Oxf). 1986 Apr;24(4):375-82.

30. Schernhammer ES, Rosner B, Willett WC, Laden F, Colditz GA, Hankinson SE. Epidemiology of urinary melatonin in women and its relation to other hormones and night work. Cancer Epidemiol Biomarkers Prev. 2004 Jun;13(6):936-43.

31. Schernhammer ES, Kroenke CH, Dowsett M, Folkerd E, Hankinson SE. Urinary 6sulfatoxymelatonin levels and their correlations with lifestyle factors and steroid hormone levels. J Pineal Res. 2006 Mar;40(2):116-24.

32. Nagata C, Nagao Y, Yamamoto S, Shibuya C, Kashiki Y, Shimizu H. Light exposure at night, urinary 6-sulfatoxymelatonin, and serum estrogens and androgens in postmenopausal japanese women. Cancer Epidemiol Biomarkers Prev. 2008 Jun;17(6):1418-23.

33. Danforth DN,Jr, Tamarkin L, Mulvihill JJ, Bagley CS, Lippman ME. Plasma melatonin and the hormone-dependency of human breast cancer. J Clin Oncol. 1985 Jul;3(7):941-8.

34. Cook MR, Graham C, Kavet R, Stevens RG, Davis S, Kheifets L. Morning urinary assessment of nocturnal melatonin secretion in older women. J Pineal Res. 2000 Jan;28(1):41-7

35. Baskett JJ, Cockrem JF, Antunovich TA. Sulphatoxymelatonin excretion in older people: Relationship to plasma melatonin and renal function. J Pineal Res. 1998 Jan;24(1):58-61.

36. Lang U, Kornemark M, Aubert ML, Paunier L, Sizonenko PC. Radioimmunological determination of urinary melatonin in humans: Correlation with plasma levels and typical 24hour rhythmicity. J Clin Endocrinol Metab. 1981 Sep;53(3):645-50.

37. Graham C, Cook MR, Kavet R, Sastre A, Smith DK. Prediction of nocturnal plasma melatonin from morning urinary measures. J Pineal Res. 1998 May;24(4):230-8.

38. Arendt J. Radioimmunoassayable melatonin: Circulating patterns in man and sheep. Prog Brain Res. 1979;52:249-58.

39. Vijayalaxmi, Thomas CR,Jr, Reiter RJ, Herman TS. Melatonin: From basic research to cancer treatment clinics. J Clin Oncol. 2002 May 15;20(10):2575-601. 
40. Claustrat B, Brun J, Chazot G. The basic physiology and pathophysiology of melatonin. Sleep Medicine Reviews. 2005;9(1):11-24.

41. Travis RC, Allen NE, Peeters PH, van Noord PA, Key TJ. Reproducibility over 5 years of measurements of 6-sulphatoxymelatonin in urine samples from postmenopausal women. Cancer Epidemiol Biomarkers Prev. 2003 Aug;12(8):806-8.

42. Gail MH, Fears TR, Hoover RN, Chandler DW, Donaldson JL, Hyer MB, et al. Reproducibility studies and interlaboratory concordance for assays of serum hormone levels: Estrone, estradiol, estrone sulfate, and progesterone. Cancer Epidemiol Biomarkers Prev. 1996 Oct;5(10):835-44.

43. Rothman KJ, Greenland S. Modern epidemiology. 2nd ed. Philadelphia: Lippencott-Raven; 1998.

44. Okatani Y, Morioka N, Wakatsuki A. Changes in nocturnal melatonin secretion in perimenopausal women: Correlation with endogenous estrogen concentrations. J Pineal Res. 2000 Mar;28(2):111-8.

45. Sanchez-Barcelo EJ, Cos S, Fernandez R, Mediavilla MD. Melatonin and mammary cancer: A short review. Endocr Relat Cancer. 2003 Jun;10(2):153-9.

46. Cos S, Gonzalez A, Martinez-Campa C, Mediavilla MD, Alonso-Gonzalez C, SanchezBarcelo EJ. Estrogen-signaling pathway: A link between breast cancer and melatonin oncostatic actions. Cancer Detect Prev. 2006;30(2):118-28.

47. Reiter RJ. The role of the neurohormone melatonin as a buffer against macromolecular oxidative damage. Neurochem Int. 1995 Dec;27(6):453-60.

48. Fraschini F, Demartini G, Esposti D, Scaglione F. Melatonin involvement in immunity and cancer. Biol Signals Recept. 1998 Jan-Feb;7(1):61-72.

49. Cui P, Luo Z, Zhang H, Su Y, Li A, Li H, et al.Effect and mechanism of melatonin's action on the proliferation of human umbilical vein endothelial cells.J Pineal Res.2006 Nov;41(4):358-62

50. Kolstad HA. Nightshift-work and risk of breast cancer and other cancers--a critical review of the epidemiologic evidence. Scand J Work Environ Health. 2008 Feb;34(1):5-22.

51. Costa G, Haus E, Stevens R. Shift work and cancer - considerations on rationale, mechanisms, and epidemiology. Scand J Work Environ Health. 2010 Mar;36(2):163-79.

52. Sephton S, Spiegel D. Circadian disruption in cancer: A neuroendocrine-immune pathway from stress to disease? Brain Behav Immun. 2003 Oct;17(5):321-8.

53. Schwartzbaum J, Ahlbom A, Feychting M. Cohort study of cancer risk among male and female shift workers. Scand J Work Environ Health. 2007 Oct;33(5):336-43.

54. Pronk A, Ji BT, Shu XO, Xue S, Yang G, Li HL, et al. Night-shift work and breast cancer risk in a cohort of chinese women. Am J Epidemiol. 2010 May 1;171(9):953-9. 


\section{Chapter 5}

\section{Additional Results}

\subsection{Introduction}

Additional results presented in this chapter were either too detailed or were beyond the scope of the main objectives of the manuscript. This chapter begins with a more detailed description of characteristics of the study population, stratified by the level of study participation. Detailed distributions of melatonin and sex hormones are provided, including further investigation of reproductive determinants of sex hormone levels. Lastly, results of sensitivity analyses and regression diagnostics of the main regression analyses are presented.

\subsection{Characteristics of the Study Population}

Characteristics of the study population, including baseline (assessed from questionnaire) and seasonal covariates (from diaries) are described in Tables $5.1 \& 5.2$, respectively. These characteristics are described separately as the former were collected for each participant once (at baseline) while the latter were collected during each season of data collection. Given varying degrees of study participation and subject drop-out, baseline characteristics are compared for subjects with complete data (have exposure and outcome measures for both seasons, $\mathrm{n}=51$ ), incomplete data (have measures for one season, $\mathrm{n}=31$ ) and for subjects that were excluded from all analyses (participated but provided no blood, $\mathrm{n}=7$ ). In addition, these characteristics are presented separately for nurses who were included in the longitudinal analysis $(n=60)$, as this specific group also differed from the overall study population.

Based on the data available, seasonal characteristics are described only for those not excluded: in total, 68 subjects have complete data for summer and 65 for winter, with an overlap of 51 women across seasons. Seasonal covariates are also described separately for subjects who 
were included in the longitudinal analysis, as this specific group was different from the former two. Here, characteristics were assessed from the second season of data collection, based on the predicted influence of seasonal variables on sex hormones at this time. However, due to the staggered recruitment of study participants, the second season of data collection was summer for some participants and winter for others - a variable was created to describe these differences such that the influence of seasonal order of data collection on the results could be later explored.

The study population for this thesis was primarily white (96.3\%) with a mean age of 35.8 \pm 8.2 years. The majority of nurses $(75 \%)$ have at least five years night shift experience. Over half of study participants $(51.7 \%)$ were overweight or obese according to their BMI classification $\left(B M I \geq 25 \mathrm{~kg} / \mathrm{m}^{2}\right)$, and $13.4 \%$ were current smokers. Subjects consumed an average of $3.4 \pm 3.8$ alcohol beverages per week with over $75 \%$ of subjects reporting weekly alcohol consumption.

In general, characteristics did not vary considerably for subjects with complete vs. incomplete data, and for the study sample overall compared to excluded women. Excluded women and women with incomplete data were slightly younger $(31.7 \pm 13.0$ and $33.0 \pm 8.2$ years, respectively) with lower BMIs $\left(26.7 \pm 7.8 \mathrm{~kg} / \mathrm{m}^{2}\right.$ and $25.0 \pm 4.7$, respectively) compared to women with complete data $\left(37.5 \pm 7.8\right.$ years; $\left.28.3 \pm 7.4 \mathrm{~kg} / \mathrm{m}^{2}\right)$. The proportions of non-white women among those excluded (28.6\% or two women) and for those with incomplete data $(6.5 \%$, two women) were higher than for women with complete data $(1.7 \%, 1$ woman), but are based on very small numbers. Lastly, excluded women consumed less alcohol (2.4 \pm 1.9 drinks/ week), whereas women with incomplete data consumed more alcohol $(4.0 \pm 4.6)$ than women with complete follow-up $(3.0 \pm 3.2)$. Women in the longitudinal analysis also did not vary systematically from the overall study population. 
Table 5.1 Baseline characteristics of the study population by degree of study participation

\begin{tabular}{|c|c|c|c|c|c|}
\hline Characteristic & $\begin{array}{c}\text { Overall } \\
\text { study } \\
\text { population } \\
(\mathbf{n}=\mathbf{8 2}) \\
\mathrm{N}(\%)\end{array}$ & $\begin{array}{c}\text { Nurses in } \\
\text { two seasons' } \\
\text { analyses } \\
(\mathbf{n}=\mathbf{5 1}) \\
\mathrm{N}(\%)\end{array}$ & $\begin{array}{c}\text { Nurses in } \\
\text { one seasons' } \\
\text { analysis } \\
(\mathbf{n}=31)^{*} \\
\mathrm{~N}(\%)\end{array}$ & $\begin{array}{l}\text { Nurses in } \\
\text { longitudinal } \\
\text { analysis } \\
(\mathbf{n}=60) \\
\mathrm{N}(\%)\end{array}$ & $\begin{array}{c}\begin{array}{c}\text { Excluded } \\
\text { nurses } \\
(\mathbf{n}=7) \\
\mathrm{N}(\%)\end{array}\end{array}$ \\
\hline \multicolumn{6}{|l|}{ Personal } \\
\hline Age $(\mathrm{yrs} ;$ mean $\pm \mathrm{SD})$ & $35.8 \pm 8.2$ & $37.5 \pm 7.8$ & $33.0 \pm 8.2$ & $36.7 \pm 7.9$ & $31.7 \pm 13.0$ \\
\hline $\begin{array}{l}20-29 \\
30-39 \\
40-49 \\
50-59\end{array}$ & $\begin{array}{c}21(25.6) \\
28(34.2) \\
30(36.6) \\
3(3.7)\end{array}$ & $\begin{array}{c}8(15.7) \\
19(37.3) \\
22(43.1) \\
2(3.9)\end{array}$ & $\begin{array}{c}13(41.9) \\
9(29.0) \\
8(25.8) \\
1(3.2)\end{array}$ & $\begin{array}{c}11(18.3) \\
23(38.3) \\
24(40) \\
2(3.3)\end{array}$ & $\begin{array}{c}5(71.4) \\
0 \\
1(14.3) \\
1(14.3)\end{array}$ \\
\hline BMI $\left(\mathrm{kg} / \mathrm{m}^{2} ;\right.$ mean $\left.\pm \mathrm{SD}\right)$ & $27.1 \pm 6.7$ & $28.3 \pm 7.4$ & $25.0 \pm 4.7$ & $27.5 \pm 7.3$ & $26.7 \pm 7.8$ \\
\hline $\begin{array}{l}\text { Underweight }(<18.5) \\
\text { Normal }(18.5-24.9) \\
\text { Overweight }(25-29.9) \\
\text { Obese }(\geq 30) \\
\text { Missing }\end{array}$ & $\begin{aligned} 2 & (2.4) \\
36 & (43.9) \\
26 & (31.7) \\
17 & (20.7) \\
1 & (1.2)\end{aligned}$ & $\begin{array}{c}0 \\
20(39.2) \\
18(35.3) \\
13(25.5) \\
0\end{array}$ & $\begin{array}{c}2(6.5) \\
16(51.6) \\
8(25.8) \\
4(12.9) \\
1(3.2)\end{array}$ & $\begin{array}{c}2(3.33) \\
25(41.67) \\
19(31.67) \\
14(23.33) \\
0\end{array}$ & $\begin{array}{c}0 \\
4(57.1) \\
2(28.6) \\
1(14.3) \\
0\end{array}$ \\
\hline \multicolumn{6}{|l|}{ Ethnicity } \\
\hline $\begin{array}{l}\text { White } \\
\text { Non-white }\end{array}$ & $\begin{array}{c}79(96.3) \\
3(3.6)\end{array}$ & $\begin{array}{c}50(98.0) \\
1(2.0)\end{array}$ & $\begin{array}{l}29(93.6) \\
2(6.5)\end{array}$ & $\begin{array}{c}57(95) \\
3(5)\end{array}$ & $\begin{array}{l}5(71.4) \\
2(28.6)\end{array}$ \\
\hline \multicolumn{6}{|l|}{ Lifestyle } \\
\hline $\begin{array}{l}\text { Smoking } \\
\text { Smoker } \\
\text { Past-smoker } \\
\text { Never-smoker }\end{array}$ & $\begin{array}{l}11(13.4) \\
19(23.2) \\
52(63.4)\end{array}$ & $\begin{array}{c}7(13.7) \\
11(21.6) \\
33(64.7)\end{array}$ & $\begin{array}{c}4(12.9) \\
8(25.8) \\
19(61.3)\end{array}$ & $\begin{array}{c}8(13.3) \\
12(20) \\
40(66.7)\end{array}$ & $\begin{array}{l}1(14.3) \\
1(14.3) \\
5(71.4)\end{array}$ \\
\hline $\begin{array}{l}\text { Alcohol consumption } \\
\text { (drinks/wk; mean } \pm \mathrm{SD})\end{array}$ & $3.4 \pm 3.8$ & $3.0 \pm 3.2$ & $4.0 \pm 4.6$ & $3.2 \pm 3.1$ & $2.4 \pm 1.9$ \\
\hline 0 & $16(19.5)$ & $12(23.5)$ & $4(12.9)$ & $12(20)$ & $1(14.3)$ \\
\hline $\begin{array}{l}1-2 \\
3-4\end{array}$ & $\begin{array}{l}27(32.9) \\
16(19.5)\end{array}$ & $\begin{array}{l}18(35.3) \\
7(13.7)\end{array}$ & $\begin{array}{l}9(29.0) \\
9(29.0)\end{array}$ & $\begin{array}{c}21(35) \\
10(16.7)\end{array}$ & $\begin{array}{l}3(42.9) \\
2(28.6)\end{array}$ \\
\hline $5+$ & $20(24.4)$ & $11(21.6)$ & $9(29.0)$ & $14(23.3)$ & $1(14.3)$ \\
\hline Missing & $3(3.7)$ & $3(5.9)$ & 0 & $3(4.6)$ & 0 \\
\hline $\begin{array}{l}\text { History of night shift- } \\
\text { work (years; mean } \pm \text { SD) }\end{array}$ & $11.0 \pm 8.4$ & $12.1 \pm 8.8$ & $9.3 \pm 7.7$ & $11.7 \pm 8.6$ & $\begin{array}{c}11.0 \pm \\
16.4\end{array}$ \\
\hline 5 and under & $22(26.8)$ & $11(21.6)$ & $11(35.5)$ & $14(23.3)$ & $5(71.4)$ \\
\hline$>5-10$ & $28(34.2)$ & $18(35.3)$ & $10(32.3)$ & $21(35.0)$ & 0 \\
\hline$>10-15$ & $9(11.0)$ & $6(11.8)$ & $3(9.7)$ & $7(11.7)$ & 0 \\
\hline$>15-20$ & $8(9.8)$ & $6(11.8)$ & $2(6.5)$ & $7(11.7)$ & $1(14.3)$ \\
\hline$>20$ & $15(18.3)$ & $10(19.6)$ & $5(16.1)$ & $11(18.3)$ & $1(14.3)$ \\
\hline
\end{tabular}

*19 subjects did summer data collection only; 12 subjects winter only 
Detailed seasonal characteristics of the study population are presented in Table 5.2. Across both seasons, over half of participants completed an average of at least two hours of physical activity per week. On average, women completed slightly more physical activity in the winter and consumed slightly more caffeinated beverages in the summer. OC use was essentially unchanged across seasons, with 19.1 and $18.5 \%$ of participants classified as current users in summer and winter, respectively. Study participation was distributed fairly evenly across luteal and follicular menstrual cycle stages, but with fewer women in the mid-cycle stage, as expected due to its shorter duration. Four women in the summer and two women in the winter were missing information on menstrual cycle stage as they reported no longer menstruating since completing the original study questionnaire (one-two months prior). These women were considered possibly peri-menopausal, and a variable was created such that the influence of these subjects on the final study results could be assessed. In addition, one woman included in the longitudinal analysis was possibly peri-menopausal, and another woman still pre-menopausal yet missing information on menstrual cycle stage. In each season, just over half of women provided blood samples within one hour of the requested time-frame (from 5-7AM), that is, before 8AM, and close to two-thirds of women before 9AM.

Table 5.2 Seasonal characteristics of the study population

\begin{tabular}{lccc}
\hline Characteristic & $\begin{array}{c}\text { Summer (n= 68)* } \\
\text { N }(\%)\end{array}$ & $\begin{array}{c}\text { Winter }(\mathbf{n}=\mathbf{6 5}) * \\
\text { N }(\%)\end{array}$ & $\begin{array}{c}\text { Longitudina } \\
\text { analysis** (n } \\
\text { N }(\%)\end{array}$ \\
\hline Reproductive & & & \\
Menstrual Cycle Stage & & & \\
$\quad$ Follicular (days 1-10) & $26(38.2)$ & $22(33.9)$ & $19(31.7)$ \\
Mid-cycle (days 11-16) & $10(14.7)$ & $9(13.9)$ & $5(8.3)$ \\
Luteal (days >16) & $28(41.2)$ & $32(49.2)$ & $34(56.7)$ \\
Missing & $4(5.9)$ & $2(3.1)$ & $2(3.3)$
\end{tabular}

Current oral contraceptive use 

Yes
$13(19.1)$
53 (77.9)
$12(18.5)$
$8(13.3)$
No
Missing
$2(2.9)$
$51(78.5)$
$50(83.3)$
$2(3.1)$
$2(3.3)$

\section{Lifestyle}

Total physical activity (hrs/

wk; mean $\pm \mathrm{SD}$ )

$\begin{array}{ccc}4.43 \pm 4.15 & 4.67 \pm 5.45 & 4.3 \pm 4.5 \\ 3(4.41) & 2(3.1) & 2(3.3) \\ 16(23.5) & 19(29.2) & 18(30) \\ 19(27.9) & 14(21.5) & 13(21.7) \\ 25(36.8) & 24(36.9) & 22(36.7) \\ 5(7.4) & 6(9.2) & 5(8.3)\end{array}$

Moderate-to-heavy

physical activity (hrs/ wk;

mean $\pm \mathrm{SD}$ )

0

0-2

$>2-4$

$>4$

$5(7.4)$

$3.3 \pm 3.7$

$3.6 \pm 5.4$

$3.2 \pm 4.4$

0

$5(7.4)$

9 (13.9)

$6(10)$

$0-2$

$>2-4$

$23(33.8)$

$22(33.9)$

$22(36.7)$

$18(26.5)$

14 (21.5)

$14(23.3)$

$17(25)$

$14(21.5)$

$13(21.7)$

Missing

$5(7.4)$

$6(9.2)$

$5(8.3)$

Caffeinated beverage

consumption (drinks/ day; mean $\pm \mathrm{SD}$ )

0
$1-2$
$3+$
Missing

$3.3 \pm 3.3$

$3.0 \pm 2.7$

$3.0 \pm 2.4$

Logistical Considerations

$5(7.4)$

$27(39.7)$

35 (51.5)

$1(1.5)$
$7(10.8)$

$28(43.1)$

$29(44.6)$

$1(1.5)$
$6(10)$

$22(36.7)$

$29(48.3)$

$2(5)$

Time of day of blood sample collection

$\begin{array}{llll}\text { Before 8AM } & 36(52.9) & 36(55.4) & 28(46.7) \\ \text { After 8AM } & 32(47.1) & 29(44.6) & 32(53.3) \\ \text { Before 9AM } & & & \\ \text { After 9AM } & 43(63.2) & 45(69.2) & 35(58.3) \\ & 25(36.8) & 20(30.8) & 25(41.7)\end{array}$

Seasonal order of data collection (for longitudinal analysis)

Summer; winter

Winter; summer

NA

NA

$35(58.3)$ $25(41.7)$

*An overlap of 51 subjects across the two seasons of data collection

**Seasonal covariates from second season of data collection were considered for analysis 


\subsection{Seasonal Melatonin Distributions}

Distributions of creatinine-adjusted urinary aMTs-6 levels, the primary exposure of interest, are presented by season in Figure 5.1. For simplicity, creatinine-adjusted urinary aMTs-6 will henceforth be referred to as "melatonin." Melatonin distributions were heavily right-skewed, and so were log-transformed to improve normality of the data. Although there is no distribution assumption for the independent variable in regression analysis, log-transformed melatonin levels were used for subsequent analyses to lessen the influence of extreme melatonin values on regression models (1). Given large inter-individual variability in melatonin levels, including among healthy individuals (2), it is difficult to define a biologically plausible range for 'normal' or healthy melatonin levels (3). As such, log-transformation was chosen as a better approach compared to outlier exclusion to control for these influential data points. Further, as all previous observational studies of melatonin-sex hormone relationships in humans have used both logtransformed melatonin and sex hormones (4-6), a similar analysis strategy was chosen to facilitate comparison.

Figure 5.1 Melatonin distributions by season (left: non-transformed; right: log-transformed)

I) Summer $(\mathrm{n}=68)$
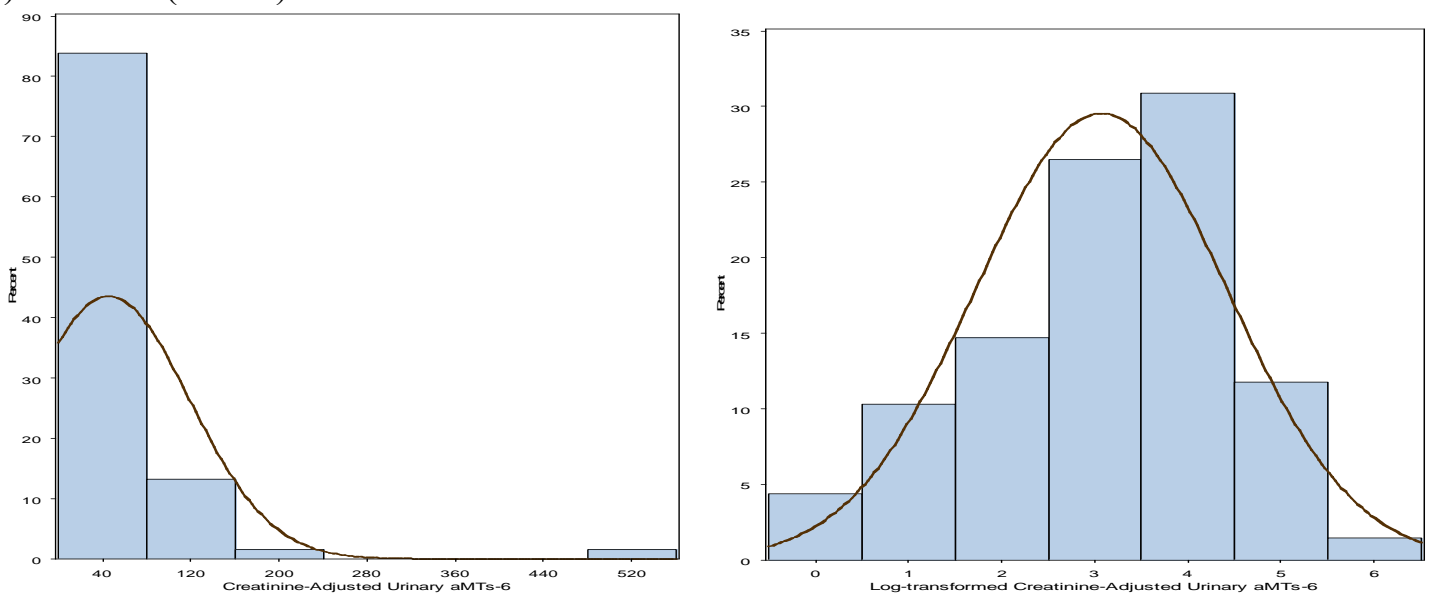
II) Winter $(\mathrm{n}=65)$
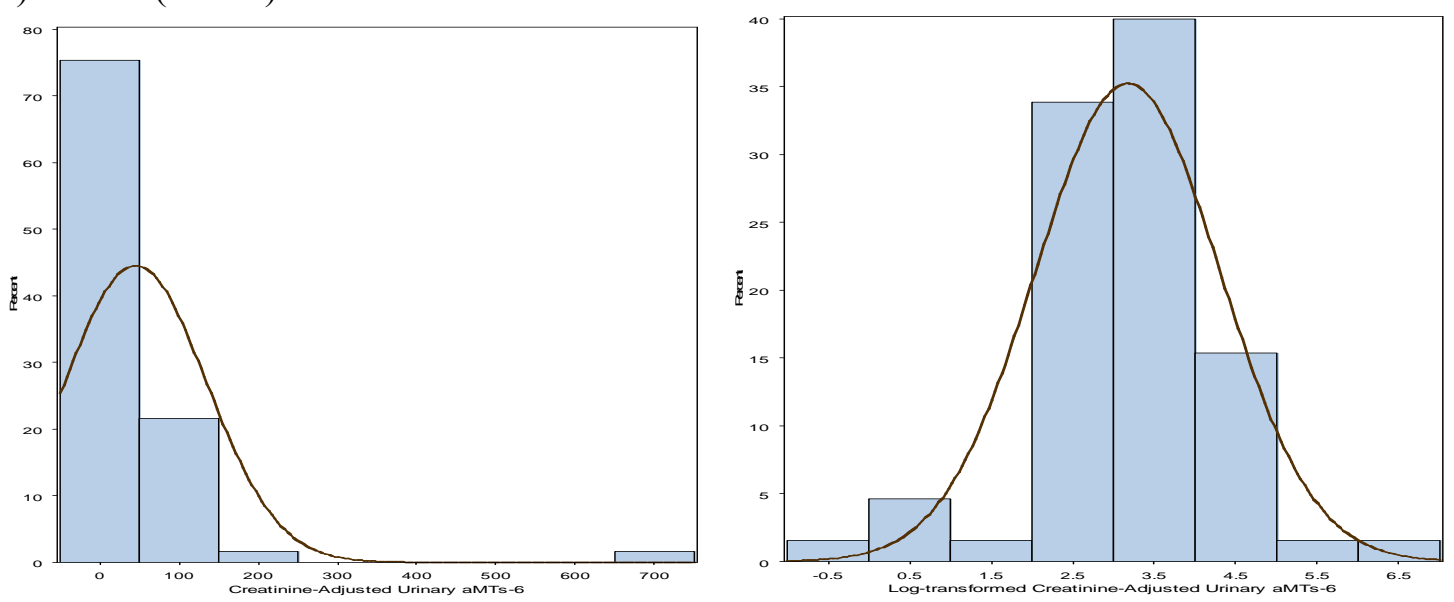

Table 5.3 presents geometric means and $95 \%$ confidence intervals $(\mathrm{CI})$ for melatonin levels by season. The geometric mean and associated CI are produced by back-transforming the mean and CI of logarithmically-transformed values. Compared to the arithmetic mean (of the untransformed data), the geometric mean was chosen as a more practical measure of central tendency since it is less influenced by outliers of the highly right-skewed data distribution (7). For comparison, non-transformed melatonin levels are also described by season including arithmetic means and standard deviations.

Geometric mean melatonin level did not vary significantly by season, according to the difference of least squares means estimates - means were compared using linear mixed modeling with a random subject effect. This approach accounts for the dependency of observations by the same individual across seasons (51 subjects provided data in both seasons), and was chosen over the simple paired t-test, since unlike the paired t-test, this test was not limited to subjects with paired data (all 82 subjects contributed to this calculation). For comparison, a paired t-test was also conducted (using only individuals with paired melatonin data; $\mathrm{n}=51$ ), and the results of this test were also non-significant (Wilcoxin signed rank test: $p=0.7394$ ). Despite non-significant 
changes in melatonin levels across seasons, the longitudinal analysis was still conducted given the novelty of this area of research and the lack of longitudinal studies to date.

Table 5.3 Mean melatonin levels by season

\begin{tabular}{lccc}
\hline \multicolumn{1}{c}{ Variable } & $\begin{array}{c}\text { Summer }(\mathbf{n}=\mathbf{6 8}) \\
\text { Geometric mean }(95 \% \mathrm{CI})\end{array}$ & $\begin{array}{c}\text { Winter }(\mathbf{n}=\mathbf{6 5}) \\
\text { Geometric mean }(95 \% \mathrm{CI})\end{array}$ & $\begin{array}{c}\text { p for } \\
\text { diff* }\end{array}$ \\
\hline $\begin{array}{l}\text { Log-transformed aMTs-6 } \\
\text { ng/ creatinine mg }\end{array}$ & 21.54 & 23.93 & 0.64 \\
$\begin{array}{l}\text { AMTs-6 ng/ creatinine mg } \\
\text { (arithmetic mean } \pm \text { SD) }\end{array}$ & $(15.52-29.85)$ & $(18.08-31.69)$ & 0.99 \\
\hline *Calculated by difference in least squares mean estimates by season using random subject effect
\end{tabular}

\subsection{Distributions and Determinants of Sex Hormones}

\subsubsection{Seasonal Distributions}

Sex hormone levels were highly variable among nurses and distributions were strongly right-skewed. To improve adherence of the data to regression assumptions (normally distributed residuals), the normality of outcome distributions were improved by log-transformation (Figure 5.2).

Figure 5.2 Sex hormone distributions by season (left: non-transformed; right: log-transformed)

I) Summer

(A) Estradiol $(n=67)$
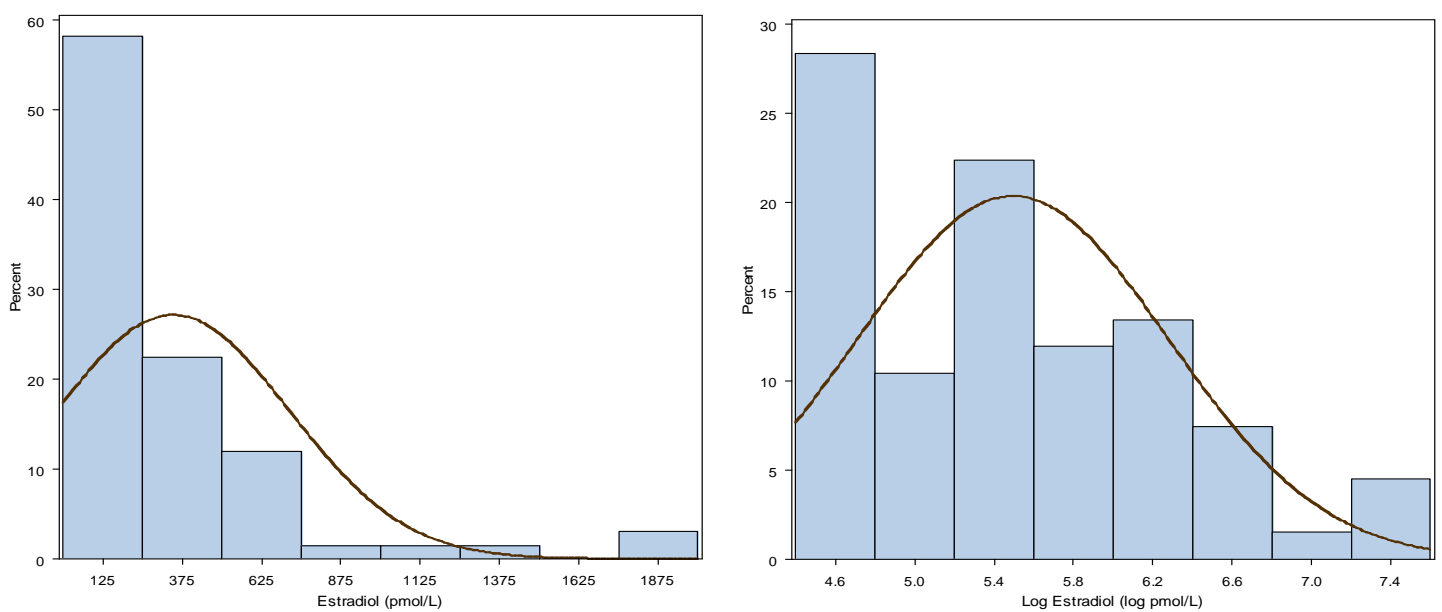
(B) Estrone $(\mathrm{n}=65)$
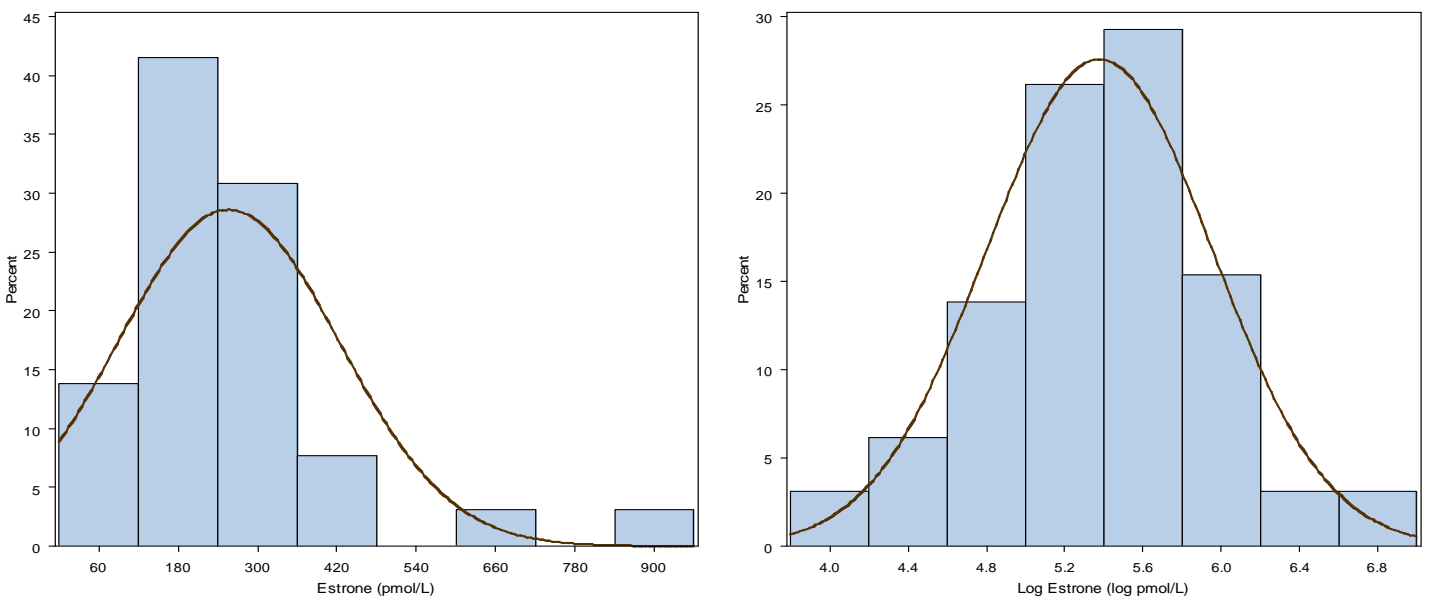

(C) Progesterone $(n=67)$
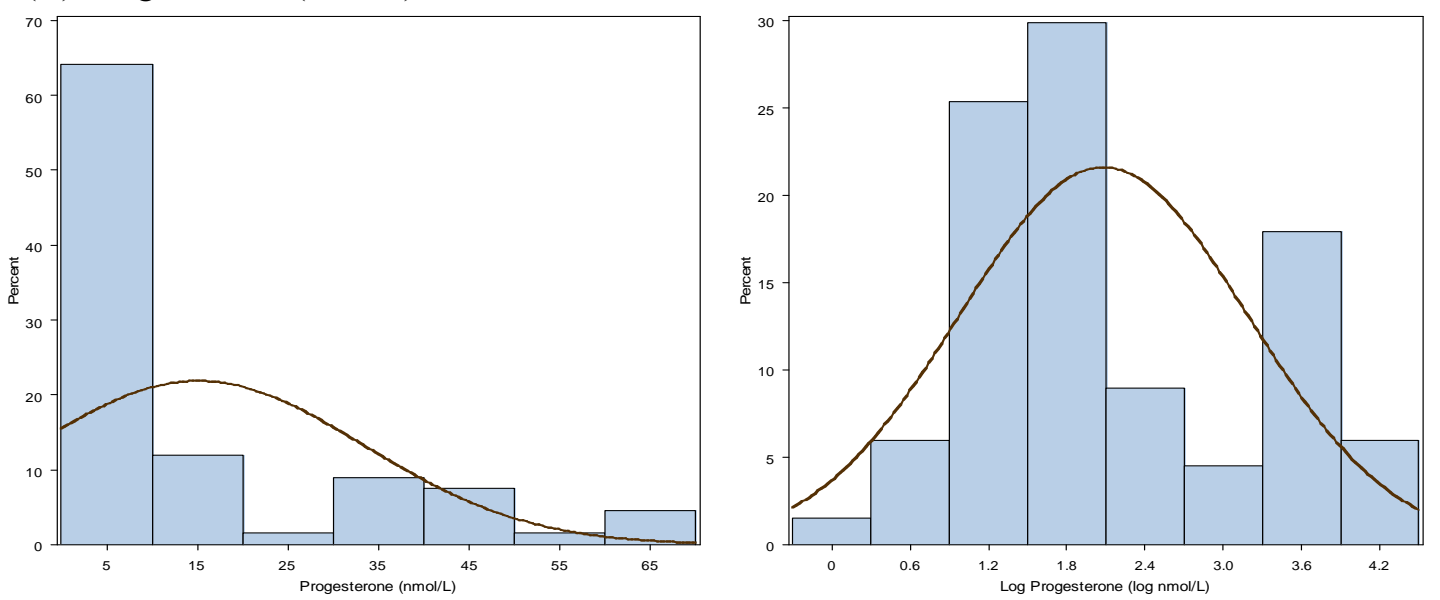

(D) Prolactin $(\mathrm{n}=65)$
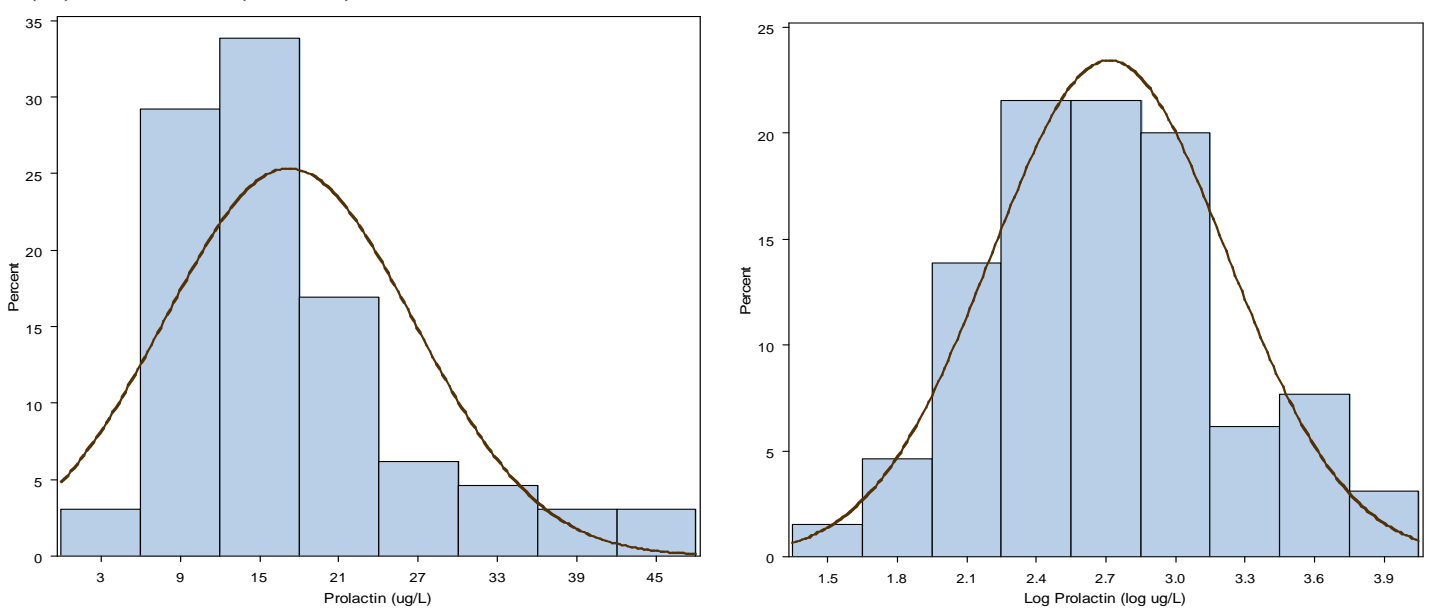


\section{II) Winter}

(A) Estradiol $(n=64)$
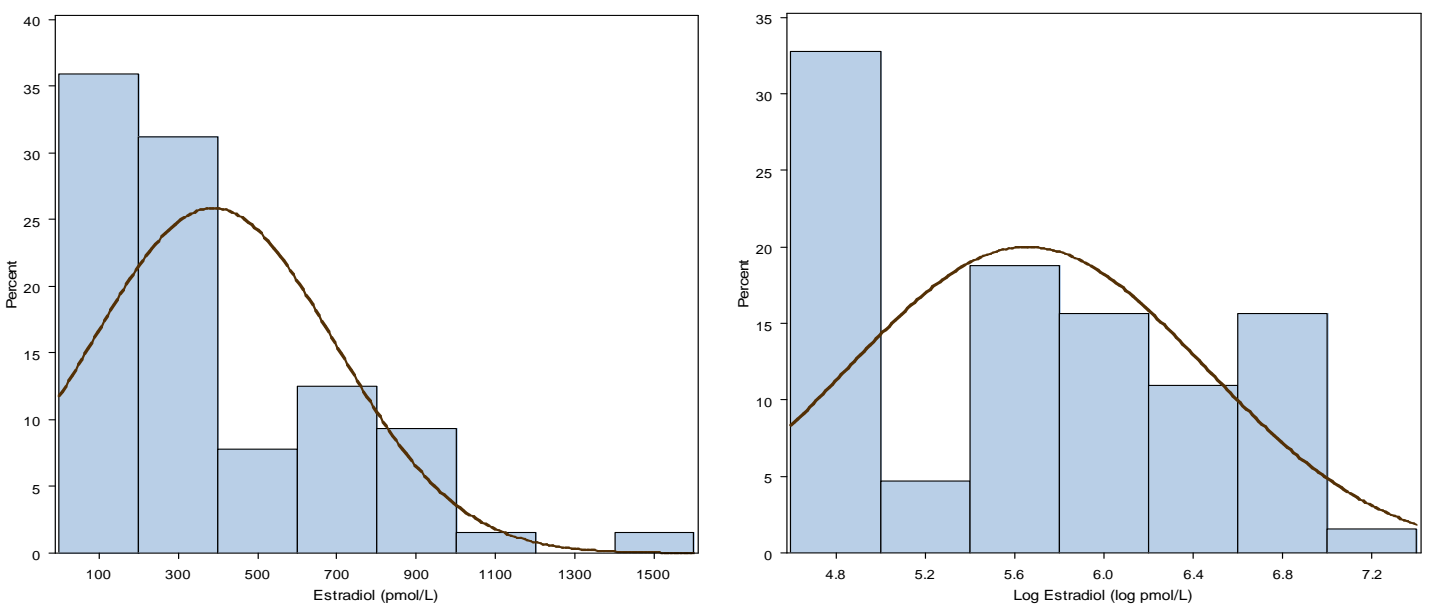

(B) Estrone $(\mathrm{n}=64)$
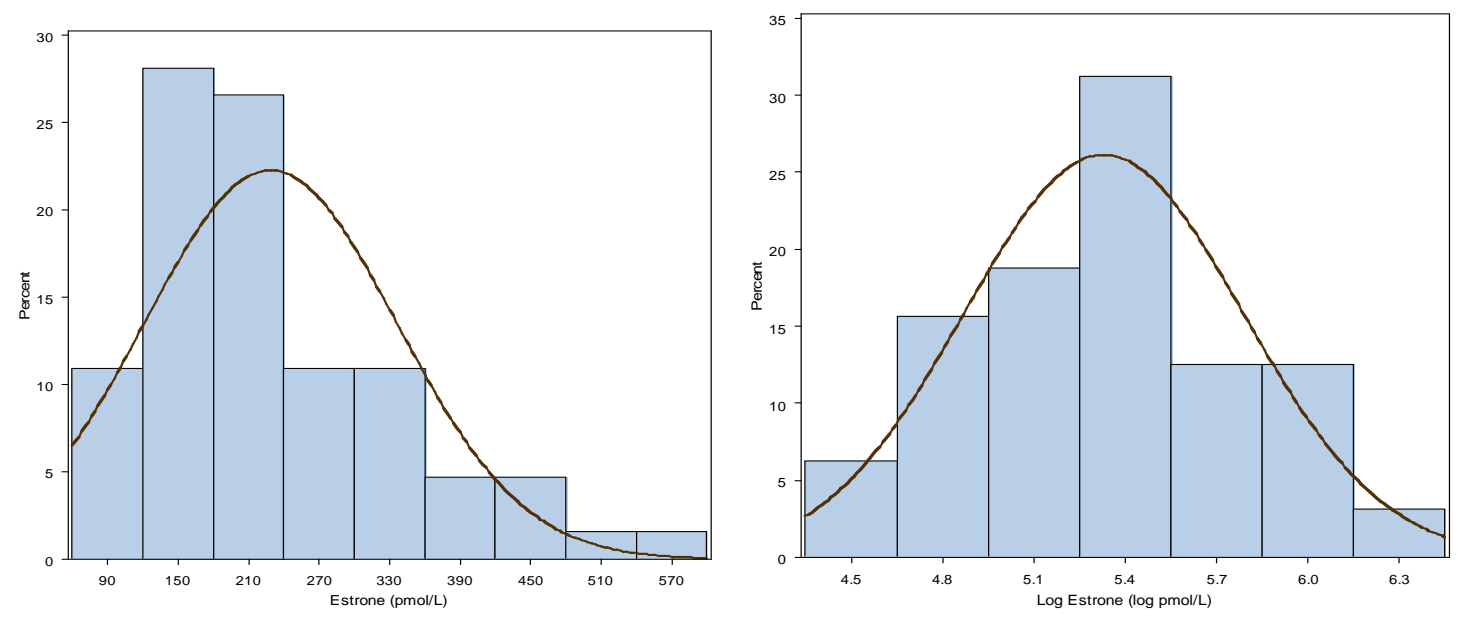

(C) Progesterone $(n=62)$
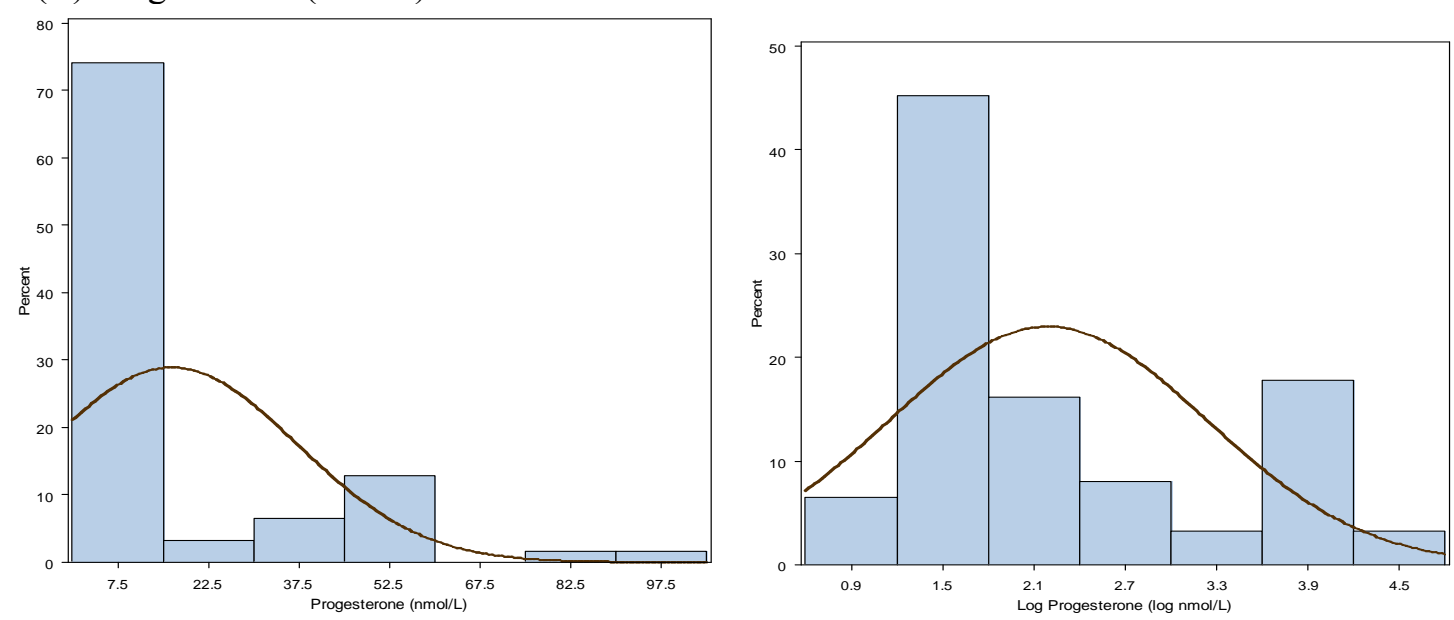
(D) Prolactin $(\mathrm{n}=64)$
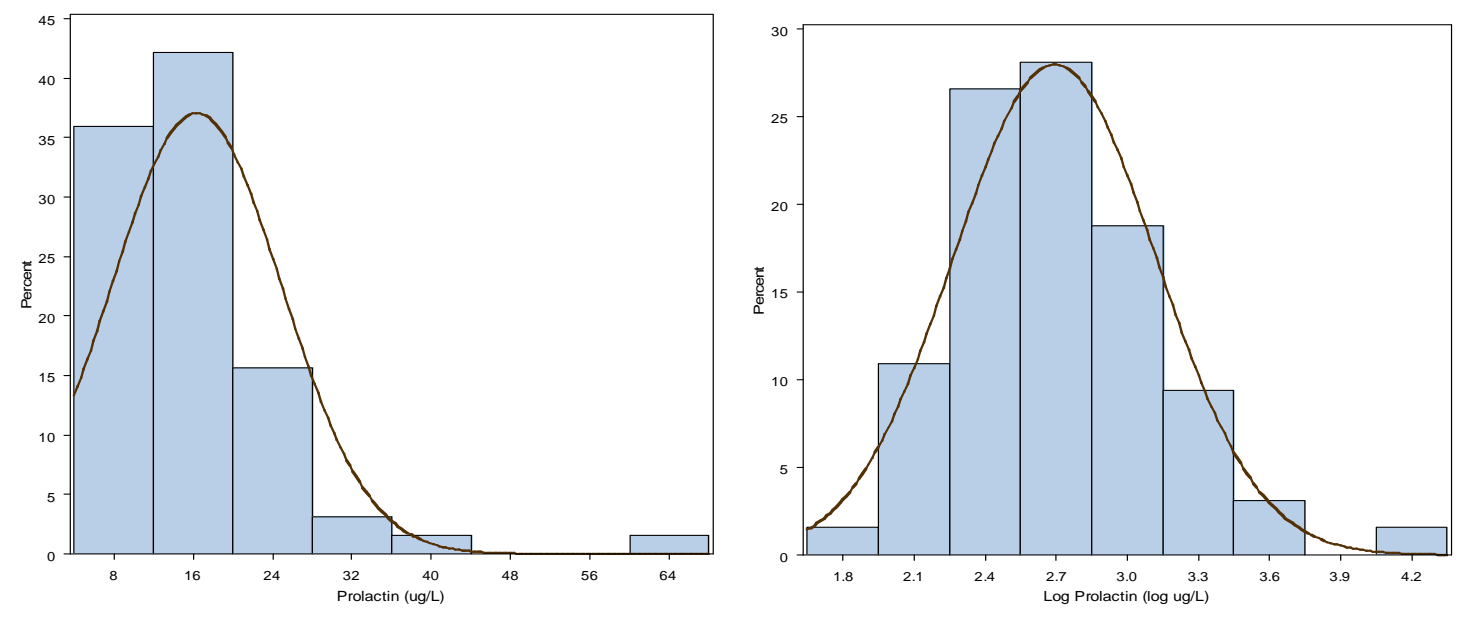

\section{III) Seasons combined}

(A) Estradiol $(n=131)$
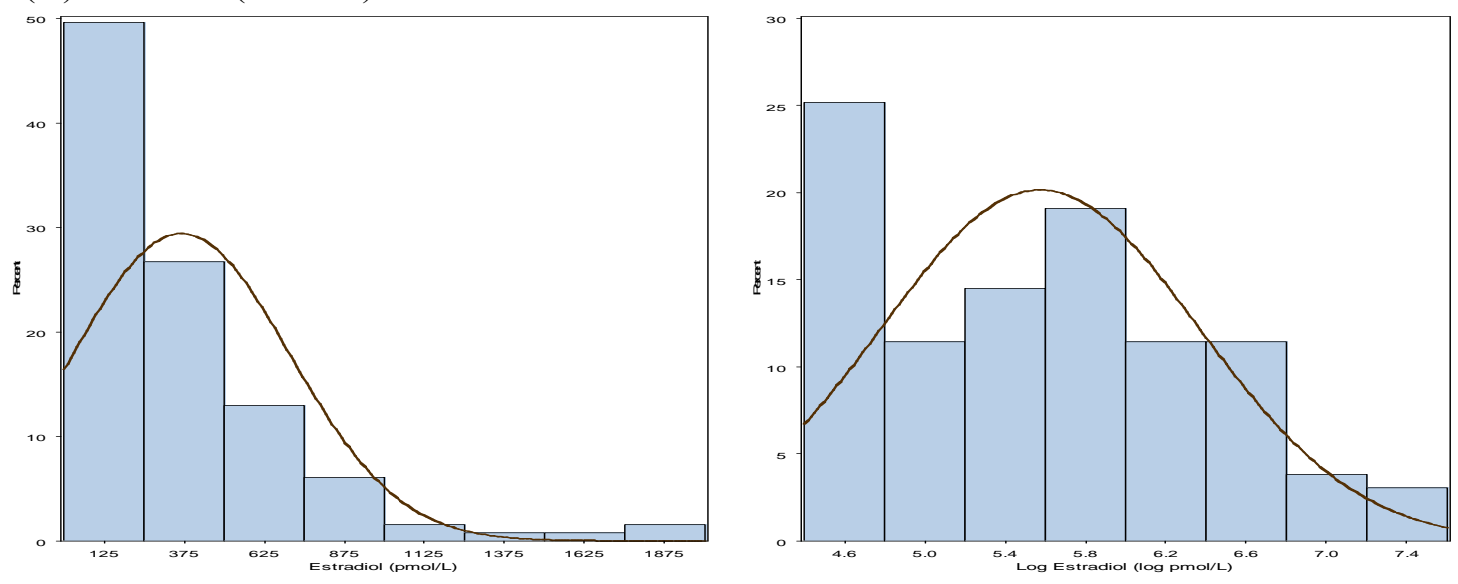

(B) Estrone $(\mathrm{n}=129)$
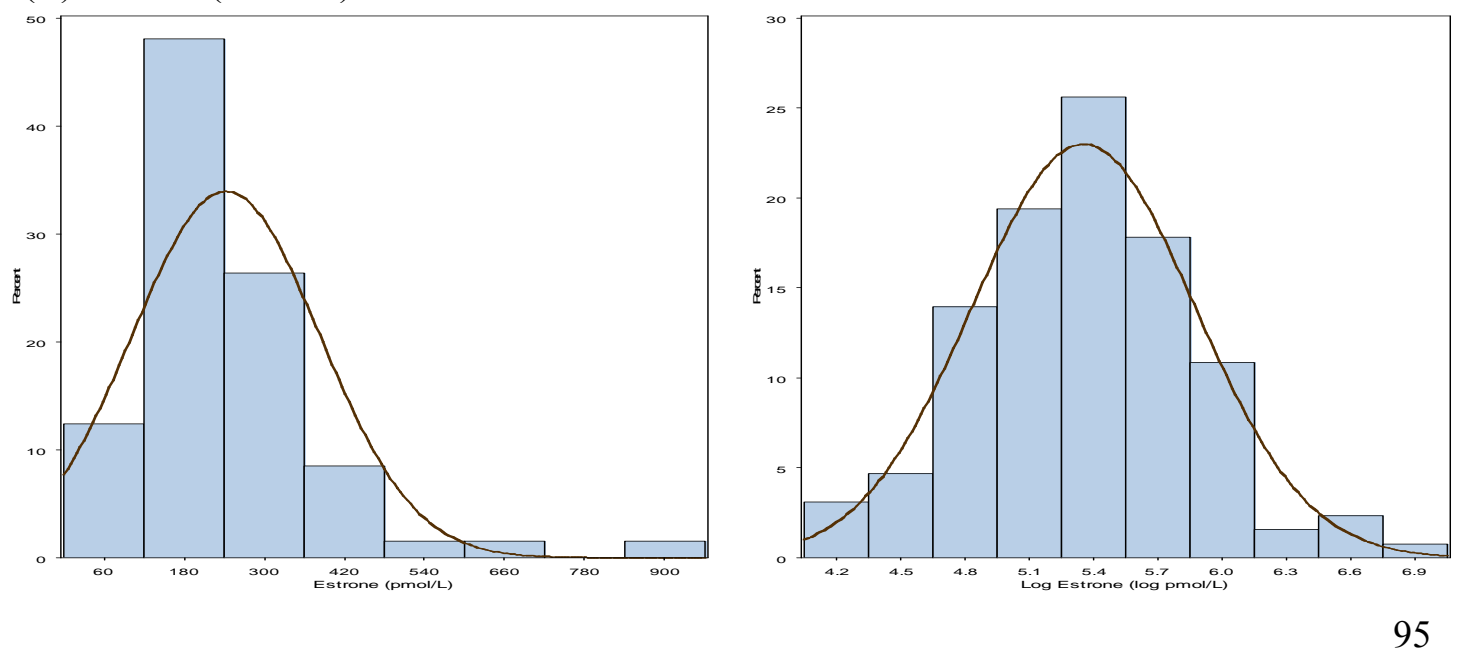
(C) Progesterone $(\mathrm{n}=129)$
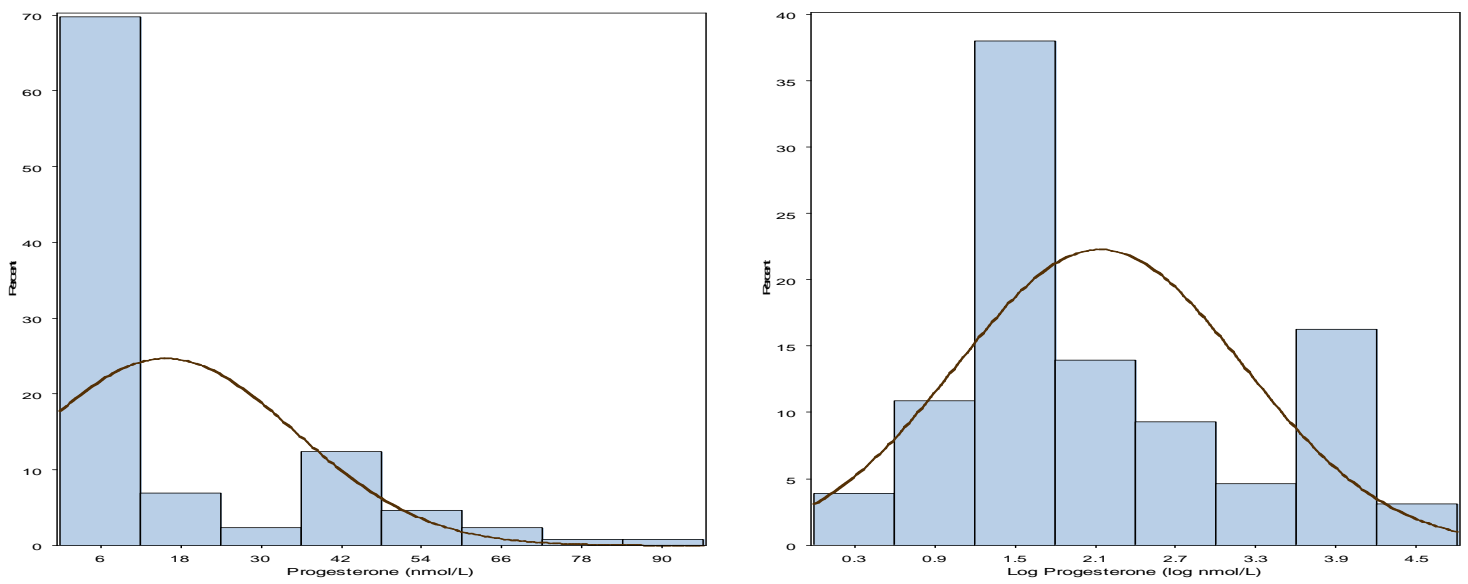

(D) Prolactin $(\mathrm{n}=129)$
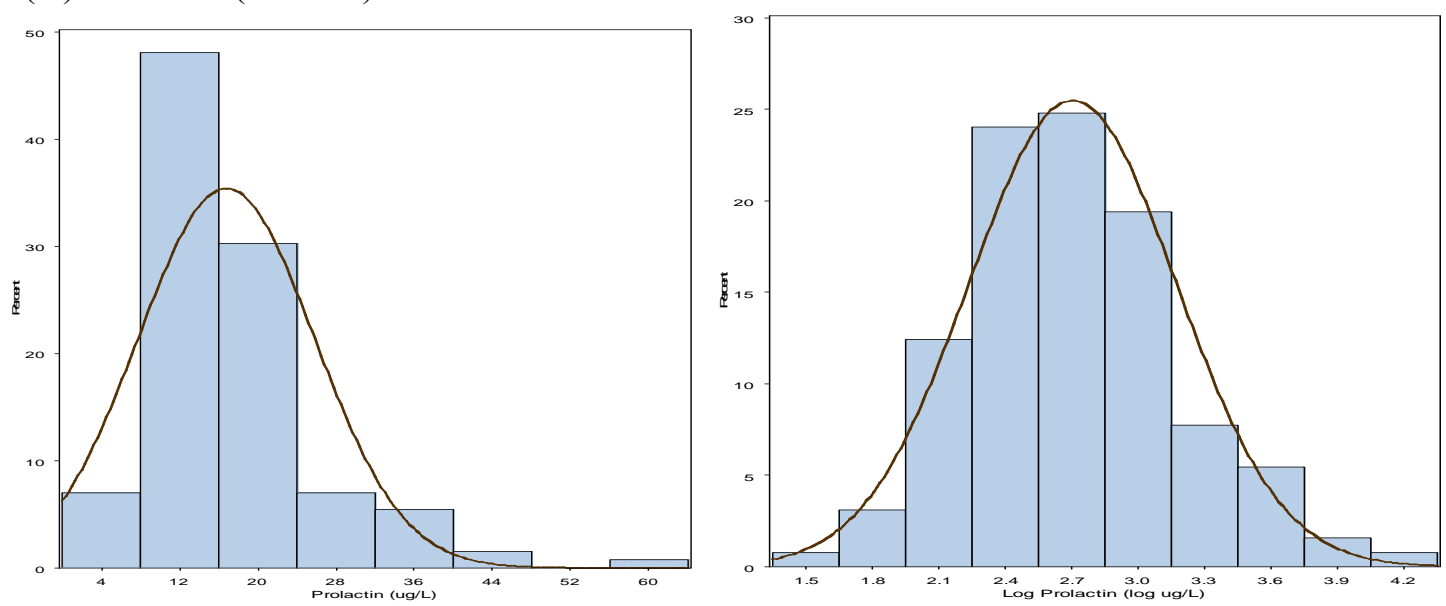

Seasonal geometric means and 95\% CI for each hormone are presented in Table 5.4, and means were compared by the difference in least squares mean estimates (as described above).

Overall, sex hormone levels did not vary significantly by season. Hormone means are also presented for data pooled across seasons, which were calculated as the least squares means using linear mixed modeling with a random subject effect. This approach adjusts for the artificially deflated variance that occurs with correlated data, and uses within- and between-person variance to estimate the true unknown population mean for the underlying study base (8). 
Table 5.4 Geometric means of sex hormones by season

\begin{tabular}{lcccc}
\hline \multicolumn{1}{c}{$\begin{array}{c}\text { Sex } \\
\text { Hormone }\end{array}$} & $\begin{array}{c}\text { Overall } \\
\text { Geometric mean } \\
(95 \% \mathrm{CI}), \mathrm{N}\end{array}$ & $\begin{array}{c}\text { Summer } \\
\text { Geometric mean } \\
(95 \% \mathrm{CI}), \mathrm{N}\end{array}$ & $\begin{array}{c}\text { Winter } \\
\text { Geometric mean } \\
(95 \% \mathrm{CI}), \mathrm{N}\end{array}$ & $\begin{array}{c}\text { P for } \\
\text { diff* }\end{array}$ \\
\hline $\begin{array}{l}\text { Estradiol } \\
(\mathrm{pmol} / \mathrm{L})\end{array}$ & 258.53 & 243.23 & 286.25 & \\
& $(221.98-301.06), 131$ & $(200.96-294.59), 67$ & $(234.52-349.41), 64$ & 0.13 \\
$\begin{array}{l}\text { Estrone } \\
(\text { pmol/L) }\end{array}$ & 207.83 & 216.52 & 206.20 & \\
& $(186.92-231.07), 129$ & $(187.60-249.89), 65$ & $(183.91-231.20), 64$ & 0.56 \\
$\begin{array}{l}\text { Progesterone } \\
(\text { nmol/L) }\end{array}$ & 8.37 & 8.02 & 8.97 & 0.58 \\
$\begin{array}{l}\text { Prolactin } \\
\text { (ug/L) }\end{array}$ & $(13.90-10.16), 129$ & $(6.12-10.51), 67$ & $(6.88-11.68), 62$ & \\
\hline
\end{tabular}

*Calculated by difference in least squares mean estimates by season using random subject effect

\subsubsection{Sex Hormones by Menstrual Cycle Stage}

Geometric means and CI were calculated for each hormone by menstrual cycle stage (Table 5.5). Within each season, geometric means of sex hormones by menstrual stage were compared using the ANOVA F-test. Hormone ranges for each cycle stage are presented along with reference ranges for pre-menopausal women described in the KGH Clinical Laboratory Reference Manual, which are based on the specific laboratory assays used. Hormone reference intervals vary greatly by both reference population and assay type (9). Further, that there is no established gold standard assay for sex hormone assessment $(10,11)$ makes the classification of normal or 'healthy' ranges near impossible. As such, the reference ranges presented should provide only a general idea of levels that may be expected for pre-menopausal women, according to the specific assays used in this study. 
Table 5.5 Mean sex hormone levels by menstrual cycle stage and season

\begin{tabular}{|c|c|c|c|c|c|}
\hline \multirow[b]{2}{*}{ Sex Hormone } & \multicolumn{2}{|c|}{ Summer } & \multicolumn{2}{|c|}{ Winter } & \multirow{2}{*}{$\begin{array}{c}\text { Laboratory } \\
\text { Reference } \\
\text { Range* } \\
\end{array}$} \\
\hline & $\begin{array}{c}\text { Geometric mean } \\
(95 \% \mathrm{CI})\end{array}$ & $\begin{array}{c}\text { Range } \\
\mathrm{N}\end{array}$ & $\begin{array}{c}\text { Geometric mean } \\
(95 \% \mathrm{CI})\end{array}$ & $\begin{array}{c}\text { Range } \\
\mathrm{N}\end{array}$ & \\
\hline \multicolumn{6}{|c|}{ Estradiol ( $\mathrm{pmol} / \mathrm{L} ; n=131$ total, 6 missing stage information) } \\
\hline $\begin{array}{l}\text { Follicular } \\
(\mathrm{n}=48)\end{array}$ & $\begin{array}{c}225.5 \\
(155.9-311.9)\end{array}$ & $\begin{array}{c}100-1823 \\
26\end{array}$ & $\begin{array}{c}207.0 \\
(151.5-283.0)\end{array}$ & $\begin{array}{c}100-756 \\
22\end{array}$ & $100-450$ \\
\hline $\begin{array}{l}\text { Ovulatory } \\
(\mathrm{n}=19)\end{array}$ & $\begin{array}{c}303.4 \\
(165.0-557.9)\end{array}$ & $\begin{array}{c}100-1226 \\
10\end{array}$ & $\begin{array}{c}307.3 \\
(158.3-596.6)\end{array}$ & $\begin{array}{c}100-899 \\
9\end{array}$ & $350-1600$ \\
\hline $\begin{array}{l}\text { Luteal } \\
(\mathrm{n}=58)\end{array}$ & $\begin{array}{c}230.3 \\
(175.4-302.5)\end{array}$ & $\begin{array}{c}100-1394 \\
27\end{array}$ & $\begin{array}{c}335.5 \\
(250.4-449.5)\end{array}$ & $\begin{array}{c}100-1582 \\
31\end{array}$ & $180-1000$ \\
\hline $\mathrm{p}$ for diff** & 0.55 & & 0.09 & & \\
\hline \multicolumn{6}{|c|}{ Estrone (pmol/L; $n=129$ total, 6 missing stage information) } \\
\hline $\begin{array}{l}\text { Follicular } \\
(\mathrm{n}=46)\end{array}$ & $\begin{array}{c}209.3 \\
(167.3-261.8)\end{array}$ & $\begin{array}{c}68-919 \\
25\end{array}$ & $\begin{array}{c}192.40 \\
(158.0-234.3)\end{array}$ & $\begin{array}{c}90-548 \\
21\end{array}$ & $137-510$ \\
\hline $\begin{array}{l}\text { Ovulatory } \\
(\mathrm{n}=18)\end{array}$ & $\begin{array}{c}295.6 \\
(159.9-546.3)\end{array}$ & $\begin{array}{c}77-845 \\
9\end{array}$ & $\begin{array}{c}205.7 \\
(149.5-283.1)\end{array}$ & $\begin{array}{c}108-396 \\
9\end{array}$ & $137-510$ \\
\hline $\begin{array}{l}\text { Luteal } \\
(\mathrm{n}=59) \\
\mathrm{p} \text { for diff** }\end{array}$ & $\begin{array}{r}191.9 \\
(157.6-233.6) \\
0.15\end{array}$ & $\begin{array}{c}62-402 \\
27\end{array}$ & $\begin{array}{r}217.6 \\
(181.5-260.9) \\
0.65\end{array}$ & $\begin{array}{c}85-495 \\
32\end{array}$ & $185-422$ \\
\hline \multicolumn{6}{|c|}{ Progesterone ( $\mathrm{nmol} / \mathrm{L} ; n=129$ total, 6 missing stage information) } \\
\hline $\begin{array}{l}\text { Follicular } \\
(\mathrm{n}=48)\end{array}$ & $\begin{array}{c}5.5 \\
(3.8-8.0)\end{array}$ & $\begin{array}{c}1-63 \\
26\end{array}$ & $\begin{array}{c}5.8 \\
(4.2-8.2)\end{array}$ & $\begin{array}{c}2-48 \\
22\end{array}$ & $0.2-4.0$ \\
\hline $\begin{array}{l}\text { Ovulatory } \\
(\mathrm{n}=18)\end{array}$ & $\begin{array}{c}7.0 \\
(3.6-13.4)\end{array}$ & $\begin{array}{c}2.8-54.1 \\
10\end{array}$ & $\begin{array}{c}10.3 \\
(4.2-25.3)\end{array}$ & $\begin{array}{c}3.7-95.8 \\
8\end{array}$ & $0.25-3.8$ \\
\hline $\begin{array}{l}\text { Luteal } \\
(\mathrm{n}=57) \\
\mathrm{p} \text { for diff** }\end{array}$ & $\begin{array}{r}12.1 \\
(7.5-19.6) \\
0.03\end{array}$ & $\begin{array}{c}1.6-69.8 \\
27\end{array}$ & $\begin{array}{r}11.5 \\
(7.6-17.5) \\
0.06\end{array}$ & $\begin{array}{c}2.6-80.6 \\
30\end{array}$ & $8-78$ \\
\hline \multicolumn{6}{|c|}{ Prolactin (ug/L; $n=129$ total, 6 missing stage information) } \\
\hline $\begin{array}{l}\text { Follicular } \\
(\mathrm{n}=46)\end{array}$ & $\begin{array}{c}14.7 \\
(12.2-17.6)\end{array}$ & $\begin{array}{c}6.8-45.7 \\
24\end{array}$ & $\begin{array}{c}12.8 \\
(10.9-15.1)\end{array}$ & $\begin{array}{c}5.8-28.2 \\
22\end{array}$ & $3.3-26.5$ \\
\hline $\begin{array}{l}\text { Ovulatory } \\
(\mathrm{n}=19)\end{array}$ & $\begin{array}{c}16.9 \\
(9.9-28.7)\end{array}$ & $\begin{array}{c}4.3-45.8 \\
10\end{array}$ & $\begin{array}{c}15.3 \\
(11.7-20.1)\end{array}$ & $\begin{array}{c}9.2-26.7 \\
9\end{array}$ & $3.3-26.5$ \\
\hline $\begin{array}{l}\text { Luteal } \\
(\mathrm{n}=58)\end{array}$ & $\begin{array}{c}15.2 \\
(12.4-18.6)\end{array}$ & $\begin{array}{c}5.6-38.9 \\
27\end{array}$ & $\begin{array}{c}16.6 \\
(14.0-19.7)\end{array}$ & $\begin{array}{c}7.1-62.8 \\
31\end{array}$ & $3.3-26.5$ \\
\hline $\mathrm{p}$ for diff** & 0.78 & & 0.10 & & \\
\hline
\end{tabular}

*Reference ranges as described in the KGH Clinical Laboratory Reference Manual and the Hospitals in Common Laboratory (HICL) Reference Manual (www.hicl.com)

**From ANOVA F-test for menstrual stage as predictor of sex hormone levels 
To provide a clearer depiction of sex hormone levels across the menstrual cycle, geometric means are presented graphically by cycle stage (Figure 5.3). In the summer, estradiol and estrone exhibited characteristic menstrual patterns, peaking mid-cycle; however, patterns were somewhat atypical in the winter, rising over the cycle and peaking in the luteal stage (see Figure 3.3 for characteristic patterns of sex hormones across the menstrual cycle). Across both seasons, progesterone exhibited a characteristic pattern, with levels rising over the course of the menstrual cycle. Unlike other sex hormones, there is no characteristic menstrual pattern for prolactin secretion. In our study, similar to estradiol and estrone, prolactin levels peaked midcycle in the summer, yet rose continuously through the cycle in winter.

Figure 5.3 Geometric sex hormone means by menstrual cycle (solid: summer, dashed: winter)

I) Estradiol (pmol/ L; $\mathrm{n}=63$ summer, $\mathrm{n}=62$ winter)

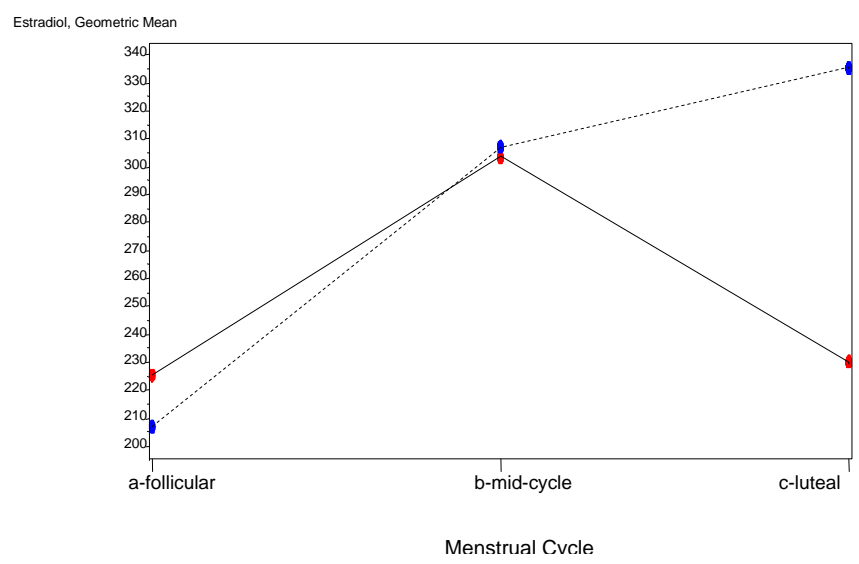

II) Estrone ( $\mathrm{pmol} / \mathrm{L} ; \mathrm{n}=61$ summer, $\mathrm{n}=62$ winter)

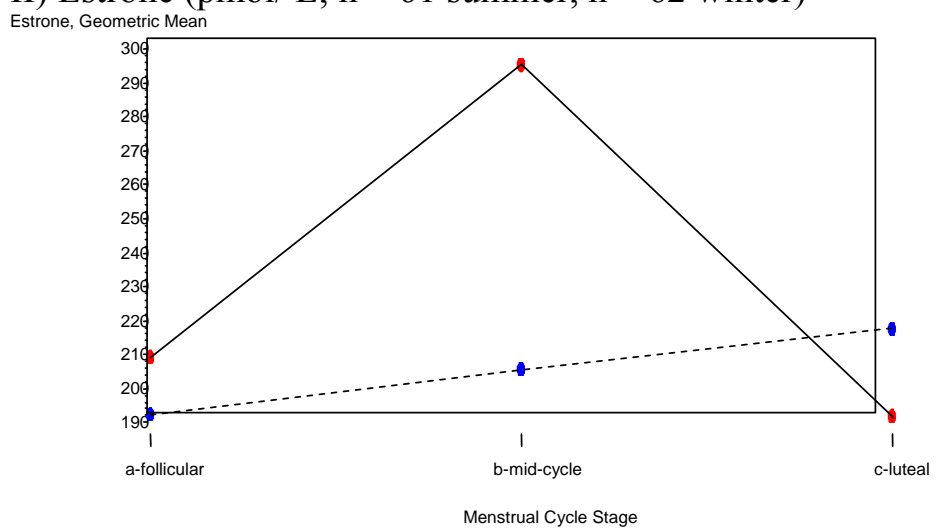


III) Progesterone (nmol/ L; $\mathrm{n}=63$ summer, $\mathrm{n}=60$ winter)

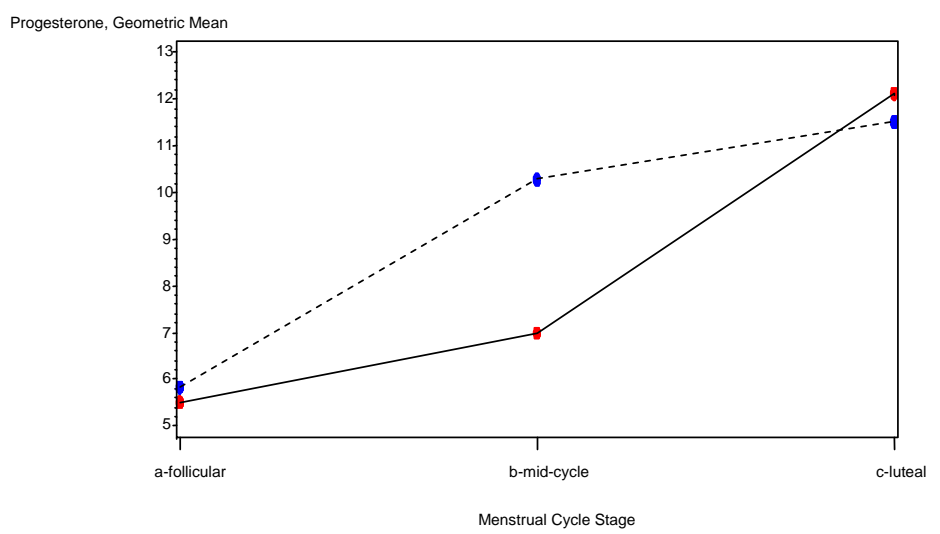

IV) Prolactin (ug/ $\mathrm{L} ; \mathrm{n}=61$ summer, $\mathrm{n}=62$ winter)

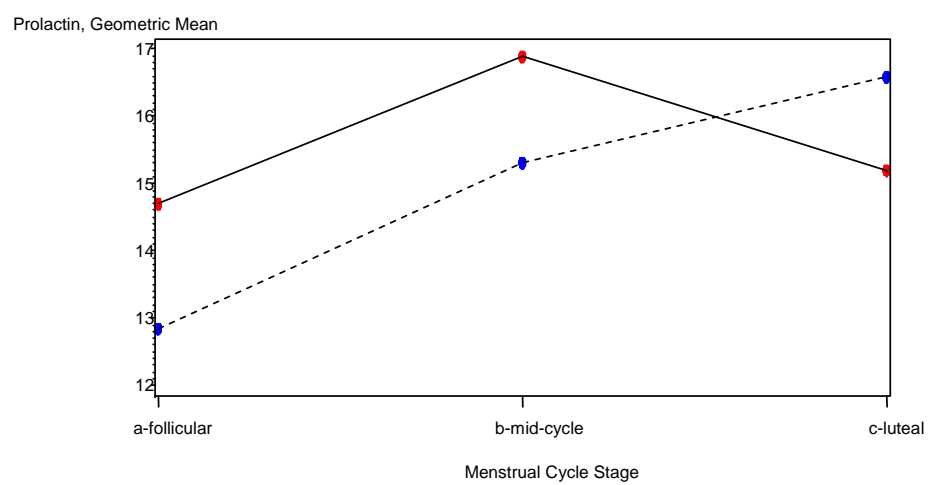

*Please note: final sample sizes for each hormone, by season, are slightly reduced due to missing menstrual cycle stage information $(n=4$ summer; $n=2$ winter $)$

\subsubsection{Sex Hormones and Other Reproductive Factors}

To better understand variability in sex hormone levels in our study, further exploratory analysis of reproductive determinants of sex hormone levels was conducted. As many women had two measures of sex hormones, linear mixed modeling was used. F-statistics and p-values were calculated for each characteristic as a regressor of each sex hormone. Sex hormone levels were associated with OC use, parity (the number of times pregnant, including live births, miscarriages and abortions) and age at first biological child, although associations of parity and age at first child with progesterone and of parity with prolactin were borderline significant. Age at menarche was not associated with sex hormone levels, and given the small number of women with either a 
family history of breast cancer or high mammographic density, associations of these variables with sex hormones were not assessed (Table 5.6).

Table 5.6 Bivariate associations of reproductive characteristics and sex hormones $(\mathrm{n}=82)$

\begin{tabular}{|c|c|c|c|c|c|}
\hline \multirow{2}{*}{ Characteristic } & \multirow{2}{*}{$\mathbf{N}(\%)$} & \multicolumn{4}{|c|}{ Association with sex hormones (F-statistic, p-value) } \\
\hline & & Estradiol & Estrone & Progesterone & Prolactin \\
\hline \multicolumn{6}{|c|}{ Current oral contraceptive use } \\
\hline $\begin{array}{l}\text { Yes } \\
\text { No } \\
\text { missing }\end{array}$ & $\begin{array}{c}19(23.2) \\
61(74.4) \\
2(2.4)\end{array}$ & $\begin{array}{c}21.74 \\
(<0.0001)\end{array}$ & $\begin{array}{c}19.11 \\
(<0.0001)\end{array}$ & $\begin{array}{c}9.38 \\
(0.004)\end{array}$ & $\begin{array}{c}5.41 \\
(0.02)\end{array}$ \\
\hline \multicolumn{6}{|l|}{ Age at menarche } \\
\hline $\begin{array}{l}\text { Under } 12 \\
12 \\
13 \\
14 \\
15 \text { and older }\end{array}$ & $\begin{array}{c}15(18.3) \\
21(25.6) \\
21(25.6) \\
17(20.7) \\
8(9.8)\end{array}$ & $\begin{array}{c}1.16 \\
(0.34)\end{array}$ & $\begin{array}{c}0.68 \\
(0.61)\end{array}$ & $\begin{array}{c}0.92 \\
(0.47)\end{array}$ & $\begin{array}{c}1.03 \\
(0.40)\end{array}$ \\
\hline \multicolumn{6}{|l|}{ Parity } \\
\hline $\begin{array}{l}\text { Nulliparous } \\
1-2 \\
3 \text { or more } \\
\text { missing }\end{array}$ & $\begin{array}{c}40(48.8) \\
26(31.7) \\
15(18.3) \\
1(1.2)\end{array}$ & $\begin{array}{c}3.41 \\
(0.04)\end{array}$ & $\begin{array}{c}8.52 \\
(0.0007)\end{array}$ & $\begin{array}{c}1.98 \\
(0.15)\end{array}$ & $\begin{array}{c}2.66 \\
(0.08)\end{array}$ \\
\hline \multicolumn{6}{|l|}{ Age at first child } \\
\hline $\begin{array}{l}\text { Nulliparous } \\
20 \text { and under } \\
>20-25 \\
>25-30 \\
>30-35 \\
>35\end{array}$ & $\begin{aligned} 40 & (48.8) \\
6 & (7.3) \\
10 & (12.2) \\
18 & (22.0) \\
6 & (7.3) \\
2 & (2.4)\end{aligned}$ & $\begin{array}{c}4.38 \\
(0.002)\end{array}$ & $\begin{array}{c}4.09 \\
(0.003)\end{array}$ & $\begin{array}{c}2.17 \\
(0.07)\end{array}$ & $\begin{array}{c}2.59 \\
(0.04)\end{array}$ \\
\hline $\begin{array}{l}\text { Family history o } \\
\text { Yes } \\
\text { No }\end{array}$ & $\begin{array}{c}\text { east cancer } \\
3(3.7) \\
79(96.3)\end{array}$ & - & - & - & - \\
\hline $\begin{array}{l}\text { High mammogra } \\
\text { Yes } \\
\text { No }\end{array}$ & $\begin{array}{l}\text { ic density } \\
2(2.4) \\
80(97.6)\end{array}$ & - & - & - & - \\
\hline
\end{tabular}

Relationships between sex hormones and menstrual cycle stage were further stratified by users vs. non-users of OC (Figure 5.4). As expected, estrogen and progesterone levels were lower in $\mathrm{OC}$ users as these medications suppress gonadotropin release, thereby reducing estrogen and progesterone production $(12,13)$. Despite these differences, similarities in the cyclical patterns of 
estradiol and estrone production were observed between the two groups. Interestingly, prolactin levels were consistently higher among $\mathrm{OC}$ users across the menstrual cycle.

Figure 5.4 Geometric sex hormone means by menstrual cycle and oral contraceptive use (solid: non-users $n=61$, dashed: users $n=19$ )

I) Estradiol (pmol/ L)

Estradiol, Geometric Mean

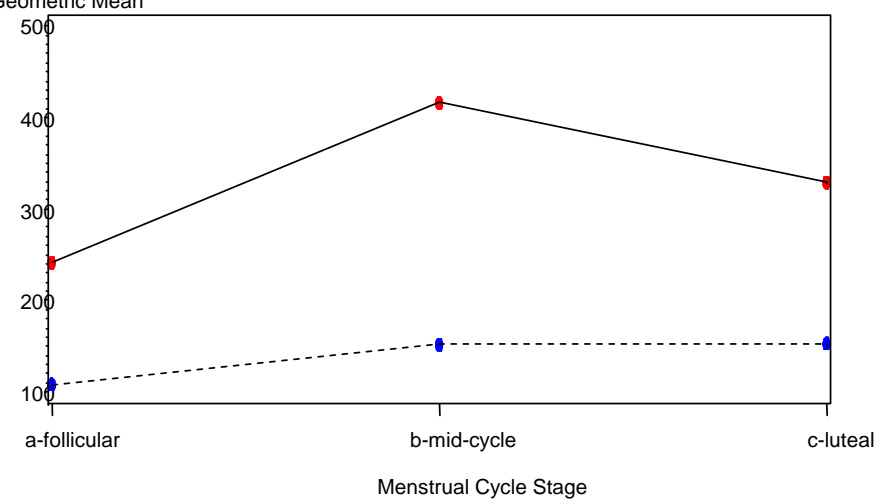

II) Estrone (pmol/ L)

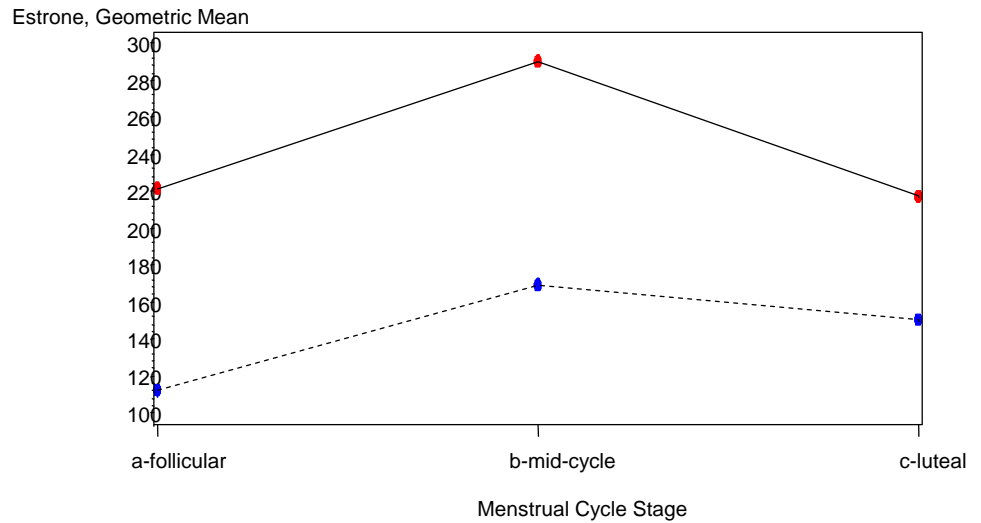

III) Progesterone (nmol/ L)

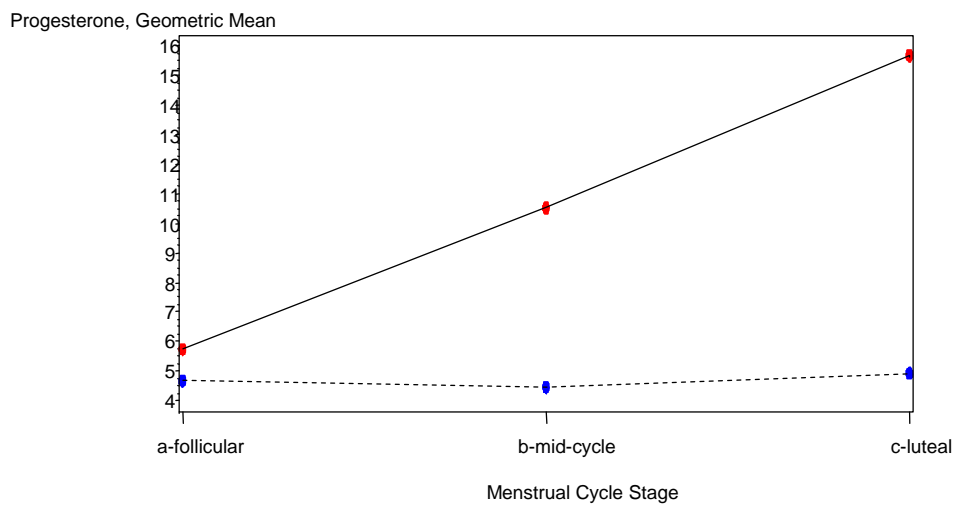


IV) Prolactin (ug/ L)

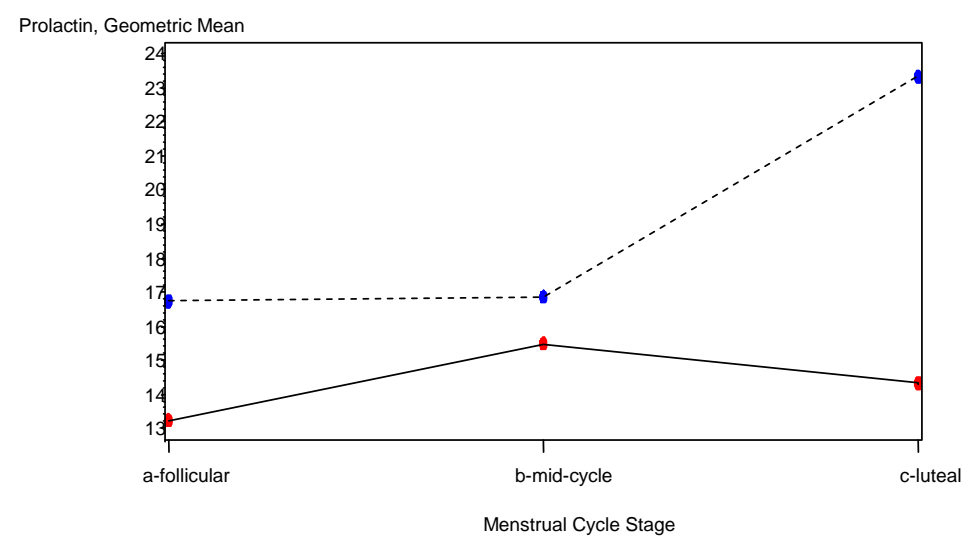

\subsubsection{Sex Hormone Inter-relationships}

Associations between sex hormones were examined to assess similarities in hormone production across the menstrual cycle. Relationships were assessed using linear mixed models with a random subject effect to account for the dependency of two hormone measures by the some individuals (Table 5.7). Estradiol, estrone and progesterone levels were all positively and significantly inter-related; indicating that individuals with high levels of one of hormone tended to have high levels of the other two. The association between estradiol and estrone was the strongest, and was consistent across the follicular and luteal stages of the menstrual cycle (stratification by the mid-cycle stage was not possible due to small numbers). Relationships between progesterone and each of estradiol and estrone were slightly weaker, and the association between progesterone and estrone was not significant during the follicular stage. Although no significant association was observed between prolactin and other hormones, parameter estimates were consistently negative, whereas associations between all other sex hormones were positive, suggesting possible inverse relationships. 
Table 5.7 Associations between log-transformed sex hormone levels

\begin{tabular}{|c|c|c|c|c|}
\hline & & $\begin{array}{c}\text { Estrone } \\
\text { Parameter Estimate } \\
(\mathrm{p} \text {-value })\end{array}$ & $\begin{array}{c}\text { Progesterone } \\
\text { Parameter Estimate } \\
\text { (p-value) }\end{array}$ & $\begin{array}{c}\text { Prolactin } \\
\text { Parameter Estimate } \\
\text { (p-value) }\end{array}$ \\
\hline \multirow{3}{*}{ Estradiol } & Overall & $0.47(<0.0001)$ & $0.21(0.001)$ & $-0.31(0.05)$ \\
\hline & Follicular & $0.49(0.0002)$ & $0.23(0.04)$ & $-0.56(0.06)$ \\
\hline & Luteal & $0.47(<0.0001)$ & $0.26(0.01)$ & $-0.21(0.34)$ \\
\hline \multirow[t]{3}{*}{ Estrone } & Overall & & $0.11(0.008)$ & $-0.14(0.19)$ \\
\hline & Follicular & - & $0.19(0.02)$ & $-0.26(0.15)$ \\
\hline & Luteal & & $0.15(0.02)$ & $-0.005(0.97)$ \\
\hline \multicolumn{2}{|c|}{ Progesterone Overall } & & & $-0.20(0.34)$ \\
\hline & Follicular & - & - & $-0.33(0.34)$ \\
\hline & Luteal & & & $-0.11(0.74)$ \\
\hline \multirow[t]{2}{*}{ Prolactin } & Overall & & & \\
\hline & $\begin{array}{l}\text { Follicular } \\
\text { Luteal }\end{array}$ & - & - & - \\
\hline
\end{tabular}

\subsection{Bivariate Melatonin-Sex Hormone Relationships}

Bivariate associations between log-transformed melatonin and sex hormones were assessed using generalized linear regression modeling. Parameter estimates and p-values for melatonin as a predictor of sex hormone levels are presented in Table 5.8. For the cross-sectional analyses, bivariate relationships were stratified by season. Melatonin was inversely related to estradiol in winter only $(\beta=-0.18, p=0.04)$, and was not associated with other hormones in either season. Longitudinally, melatonin measures from the first seasons' study period were not associated with sex hormone measures from the second.

Table 5.8 Bivariate relationships between log-transformed melatonin and sex hormones

\begin{tabular}{lccc}
\hline \multirow{2}{*}{ Sex Hormone } & \multicolumn{2}{c}{ Cross-sectional analysis } & Longitudinal analysis \\
\cline { 2 - 3 } & $\begin{array}{c}\text { Summer } \\
\text { Parameter Estimate } \\
(\mathrm{p} \text {-value), N }\end{array}$ & $\begin{array}{c}\text { Winter } \\
\text { Parameter Estimate } \\
(\mathrm{p} \text {-value), N }\end{array}$ & $\begin{array}{c}\text { Parameter Estimate } \\
\text { (p-value; } \mathrm{n}=60)\end{array}$ \\
\hline Estradiol & $-0.01(0.84), 67$ & $\mathbf{- 0 . 1 8 ( \mathbf { 0 . 0 4 } ) , 6 4}$ & $-0.11(0.21)$ \\
Estrone & $0.05(0.39), 65$ & $-0.05(0.37), 64$ & $0.007(0.86)$ \\
Progesterone & $-0.05(0.65), 67$ & $0.04(0.71), 62$ & $-0.008(0.92)$ \\
Prolactin & $0.04(0.42), 65$ & $0.01(0.84), 64$ & $0.03(0.44)$ \\
\hline
\end{tabular}




\subsection{Confounder Assessment}

A systematic strategy was used to examine potential confounding of melatonin-sex hormone relationships by various personal, lifestyle and reproductive characteristics (see Section 3.8.3). Bivariate associations of potential confounders and sex hormones meeting the screening criterion of $\mathrm{p} \leq 0.20$ included age, BMI, menstrual cycle stage, smoking status, alcohol consumption, moderate-to-heavy physical activity, total physical activity, caffeinated beverage consumption and $\mathrm{OC}$ use, although relationships were not consistent across hormones nor season (Appendix E, Table 1). Only OC use was statistically significantly associated with all hormones in both seasons (although the association of progesterone in summer was borderline significant, $p$ $=0.067)$. Age, BMI and menstrual cycle stage were identified $a$ priori as important confounders of interest that are included in all final adjusted models. Base models were developed adjusting for each of age; age and BMI; and age, BMI, and menstrual cycle stage to assess the contributions of each grouping of variables on relationships under study (Appendix E, Table 2).

\subsection{Regression Diagnostics and Sensitivity Analyses}

\subsubsection{Regression Diagnostics}

Regression diagnostics were performed on all final multivariate-adjusted models to check assumptions of regression analysis, to evaluate model fitting, and to identify outliers and/ or influential data points. Pre-regression outlier analysis, for the detection of improbable exposure and outcome measures, was not conducted given the difficulties in defining clinically meaningful or biologically plausible reference ranges for melatonin and sex hormone levels. Large inter-individual variability, and the lack of clearly defined cut-points for normal or healthy levels, makes the exclusion of individuals based on these criteria alone difficult. Outlier analysis and influence diagnostics were performed on final adjusted models to identify observations that exerted strong influences on regression parameters. Analysis of jackknife residuals and Cook's D 
statistics revealed no strong outliers or influential data points. Normal probability and residual plots confirmed adherence of data to regression assumptions of normality and homogeneity.

\subsubsection{Sensitivity Analyses}

Sensitivity analyses were conducted to assess whether relationships changed with consideration of the time of day of blood sample collection, OC use, the seasonal order of data collection (for longitudinal analyses) and when non-transformed variables were used for analyses. The influences of OC use and time of day were assessed by excluding each of OC users and subjects who gave blood after 8AM from final adjusted models. Final models were also compared using non-transformed variables to assess the influence of these transformations on regression results (Table 5.9). Results did not change meaningfully with these considerations: while some parameter estimates changed slightly, no relationships were significant before or after exclusions. Regression diagnostics performed on the non-transformed models presented strong residuals thereby confirming the better fit of the former model.

Table 5.9 Sensitivity analyses I

\begin{tabular}{lcccc}
\hline \multirow{2}{*}{ Regression analysis } & \multicolumn{4}{c}{ Melatonin parameter estimate (p-value) } \\
\cline { 2 - 5 } & $\begin{array}{c}\text { Original } \\
\text { (final model) }\end{array}$ & $\begin{array}{c}\text { Exclusion of } \\
\text { OC users* }\end{array}$ & $\begin{array}{c}\text { Exclusion of } \\
\text { blood }>8 \mathrm{AM}^{*}\end{array}$ & $\begin{array}{c}\text { Nontransformed } \\
\text { variables* }\end{array}$ \\
\hline Estradiol & & & & \\
$\quad$ Summer $(\mathrm{n}=61)$ & $0.005(0.94)^{\mathrm{a}}$ & $-0.02(0.83)$ & $-0.05(0.67)$ & $-0.13(0.82)$ \\
$\quad$ Winter $(\mathrm{n}=56)$ & $-0.13(0.11)^{\mathrm{b}}$ & $-0.13(0.10)$ & $-0.16(0.15)$ & $0.02(0.96)$ \\
$\quad$ Longitudinal $(\mathrm{n}=54)$ & $-0.05(0.54)^{\mathrm{c}}$ & $-0.06(0.45)$ & $0.03(0.81)$ & $-0.09(0.73)$ \\
Estrone & & & & \\
$\quad$ Summer $(\mathrm{n}=59)$ & $0.05(0.36)^{\mathrm{a}}$ & $0.02(0.68)$ & $0.03(0.67)$ & $0.24(0.70)$ \\
$\quad$ Winter $(\mathrm{n}=59)$ & $-0.03(0.61)^{\mathrm{d}}$ & $0.04(0.68)$ & $0.01(0.90)$ & $0.04(0.79)$ \\
$\quad$ Longitudinal $(\mathrm{n}=53)$ & $0.05(0.40)^{\mathrm{b}}$ & $0.03(0.62)$ & $0.04(0.67)$ & $-0.03(0.76)$ \\
Progesterone & & & & \\
$\quad$ Summer $(\mathrm{n}=61)$ & $0.07(0.46)^{\mathrm{a}}$ & $0.02(0.68)$ & $-0.05(0.67)$ & $-0.007(0.80)$ \\
$\quad$ Winter $(\mathrm{n}=58)$ & $0.14(0.22)^{\mathrm{a}}$ & $-0.02(0.71)$ & $0.18(0.28)$ & $0.028(0.33)$ \\
$\quad$ Seasons pooled $(\mathrm{n}=119)$ & $0.06(0.43)^{\mathrm{a}}$ & $0.07(0.41)$ & $-0.03(0.73)$ & $0.008(0.66)$ \\
$\quad$ Longitudinal $(\mathrm{n}=56)$ & $-0.02(0.86)^{\mathrm{a}}$ & $0.03(0.61)$ & $-0.27(0.25)$ & $-0.01(0.53)$
\end{tabular}


Prolactin

$\begin{array}{llccc}\text { Summer }(\mathrm{n}=59) & 0.01(0.78)^{\mathrm{e}} & 0.03(0.61) & 0.03(0.70) & -0.0002(0.99) \\ \text { Winter }(\mathrm{n}=59) & 0.003(0.94)^{\mathrm{f}} & -0.004(0.94) & -0.007(0.92) & -0.01(0.41) \\ \text { Seasons pooled }(\mathrm{n}=118) & 0.002(0.95)^{\mathrm{h}} & 0.01(0.64) & 0.01(0.77) & -0.007(0.42) \\ \text { Longitudinal }(\mathrm{n}=52) & -0.05(0.40)^{\mathrm{g}} & 0.04(0.53) & -0.10(0.19) & -0.002(0.73)\end{array}$

Exclusion of OC users: $\mathrm{n}=13$ summer, $\mathrm{n}=12$ winter, $\mathrm{n}=8$ longitudinal

Exclusion of blood samples after 8AM: $n=32$ summer, $n=29$ winter, $n=32$ longitudinal

*Adjusted for all variables of corresponding original final model

Adjusted for age, BMI, menstrual cycle stage and:

a: OC use

b: OC use, alcohol consumption

c: alcohol consumption, caffeine consumption

d: OC use, alcohol and caffeine consumption, smoking status, total physical activity levels

e: OC use, smoking status

f: OC use, caffeine consumption

g: caffeine consumption, moderate-to-heavy physical activity

h: OC use, caffeine consumption, smoking status

The influence of the seasonal order of data collection (for the longitudinal analysis) was assessed by stratifying the final adjusted models according to this variable (Table 5.10). Models were stratified following confounder selection (as opposed to building separate multivariateadjusted models for each strata), as the original sample size for this analysis was particularly small $(n=60)$. Similar to the original models, melatonin was not significantly associated with sex hormones in the stratified models. While parameter estimates may have changed slightly, there is no obvious trend in these results. In terms of peri-menopausal status, as women who were considered potentially peri-menopausal did not have information regarding menstrual cycle stage, these women were automatically excluded from all final models (which adjusted for menstrual cycle stage) and so sensitivity analyses were not required.

Table 5.10 Sensitivity analyses II

\begin{tabular}{lccc}
\hline \multirow{2}{*}{ Analysis } & $\begin{array}{c}\text { Original (final } \\
\text { adjusted model) } \\
\text { Melatonin parameter } \\
\text { estimate }(\mathrm{p} \text {-value) }\end{array}$ & \multicolumn{2}{c}{$\begin{array}{c}\text { By seasonal order of data collection } \\
\text { Melatonin parameter estimate (p-value) }\end{array}$} \\
\cline { 3 - 4 } & $-0.05(0.54)$ & $\begin{array}{c}\text { Summer; winter* } \\
(\mathrm{n}=35)\end{array}$ & $\begin{array}{c}\text { Winter; summer* } \\
(\mathrm{n}=25)\end{array}$ \\
\hline Estradiol $(\mathrm{n}=54)^{\mathrm{c}}$ & $0.05(0.40)$ & $-0.101(0.42)$ & $0.07(0.64)$ \\
Estrone $(\mathrm{n}=53)^{\mathrm{b}}$ & $-0.02(0.86)$ & $0.0431(0.65)$ & $0.01(0.90)$ \\
Progesterone $(\mathrm{n}=56)^{\mathrm{a}}$ & & & $-0.29(0.19)$
\end{tabular}


Prolactin $(\mathrm{n}=52)^{\mathrm{d}}$

$-0.05(0.40)$

$-0.0485(0.48)$

$-0.02(0.89)$

* adjusted for all variables of corresponding original final model

Adjusted for age, BMI, menstrual cycle stage and:

a: OC use

b: OC use, alcohol consumption

c: alcohol consumption, caffeine consumption

d: caffeine consumption, moderate-to-heavy physical activity

\section{References}

1. Manaster BJ, Manaster S. Techniques for estimating allometric equations. J Morphol. 1975;147(3):299-307.

2. Bergiannaki JD, Soldatos CR, Paparrigopoulos TJ, Syrengelas M, Stefanis CN. Low and high melatonin excretors among healthy individuals. J Pineal Res. 1995 Apr;18(3):159-64.

3. Reiter RJ, Tan DX. What constitutes a physiological concentration of melatonin? J Pineal Res. 2003 Jan;34(1):79-80.

4. Schernhammer ES, Kroenke CH, Dowsett M, Folkerd E, Hankinson SE. Urinary 6sulfatoxymelatonin levels and their correlations with lifestyle factors and steroid hormone levels. J Pineal Res. 2006 Mar;40(2):116-24.

5. Schernhammer ES, Rosner B, Willett WC, Laden F, Colditz GA, Hankinson SE. Epidemiology of urinary melatonin in women and its relation to other hormones and night work. Cancer Epidemiol Biomarkers Prev. 2004 Jun;13(6):936-43.

6. Nagata C, Nagao Y, Yamamoto S, Shibuya C, Kashiki Y, Shimizu H. Light exposure at night, urinary 6-sulfatoxymelatonin, and serum estrogens and androgens in postmenopausal japanese women. Cancer Epidemiol Biomarkers Prev. 2008 Jun;17(6):1418-23.

7. Olivier J, Johnson WD, Marshall GD. The logarithmic transformation and the geometric mean in reporting experimental IgE results: What are they and when and why to use them?[article]. Annals of Allergy, Asthma, \& Immunology. 2008 April;100(4):333-7.

8. Goldstein H. Multilevel statistical models. 2nd ed. London: Edward Arnold; 1995.

9. Anttila L, Koskinen P, Irjala K, Kaihola HL. Reference intervals for serum sex steroids and gonadotropins in regularly menstruating women. Acta Obstet Gynecol Scand. 1991;70(6):475-81.

10. Stanczyk FZ, Lee JS, Santen RJ. Standardization of steroid hormone assays: Why, how, and when? Cancer Epidemiol Biomarkers Prev. 2007 Sep;16(9):1713-9.

11. Demers LM. Testosterone and estradiol assays: Current and future trends. Steroids. 2008 Dec 12;73(13):1333-8.

12. Briggs M, Briggs M. Plasma hormone concentrations in women receiving steroid contraceptives. J Obstet Gynaecol Br Commonw. 1972 Oct;79(10):946-50.

13. Gaspard UJ, Romus MA, Gillian D, Duvivier J, Demey-Ponsart E, Franchimont P. Plasma hormone levels in women receiving new oral contraceptives containing ethinyl estradiol plus levonorgestrel or desogestrel. Contraception. 1983;27(6):577-590. 


\section{Chapter 6 \\ Discussion}

\subsection{Summary of Main Findings}

The purpose of this thesis was to examine relationships between melatonin and sex hormones, both cross-sectionally (within each of two seasons) and longitudinally (across seasons). This thesis also sought to describe relationships of night shift-work history with sex hormone levels. In addition, exploratory analysis of reproductive determinants of sex hormones was conducted post-hoc in attempt to better understand variability in the data.

\subsubsection{Seasonal Distributions of Melatonin and Sex Hormones}

Melatonin levels were highly variable among study participants, with large interindividual differences in peak melatonin production, a finding that is consistent with other studies $(1,2)$. Contrary to the study hypotheses, no seasonal difference in melatonin levels was observed,

a finding consistent with some (3) but not all $(1,4-7)$ studies. It is possible that widespread use of artificial lighting in our society diminishes the influence of seasonal differences in day length and natural light exposure on melatonin secretion. Sex hormone levels also did not vary significantly by season, and this was expected since no source of seasonal variability was anticipated besides seasonal changes in melatonin.

\subsubsection{Other Determinants of Sex Hormones}

In attempt to better understand large variability in sex hormone levels observed in our study, further exploratory analysis of reproductive determinants of sex hormones was conducted. While some reproductive influences were controlled for by study design (exclusion criteria included pregnancy or lactation in the previous six months), other characteristics varied among participants (menstrual cycle stage and OC use) and were responsible for much noise in the data. 
Sex hormones exhibited mostly characteristic patterns over the menstrual cycle, with geometric means of estradiol and estrone peaking mid-cycle in the summer and progesterone means increasing through the menstrual cycle in both seasons (see Figure 3.2 for characteristic patterns of sex hormones across the menstrual cycle). However, estradiol and estrone exhibited less characteristic patterns in the winter, peaking in the luteal phase. Nevertheless, given large inter-individual variability in sex hormone levels (for example due to other reproductive or personal influences) $(8,9)$, it may be difficult to capture such clear menstrual patterns without large samples of women across all stages of the menstrual cycle, or without consistency in cycle stage across individuals. Among reproductive influences, sex hormone levels were found to associate with parity, age at first child, and current $\mathrm{OC}$ use, findings consistent with previous studies $(10,11)$, although relations were not consistent across hormones.

As expected, estrogen and progesterone levels were lower in OC users vs. non-users, as these medications suppress gonadotropin release, thereby reducing estrogen and progesterone production $(12,13)$. However, similarities in the cyclical patterns of estradiol and estrone production across the menstrual cycle were observed between these groups. Because non-users, who have variable cycle length, were similar to users who have a controlled 28-day cycle, the assumption of a 28-day cycle may be appropriate as there is no obvious misclassification of cycle stage. Interestingly, prolactin levels were consistently higher among OC users, a finding that has been observed in other studies $(14,15)$ but remains controversial (16).

Significant positive associations were observed between each of estradiol, estrone and progesterone across cycle stages, findings consistent with previous research (17), indicating that individuals with high levels of one hormone tended to have high levels of the other two.

Lastly, age was also a strong predictor of sex hormone levels (see Table 1, Appendix). Taken together, this exploration of hormonal determinants adds validity to the sex hormone data 
of this study. That many characteristic hormone patterns and associations were observed suggests that despite substantial noise in the data, sex hormone measures are likely accurate.

\subsubsection{Melatonin-Sex Hormone Relationships}

For the cross-sectional analyses, no significant association was observed between melatonin and sex hormones in summer or winter. While in bivariate analyses melatonin was statistically significantly related to estradiol in winter $(\beta=-0.18, p=0.04)$, this was slightly attenuated after confounder-adjustment $(\beta=-0.13, \mathrm{p}=0.11$, adjusted for age, BMI, menstrual cycle stage, OC use and alcohol consumption). Because relationships of melatonin with progesterone and prolactin did not vary meaningfully by season (multivariate-adjusted melatonin parameter estimates were in the same direction and of comparable magnitude), data were pooled across seasons for these two hormones. Despite increased sample size, no association was observed between melatonin and these hormones. Longitudinally, melatonin from the first season's data collection was not associated with sex hormones in the second.

Upon further analysis of these relationships using tertiles of melatonin level, no obvious trends in geometric sex hormone means were observed. A relationship between melatonin and estrone was suggested in summer, whereby geometric estrone means increased with a step-wise increase melatonin tertile $(p=0.07)$, the direction opposite to study hypotheses. The inverse relationship between melatonin and estradiol that was suggested using continuous melatonin was less apparent with tertiles $(\mathrm{p}=0.15)$.

Previous studies have identified inverse relationships between melatonin and follicle stimulating hormone (FSH) and luteinizing hormone (LH) (18), and estradiol (19) under observational settings; however, these results may be attributed to uncontrolled confounding. In a report from a melatonin trial of pre- and post-menopausal women, associations observed between baseline melatonin and FSH $(r=-0.322, \mathrm{p}<0.05)$ and LH $(\mathrm{r}=-0.314, \mathrm{p}<0.05)$ levels did not 
account for potential confounders in the analysis (18). In another study that reported an inverse relationship between melatonin and estradiol $(\mathrm{r}=-0.661, \mathrm{p}<0.0005)$, only menstrual cycle stage and OC use were controlled; further, this relationship was confined to a small sub-group $(n=25)$ of pre-menopausal women aged 40-50 (19). Age and BMI are important variables that were observed to confound melatonin-sex hormone relationships in this and other studies $(3,20,21)$, and so results unadjusted for these variables should be interpreted with caution.

The results of more recent observational studies having more comprehensive confounder assessment have been less convincing. Two studies have investigated relationships between melatonin and sex hormones in women of the Nurses Health Study (NHS) cohort $(3,20)$. Among 80 premenopausal nurses who did not use OC, melatonin was associated with bioavailable estradiol (circulating estradiol not bound to plasma proteins; $r=-0.25, \mathrm{p}=0.05$ ), and progesterone $(\mathrm{r}=0.31, \mathrm{p}=0.01)$ measured during the luteal menstrual stage: these relationships were slightly attenuated and no longer statistically significant after adjustment for age and BMI. No association was observed between melatonin and total estradiol (bioavailable and proteinbound), estrone or prolactin levels (3). Two years later, the same group published a second study involving an additional 384 women, also mostly premenopausal and belonging to the NHS (20). Melatonin was weakly associated with estrone sulfate levels $(r=0.13, p=0.02)$, and a step-wise decline in follicular estradiol levels was suggested for increasing quartile of melatonin $(p=0.07)$. However, no other hormone (estrone, progesterone, DHEA, DHEAS, testosterone and androstenedione) was associated with melatonin. Most recently, among 206 post-menopausal Japanese women, no association was observed between melatonin and estradiol, estrone, testosterone or DHEAS (21).

While findings from observational studies have been mostly null, stronger support for melatonin-sex hormone relationships has been provided under various reproductive, pathological 
and experimental conditions. Unusually high melatonin levels have been associated with anovulation, oophrectomy and other abnormal ovarian conditions (19, 22-24), and some experimental melatonin trials have shown reductions in estrogen, $\mathrm{LH}, \mathrm{FSH}$, and even inhibition of ovulation with pharmacologic doses of melatonin $(18,25-29)$. If melatonin is truly related to sex hormones, it is possible that in circumstances of extreme or unnatural melatonin and/ or sex hormone levels, relationships may be more apparent.

Along the lines of this type of reasoning, it could be expected that melatonin-sex hormone relationships may be more evident among shift-workers who may have more extreme variability in melatonin secretion. Despite our recruitment of rotating shift nurses, a novel aspect of this study, no association between melatonin and sex hormones was evident. It is possible that the particular shift-work schedule studied is not "disruptive" enough to circadian rhythms to cause detectable changes in melatonin and/ or sex hormone levels. Further, given that risk estimates for shift-work and breast cancer are strongest and most consistent for longer durations of shift-work, our study population may not have had long enough durations of shift-work history for measurable associations between melatonin and sex hormones.

The longitudinal analysis, novel to this study, also did not reveal melatonin-sex hormone relationships. These relationships were explored based on a hypothesized latency for influences of changes in melatonin on sex hormones. The change in season was considered a possible source of melatonin variability which may cause subsequent changes in sex hormone production, either acutely or over the course of several months. However, as melatonin levels were fairly consistent across seasons in this study, it was unlikely that melatonin measures from the former (compared to the current) season would have a different relationship with current sex hormone levels.

The relative latency or acuteness of proposed influences of melatonin on sex hormone levels is unknown. If changes in melatonin and sex hormone levels are acute following exposure 
to LAN, it is possible that relationships will be missed or less obvious when hormones are measured during day shifts compared to nights, as was done in this study.

Overall, this study adds to the mostly null findings to date indicating no relationship between melatonin and sex hormones under observational settings. These findings do not support the proposed biological pathway, which implicates altered melatonin and sex hormone levels as intermediates between shift-work and breast cancer risk. Nevertheless, these findings cannot rule out the possible role for melatonin and sex hormones in breast cancer progression. As described previously (see Section 2.6), both direct and indirect melatonin-sex hormone relationships have been proposed. While results of this study do not support the hypothesized indirect neuroendocrine mechanism whereby melatonin down-regulates sex hormone production (of interest to breast cancer initiation), a second direct mechanism has been described which may be more relevant to influences of melatonin and sex hormones on breast cancer progression $(30,31)$. Melatonin is believed to act at the level of the breast tumor cell to interfere with estrogenmediated proliferative signaling. While this alternative mechanism may be less likely to explain an increased breast cancer incidence observed among shift-workers, it still implicates a cancerprotective role for melatonin and emphasizes the need for shift-workers and others exposed to LAN to maintain healthy melatonin levels.

Besides relationships with sex hormones, several other cancer-protective properties of melatonin have been proposed including anti-oxidant properties, immodulatory functions, and direct anti-mitotic and pro-apoptotic pathways (see Section 2.5.3). In addition, several alternative pathways have been suggested to explain the increased cancer risk among shift workers, outside of the melatonin pathway, including behavioral or lifestyle changes (32), sleep disturbances (33), and stress (34). In terms of behavioral changes, a recent review describes a higher prevalence of smoking and alcohol consumption, and higher BMIs among many studies of shift-workers (32), a 
finding somewhat consistent with our study where over $20 \%$ of nurses were obese (BMI $\geq 30$ ) and $13 \%$ current smokers (compared to the 2009 national averages for Canadian females of $16.7 \%$ obesity and $17.7 \%$ current smokers) (35). In support of this pathway, shift workers also experience increased risks of other diseases that are related to unhealthy lifestyles such as diabetes mellitus $(36)$, metabolic syndrome $(37)$, obesity $(38,39)$ and cardiovascular disease $(40)$.

\subsubsection{Night Shift-work and Sex Hormones}

Associations between night shift-work history and sex hormone levels were also assessed. While years of night shift-work was significantly associated with increased estradiol, estrone and progesterone levels in bivariate analyses, these results were strongly confounded by age and other variables, and were attenuated following multivariate adjustments. Further, multivariate-adjusted geometric sex hormone means were not statistically different between women with under 20 vs. 20 or more years of night shift-work experience. Two previous studies have examined associations of night shift history and sex hormone levels: among participants of the NHS, significantly reduced estradiol levels were observed in pre-menopausal nurses who had worked 15 or more years of night shifts compared to nurses with no night shift experience ( $p=$ 0.03) (20), and among a group of post-menopausal Japanese women, having ever worked nights was associated with significantly reduced estrone levels $(\mathrm{p}=0.006)(21)$.

\subsection{Strengths and Limitations}

This study has several strengths. In terms of observational research to date, the shiftworking study population and the collection of cross-seasonal melatonin and sex hormone levels are novel aspects of this study. Shift-workers, who are prone to LAN exposure, may have disrupted melatonin production and therefore greater extremes in melatonin variability. Under such conditions, proposed relationships between melatonin and sex hormones may be more apparent. Further, it may be of greater relevance to know whether these relationships exist among 
shift-workers, as it is of interest to know their relevance to shift-work and cancer. In this study, the collection of longitudinal data, across seasons, allowed for the investigation of additional latency periods for relationships between melatonin and sex hormones, which is useful towards elucidating the as yet unknown biologically relevant time-frame for these relationships.

The comprehensive assessment of confounding is another benefit to this study. Many studies that have identified relationships between melatonin and sex hormones under observational settings are limited by uncontrolled confounding and so relationships may be biased. While bivariate relationships between melatonin and estradiol (in winter) and between years of night shift-work and estradiol, estrone, and progesterone levels were observed in this study, results were no longer significant after confounder adjustment.

In addition to these strengths, there are some limitations. Large variability in sex hormone levels among participants created substantial noise in the data, limiting the ability to detect associations of other variables, namely melatonin, for which effects may be small. While several steps were taken to reduce or standardize the influences of strong predictors on sex hormone levels across study participants (subjects were excluded if they had been pregnant or lactating in the previous six months; blood samples were instructed to be fasting and were collected at a consistent time of day), logistical difficulties prevented the scheduling of data collections across consistent menstrual cycle stage, and recruitment restraints prevented the exclusion of women who used OC. That this work was nested within a larger observational study for which data collection strategies were guided by separate objectives explains some of these logistical limitations. While potential confounding by these factors was assessed and controlled for in the analyses, the large variability in sex hormone levels contributed by these influences may have limited study power. 
The small sample size may have similarly limited study power, and these power issues may be of particular interest if proposed relationships between melatonin and sex hormones are small. Based on a priori minimum detectable effect calculations, this study was sufficiently powered $(80 \%, \alpha=0.05)$ to detect associations as small as $\beta= \pm 0.33$ based on a suspected sample size of 76 (for the longitudinal analysis) and $\beta= \pm 0.30$ based on a sample of 89 (for the cross-sectional analyses by season). As little is known regarding the "normal" inter-individual variability in these hormones, these calculations were based on standardized exposure and outcome variables (where $\mathrm{SD}=1)$.

Given that final sample sizes were much smaller than originally anticipated, and that some results of this study were close to statistical significance, post-hoc minimum detectable effect estimates (MDE) were calculated using the final sample sizes obtained and the empirical variability observed in the data (Table 6.1). Based on the post-hoc MDE calculations, the possibility of large relationships between melatonin and sex hormones (i.e. $\beta \geq 0.5$ ) can be ruled out as the present study was sufficiently powered to detect such associations. However, given that MDE are higher than associations observed, we cannot rule out a lack of power as a possible explanation for the lack of statistically significant findings, particularly those results that approached statistical significance.

Table 6.1 Post hoc minimum detectable effect (MDE) calculations

\begin{tabular}{lcccc}
\hline Analysis & $\begin{array}{c}\text { Estradiol } \\
\text { MDE, N }\end{array}$ & $\begin{array}{c}\text { Estrone } \\
\text { MDE, N }\end{array}$ & $\begin{array}{c}\text { Progesterone } \\
\text { MDE, N }\end{array}$ & $\begin{array}{c}\text { Prolactin } \\
\text { MDE, N }\end{array}$ \\
\hline $\begin{array}{l}\text { Cross-sectional } \\
\text { Summer }\end{array}$ & & & & \\
$\quad$ Winter & $\pm 0.21,61$ & $\pm 0.16,59$ & $\pm 0.30,61$ & $\pm 0.41,59$ \\
$\quad \begin{array}{l}\text { Pooled seasons } \\
\text { Longitudinal }\end{array}$ & $\pm 0.27,56$ & $\pm 0.15,59$ & $\pm 0.33,58$ & $\pm 0.14,59$ \\
$\quad$ Across seasons & - & - & $\pm 0.23,119$ & $\pm 0.09,118$ \\
\hline
\end{tabular}

*Due to use of mixed model and reduced power with random effects modeling, MDE for analyses of pooled seasons may be slightly underestimated 
While exposure and outcome variables were measured objectively through the use of biomarkers, the assessment of circulating sex hormone levels by RIA has several challenges. A lack of standardized, validated assays has been described as a major limitation of sex hormone research to date (41). While standard medical diagnostic assays available at KGH and MUMC were used for sex hormone assessment in this study, the lack of gold standard tools limits our ability to quantify the validity of these assays. Further, the reproducibility of these techniques is difficult to assess given the challenges in accounting for the highly variable nature of sex hormone levels that fluctuate with many personal, reproductive and circadian influences. Nevertheless, as previously described, the characteristic cyclical hormone patterns and determinants observed in our study add validity to the sex hormone data. Peak nocturnal melatonin levels were assessed using a validated assay (aMTs-6 ELISA), which is highly comparable to the gold standard RIA $(r=0.969)(42)$. The WSIB pilot study ensured accuracy for the reflection of nocturnal melatonin secretion by this measure in our source population of rotating shift nurses (4). Several quality control procedures were followed to ensure precision of melatonin and hormone assays and to reduce the risk of measurement error (see Sections 3.5.4, 3.6.4).

The validity of a single sex hormone measure to portray long-term levels in premenopausal women, of relevance to breast cancer risk, is unclear (see Section 3.6.1). Nevertheless, so long as sex hormone measures accurately characterize hormone levels at the time of study (of interest to relationships with melatonin levels), the investigation of relationships between these intermediates is valid.

In the interest of cost and the amount of blood drawn, analysis was restricted to four sex hormones for which relationships with melatonin were plausible. It may be of interest to study relationships between melatonin and gonadotropic hormones, namely FSH and LH: if melatonin's 
proposed down-regulation of sex hormone levels occurs by interference at the level of the hypothalamic pituitary axis, relationships between melatonin and FSH and LH may be more direct and therefore stronger than those of more downstream ovarian hormones.

Despite the objective measures of exposure and outcome through the use of biomarkers, most covariates were characterized using self-reported data, which presents the opportunity for misclassification of confounder information. Misclassification that is non-differential with respect to exposure or outcome, as is likely in this study, results in diluted associations of confounders with these variables, which in turn reduces the effectiveness of confounder adjustment (43). As such, multivariate-adjusted results of this study could be subject to residual confounding, and this may mask true relationships which could be either weaker or stronger.

This is of particular importance to menstrual cycle stage, which was additionally limited by a lack of information regarding menstrual cycle length. Here, based on the reported first day of their last menstrual period, subjects were categorized into follicular (days 0-10), mid-cycle (days 11-16) and luteal menstrual stages ( $>$ day 16) assuming a 28-day cycle. This created potential misclassification among women with variable overall and phase-specific cycle lengths. The accuracy of this classification may have been improved if menstrual cycle length was known, or if women were scheduled to participate at specific stages of the menstrual cycle. That most variability in menstrual cycle length is due to differences in the length of the follicular phase (13) makes this classification especially challenging, given that this category had to be strictly defined (0-10 days). As menstrual cycle patterns of estradiol and estrone were less obvious in winter (geometric means did not follow characteristic menstrual trends), residual confounding by menstrual stage in winter is possible. Nevertheless, given large inter-individual differences in sex hormone levels, it may be difficult to capture such characteristic patterns without large samples of women across all stages of the menstrual cycle, or without consistency in cycle stage across 
individuals. Further, similarities in the cyclical patterns of estradiol and estrone production between OC users (who have a controlled 28-day cycle) and non-users (who may have variable cycle length) suggests that the assumption of a 28-day cycle was not inappropriate as there is no obvious misclassification of cycle stage.

The accuracy of menstrual stage classification may have been improved if menstrual cycle length was known, or if women were scheduled to participate at specific stages of the menstrual cycle. Previous research based out of the NHS has ensured accuracy of menstrual stage by scheduling study participation at specific menstrual cycle days that can be reasonably assumed to accurately represent specific phases (follicular: 3-5 days following the onset of menstruation; luteal: 7-9 days prior to the onset of the next menstruation) $(3,20)$. However, this complex data collection scheduling is challenging for observational studies.

Given that nurses volunteered to participate, selection bias may be a concern for the internal validity of this study. However, for this bias to occur, selection into (or out of) the study must be related to both the exposure and outcome. While it is possible that nurses with greater shift-work experience (and possibly therefore lower melatonin levels) may have been more keen to participate, shift-work experience is unlikely to have been independently related to sex hormones. Other factors that may have influenced study participation, such as general health status, are also unlikely to be independently related to each of melatonin and sex hormone levels and therefore unlikely to bias relationships. As characteristics of the overall premenopausal shiftworking population of nurses at KGH are unknown, our sample of nurses cannot be compared to the underlying study base. Further, as it is unknown how many nurses were eligible to participate in this study, the typical "response rate" cannot be calculated and the representativeness of our sample to the study base is difficult to assess. 
Given the multiple data collection periods and varying degrees of study participation and follow-up, selection out of the study was assessed. Characteristics were compared between individuals who participated (and had full data) in both seasons compared to one, and for those who completed the original study questionnaire but did not take part in either seasonal study period. As there were no meaningful differences in characteristics between groups, selection out of the study is unlikely to have biased study results.

A further limitation of this study is unknown generalizability of results beyond the specific study base, premenopausal nurses at one hospital who follow one shift schedule. Relationships are likely not generalizable to men given differences in the relative importance of certain sex hormones by gender, and generalizability to post-menopausal women, whose hormone secretion patterns and determinants differ from pre-menopausal women, is also unclear. It is also possible that within pre-menopausal women, these relationships will vary depending on shiftwork status and the "disruptive" potential of the particular shift schedule followed to normal circadian rhythms.

\subsection{Future Directions}

Overall, this study adds to the mostly null findings to date indicating no relationship between melatonin and sex hormones under observational settings. It is possible that the particular shift-work schedule followed by study participants is not sufficiently disruptive to cause meaningful, measurable changes in melatonin and/ or sex hormone levels. As such, it may be useful to investigate these relationships among other shift-work schedules including permanent night shift-workers. Further, given that risk estimates for shift-work and breast cancer are strongest and most consistent for longer durations of shift-work, these relationships may also be more apparent among longer term shift-workers. It may therefore be useful to also study these relationships among women who have longer histories of shift-work. 
If changes in melatonin and sex hormone levels are acute following LAN exposure, it is possible that relationships will be missed or less obvious when hormones are measured during day shifts, as was done in this study. Future studies may therefore consider investigating these relationships during night shifts.

To improve study power, future studies may also consider increasing sample size, and coordinating data collection at a consistent menstrual cycle stage and/ or excluding the use of OC prior to study enrollment to reduce variability in sex hormone levels. This may in turn, maximize study power through reducing noise in the data, and may aid in the detection of less influential predictor variables of interest, namely melatonin.

\subsection{Contribution of Research and Conclusions}

Given the limitations of research on shift-work and breast cancer to date, including recent studies which show no associations $(44,45)$, the investigation of potential intermediates in this pathway may help to clarify the existence and plausibility of this link. Further, if shift-work is scientifically validated as breast cancer agent, an identification and understanding of the pathways mediating this link is of critical importance to the development of strategies to minimize health impacts of this work schedule. This study contributes observational evidence concerning the relationships between melatonin and sex hormones, an area with few existing studies with mostly null findings. While much support for these relationships has been provided under various reproductive, pathological and experimental conditions (see Section 2.6); it appears that these relationships are less applicable to normal human physiology. Despite several novelties compared to previous research, including the use of a shift-working population, the assessment of longitudinal relationships, and comprehensive confounder assessment, this study did not identify associations between melatonin and sex hormones. While it is possible that these results were limited by low study power and residual confounding by menstrual stage or other variables, these 
findings do not support the hypothesized biological pathway which implicates altered melatonin

and sex hormone levels as intermediates between shift-work and increased breast cancer risk.

\section{References}

1. Lerchl A, Partsch CJ. Reliable analysis of individual human melatonin profiles by complex cosinor analysis. J Pineal Res. 1994 Mar;16(2):85-90.

2. Bergiannaki JD, Soldatos CR, Paparrigopoulos TJ, Syrengelas M, Stefanis CN. Low and high melatonin excretors among healthy individuals. J Pineal Res. 1995 Apr;18(3):159-64.

3. Schernhammer ES, Kroenke CH, Dowsett M, Folkerd E, Hankinson SE. Urinary 6sulfatoxymelatonin levels and their correlations with lifestyle factors and steroid hormone levels. J Pineal Res. 2006 Mar;40(2):116-24.

4. Grundy A, Sanchez M, Richardson H, Tranmer J, Borugian M, Graham CH, et al. Light intensity exposure, sleep duration, physical activity, and biomarkers of melatonin among rotating shift nurses. Chronobiol Int. 2009 Oct;26(7):1443-61.

5. Arendt J. Melatonin and the mammalian pineal gland. London: Chapman and Hall; 1995.

6. Wehr TA, Duncan WC,Jr, Sher L, Aeschbach D, Schwartz PJ, Turner EH, et al. A circadian signal of change of season in patients with seasonal affective disorder. Arch Gen Psychiatry. 2001 Dec;58(12):1108-14.

7. Wehr TA. Melatonin and seasonal rhythms. J Biol Rhythms. 1997 Dec;12(6):518-27.

8. Anttila L, Koskinen P, Irjala K, Kaihola HL. Reference intervals for serum sex steroids and gonadotropins in regularly menstruating women.Acta Obstet Gynecol Scand. 1991;70(6):475-81

9. Verkasalo PK, Thomas HV, Appleby PN, Davey GK, Key TJ. Circulating levels of sex hormones and their relation to risk factors for breast cancer: A cross-sectional study in 1092 pre- and postmenopausal women (UK). Cancer Causes Control. 2001;12(1):47-59.

10. Bernstein L, Pike MC, Ross RK, Henderson BE. Age at menarche and estrogen concentrations of adult women. Cancer Causes Control. $1991 \mathrm{Jul} ; 2$ (4):221-5.

11. Windham GC, Elkin E, Fenster L, Waller K, Anderson M, Mitchell PR, et al. Ovarian hormones in premenopausal women: Variation by demographic, reproductive and menstrual cycle characteristics. Epidemiology. 2002 Nov;13(6):675-84.

12. Briggs M, Briggs M. Plasma hormone concentrations in women receiving steroid contraceptives. J Obstet Gynaecol Br Commonw. 1972 Oct;79(10):946-50.

13. Gaspard UJ, Romus MA, Gillian D, Duvivier J, Demey-Ponsart E, Franchimont P. Plasma hormone levels in women receiving new oral contraceptives containing ethinyl estradiol plus levonorgestrel or desogestrel. Contraception. 1983;27(6):577-590.

14. Abu-Fadil S, DeVane G, Siler TM, Yen SS. Effects of oral contraceptive steroids on pituitary prolactin secretion. Contraception. 1976 Jan;13(1):79-85.

15. Mishell DR,Jr, Kletzky OA, Brenner PF, Roy S, Nicoloff J. The effect of contraceptive steroids on hypothalamic-pituitary function. Am J Obstet Gynecol. 1977 May 1;128(1):60-74.

16. Davis JR, Selby C, Jeffcoate WJ. Oral contraceptive agents do not affect serum prolactin in normal women. Clin Endocrinol (Oxf). 1984 Apr;20(4):427-34.

17. Missmer SA, Spiegelman D, Bertone-Johnson ER, Barbieri RL, Pollak MN, Hankinson SE. Reproducibility of plasma steroid hormones, prolactin, and insulin-like growth factor levels among premenopausal women over a 2- to 3-year period. Cancer Epidemiol Biomarkers Prev. 2006 May;15(5):972-8. 
18. Bellipanni G, Bianchi P, Pierpaoli W, Bulian D, Ilyia E. Effects of melatonin in perimenopausal and menopausal women: A randomized and placebo controlled study. Exp Gerontol. 2001 Feb;36(2):297-310.

19. Okatani Y, Morioka N, Wakatsuki A. Changes in nocturnal melatonin secretion in perimenopausal women: Correlation with endogenous estrogen concentrations. J Pineal Res. 2000 Mar;28(2):111-8.

20. Schernhammer ES, Rosner B, Willett WC, Laden F, Colditz GA, Hankinson SE. Epidemiology of urinary melatonin in women and its relation to other hormones and night work. Cancer Epidemiol Biomarkers Prev. 2004 Jun;13(6):936-43.

21. Nagata C, Nagao Y, Yamamoto S, Shibuya C, Kashiki Y, Shimizu H. Light exposure at night, urinary 6-sulfatoxymelatonin, and serum estrogens and androgens in postmenopausal japanese women. Cancer Epidemiol Biomarkers Prev. 2008 Jun;17(6):1418-23.

22. Brzezinski A. Melatonin in humans. N Engl J Med. 1997 Jan 16;336(3):186-95.

23. Brzezinski A, Lynch HJ, Seibel MM, Deng MH, Nader TM, Wurtman RJ. The circadian rhythm of plasma melatonin during the normal menstrual cycle and in amenorrheic women. $\mathrm{J}$ Clin Endocrinol Metab. 1988 May;66(5):891-5.

24. Berga SL, Mortola JF, Yen SS. Amplification of nocturnal melatonin secretion in women with functional hypothalamic amenorrhea. J Clin Endocrinol Metab. 1988 Jan;66(1):242-4.

25. Kripke DF, Kline LE, Shadan FF, Dawson A, Poceta JS, Elliott JA. Melatonin effects on luteinizing hormone in postmenopausal women: A pilot clinical trial NCT00288262. BMC Womens Health. 2006 May 16;6:8.

26. Voordouw BC, Euser R, Verdonk RE, Alberda BT, de Jong FH, Drogendijk AC, et al. Melatonin and melatonin-progestin combinations alter pituitary-ovarian function in women and can inhibit ovulation. J Clin Endocrinol Metab. 1992 Jan;74(1):108-17.

27. Pawlikowski M, Kolomecka M, Wojtczak A, Karasek M. Effects of six months melatonin treatment on sleep quality and serum concentrations of estradiol, cortisol, dehydroepiandrosterone sulfate, and somatomedin C in elderly women. Neuro Endocrinol Lett. 2002 Apr;23 Suppl 1:17-9.

28. Nordlund JJ, Lerner AB. The effects of oral melatonin on skin color and on the release of pituitary hormones. J Clin Endocrinol Metab. 1977 Oct;45(4):768-74.

29. Wright J, Aldhous M, Franey C, English J, Arendt J. The effects of exogenous melatonin on endocrine function in man. Clin Endocrinol (Oxf). 1986 Apr;24(4):375-82.

30. Sanchez-Barcelo EJ, Cos S, Fernandez R, Mediavilla MD. Melatonin and mammary cancer: A short review. Endocr Relat Cancer. 2003 Jun;10(2):153-9.

31. Cos S, Gonzalez A, Martinez-Campa C, Mediavilla MD, Alonso-Gonzalez C, SanchezBarcelo EJ. Estrogen-signaling pathway: A link between breast cancer and melatonin oncostatic actions. Cancer Detect Prev. 2006;30(2):118-28.

32. Kolstad HA. Nightshift work and risk of breast cancer and other cancers--a critical review of the epidemiologic evidence. Scand J Work Environ Health. 2008 Feb;34(1):5-22.

33. Costa G, Haus E, Stevens R. Shift work and cancer - considerations on rationale, mechanisms, and epidemiology. Scand J Work Environ Health. 2010 Mar;36(2):163-79.

34. Sephton S, Spiegel D. Circadian disruption in cancer: A neuroendocrine-immune pathway from stress to disease? Brain Behav Immun. 2003 Oct;17(5):321-8.

35. Health indicator profile, annual estimates (CANSIM database) [homepage on the Internet]. . Available from: http://cansim2.statcan.gc.ca/cgi-win/cnsmcgi.exe?Lang=E\&CNSM$\mathrm{Fi}=\mathrm{CII} / \mathrm{CII}$ _1-eng.htm. 
36. Suwazono Y, Sakata K, Okubo Y, Harada H, Oishi M, Kobayashi E, et al. Long-term longitudinal study on the relationship between alternating shift work and the onset of diabetes mellitus in male japanese workers. J Occup Environ Med. 2006 May;48(5):455-61.

37. Sookoian S, Gemma C, Fernandez Gianotti T, Burgueno A, Alvarez A, Gonzalez CD, et al. Effects of rotating shift work on biomarkers of metabolic syndrome and inflammation. $\mathrm{J}$ Intern Med. 2007 Mar;261(3):285-92.

38. Niedhammer I, Lert F, Marne MJ. Prevalence of overweight and weight gain in relation to night work in a nurses' cohort. Int J Obes Relat Metab Disord. 1996 Jul;20(7):625-33.

39. Suwazono Y, Dochi M, Sakata K, Okubo Y, Oishi M, Tanaka K, et al. A longitudinal study on the effect of shift work on weight gain in male japanese workers. Obesity (Silver Spring). 2008 Aug; 16(8):1887-93.

40. Puttonen S, Harma M, Hublin C. Shift work and cardiovascular disease - pathways from circadian stress to morbidity. Scand J Work Environ Health. 2010 Mar;36(2):96-108.

41. Stanczyk FZ, Lee JS, Santen RJ. Standardization of steroid hormone assays: Why, how, and when? Cancer Epidemiol Biomarkers Prev. 2007 Sep;16(9):1713-9.

42. Peniston-Bird JF, Di WL, Street CA, Edwards R, Little JA, Silman RE. An enzyme immunoassay for 6-sulphatoxy-melatonin in human urine. J Pineal Res. 1996 Mar;20(2):51-6.

43. Savitz DA, Baron AE. Estimating and correcting for confounder misclassification. Am J Epidemiol. 1989;129(5):1062-71.

44. Schwartzbaum J, Ahlbom A, Feychting M. Cohort study of cancer risk among male and female shift workers. Scand J Work Environ Health. 2007 Oct;33(5):336-43.

45. Pronk A, Ji BT, Shu XO, Xue S, Yang G, Li HL, et al. Night-shift work and breast cancer risk in a cohort of chinese women. Am J Epidemiol. 2010 May 1;171(9):953-9. 


\title{
Appendix A
}

\section{Ethics Approval}

\author{
QUEEN'S UNIVERSITY HEALTH SCIENCES \& AFFILIATED TEACHING \\ HOSPITALS RESEARCH ETHICS BOARD
}

Ms. Annie Langley

Expedited Review

Department of Community Health and Epidemiology

Cancer Research Institute

10 Stuart Street, Room 236

Queen's University

Dear Ms. Langley,

Study Title: $\quad$ Hormones and melatonin as intermediate markers of breast cancer risk Co-Investigators: Dr. K. Aronson and Dr. C. Graham

I am writing to acknowledge receipt of your recent ethics submission. We have examined the protocol for your project (as stated above) and consider it to be ethically acceptable. This approval is valid for one year from the date of the Chair's signature below. This approval will be reported to the Research Ethics Board. Please attend carefully to the following list of ethics requirements you must fulfill over the course of your study:

Reporting of Amendments: If there are any changes to your study (e.g. consent, protocol, study procedures, etc.), you must submit an amendment to the Research Ethics Board for approval. (see http://www.queensu.ca/vpr/reb.htm).

> Reporting of Serious Adverse Events: Any unexpected serious adverse event occurring locally must be reported within 2 working days or earlier if required by the study sponsor. All other serious adverse events must be reported within 15 days after becoming aware of the information.

> Reporting of Complaints: Any complaints made by participants or persons acting on behalf of participants must be reported to the Research Ethics Board within 7 days of becoming aware of the complaint. Note: All documents supplied to participants must have the contact information for the Research Ethics Board.

$>$ Annual Renewal: Prior to the expiration of your approval (which is one year from the date of the Chair's signature below), you will be reminded to submit your renewal form along with any new changes or amendments you wish to make to your study. If there have been no major changes to your protocol, your approval may be renewed for another year.

Yours sincerely,

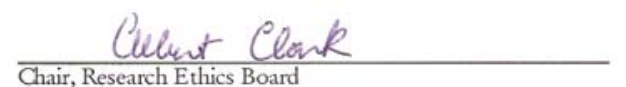

Chair, Research Ethics Board

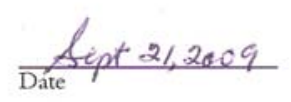

ORIGINAL TO INVESIIGATOR - COPY TO DEPARTMENT HEAD- COPY TO HOSPITAL(S) /P\&T (If appropriate) - FLLE COPY

Study Code: EPID-296-09

$>\quad$ Investigators please note that if your trial is registered by the sponsor, you must take responsibility to ensure that the registration information is accurate and complete 


\section{Appendix B}

\section{Consent Form}

\section{StUdy of Light AT Night, PHYSical Activity ANd MeLATONIN IN NURSES} Consent form

Study No:

By signing below, I am indicating that I have read and understand the information for the study on physical activity, light and melatonin levels. I have been assured that records relating to my study participation will be kept confidential and that no information will be released or printed that would disclose my personal identity without my permission. I understand that my participation is voluntary, will not affect my work status, and I am free to withdraw from the study at any time without any penalty.

If you are a First Nations person or an indigenous person who has contact with spiritual elders, you may want to talk with them before you proceed with being part of this study. Elders may have reservations about genetic procedures.

I agree to participate and do the following:

- Provide questionnaire responses

- Wear a light data-logger

- Provide diary responses

- Provide sixteen saliva samples

- Wear a pedometer

- Provide eight urine samples

- Pre-menopausal subjects only: I agree to provide one $30 \mathrm{~mL}$ and one $15 \mathrm{~mL}$ blood sample.

I agree to provide access to my mammograms to be assessed for breast density

If yes: Date and location of most recent mammogram

I agree that this information can be used for research purposes in future studies

I would like a copy of study results sent to me at study completion

$\square$ I do NOT consent to participate

Printed Name of Participant
Printed Name of Witness

Printed Name of Witness

$$
\text { Signature of Participant }
$$

Signature of Witness

\section{Date}

Date

Contact Name: If you requested study information to be sent to you (see above), please give us the name, address, and phone number of a relative or close fiend who will know your whereabouts so we can get your new address to send you the results of this study if you move.

Name:

Phone \#:

Address:

Please complete and sign two copies of this consent form and return one copy to us during your first scheduled meeting with the study team. Retain the duplicate copy of the consent form and the study guide for your information.

Principal Investigator

Dr. Kristan J. Aronson

Professor

Division of Cancer Care and Epidemiology

Cancer Research Institute, Queen's University

Tel: (613) 533-6000 ext 78522

Fax: (613) 533-6794

Email: aronson@queensuca

\author{
Project Coordinator \\ Kathryn Bowes \\ Clinical Research Unit \\ Kingston General Hospital \\ Tel: (613) 549-6666 ×2738 \\ Fax: (613) 533-6794 \\ Email: bowesk@kgh.kaninet
}

\footnotetext{
If you have any questions concerning your rights as a study participant, please contact: Dr. Albert Clark, Chair of Ethics Board at Queen's University

Telephone: (613) 533-6081 Fax: (613) 533-6806 E-mail: clarkafa.cueensu.ca
} 


\section{Appendix C}

\section{Study Questionnaire}

Study ID
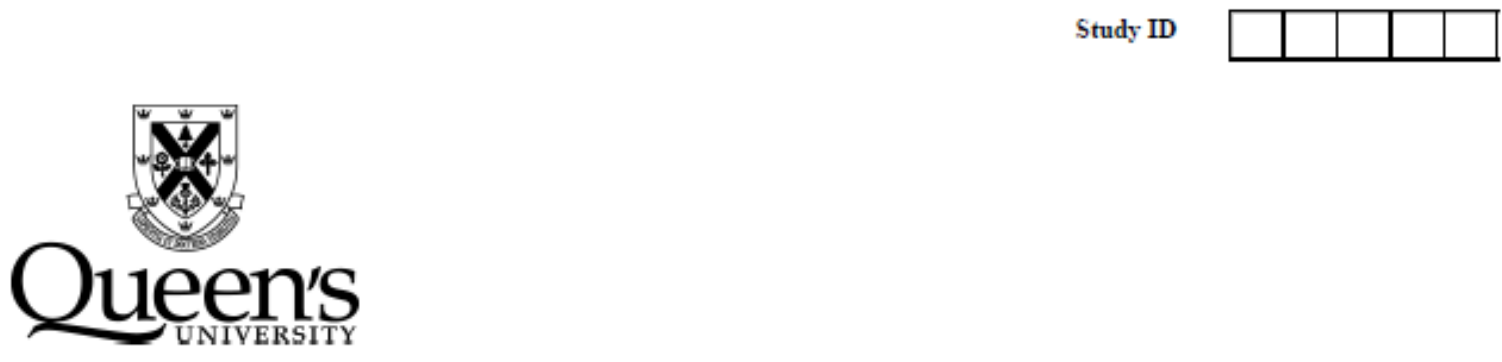

\section{Study of Light at Night, Physical Activity and Melatonin in NuRses \\ QUESTIONNAIRE}

This questionnaire is part of our research study to understand the relationship between a woman's environment, behavioural patterns and melatonin production. The specific objectives are to investigate the association between melatonin levels produced by the body and exposure to certain environmental factors, including light exposure and physical activity.

The following questions should be completed on , the first day of study participation.

The answers that you share with us will be kept strictly confidential and identified by a study ID number, known only by selected members of our research team. Your honesty is important for the success of this research, and a partial answer is better than no answer at all.

We appreciate your cooperation.

Thank you! 
Please answer each question as completely as possible. If you are unsure of an exact answer, give your best estimate.

Today's Date: Month / day/year

1) What is your date of birth?

$$
\text { Month / day / year }
$$

2) What was your weight at age 30 ? (kg) or (lbs)

3) At age 14 what was your height? (feet and inches) or $(\mathrm{cm})$

4) Relative to your peers at age 14 (grade 8 or 9), were you:
a Taller
a Shorter
a Average
D Don't remember

5) How would you best describe you and your grandparents' race, ethnicity or colour? Please specify as many as applicable:

\begin{tabular}{|c|c|c|c|c|c|}
\hline $\begin{array}{l}\text { Race, ethnicity or } \\
\text { colour }\end{array}$ & Yourself & $\begin{array}{c}\text { Maternal } \\
\text { Grandmother }\end{array}$ & $\begin{array}{c}\text { Maternal } \\
\text { Grandfather }\end{array}$ & $\begin{array}{c}\text { Paternal } \\
\text { Grandmother }\end{array}$ & $\begin{array}{c}\text { Paternal } \\
\text { Grandfather }\end{array}$ \\
\hline White & $\square$ & $\square$ & $\square$ & a & $\square$ \\
\hline Black & ב & ב & ב & ב & ב \\
\hline $\begin{array}{l}\text { Native/Aboriginal } \\
\text { peoples of North } \\
\text { America }\end{array}$ & $\square$ & 口 & 口 & 口 & 口 \\
\hline Filipino & ב & ב & ב & ב & ב \\
\hline Chinese & ב & ב & ב & ב & 口 \\
\hline Japanese & $\square$ & ב & ב & ב & 口 \\
\hline Korean & 口 & 口 & ב & ב & 口 \\
\hline $\begin{array}{l}\text { South Asian (e.g. } \\
\text { East Indian, } \\
\text { Pakistani, } \\
\text { Punjabi, Sri } \\
\text { Lankan) }\end{array}$ & $\square$ & 口 & 口 & 口 & 口 \\
\hline $\begin{array}{l}\text { South East Asian } \\
\text { (e.g. Cambodian, } \\
\text { Indonesian, } \\
\text { Laotian, } \\
\text { Vietnamese) }\end{array}$ & $\square$ & 口 & 口 & घ & 口 \\
\hline $\begin{array}{l}\text { Arab/West Asian } \\
\text { (e.g. Armenian, } \\
\text { Egyptian, Iranian, } \\
\text { Lebanese, } \\
\text { Moroccan) }\end{array}$ & $\square$ & $\square$ & 口 & 口 & 口 \\
\hline Latin America & 口 & 口 & ב & 口 & 口 \\
\hline Other (Specify) & & & & & \\
\hline
\end{tabular}




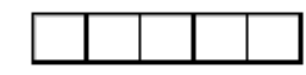

6) What is the highest degree or diploma you have obtained?
a High school
a Postsecondary (certificate/diploma)
a University undergraduate degree
a Graduate degree (Master's, $\mathrm{PhD}$ )
a Other

\section{HEALTH BACKGROUND}

7) How old were you when you had your first menstrual period?

$$
\text { years of age } \quad \square \text { Have never menstruated (go to question \#11) }
$$

8) Are you still menstruating?

Do $\rightarrow$ How many years has it been since your last menstrual period? years

口 Yes (go to question \#8)

9) How did your menstrual periods stop?

$\square$ Naturally (through onset of menopause) $\square$ As a result of radiation or chemotherapy

a As a result of a hysterectomy

$\square$ Other - please specify:

8) Have you ever been pregnant?

$\square$ No (go to question \#10) $\square$ Yes $\rightarrow$ Please indicate the total number of times you have been pregnant (please include any live births, miscarriages or abortions).

9) Do you have any biological children?

$\square$ No (go to question \#10) $\square$ Yes $\rightarrow$ Please indicate how old you were when you gave birth to your first child.

10) Have you ever had a mammogram (i.e. a breast $x$-ray?)

$\square$ Yes $\square$ No (go to question \#13) $\downarrow$

How old were you the first time you went for a mammogram? Years

What was the reason?

How many times have you had a mammogram since the first time?

When was the last time? (ie. 6 months ago? 5 or more years ago?)

11) Have you ever been told that you have high breast (mammographic) density?
$\square$ Yes
$\square$ No (go to question \#13) 


\section{HEALTH BACKGROUND (Cont'd)}

12) These questions are about breast lumps or cysts that you may have had.

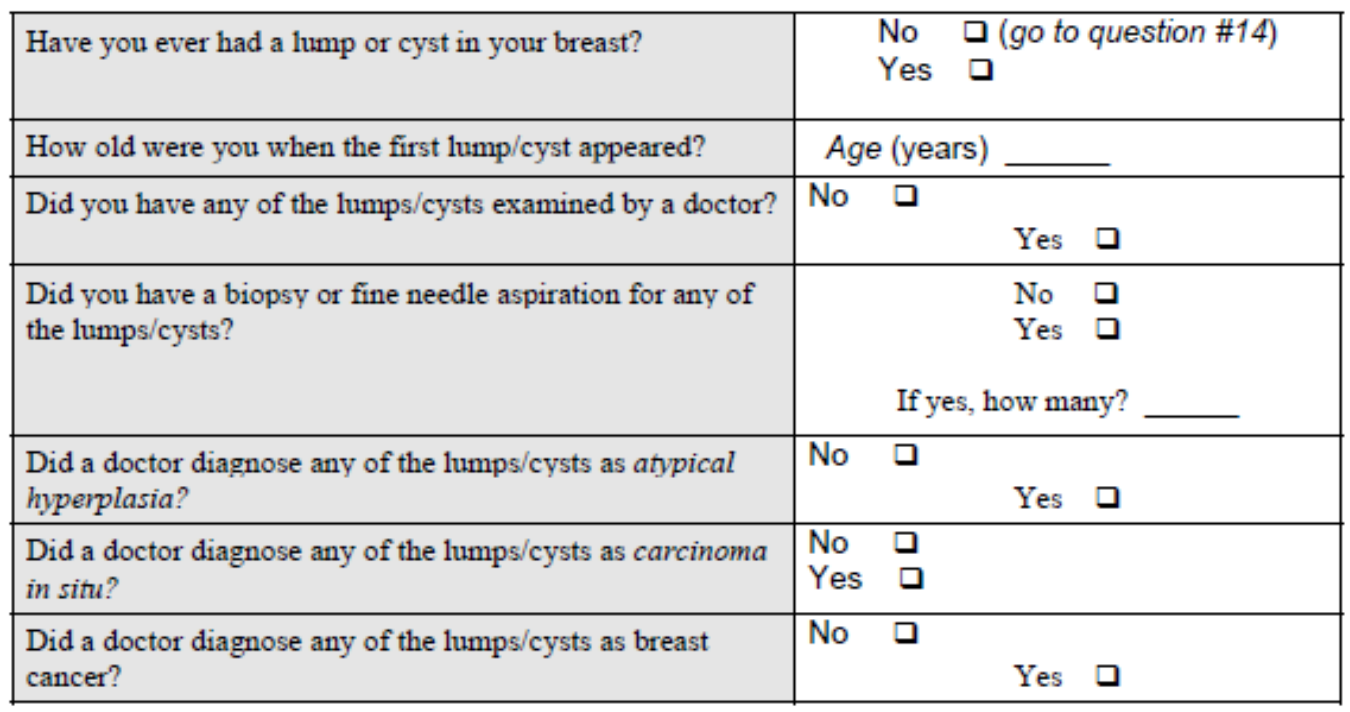

13) These questions are about your sleep patterns.

\begin{tabular}{|l|c|}
\hline Do you experience problems sleeping? & No \\
& Yes \\
\hline $\begin{array}{l}\text { Have you ever been diagnosed with a sleep } \\
\text { disorder? }\end{array}$ & No \\
& If yes: Name: \\
& Date of diagnosis: \\
\hline
\end{tabular}




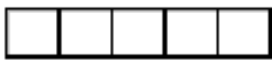

FAMII Y

14) Have any of the following relatives been diagnosed with cancer? (A full sibling is one who has both the same mother and father as you)

\begin{tabular}{|c|c|c|}
\hline Relative & $\begin{array}{c}\text { Have they ever been diagnosed } \\
\text { with cancer? }\end{array}$ & Type(s) of cancer \\
\hline Mother & $\begin{array}{l}\text { Yes } \square \text { No } \\
\text { a Don't know }\end{array}$ & \\
\hline Father & $\begin{array}{l}\text { Yes } \square \text { No } \\
\square \text { Don't know }\end{array}$ & \\
\hline Full Sister 1 & $\begin{array}{l}\text { Yes } \square \text { No } \\
\text { 口Don't know }\end{array}$ & \\
\hline Full Sister 2 & $\begin{array}{l}\text { Yes } \square \text { No } \\
\square \text { Don't know }\end{array}$ & \\
\hline Full Brother 1 & $\begin{array}{l}\text { Yes } \square \text { No } \\
\square \text { Don't know }\end{array}$ & \\
\hline Full Brother 2 & $\begin{array}{l}\text { Yes } \square \text { No } \\
\text { 口 Don't know }\end{array}$ & \\
\hline Son 1 & $\begin{array}{l}\text { Yes } \square \text { No } \\
\text { 口 Don't know }\end{array}$ & \\
\hline Son 2 & $\begin{array}{l}\text { Yes } \square \text { No } \\
\text { 口 Don't know }\end{array}$ & \\
\hline Daughter 1 & $\begin{array}{l}\text { Yes } \square \text { No } \\
\square \text { Don't know }\end{array}$ & \\
\hline Daughter 2 & $\begin{array}{l}\text { Yes } \square \text { No } \\
\square \text { Don't know }\end{array}$ & \\
\hline
\end{tabular}

If more space is required please use an additional page. 


\section{LIFESTYLE HABITS}

15) Have you ever smoked more than 100 cigarettes in your lifetime?

$\square$ Yes $\square$ No (go to question \#18)

16) How old were you when you STARTED smoking? years of age

17) Are you currently smoking?

$\square$ Yes $\square$ No-If no, at what age did you quit? years of age

18) How many years in total have you smoked cigarettes? (excluding the years that you quit) years

19) For the entire time you smoked, on average, how many cigarettes a day did you usually smoke? cigarettes/day $O R$ cigarettes/week

20) This question asks about your family's smoking habits when you were 19 or younger.

\begin{tabular}{|l|l|l|c|}
\hline FAMILY'S SMOKING HABITS & $\begin{array}{c}\text { FATHER/ } \\
\text { GUARDIAN }\end{array}$ & $\begin{array}{c}\text { MOTHER/ } \\
\text { GUARDIAN }\end{array}$ & $\begin{array}{c}\text { OTHER } \\
\text { MEMBER }\end{array}$ \\
\hline $\begin{array}{l}\text { Did your parent(s) or other household } \\
\text { member(s) ever smoke in your presence } \\
\text { when you were } 19 \text { or younger? (go to } \\
\text { question } \# 22 \text { if "no" for all) }\end{array}$ & $\begin{array}{l}\square \text { Yes } \\
\square \text { No }\end{array}$ & $\begin{array}{l}\square \text { Yes } \\
\square \text { No } \\
\square \text { No }\end{array}$ & \\
\hline $\begin{array}{l}\text { For the entire time that s/he smoked, on } \\
\text { average, how many cigarettes a day did s/he } \\
\text { usually smoke? (cigarettes/day) }\end{array}$ & cigarettes/day & cigarettes/day & cigarettes/day \\
\hline $\begin{array}{l}\text { What age were you when first exposed to } \\
\text { your father's \&/or mother's tobacco smoke? } \\
\text { (years) }\end{array}$ & years old & years old & years old \\
\hline $\begin{array}{l}\text { What age were you when no longer exposed } \\
\text { to your father's \&/or mother's tobacco } \\
\text { smoke? (years) }\end{array}$ & years old & years old & years old \\
\hline
\end{tabular}


LIFESTYLE HABITS (Cont'd)

21) During this time period (19 or younger), on average, how many hours per week were you exposed to someone else's tobacco smoke?

\begin{tabular}{|l|c|c|c|c|c|c|c|}
\hline & \multicolumn{6}{|c|}{ Hours per week exposed to "second-hand" tobacco smoke } \\
\hline & 0 & $<1$ & $1-2$ & $3-4$ & $5-6$ & $7-9$ & $>9$ \\
\hline $\begin{array}{l}\text { Age: } 19 \text { years and } \\
\text { younger }\end{array}$ & & & & & & & \\
\hline
\end{tabular}

22) In the past (during different decades of your life), on average, how many hours per week, outside of the workplace, were you exposed to someone else's tobacco smoke?

\begin{tabular}{|c|c|c|c|c|c|c|c|}
\hline & \multicolumn{7}{|c|}{ Hours per week exposed to "second-hand" tobacco smoke } \\
\hline Age (decades) & 0 & $<1$ & $1-2$ & $3-4$ & $5-6$ & $7-9$ & $>9$ \\
\hline 20-29 years & & & & & & & \\
\hline 30-39 years & & & & & & & \\
\hline 40-49 years & & & & & & & \\
\hline 50-59 years & & & & & & & \\
\hline 2 years ago (if $>60$ ) & & & & & & & \\
\hline
\end{tabular}

23) This question asks about your alcohol consumption habits.

\begin{tabular}{|c|c|c|c|c|}
\hline & & Beer & Wine & Spirits \\
\hline $\begin{array}{l}\text { Have you ever drank the following more } \\
\text { than twice a year? (if "no" to all } 3 \text {, i.e. beer, } \\
\text { wine and spirits, go to question \#41) }\end{array}$ & $\begin{array}{l}\text { Yes } \\
\text { No }\end{array}$ & $\begin{array}{l}\square \\
\square\end{array}$ & $\begin{array}{l}\text { a } \\
\text { a }\end{array}$ & $\begin{array}{l} \\
a\end{array}$ \\
\hline \multicolumn{5}{|c|}{$\begin{array}{l}\text { On average, how many drinks per week did you consume during different decades of your life? } \\
\text { One drink=1 glass of wine or } 1 \text { bottle of beer or } 1 \text { oz of spirits }\end{array}$} \\
\hline Teens $(15-19) ?$ & \# Drinks/week & $\underset{\text { wk }}{\text { per }}$ & $\underset{\text { wk }}{\text { per }}$ & $\underset{\text { wk }}{\text { per }}$ \\
\hline $20-29$ years & \# Drinks/week & per & $\begin{array}{c}\text { per } \\
\text { wk }\end{array}$ & $\begin{array}{c}\text { per } \\
\text { wk }\end{array}$ \\
\hline $30-39$ years & \# Drinks/week & per & per & $\begin{array}{c}\text { per } \\
\text { wk }\end{array}$ \\
\hline $40-49$ years & \# Drinks/week & wer & $\begin{array}{l}\text { per } \\
\text { wk }\end{array}$ & per \\
\hline $50-59$ years & \# Drinks/week & per & per & per \\
\hline 2 years ago (if over 60 years of age) & \# Drinks/week & $\begin{array}{c}\text { per } \\
\text { wk }\end{array}$ & $\begin{array}{c}\text { per } \\
\text { wk }\end{array}$ & $\begin{array}{c}\text { per } \\
\text { wk }\end{array}$ \\
\hline
\end{tabular}


24) Please tell us about EACH job or occupation you had for at least 6 months, including volunteer and military service, but not including schooling or homemaker. Include only seasonal or part-time work that is equivalent to 6 months or more. Begin with your most recent job and continue back to your first job. Include any absences from the work force and jobs you have done outside of Canada.

\begin{tabular}{|c|c|c|c|c|c|c|}
\hline \multirow{2}{*}{$\begin{array}{l}\text { Job } \\
\text { No. }\end{array}$} & \multicolumn{2}{|c|}{ Time Period } & \multirow{2}{*}{$\begin{array}{l}\text { Type of Industry, } \\
\text { Business or Service }\end{array}$} & \multirow{2}{*}{$\begin{array}{l}\text { Company Name and } \\
\text { Location }\end{array}$} & \multirow{2}{*}{ Job Title } & \multirow{2}{*}{$\begin{array}{c}\text { Intensity* } \\
\text { (Please check one for each job) }\end{array}$} \\
\hline & $\begin{array}{c}\text { Start } \\
\text { (Month- } \\
\text { Year) } \\
\end{array}$ & $\begin{array}{l}\text { End } \\
\text { (Month- } \\
\text { Year) } \\
\end{array}$ & & & & \\
\hline Eg. & Nov-1993 & Feb-2003 & Hairdressing & $\begin{array}{l}\text { Suki's Hair Salon, } \\
\text { Vancouver, BC }\end{array}$ & $\begin{array}{l}\text { Colour } \\
\text { Specialist }\end{array}$ & $\begin{array}{ll}\square \text { Sedentary } & \square \text { Moderate } \\
\square \text { Light } & \square \text { Heavy }\end{array}$ \\
\hline 1 & & & & & & $\begin{array}{ll}\square \text { Sedentary } & \square \text { Moderate } \\
\square \text { Light } & \square \text { Heavy }\end{array}$ \\
\hline 2 & & & & & & $\begin{array}{ll}\square \text { Sedentary } & \square \text { Moderate } \\
\square \text { Light } & \square \text { Heavy }\end{array}$ \\
\hline 3 & & & & & & $\begin{array}{ll}\square \text { Sedentary } & \square \text { Moderate } \\
\square \text { Light } & \square \text { Heavy }\end{array}$ \\
\hline 4 & & & & & & $\begin{array}{ll}\square \text { Sedentary } & \square \text { Moderate } \\
\square \text { Light } & \square \text { Heavy }\end{array}$ \\
\hline 5 & & & & & & $\begin{array}{ll}\square \text { Sedentary } & \square \text { Moderate } \\
\square \text { Light } & \square \text { Heavy }\end{array}$ \\
\hline
\end{tabular}

Intensity of job or occupation defined as:

Sedentary $=$ work that involves sitting only, with minimal walking,

Light $=$ work that involves minimal physical effort such as standing and slow walking with no increase in heart rate and no perspiration,

Moderate $=$ work that is not exhausting, that increases the heart rate slightly and may cause some light perspiration, such as those that

require carrying light loads $(5-10 \mathrm{lbs})$ or that have continuous walking,

Heavy $=$ work that is vigorous, increases the heart rate substantially and causes heavy sweating such as those that involve lifting, carrying heavy loads ( $10 \mathrm{lbs})$, brisk walking, or climbing. 
25) Please tell us about the corresponding shift work for each job you listed

\begin{tabular}{|c|c|c|c|c|c|c|c|}
\hline \multirow{3}{*}{$\begin{array}{l}\text { Job } \\
\text { No. }\end{array}$} & \multirow{3}{*}{$\begin{array}{c}\text { Average number } \\
\text { of hours worked } \\
\text { per week }\end{array}$} & \multicolumn{2}{|c|}{ Percentage of time worked at each shift } & \multicolumn{4}{|c|}{ Usual hours worked at each shift } \\
\hline & & \multirow{2}{*}{ Day Shifts } & \multirow{2}{*}{ Night Shifts } & \multicolumn{2}{|c|}{ Day Shifts } & \multicolumn{2}{|c|}{ Evening Shifts } \\
\hline & & & & Start & End & Start & End \\
\hline $\mathrm{Eg}$. & 35 & $80 \%$ & $20 \%$ & $10: 00 \mathrm{am}$ & $5: 30 \mathrm{pm}$ & $5: 30 \mathrm{pm}$ & 9:00 pm \\
\hline 1 & & & & & & & \\
\hline 2 & & & & & & & \\
\hline 3 & & & & & & & \\
\hline 4 & & & & & & & \\
\hline 5 & & & & & & & \\
\hline
\end{tabular}

Thank you very much for completing this questionnaire 


\title{
Appendix D
}

\author{
Study Diary
}

Study ID

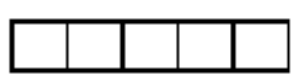

Queen's

\section{Study of Light at Night, Physical Activity and Melatonin in Nurses ONE-DAY DIARY}

This one-day diary is part of our research study to understand the relationship between a woman's environment, behavioural patterns and melatonin production. This one-day diary should be completed over a twenty-four hour period, beginning and ending

All questions included in this one-day diary pertain to activities completed and conditions experienced within this twenty-four hour period only.

The answers that you share with us will be kept strictly confidential and identified by a study ID number, known only by selected members of our research team. Please note that although there are questions in this one-day diary that bear some similarity to those found in the questionnaire completed on the first day of study participation, it is imperative that you answer all questions. Your honesty is important for the success of this research, and a partial answer is better than no answer at all.

We appreciate your cooperation.

Thank you! 
Study ID

\section{SAMPLE TIMES AND PEDOMETER VALUES}

Please record the exact time and date of collection for all urine and saliva samples. Please also record the value on your pedometer at the time of each saliva sample collection.

\section{Saliva Samples:}

Time and date of saliva sample \#1 collection:

Time and date of saliva sample $\# 2$ collection:

Time and date of saliva sample $\# 3$ collection:

Time and date of saliva sample $\# 4$ collection:

Urine Samples:

Time and date of urine sample $\# 1$ collection:

Time and date of urine sample $\# 2$ collection:

\section{Pedometer Values:}

Value at time of saliva sample $\# 1$ collection:

Value at time of saliva sample $\# 2$ collection:

Value at time of saliva sample $\# 3$ collection:

Value at time of saliva sample \#4 collection: 


\section{Study ID}

Today's Date:

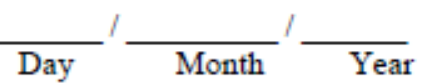

Shift worked during specified 24-hr period (day/night):

Shift worked yesterday (day/night/off):

\section{HEALTH BACKGROUND}

1) Are you still menstruating?

$\square$ Yes $\rightarrow$ what was the date of the first day of your last menstrual period?

\section{$\square$ No}

month/day/year

2) Have you taken aspirin, ibuprofen, other nonsteroidal anti-inflammatory (NSAIDs) pain medication or Tylenol/other acetaminophen pain medication in the 24-hour period specified on the front cover of this one-day diary??

$\square$ No (go to question \#3)

$\square$ Yes $\rightarrow$ Please provide details. If you do not remember the brand name, fill in the type, dose and number of tablets taken.

\begin{tabular}{|c|c|c|}
\hline Brand Name & Dose (milligrams) & Number of Tablets \\
\hline Example: Tylenol & 200 & 1 \\
\hline & & \\
\hline & & \\
\hline
\end{tabular}

3) Have you used sedatives or muscle relaxants in the 24-hour period specified on the front cover of this one-day diary??

No (go to question \#4)

- Yes $\rightarrow$ Please provide details. If you do not remember the brand name, fill in the type, dose and number of tablets taken.

\begin{tabular}{|c|c|c|}
\hline Brand Name & Dose (milligrams) & Number of Tablets \\
\hline Example: Methocarbamol (Robaxin) & 200 & 1 \\
\hline & & \\
\hline & & \\
\hline
\end{tabular}


Study ID

HEALTH BACKGROUND (cont'd)

4) During the 24-hour period specified on the on the front cover of this one-day diary, did you suffer from a migraine?

$\square$ No (go to question \#5) $\quad \square$ Yes $\rightarrow$ Please provide details of the medication taken (including brand name, dose and number of tablets)

\begin{tabular}{|l|l|l|}
\hline Brand Name & Dose (milligrams) & Number of Tablets \\
\hline & & \\
\hline & & \\
\hline
\end{tabular}

5) Have you taken prescribed birth control medication in the 24-hour period specified on the front cover of this diary? (eg. Norplant, Norinyl, Demulen, Depo-Provera, Tri-Cyclen, Alesse, etc.)

$\square$ No (go to question \#6) $\quad \square$ Yes $\rightarrow$ Please provide details of the medication taken (including brand name, dose and number of tablets)

\begin{tabular}{|l|l|l|}
\hline Brand Name & Dose (milligrams) & Number of Tablets \\
\hline & & \\
\hline & & \\
\hline
\end{tabular}

\section{LIFESTYLE HABITS - Smoking}

6) Did you smoke during the 24-hour period specified on the cover of this one-day diary?

$\square$ No (go to question $\# 7$ ) $\quad \square$ Yes $\rightarrow$ Please estimate the number of cigarettes you smoked today.

7) On average, how many hours, during the 24-hour period specified on the cover of this one-day diary, were you exposed to someone else's tobacco smoke?

\begin{tabular}{|c|c|c|c|c|c|c|}
\hline \multicolumn{7}{|c|}{ The number of hours exposed to "second-hand" tobacco smoke } \\
\hline 0 & $<1$ & $1-2$ & $3-4$ & $5-6$ & $7-9$ & $>9$ \\
\hline$\square$ & $\square$ & $\square$ & $\square$ & $\square$ & $\square$ & $\square$ \\
\hline
\end{tabular}




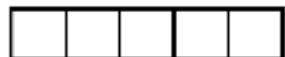

LIFESTYLE HABITS - Alcohol and caffeinated products consumption

8) Did you drink any of the following in the 24-hour period specified on the front cover of this oneday diary?

\begin{tabular}{|c|c|c|c|c|c|c|}
\hline & Beer & Wine & Spirits & Coffee & Tea & $\begin{array}{c}\text { Other } \\
\text { caffeinated } \\
\text { beverages }\end{array}$ \\
\hline Yes & $\square$ & $\square$ & $\square$ & $\square$ & $\square$ \\
No & $\square$ & $\square$ & $\square$ & $\square$ & $\square$ & $\square$ \\
\hline
\end{tabular}

On average, how many drinks did you consume? One drink=1 glass of wine or 1 bottle of beer or 1 oz of spirits. For caffeinated beverages, specify size (e.g. small/single shot) and type (e.g. espresso). (If "no" to all, i.e. beer, wine, spirits, coffee, tea, other caffeinated beverages, go to question \#9)

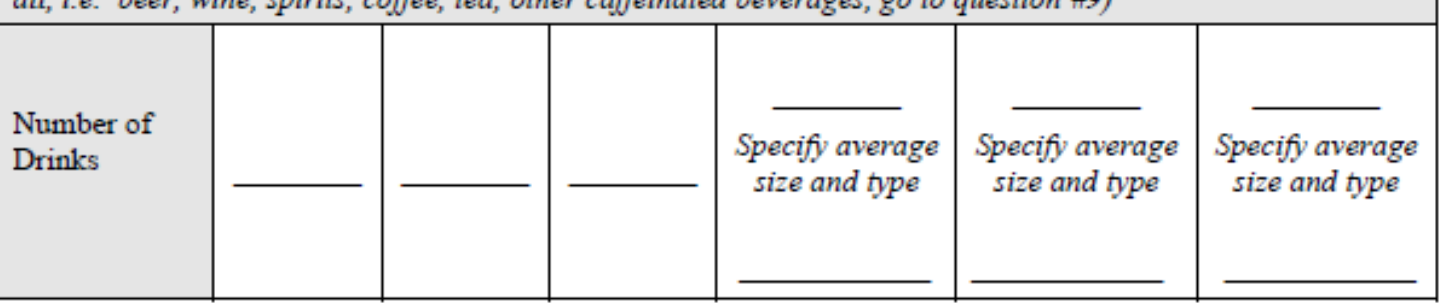

\section{LIGHTING CONDITIONS}

9) Please answer the following questions:

\begin{tabular}{|c|c|c|c|}
\hline $\begin{array}{l}\text { What time did you wake-up at the start of the 24-hour period } \\
\text { specified on the front cover of this one-day diary? }\end{array}$ & & & \\
\hline \multicolumn{4}{|l|}{ What time did you go to sleep? } \\
\hline \multicolumn{4}{|l|}{$\begin{array}{l}\text { What time did you wake-up at the end of the } 24 \text {-hour period } \\
\text { specified on the front cover of this one-day diary? }\end{array}$} \\
\hline $\begin{array}{l}\text { If sleep was interrupted, were lights turned on? (Please } \\
\text { choose N/A if sleep was not interrupted.) }\end{array}$ & $\square$ NO & 口YES & $\square$ N/A \\
\hline $\begin{array}{l}\text { If the lights were on, were they on for more than } 1 \text { hour? } \\
\text { (Please choose N/A if sleep was not internupted.) }\end{array}$ & $\square$ NO & $\square$ YES & $\square$ N/A \\
\hline
\end{tabular}

10) When you sleep at night do you usually wear a sleep mask?

$$
\text { ayes } \square \text { No }
$$

11) When you sleep during the day do you usually wear a sleep mask?

$$
\text { ares } \square \text { No }
$$




\section{PHYSICAL ACTIVITY (Past 24 hours)}

12) In the table below, please record which physical activities that you have participated in during the 24-hour period specified on the front cover of this one-day diary. It is important to indicate the duration you performed each of these activities in the morning-afternoon (7:00 AM - 3:00 $\mathrm{PM}$ ), afternoon-evening (3:00 PM - 11:00 AM), or evening-morning (11:00 PM - 7:00 AM). It is also important to indicate whether the intensity of the physical activity was light, moderate, and heavy. These activities include both sports/exercise and active forms of transportation (e.g., walking to work).

The 3 intensity categories can be defined as follows:

Light: Require minimal physical effort such as slow walking

Moderate: Activities that are not exhausting, but that increase heart rate and breathing rate slightly and may cause some light sweating

Heavy: Activities that substantially increase heart rate and breathing and cause heavy sweating.

\begin{tabular}{|c|c|c|c|c|c|c|}
\hline \multirow[b]{2}{*}{ Type of Activity } & \multicolumn{3}{|c|}{$\begin{array}{c}\text { Duration Performed (in minutes) at } \\
\text { Different Times of the Day }\end{array}$} & \multicolumn{3}{|c|}{$\begin{array}{l}\text { Typical Intensity of } \\
\text { Activity } \\
\text { (Please check only one } \\
\text { for each activity) }\end{array}$} \\
\hline & $\begin{array}{l}\text { Morning- } \\
\text { Afternoon } \\
(07: 00-15: 00)\end{array}$ & $\begin{array}{l}\text { Afternoon- } \\
\text { Evening } \\
(15: 00-23: 00)\end{array}$ & $\begin{array}{c}\text { Evening- } \\
\text { Morning } \\
(23: 00-07: 00)\end{array}$ & Low & Moderate & High \\
\hline $\begin{array}{l}\text { Walking (at least } 10 \\
\text { minutes) }\end{array}$ & & & & $\square$ & 口 & $\square$ \\
\hline $\begin{array}{l}\text { Bicycling (stationary or } \\
\text { outdoor) }\end{array}$ & & & & 口 & $\square$ & $\square$ \\
\hline Elliptical Trainer & & & & 口 & a & a \\
\hline $\begin{array}{l}\text { Jogging or running } \\
\text { (outdoors or treadmill) }\end{array}$ & & & & 口 & 口 & 口 \\
\hline Aerobics class & & & & 口 & 口 & 口 \\
\hline Yoga & & & & 口 & 口 & 口 \\
\hline $\begin{array}{l}\text { Strength training } \\
\text { (including lifting weights) }\end{array}$ & & & & 口 & 口 & 口 \\
\hline Rowing & & & & a & a & a \\
\hline Tennis & & & & 口 & 口 & $\square$ \\
\hline Squash/racquetball & & & & D & 口 & 口 \\
\hline $\begin{array}{l}\text { Calisthenics (sit-ups, push- } \\
\text { ups, etc.) }\end{array}$ & & & & 口 & 口 & 口 \\
\hline
\end{tabular}




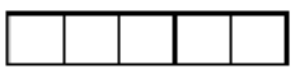

PHYSICAL ACTIVITY (Cont'd)

12) (cont'd)

\begin{tabular}{|l|l|c|c|c|c|c|}
\hline \multirow{2}{*}{ Type of Activity } & \multicolumn{2}{c|}{$\begin{array}{c}\text { Duration Performed (in minutes) at } \\
\text { Different Times of the Day }\end{array}$} & \multicolumn{2}{c|}{$\begin{array}{c}\text { Typical Intensity of } \\
\text { Activity } \\
\text { (Please check only one } \\
\text { for each activity) }\end{array}$} \\
\cline { 2 - 7 } & $\begin{array}{c}\text { Moming- } \\
\text { Afternoon } \\
(07: 00-15: 00)\end{array}$ & $\begin{array}{c}\text { Aftemoon- } \\
\text { Evening } \\
(15: 00-23: 00)\end{array}$ & $\begin{array}{c}\text { Evening- } \\
\text { Moming } \\
(23: 00-07: 00)\end{array}$ & Low & Moderate & High \\
\hline Hiking & & & & $\square$ & $\square$ & $\square$ \\
\hline Swimming & & & & $\square$ & $\square$ & $\square$ \\
\hline Golfing & & & & $\square$ & $\square$ & $\square$ \\
\hline Dancing & & & & $\square$ & $\square$ & $\square$ \\
\hline OTHER (please list below) & & & & $\square$ & $\square$ & $\square$ \\
\hline & & & & $\square$ & $\square$ & $\square$ \\
\hline & & & & $\square$ & $\square$ & $\square$ \\
\hline
\end{tabular}

In the above box be sure to indicate up to 3 additional activities that were not listed but which you performed in the specified 24 hour period. For these activities also list the duration and intensity of the physical activity session.

13) The following are questions about your household activity levels.

a) In the $\mathbf{2 4}$ hour period specified on the cover of this one-day diary, about how many hours did you watch television (including videos and DVDs)? Please mark one box for each of the 3 times of day listed

Morning - Afternoon
$(07: 00-15: 00$ hours)
$\square$ None at all
$\square$ About half an hour
$\square$ About 1 hour
$\square$ About 2 hours
$\square 3$ or more hours

Morning - Afternoon (07:00 - 15:00 hours)

$\square$ None at all

About half an hour

About 2 hours

3 or more hours

\author{
Afternoon - Evening \\ (15:00 - 23:00 hours) \\ $\square$ None at all \\ About half an hour \\ a About 1 hour \\ About 2 hours \\ $\square 3$ or more hours
}

Evening - Morning
(23:00-07:00 hours)
$\square$ None at all
$\square$ About half an hour
$\square$ About 1 hour
$\square$ About 2 hours
$\square 3$ or more hours 


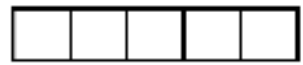

PHYSICAL ACTIVITY (Cont'd)

13) (cont'd)

b) In the $\mathbf{2 4}$ hour period specified on the cover of this one-day diary, about how many hours did you use the computer (including Internet, email, chatting, etc.)? Please mark one box for each of the 3 times of day listed

\begin{tabular}{|c|c|c|}
\hline$\frac{\text { Morning - Afternoon }}{(07: 00-15: 00 \text { hours })}$ & $\frac{\text { Afternoon }- \text { Evening }}{(15: 00-23: 00 \text { hours })}$ & $\frac{\text { Evening }- \text { Morning }}{(23: 00-07: 00 \text { hours })}$ \\
\hline $\begin{array}{l}\text { None at all } \\
\text { About half an hour } \\
\text { About } 1 \text { hour } \\
\text { About } 2 \text { hours } \\
3 \text { or more hours }\end{array}$ & $\begin{array}{l}\text { None at all } \\
\text { About half an hour } \\
\text { About } 1 \text { hour } \\
\text { About } 2 \text { hours } \\
3 \text { or more hours }\end{array}$ & $\begin{array}{l}\text { None at all } \\
\square \text { About half an hour } \\
\square \text { About } 1 \text { hour } \\
\text { About } 2 \text { hours } \\
33 \text { or more hours }\end{array}$ \\
\hline
\end{tabular}

c) In the $\mathbf{2 4}$ hour period specified on the cover of this one-day diary, about how many hours did you sit quietly around the home doing things such as reading, knitting, playing board games, etc?. This does not include time spent watching television or on the computer. Please mark one box for each of the 3 times of day listed

\begin{tabular}{|c|c|c|}
\hline $\begin{array}{l}\text { Morning - Afternoon } \\
\text { (07:00-15:00 hours) } \\
\square \text { None at all } \\
\text { About half an hour } \\
\text { About } 1 \text { hour } \\
\text { About } 2 \text { hours } \\
\square 3 \text { or more hours }\end{array}$ & $\begin{array}{l}\text { Afternoon - Evening } \\
\text { (15:00-23:00 hours) } \\
\square \text { None at all } \\
\square \text { About half an hour } \\
\square \text { About } 1 \text { hour } \\
\text { About } 2 \text { hours } \\
\square 3 \text { or more hours }\end{array}$ & $\begin{array}{l}\text { Evening }- \text { Morning } \\
(23: 00-07: 00 \text { hours }) \\
\square \text { None at all } \\
\square \text { About half an hour } \\
\square \text { About } 1 \text { hour } \\
\square \text { About } 2 \text { hours } \\
\square 3 \text { or more hours }\end{array}$ \\
\hline
\end{tabular}

d) In the $\mathbf{2 4}$ hour period specified on the cover of this one-day diary, about how many hours did you perform light chores around the home such as cooking and cleaning? Please mark one box for each of the 3 times of day listed

Morning - Afternoon (07:00 - 15:00 hours)

$\square$ None at all

a About half an hour

about 1 hour

$\square$ About 2 hours

3 or more hours

\begin{tabular}{ll} 
Afternoon - Evening & Evening - Morning \\
\hline (15:00-23:00 hours $)$ & $(23: 00-07: 00$ hours $)$ \\
$\square$ None at all & $\square$ None at all \\
about half an hour & $\square$ About half an hour \\
About 1 hour & $\square$ About 1 hour \\
A About 2 hours & $\square$ About 2 hours \\
$\square 3$ or more hours & $\square 3$ or more hours
\end{tabular}

Afternoon-Evening

$\square$ None at all

About half an hour

About 2 hours

3 or more hours
Evening - Morning

$\square$ None at al

About 1 hour

3 or more hours 


\begin{tabular}{|l|l|l|l|l|}
\hline & & & & \\
\hline
\end{tabular}

\section{PHYSICAL ACTIVITY (Cont'd)}

14) The following questions are about activities you performed while at work in the 24 hour period specified on the front of this diary.

a) About how much time did you spend on your feet while at work?

$\square$ None at all

About half an hour

About 1 hour

About 2 hours

About 3 hours

About 4 hours

About 5 hours

About 6 hours

口 7 or more hours

b) About how much time do you spend doing heavier activities such as lifting or bathing patients?

$\square$ None at all

About half an hour

About 1 hour

About 2 hours

About 3 hours

About 4 hours

About 5 hours

About 6 hours

ㄱ 7 or more hours 


\section{PHYSICAL ACTIVITY (Past Month)}

15) Please indicate which of the following physical activities you have performed in the last 30 days (1 month). For each activity you performed, indicate the number of times you have participated in the past 30 days, the average length/duration of participation for a given session, and whether the typical intensity was light, moderate, and heavy. These activities include both sports/exercise and active forms of transportation (e.g., walking to work).

The 3 intensity categories can be defined as follows:

Light: $\quad$ Require minimal physical effort such as slow walking

Moderate: Activities that are not exhausting, but that increase heart rate and breathing rate slightly and may cause some light sweating

Heavy: Activities that substantially increase heart rate and breathing and cause heavy sweating.

\begin{tabular}{|c|c|c|c|c|c|}
\hline \multirow[t]{2}{*}{ Type of Activity } & \multirow[t]{2}{*}{$\begin{array}{l}\text { Number of } \\
\text { times } \\
\text { performed in } \\
\text { past } 30 \text { days }\end{array}$} & \multirow{2}{*}{$\begin{array}{c}\text { Average } \\
\text { duration of } \\
\text { physical } \\
\text { activity } \\
\text { session }\end{array}$} & \multicolumn{3}{|c|}{$\begin{array}{l}\text { Typical Intensity } \\
\text { of Activity } \\
\text { (Please check only one } \\
\text { for each activity) }\end{array}$} \\
\hline & & & Low & Moderate & High \\
\hline Walking (at least 10 minutes) & & & 口 & 口 & $\square$ \\
\hline Bicycling (stationary or outdoor) & & & $\square$ & 口 & 口 \\
\hline Elliptical Trainer & & & 口 & 口 & 口 \\
\hline $\begin{array}{l}\text { Jogging or running } \\
\text { (outdoors or treadmill) }\end{array}$ & & & $\square$ & $\square$ & $\square$ \\
\hline Aerobics class & & & $\square$ & 口 & $\square$ \\
\hline Yoga & & & $\square$ & 口 & $\square$ \\
\hline $\begin{array}{l}\text { Strength training } \\
\text { (including lifting weights) }\end{array}$ & & & $\square$ & 口 & $\square$ \\
\hline Rowing & & & $\square$ & a & a \\
\hline Tennis & & & $\square$ & a & a \\
\hline Squash/racquetball & & & a & 口 & a \\
\hline Calisthenics (sit-ups, push-ups, etc.) & & & $\square$ & 口 & 口 \\
\hline Hiking & & & $\square$ & 口 & $\square$ \\
\hline Swimming & & & $\square$ & a & a \\
\hline Golfing & & & $\square$ & a & a \\
\hline
\end{tabular}


Study ID

PHYSICAL ACTIVITY (Cont'd)

15) (cont'd)

\begin{tabular}{|c|c|c|c|c|c|}
\hline \multirow{2}{*}{ Type of Activity } & \multirow{2}{*}{$\begin{array}{l}\text { Number of } \\
\text { times } \\
\text { performed in } \\
\text { past } 30 \text { days }\end{array}$} & \multirow{2}{*}{$\begin{array}{c}\text { Average } \\
\text { duration of } \\
\text { physical } \\
\text { activity } \\
\text { session }\end{array}$} & \multicolumn{3}{|c|}{$\begin{array}{l}\text { Typical Intensity of } \\
\text { Activity (Please check } \\
\text { one for each activity) }\end{array}$} \\
\hline & & & Low & Moderate & High \\
\hline Dancing & & & ם & a & ם \\
\hline Hiking & & & ם & a & a \\
\hline \multirow[t]{4}{*}{ OTHER (please list below) } & & & ם & a & a \\
\hline & & & ם & घ & ם \\
\hline & & & 口 & घ & $\square$ \\
\hline & & & ם & घ & ם \\
\hline
\end{tabular}

In the above box be sure to indicate up to 3 additional activities that were not listed but which you performed in the past month. For these activities also list the number of times you have participated, the average duration, and the typical intensity.

16) Was the amount of physical activity you performed in the past month typical for you? Please check the correct response option.

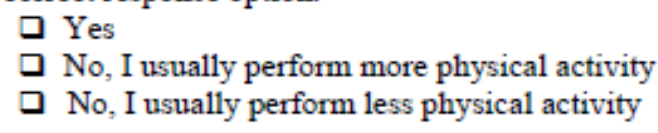

17) The following questions are about your household activity levels.

a) About how many hours a day in the past $\mathbf{3 0}$ days did you usually watch television (including videos and DVDs) in your free time? (Please mark one box for days that you work and one box for days that you have off

Days that you work

$\square$ None at all

about half an hour a day

about 1 hour a day

About 2 hours a day

About 3 hours a day

About 4 hours a day

About 5 hours a day

About 6 hours a day

a About 7 hours or more a day
Days that you have off

$\square$ None at all

about half an hour a day

About 1 hour a day

About 2 hours a day

About 3 hours a day

About 4 hours a day

About 5 hours a day

About 6 hours a day

about 7 hours or more a day 


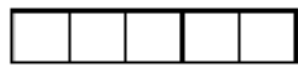

PHYSICAL ACTIVITY (Cont'd)

17) (cont'd)

b) About how many hours a day in the past 30 days did you use the computer (including Internet, email, chatting, etc.)? (Please mark one box for days that you work and one box for days that you do not work)

Days that you work
None at all
About half an hour a day
About 1 hour a day
About 2 hours a day
About 3 hours a day
About 4 hours a day
About 5 hours a day
About 6 hours a day
About 7 hours or more a day

Days that you have off

$\square$ None at all

About half an hour a day

$\square$ About 1 hour a day

About 2 hours a day

About 3 hours a day

About 4 hours a day

About 5 hours a day

About 6 hours a day

$\square$ About 7 hours or more a day

c) About how many hours a day in the past $\mathbf{3 0}$ days do you sit quietly around the home doing things such as reading, knitting, playing board games, etc. This does not include time spent watching television or on the computer? (Please mark one box for days that vou work and one box for days that you do not work)

Days that you work
$\square$ None at all
About half an hour a day
$\square$ About 1 hour a day
$\square$ About 2 hours a day
About 3 hours a day
About 4 hours a day
About 5 hours a day
About 6 hours a day
About 7 hours or more a day

Days that you have off

$\square$ None at all

About half an hour a day

About 1 hour a day

About 2 hours a day

About 3 hours a day

About 4 hours a day

About 5 hours a day

About 6 hours a day

About 7 hours or more a day

About 7 hours or more a day

d) About how many hours a day in the past $\mathbf{3 0}$ days do you perform light chores around the home such as cooking and cleaning? (Please mark one box for days that you work and one box for days that you do not work)

Days that you work

$\square$ None at all

$\checkmark$ About half an hour a day

About 1 hour a day

About 2 hours a day

About 3 hours a day

About 4 hours a day

About 5 hours a day

About 6 hours a day

About 7 hours or more a day
Days that you have off

$\square$ None at all

About half an hour a day

About 1 hour a day

$\checkmark$ About 2 hours a day

About 3 hours a day

$\checkmark$ About 4 hours a day

About 5 hours a day

About 6 hours a day

About 7 hours or more a day 


\section{PHYSICAL ACTIVITY (Cont'd)}

e) About how many hours a day in the past $\mathbf{3 0}$ days do you perform light chores around the home such as cooking and cleaning? (Please mark one box for days that you work and one box for days that you do not work)

Days that you work

$\square$ None at all

About half an hour a day

About 1 hour a day

About 2 hours a day

About 3 hours a day

About 4 hours a day

About 5 hours a day

About 6 hours a day

About 7 hours or more a day
Days that you have off

$\square$ None at all

$\checkmark$ About half an hour a day

About 1 hour a day

$\square$ About 2 hours a day

About 3 hours a day

About 4 hours a day

$\square$ About 5 hours a day

About 6 hours a day

About 7 hours or more a day

f) About how many hours a day in the past $\mathbf{3 0}$ days do you perform heavy chores around the home such as gardening, shoveling snow, etc.? (Please mark one box for days that you work and one box for days that you do not work)

Days that you work

$\square$ None at all

Days that you have off

- About half an hour a day

About 1 hour a day

About 2 hours a day

About 3 hours a day

About 4 hours a day

About 5 hours a day

About 6 hours a day

About 7 hours or more a day

None at all

About half an hour a day

about 1 hour a day

$\square$ About 2 hours a day

$\square$ About 3 hours a day

$\checkmark$ About 4 hours a day

About 5 hours a day

$\square$ About 6 hours a day

About 7 hours or more a day 


\section{PHYSICAL ACTIVITY (Cont'd)}

18) The following questions are about activities you performed while at work in the past 30 days.

a) About how much time do you spend on your feet while at work?

$\square$ None at all

About half an hour a day

About 1 hour a day

About 2 hours a day

About 3 hours a day

About 4 hours a day

About 5 hours a day

About 6 hours a day

About 7 hours or more a day

b) About how much time do you spend doing heavier activities such as lifting or bathing patients?

$\square$ None at all

About half an hour a day

About 1 hour a day

About 2 hours a day

About 3 hours a day

About 4 hours a day

$\square$ About 5 hours a day

About 6 hours a day

About 7 hours or more a day 


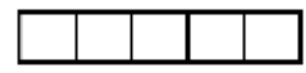

\section{CHANGES MADE TO LIGHTING CONDITIONS}

19) By participating in this study, have you changed the lighting conditions in your home and/or bedroom?

$\square$ No

$\square$ Yes $\rightarrow$ Please provide details in the space provided specifying what type of changes you have made.

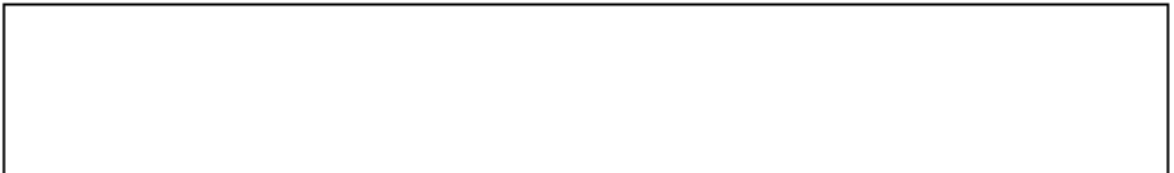

20) By participating in this study, will you change the lighting conditions in your home and/or bedroom?

$\square$ No

$\square$ Yes $\rightarrow$ Please provide details in the space provided specifying what type of changes you will make.

Because we want to be able to use all the information you have provided, please take a moment to review each page, making sure that you did not skip any pages.

If you have any additional comments, please provide them in the space provided below.

Thank you again for the information you have provided! Your input is very valuable to us. 


\section{Appendix E}

\section{Additional Tables \& Figures}

Table 1 Bivariate associations between potential confounders and sex hormone levels (logtransformed)

I) Summer

\begin{tabular}{lcccc}
\hline \multicolumn{1}{c}{ Covariate } & $\begin{array}{c}\text { Estradiol } \\
\text { Parameter } \\
\text { estimate } \\
\text { (p-value) }\end{array}$ & $\begin{array}{c}\text { Estrone } \\
\text { Parameter } \\
\text { estimate } \\
\text { (p-value) }\end{array}$ & $\begin{array}{c}\text { Progesterone } \\
\text { Parameter } \\
\text { estimate } \\
\text { (p-value) }\end{array}$ & $\begin{array}{c}\text { Prolactin } \\
\text { Parameter } \\
\text { estimate } \\
\text { (p-value) }\end{array}$ \\
\hline $\begin{array}{l}\text { Personal Characteristics } \\
\text { Age (years) }\end{array}$ & $0.03(<0.0001)$ & $0.02(0.007)$ & $0.04(0.01)$ & $-0.01(0.11)$ \\
$\begin{array}{l}\text { BMI (kg/m }) \\
\text { Lifestyle Factors }\end{array}$ & $0.003(0.83)$ & $0.01(0.24)$ & $-0.04(0.03)$ & $0.01(0.24)$ \\
$\begin{array}{l}\text { Smoking status } \\
\quad \text { Current smoker }\end{array}$ & $0.01(0.97)$ & $0.22(0.33)$ & $0.009(0.98)$ & $-0.007(0.97)$ \\
$\quad \begin{array}{l}\text { Past-smoker } \\
\text { Never-smoker (ref) }\end{array}$ & $0.22(0.37)$ & $0.20(0.27)$ & $0.25(0.46)$ & $-0.25(0.12)$ \\
$\begin{array}{l}\text { Alcohol consumption } \\
\text { (drinks/ wk) }\end{array}$ & $-0.03(0.31)$ & $-0.02(0.37)$ & $0.01(0.83)$ & $-0.007(0.72)$ \\
$\begin{array}{l}\text { Moderate-to-heavy } \\
\text { physical activity (hrs/ wk) }\end{array}$ & $-0.03(0.28)$ & $-0.03(0.16)$ & $-0.02(0.67)$ & $-0.01(0.49)$ \\
$\begin{array}{l}\text { Total physical activity } \\
\text { (hrs/ week) }\end{array}$ & $-0.01(0.54)$ & $-0.02(0.26)$ & $0.01(0.73)$ & $-0.007(0.65)$ \\
$\begin{array}{l}\text { Caffeinated beverage } \\
\text { consumption (drinks/ } \\
\text { day) }\end{array}$ & $-0.0009(0.98)$ & $0.02(0.41)$ & $0.03(0.48)$ & $-0.02(0.22)$ \\
$\begin{array}{l}\text { Reproductive Characteristics } \\
\text { Menstrual cycle stage }\end{array}$ & $-0.02(0.92)$ & $0.09(0.58)$ & $-0.79(0.009)$ & $-0.03(0.82)$ \\
$\quad \begin{array}{l}\text { Follicular } \\
\text { Ovulatory } \\
\text { Luteal (ref) }\end{array}$ & $0.28(0.33)$ & $0.43(0.05)$ & $-0.55(0.17)$ & $0.10(0.59)$ \\
$\begin{array}{l}\text { Oral contraceptive use } \\
\quad \text { Yes }\end{array}$ & $-0.77(0.001)$ & $-0.64(0.0002)$ & $-0.64(0.07)$ & $0.44(0.006)$ \\
$\quad$ No (ref) & & & & \\
\hline
\end{tabular}


II) Winter

\begin{tabular}{|c|c|c|c|c|}
\hline Covariate & $\begin{array}{l}\text { Estradiol } \\
\text { Parameter } \\
\text { estimate } \\
\text { (p-value) } \\
\end{array}$ & $\begin{array}{l}\text { Estrone } \\
\text { Parameter } \\
\text { estimate } \\
\text { (p-value) }\end{array}$ & $\begin{array}{c}\text { Progesterone } \\
\text { Parameter } \\
\text { estimate } \\
\text { (p-value) } \\
\end{array}$ & $\begin{array}{l}\text { Prolactin } \\
\text { Parameter } \\
\text { estimate } \\
\text { (p-value) } \\
\end{array}$ \\
\hline \multicolumn{5}{|l|}{ Personal Characteristics } \\
\hline Age (years) & $0.03(0.007)$ & $0.01(0.17)$ & $0.01(0.52)$ & $-0.02(0.01)$ \\
\hline BMI $\left(\mathrm{kg} / \mathrm{m}^{2}\right)$ & $-0.001(0.93)$ & $0.01(0.24)$ & $0.03(0.11)$ & $0.02(0.01)$ \\
\hline \multicolumn{5}{|l|}{ Lifestyle Factors } \\
\hline $\begin{array}{l}\text { Smoking status } \\
\text { Current smoker }\end{array}$ & $0.10(0.73)$ & $0.26(0.11)$ & $0.07(0.85)$ & $-0.003(0.99)$ \\
\hline $\begin{array}{l}\text { Past-smoker } \\
\text { Never-smoker (ref) }\end{array}$ & $-0.24(0.32)$ & $0.006(0.97)$ & $-0.07(0.83)$ & $-0.15(0.23)$ \\
\hline $\begin{array}{l}\text { Alcohol consumption } \\
\text { (drinks/wk) }\end{array}$ & $-0.063(0.02)$ & $-0.02(0.17)$ & $0.009(0.79)$ & $0.01(0.44)$ \\
\hline $\begin{array}{l}\text { Moderate-to-heavy } \\
\text { physical activity (hrs/ wk) }\end{array}$ & $-0.02(0.39)$ & $-0.01(0.24)$ & $-0.004(0.87)$ & $\begin{array}{c}-0.0004 \\
(0.97)\end{array}$ \\
\hline $\begin{array}{l}\text { Total physical activity } \\
\text { (hrs/ week) }\end{array}$ & $-0.02(0.44)$ & $-0.01(0.21)$ & $0.0002(0.99)$ & $-0.001(0.93)$ \\
\hline $\begin{array}{l}\text { Caffeinated beverage } \\
\text { consumption (drinks/ } \\
\text { day) }\end{array}$ & $0.06(0.10)$ & $0.03(0.19)$ & $-0.05(0.31)$ & $-0.05(0.008)$ \\
\hline \multicolumn{5}{|c|}{ Reproductive Characteristics } \\
\hline $\begin{array}{l}\text { Menstrual cycle stage } \\
\text { Follicular }\end{array}$ & $-0.48(0.03)$ & $-0.12(0.35)$ & $-0.68(0.02)$ & $-0.26(0.03)$ \\
\hline $\begin{array}{l}\text { Ovulatory } \\
\text { Luteal (ref) }\end{array}$ & $-0.09(0.77)$ & $-0.06(0.75)$ & $-0.11(0.78)$ & $-0.08(0.62)$ \\
\hline $\begin{array}{l}\text { Oral contraceptive use } \\
\text { Yes } \\
\text { No (ref) }\end{array}$ & $-0.79(0.002)$ & $-0.30(0.04)$ & $-0.80(0.02)$ & $0.28(0.04)$ \\
\hline
\end{tabular}


III) Seasons pooled

\begin{tabular}{|c|c|c|c|c|}
\hline Covariate & $\begin{array}{l}\text { Estradiol } \\
\text { Parameter } \\
\text { estimate } \\
\text { (p-value) }\end{array}$ & $\begin{array}{l}\text { Estrone } \\
\text { Parameter } \\
\text { estimate } \\
\text { (p-value) }\end{array}$ & $\begin{array}{l}\text { Progesterone } \\
\text { Parameter } \\
\text { estimate } \\
\text { (p-value) }\end{array}$ & $\begin{array}{l}\text { Prolactin } \\
\text { Parameter } \\
\text { estimate } \\
\text { (p-value) }\end{array}$ \\
\hline \multicolumn{5}{|l|}{ Personal Characteristics } \\
\hline Age (years) & $0.03(0.0007)$ & $0.02(0.003)$ & $0.03(0.02)$ & $-0.01(0.03)$ \\
\hline BMI $\left(\mathrm{kg} / \mathrm{m}^{2}\right)$ & $0.004(0.75)$ & $0.01(0.09)$ & $-0.009(0.53)$ & $0.01(0.07)$ \\
\hline \multicolumn{5}{|l|}{ Lifestyle Factors } \\
\hline $\begin{array}{l}\text { Smoking status } \\
\text { Current smoker } \\
\text { Past-smoker }\end{array}$ & $0.06(0.78)$ & $0.18(0.24)$ & $0.08(0.78)$ & $-0.04(0.78)$ \\
\hline Never-smoker (ref) & $0.002(0.99)$ & $0.08(0.51)$ & $0.10(0.68)$ & $-0.19(0.09)$ \\
\hline $\begin{array}{l}\text { Alcohol consumption } \\
\text { (drinks/wk) }\end{array}$ & $-0.05(0.02)$ & $-0.02(0.14)$ & $0.009(0.74)$ & $\begin{array}{c}-0.0008 \\
(0.95)\end{array}$ \\
\hline $\begin{array}{l}\text { Moderate-to-heavy } \\
\text { physical activity (hrs/ } \\
\text { wk) }\end{array}$ & $-0.02(0.24)$ & $-0.01(0.31)$ & $-0.006(0.76)$ & $-0.006(0.47)$ \\
\hline $\begin{array}{l}\text { Total physical activity } \\
\text { (hrs/ week) }\end{array}$ & $-0.01(0.44)$ & $-0.01(0.33)$ & $0.007(0.71)$ & $-0.006(0.49)$ \\
\hline $\begin{array}{l}\text { Caffeinated beverage } \\
\text { consumption (drinks/ } \\
\text { day) }\end{array}$ & $0.02(0.45)$ & $0.02(0.24)$ & $0.0001(0.99)$ & $-0.02(0.13)$ \\
\hline \multicolumn{5}{|c|}{ Reproductive Characteristics } \\
\hline \multicolumn{5}{|l|}{ Menstrual cycle stage } \\
\hline $\begin{array}{l}\text { Follicular } \\
\text { Ovulatory }\end{array}$ & $-0.25(0.09)$ & $-0.07(0.49)$ & $-0.75(0.0005)$ & $-0.04(0.63)$ \\
\hline Luteal (ref) & $0.007(0.97)$ & $0.09(0.49)$ & $-0.39(0.16)$ & $0.09(0.35)$ \\
\hline \multicolumn{5}{|l|}{ Oral contraceptive use } \\
\hline $\begin{array}{l}\text { Yes } \\
\text { No (ref) }\end{array}$ & $-0.79(<0.0001)$ & $-0.49(<0.0001)$ & $-0.71(0.004)$ & $0.24(0.02)$ \\
\hline
\end{tabular}

*Please note: regression analysis using data pooled across seasons was only conducted if final multivariate-adjusted models did not vary meaningfully by season 
IV) Longitudinal analysis

\begin{tabular}{|c|c|c|c|c|}
\hline Covariate & $\begin{array}{l}\text { Estradiol } \\
\text { Parameter } \\
\text { estimate } \\
\text { (p-value) }\end{array}$ & $\begin{array}{l}\text { Estrone } \\
\text { Parameter } \\
\text { estimate } \\
\text { (p-value) }\end{array}$ & $\begin{array}{l}\text { Progesterone } \\
\text { Parameter } \\
\text { estimate } \\
\text { (p-value) }\end{array}$ & $\begin{array}{l}\text { Prolactin } \\
\text { Parameter } \\
\text { estimate } \\
\text { (p-value) }\end{array}$ \\
\hline \multicolumn{5}{|l|}{ Personal Characteristics } \\
\hline Age (years) & $0.03(0.004)$ & $0.02(0.02)$ & $0.02(0.26)$ & $-0.007(0.31)$ \\
\hline BMI $\left(\mathrm{kg} / \mathrm{m}^{2}\right)$ & $-0.01(0.34)$ & $0.002(0.81)$ & $-0.008(0.70)$ & $0.01(0.15)$ \\
\hline \multicolumn{5}{|l|}{ Lifestyle Factors } \\
\hline $\begin{array}{l}\text { Smoking status } \\
\text { Current smoker } \\
\text { Past-smoker }\end{array}$ & $0.08(0.78)$ & $0.34(0.06)$ & $-0.26(0.57)$ & $0.17(0.29)$ \\
\hline Never-smoker (ref) & $-0.23(0.34)$ & $0.04(0.81)$ & $0.17(0.68)$ & $-0.09(0.50)$ \\
\hline $\begin{array}{l}\text { Alcohol consumption } \\
\text { (drinks/ wk) }\end{array}$ & $\begin{array}{c}-0.11 \\
(0.0002)\end{array}$ & $-0.05(0.02)$ & $0.01(0.77)$ & $0.005(0.80)$ \\
\hline $\begin{array}{l}\text { Moderate-to-heavy } \\
\text { physical activity (hrs/ wk) }\end{array}$ & $\begin{array}{l}-0.008 \\
(0.73)\end{array}$ & $-0.01(0.35)$ & $-0.03(0.46)$ & $-0.03(0.05)$ \\
\hline $\begin{array}{l}\text { Total physical activity } \\
\text { (hrs/ week) }\end{array}$ & $-0.01(0.63)$ & $-0.01(0.33)$ & $-0.04(0.32)$ & $-0.02(0.09)$ \\
\hline $\begin{array}{l}\text { Caffeinated beverage } \\
\text { consumption (drinks/ } \\
\text { day) }\end{array}$ & $0.05(0.19)$ & $0.03(0.31)$ & $-0.07(0.30)$ & $-0.06(0.01)$ \\
\hline \multicolumn{5}{|c|}{ Reproductive Characteristics } \\
\hline $\begin{array}{l}\text { Menstrual cycle stage } \\
\text { Follicular }\end{array}$ & $-0.16(0.45)$ & $-0.25(0.86)$ & $-0.81(0.01)$ & $-0.09(0.47)$ \\
\hline $\begin{array}{l}\text { Ovulatory } \\
\text { Luteal (ref) }\end{array}$ & $0.13(0.71)$ & $-0.05(0.84)$ & $-0.48(0.36)$ & $-0.02(0.90)$ \\
\hline $\begin{array}{l}\text { Oral contraceptive use } \\
\text { Yes } \\
\text { No (ref) }\end{array}$ & $0.95(0.0004)$ & $0.55(0.002)$ & $0.93(0.03)$ & $-0.33(0.04)$ \\
\hline
\end{tabular}


Table 2 Associations between melatonin and sex hormones (all log-transformed)

\begin{tabular}{|c|c|c|c|c|c|}
\hline \multirow[b]{2}{*}{ Sex Hormone } & \multirow{2}{*}{$\begin{array}{c}\text { Bivariate } \\
\text { Parameter } \\
\text { Estimate } \\
\text { (p-value) }\end{array}$} & \multicolumn{3}{|c|}{$\begin{array}{c}\text { Base Models } \\
\text { Parameter Estimate (p-value) } \\
\end{array}$} & \multirow{2}{*}{$\begin{array}{c}\text { Multivariate- } \\
\text { adjusted } \\
\text { Parameter } \\
\text { Estimate } \\
\text { (p value); } \mathrm{R}^{2}\end{array}$} \\
\hline & & $\begin{array}{l}\text { Age } \\
\text { adjusted }\end{array}$ & $\begin{array}{l}\text { Age, BMI } \\
\text { adjusted }\end{array}$ & $\begin{array}{c}\text { Age, BMI, } \\
\text { menstrual } \\
\text { stage }\end{array}$ & \\
\hline \multicolumn{5}{|l|}{ Estradiol } & \\
\hline Summer & $-0.01(0.84)$ & $-0.03(0.70)$ & $-0.04(0.59)$ & $-0.01(0.89)$ & $(0.94) ; 0.24^{\mathrm{a}}$ \\
\hline Winter & $-0.18(0.04)$ & $-0.19(0.02)$ & $-0.19(0.03)$ & $-0.18(0.03)$ & $\begin{array}{c}-0.13 \\
(0.11) ; 0.37^{b}\end{array}$ \\
\hline Longitudinal & $-0.11(0.20)$ & $-0.10(0.27)$ & $-0.09(0.27)$ & $-0.09(0.31)$ & $\begin{array}{c}-0.05 \\
(0.54) ; 0.36^{\mathrm{c}}\end{array}$ \\
\hline \multicolumn{5}{|l|}{ Estrone } & \\
\hline Summer & $0.05(0.39)$ & $0.03(0.53)$ & $0.009(0.86)$ & $0.03(0.65)$ & $\begin{array}{c}0.05 \\
(0.36) ; 0.34^{\mathrm{a}}\end{array}$ \\
\hline Winter & $-0.05(0.37)$ & $-0.05(0.35)$ & $-0.04(0.41)$ & $-0.04(0.48)$ & $\begin{array}{c}-0.03 \\
(0.61) ; 0.33^{\mathrm{d}}\end{array}$ \\
\hline Longitudinal & $0.01(0.79)$ & $0.03(0.64)$ & $0.02(0.69)$ & $0.03(0.65)$ & $\begin{array}{c}0.05 \\
(0.40) ; 0.25^{\mathrm{b}}\end{array}$ \\
\hline \multicolumn{5}{|l|}{ Progesterone } & 0.07 \\
\hline Summer & $-0.05(0.65)$ & $-0.06(0.55)$ & $-0.02(0.87)$ & $0.04(0.70)$ & $(0.46) ; 0.38^{\mathrm{a}}$ \\
\hline Winter & $0.04(0.71)$ & $0.04(0.75)$ & $0.07(0.55)$ & $0.11(0.35)$ & $\begin{array}{c}0.14 \\
(0.22) ; 0.26^{\mathrm{a}}\end{array}$ \\
\hline Longitudinal & $-0.12(0.39)$ & $-0.11(0.45)$ & $-0.11(0.46)$ & $-0.05(0.73)$ & $\begin{array}{c}-0.02 \\
(0.86) ; 0.28^{\mathrm{a}}\end{array}$ \\
\hline Seasons pooled & $-0.02(0.82)$ & $-0.02(0.74)$ & $-0.02(0.76)$ & $0.03(0.69)$ & $0.06(0.43)^{\mathrm{a}}$ \\
\hline $\begin{array}{l}\text { Prolactin } \\
\quad \text { Summer }\end{array}$ & $0.04(0.42)$ & $0.04(0.35)$ & $0.03(0.47)$ & $0.05(0.38)$ & $\begin{array}{c}0.01 \\
(0.78) ; 0.20^{\mathrm{e}}\end{array}$ \\
\hline Winter & $0.01(0.84)$ & $0.01(0.75)$ & $0.02(0.60)$ & $0.03(0.50)$ & $\begin{array}{c}0.003 \\
(0.94) ; 0.29^{\mathrm{f}}\end{array}$ \\
\hline Longitudinal & $0.02(0.64)$ & $0.02(0.68)$ & $0.02(0.76)$ & $0.01(0.78)$ & $\begin{array}{c}-0.05 \\
(0.40) ; 0.27^{\mathrm{g}}\end{array}$ \\
\hline Seasons pooled & $0.03(0.30)$ & $0.03(0.26)$ & $0.03(0.31)$ & $0.03(0.38)$ & $0.002(0.95)^{\mathrm{f}}$ \\
\hline
\end{tabular}

Adjusted for age, BMI, menstrual cycle stage, and:

a- OC use

b- OC use, alcohol consumption

c- alcohol consumption, caffeine consumption

d- OC use, alcohol/ caffeine consumption, smoking status, total physical activity levels

e- OC use, smoking status

f- OC use, caffeine consumption

g- caffeine consumption, moderate-to-heavy physical activity 
Table 3 Association of night shift-work history with sex hormone levels (log-transformed)

\begin{tabular}{|c|c|c|c|c|c|}
\hline \multirow[b]{2}{*}{$\begin{array}{c}\text { Sex } \\
\text { Hormone }\end{array}$} & \multirow{2}{*}{$\begin{array}{l}\text { Bivariate } \\
\text { Parameter } \\
\text { Estimate } \\
\text { (p-value) }\end{array}$} & \multicolumn{3}{|c|}{$\begin{array}{c}\text { Base Models } \\
\text { Parameter Estimate (p-value) }\end{array}$} & \multirow{2}{*}{$\begin{array}{c}\text { Multivariate- } \\
\text { adjusted } \\
\text { Parameter } \\
\text { Estimate } \\
\text { (p-value) }\end{array}$} \\
\hline & & Age adjusted & $\begin{array}{l}\text { Age, BMI } \\
\text { adjusted }\end{array}$ & $\begin{array}{c}\text { Age, BMI, } \\
\text { menstrual } \\
\text { stage adjusted }\end{array}$ & \\
\hline Estradiol & $0.02(0.04)$ & $-0.002(0.85)$ & $0.0003(0.98)$ & $-0.003(0.76)$ & $-0.002(0.87)^{\mathrm{a}}$ \\
\hline Estrone & $0.01(0.02)$ & $0.004(0.55)$ & $0.007(0.28)$ & $0.006(0.37)$ & $0.005(0.48)^{\mathrm{b}}$ \\
\hline Progesterone & $0.03(0.02)$ & $0.02(0.26)$ & $0.02(0.26)$ & $0.002(0.90)$ & $-0.002(0.86)^{b}$ \\
\hline Prolactin & $-0.006(0.27)$ & $0.0008(0.90)$ & $0.002(0.79)$ & $0.002(0.78)$ & $0.002(0.79)^{\mathrm{c}}$ \\
\hline
\end{tabular}

Adjusted for age, BMI, menstrual cycle stage, and:

a- OC use, alcohol consumption

b- OC use

c- OC use, caffeine consumption 
Figure 1 Multivariate-adjusted associations between melatonin and sex hormones (all logtransformed)

\section{I) Estradiol}

(A) Summer $-\beta=0.005(\mathrm{p}=0.94)$; adjusted for age, BMI, menstrual cycle stage, OC use ( $\mathrm{n}$ $=61)$

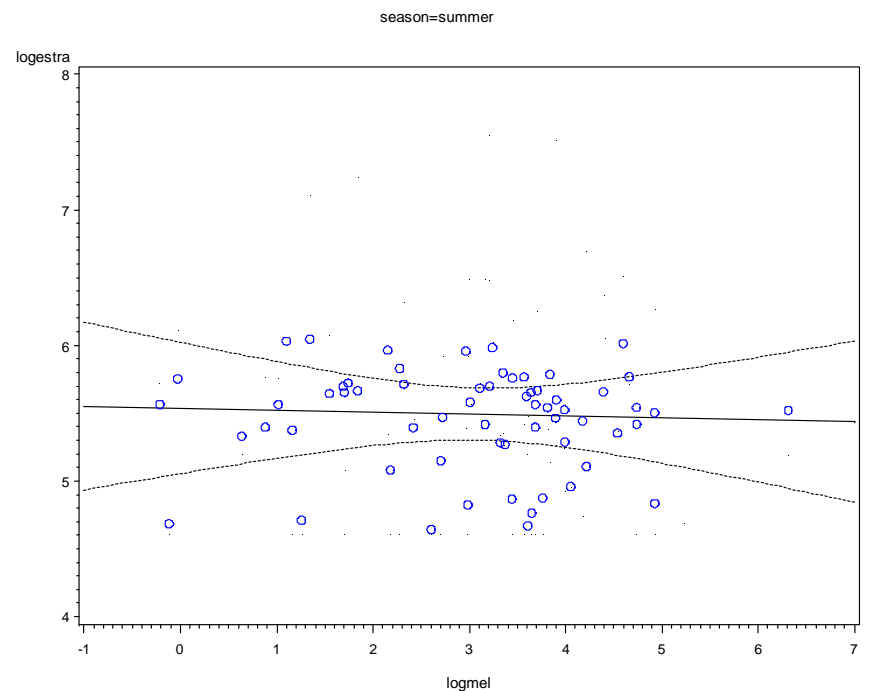

(B) Winter $-\beta=-0.13(p=0.11)$; adjusted for age, BMI, menstrual cycle stage, OC use, alcohol consumption $(n=56)$

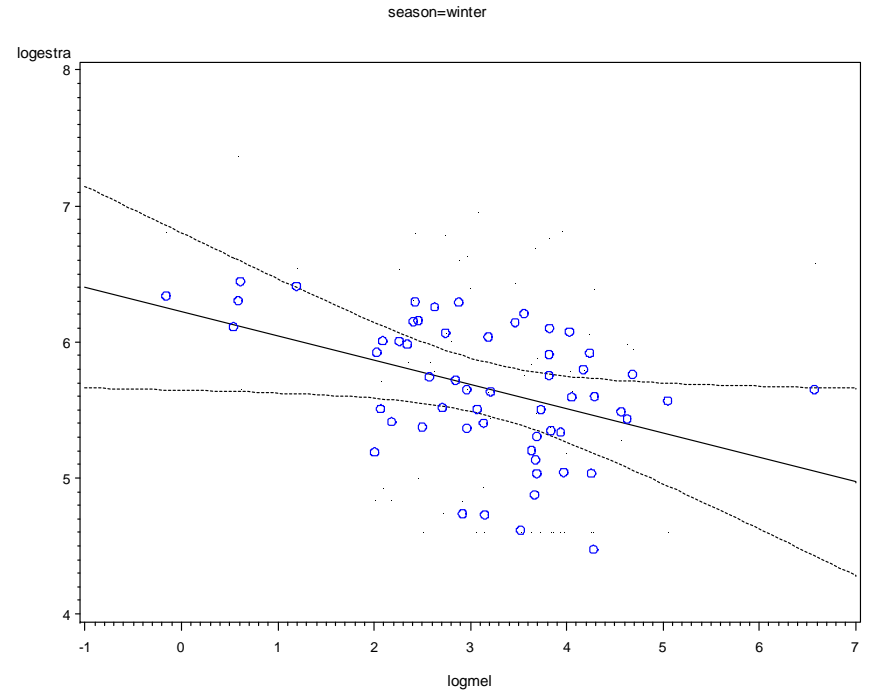


(C) Longitudinal $-\beta=-0.05(\mathrm{p}=0.54)$; adjusted for age, BMI, menstrual cycle stage, OC use, caffeine consumption $(\mathrm{n}=54)$

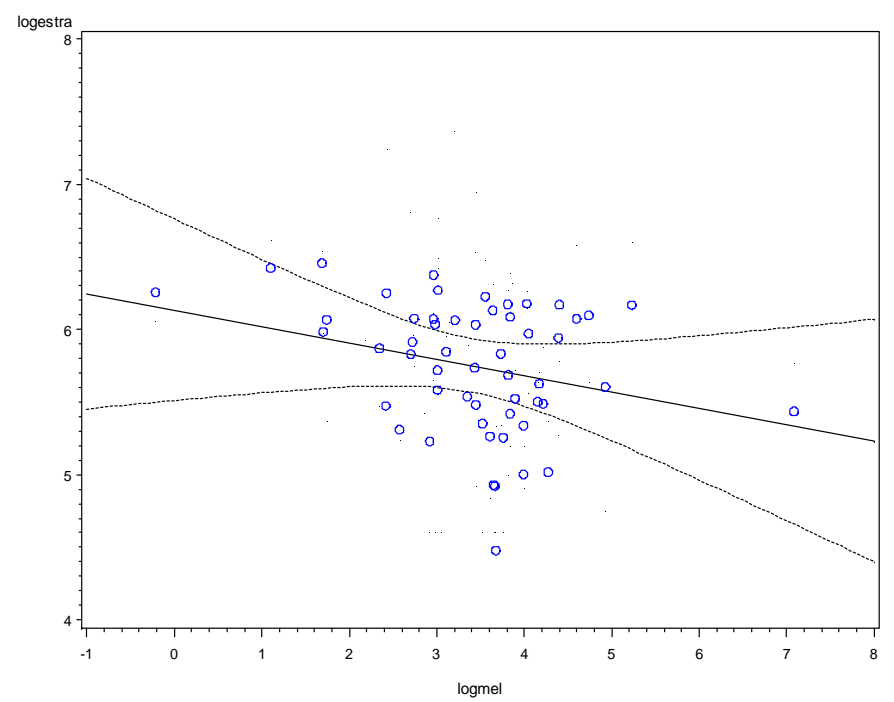

II) Estrone

(A) Summer $-\beta=0.05(\mathrm{p}=0.36)$; adjusted for age, BMI, menstrual cycle stage, OC use ( $\mathrm{n}=$ 59)

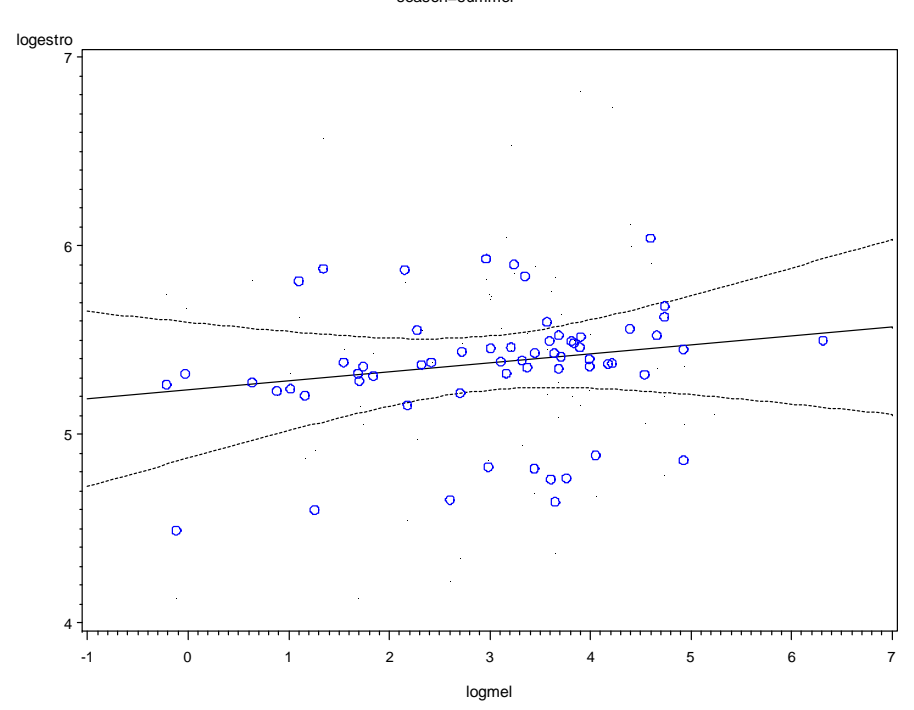


(B) Winter $-\beta=-0.03(\mathrm{p}=0.61)$; adjusted for age, BMI, menstrual cycle stage, OC use, alcohol consumption, caffeine consumption, smoking status, total physical activity level $(\mathrm{n}=59)$

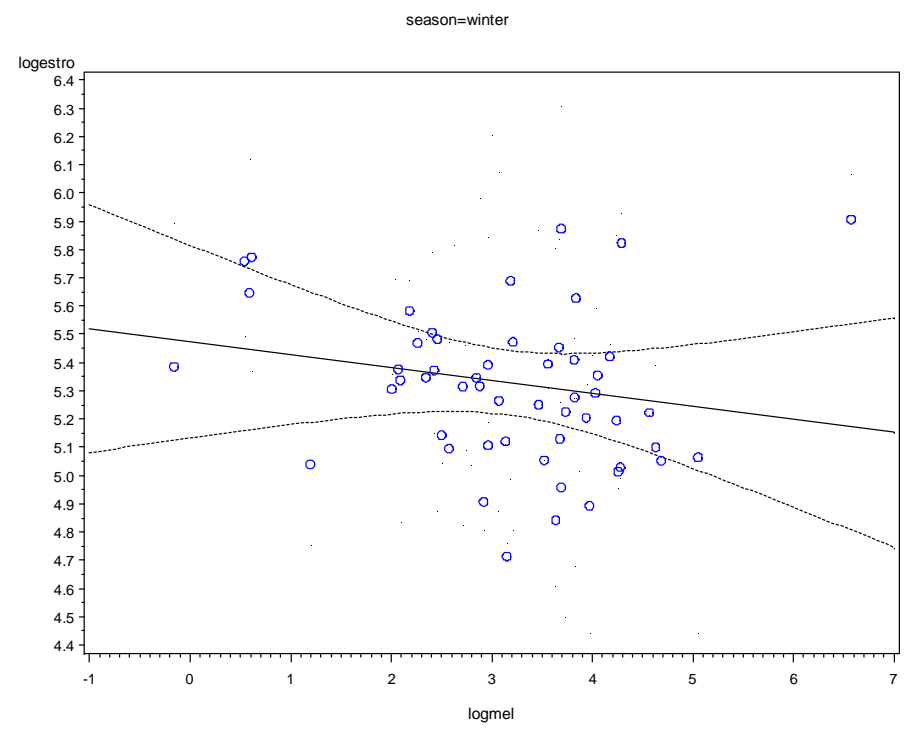

(C) Longitudinal $-\beta=0.05(\mathrm{p}=0.40)$; adjusted for age, BMI, menstrual cycle stage, OC use, alcohol consumption $(n=53)$

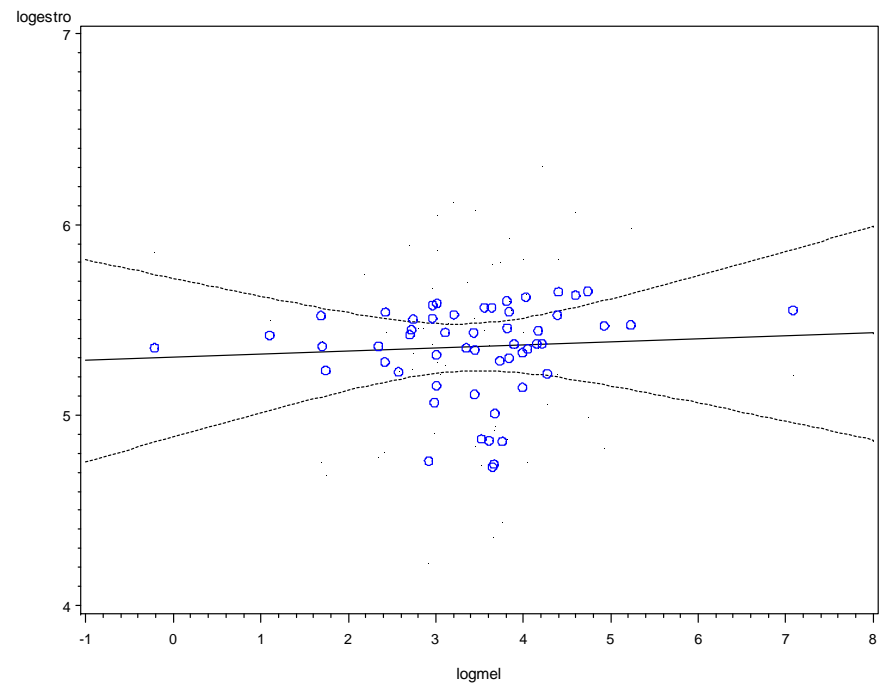




\section{III) Progesterone}

(A) Summer $-\beta=0.07(\mathrm{p}=0.46)$; adjusted for age, BMI, menstrual cycle stage, OC use ( $\mathrm{n}=$ 61)

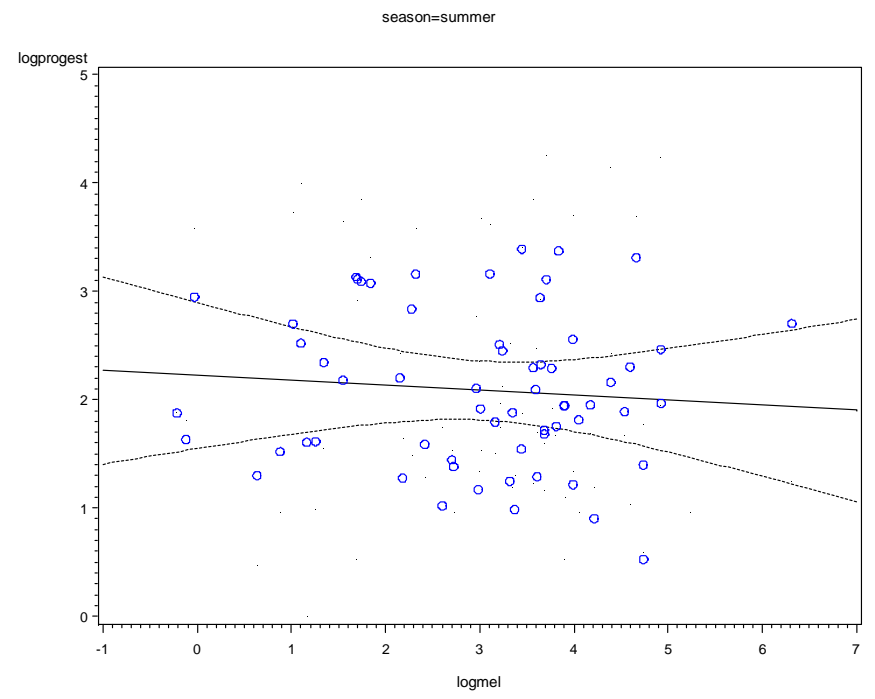

(B) Winter $-\beta=0.14(\mathrm{p}=0.22)$; adjusted for age, BMI, menstrual cycle stage, OC use ( $\mathrm{n}=$ 58)

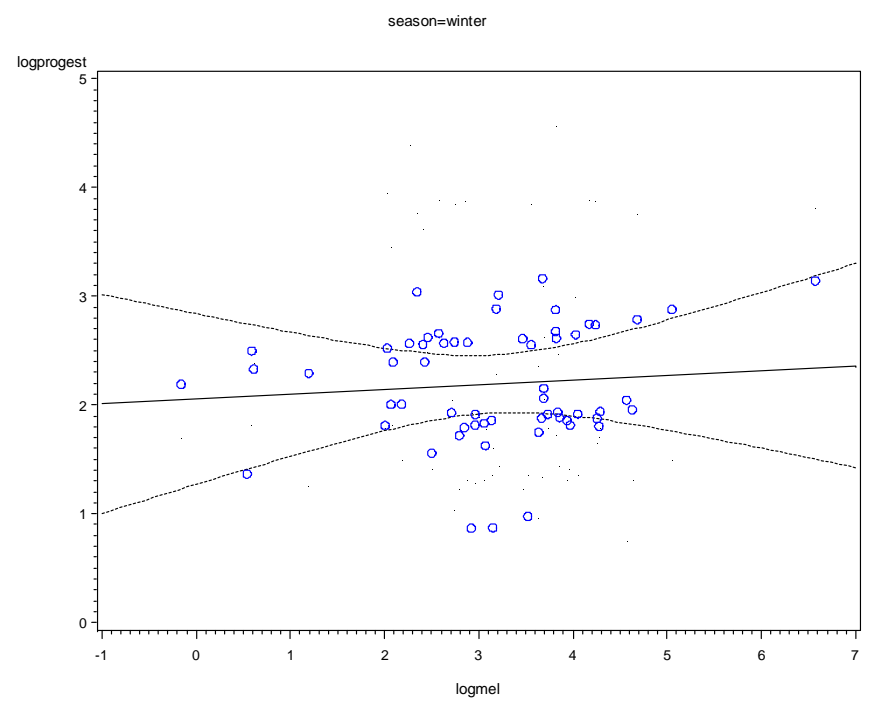


(C) Longitudinal $-\beta=-0.02(\mathrm{p}=0.86)$; adjusted for age, BMI, menstrual cycle stage, OC use $(n=56)$

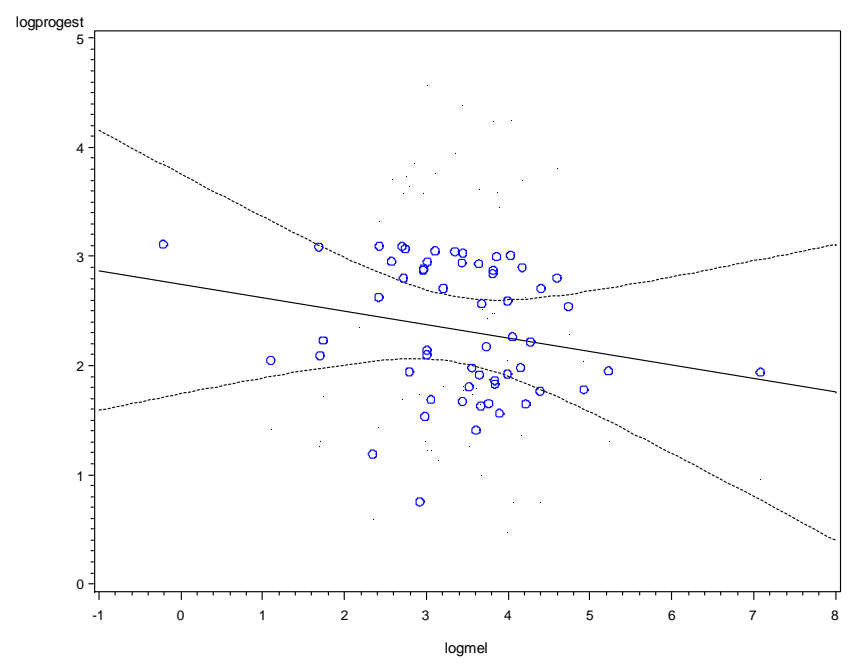

(D) Seasons pooled $-\beta=-0.02(\mathrm{p}=0.86)$; adjusted for age, BMI, menstrual cycle stage, OC use $(n=119)$

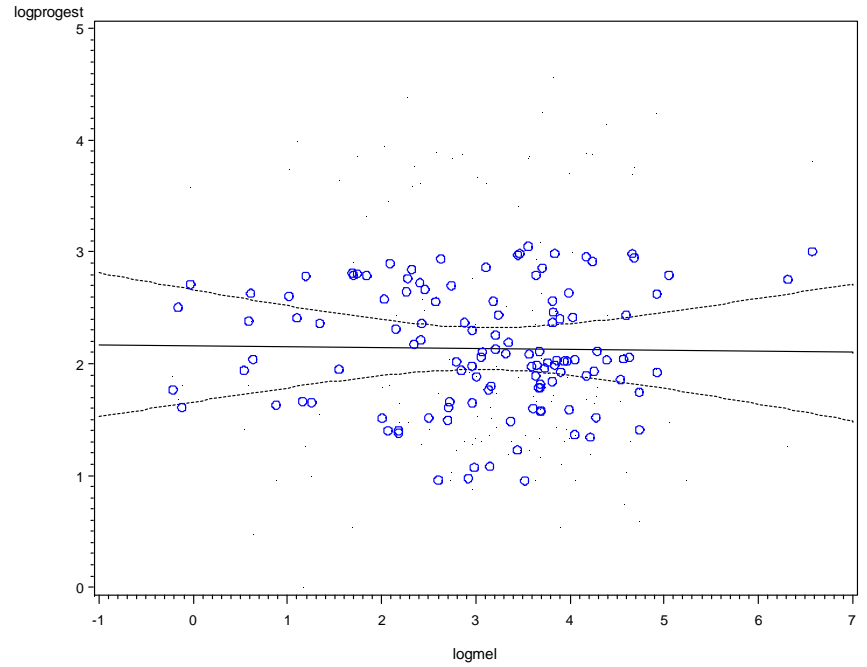




\section{IV) Prolactin}

(A) Summer $-\beta=0.01(\mathrm{p}=0.78)$; adjusted for age, BMI, menstrual cycle stage, OC use, alcohol consumption, caffeine consumption $(\mathrm{n}=59)$

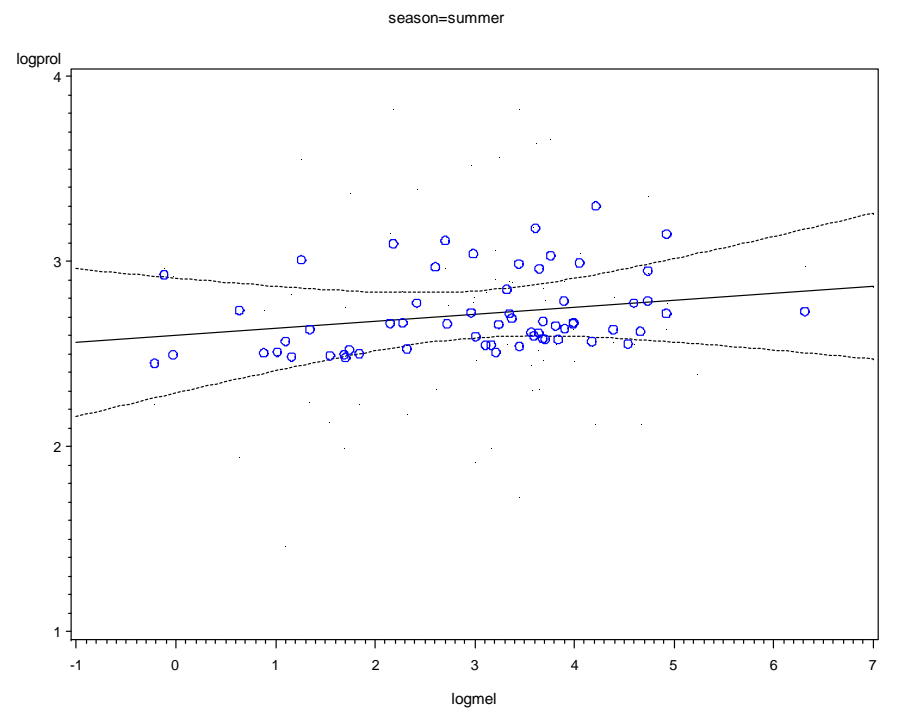

(B) Winter $-\beta=0.003(\mathrm{p}=0.94)$; adjusted for age, BMI, menstrual cycle stage, OC use, caffeine consumption $(\mathrm{n}=59)$

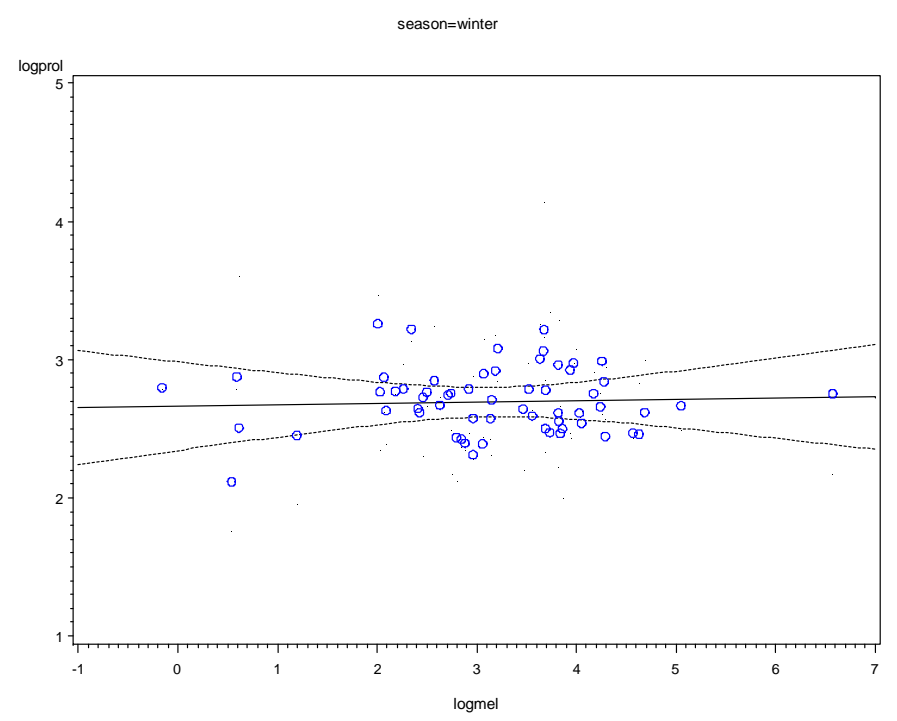


(C) Longitudinal $-\beta=-0.05(\mathrm{p}=0.40)$; adjusted for age, BMI, menstrual cycle stage, OC use, caffeine consumption, moderate-vigorous physical activity $(\mathrm{n}=52)$

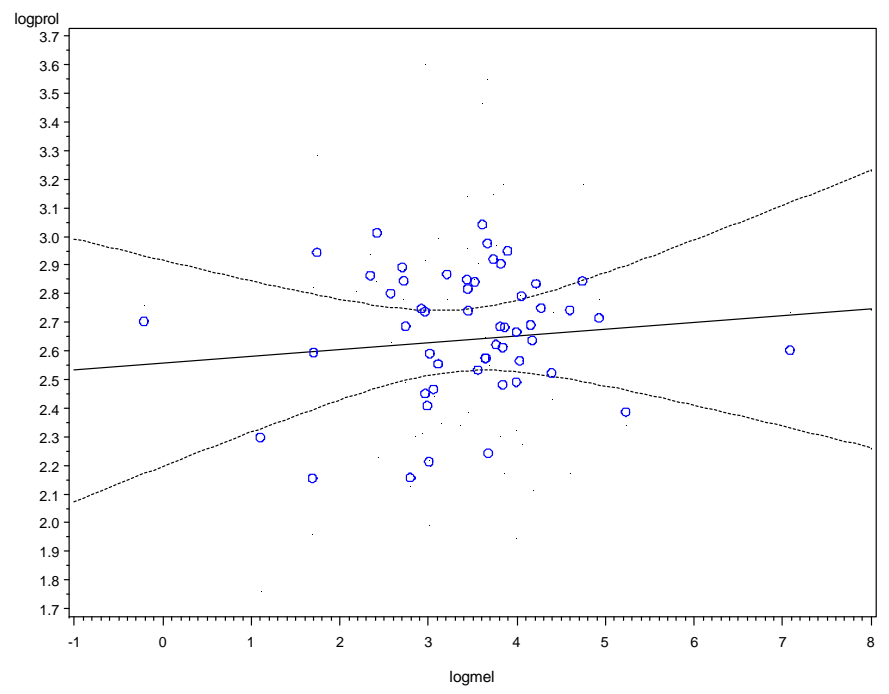

(D) Seasons pooled $-\beta=0.002(\mathrm{p}=0.95)$; adjusted for age, BMI, menstrual cycle stage, OC use, caffeine consumption, smoking status $(n=118)$

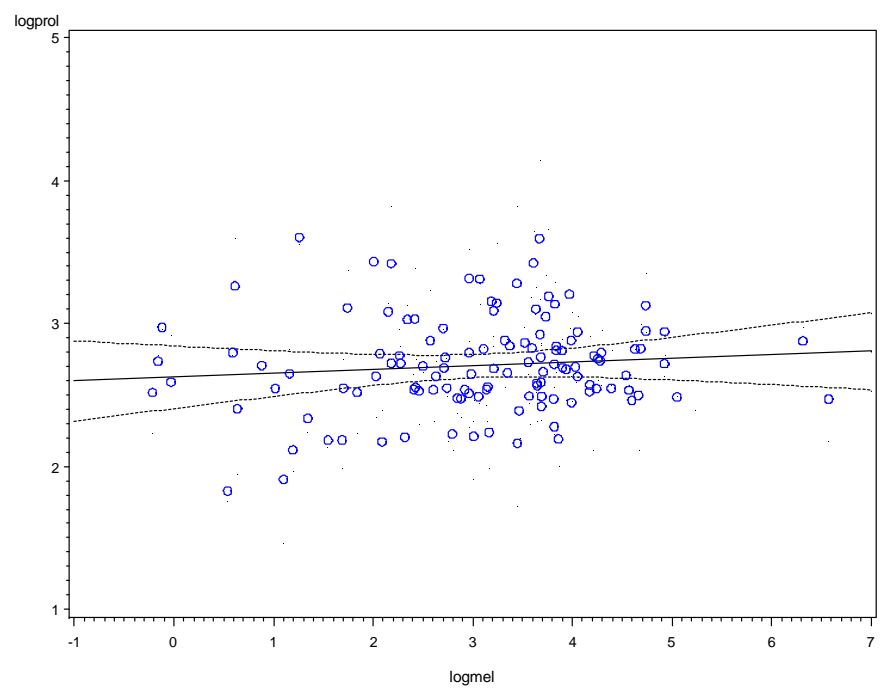

